\title{
The Role of Institutional Structures, Interest Groups, and Framing in Explaining Occupational Road Safety Policy in the European Union and Member States: An Application of the Advocacy Coalition Framework and Multi-level Governance
}

Stephanie G. Pratt

West Virginia University

Follow this and additional works at: https://researchrepository.wvu.edu/etd

\section{Recommended Citation}

Pratt, Stephanie G., "The Role of Institutional Structures, Interest Groups, and Framing in Explaining Occupational Road Safety Policy in the European Union and Member States: An Application of the Advocacy Coalition Framework and Multi-level Governance" (2011). Graduate Theses, Dissertations, and Problem Reports. 3461.

https://researchrepository.wvu.edu/etd/3461

This Dissertation is protected by copyright and/or related rights. It has been brought to you by the The Research Repository @ WVU with permission from the rights-holder(s). You are free to use this Dissertation in any way that is permitted by the copyright and related rights legislation that applies to your use. For other uses you must obtain permission from the rights-holder(s) directly, unless additional rights are indicated by a Creative Commons license in the record and/ or on the work itself. This Dissertation has been accepted for inclusion in WVU Graduate Theses, Dissertations, and Problem Reports collection by an authorized administrator of The Research Repository @ WVU.

For more information, please contact researchrepository@mail.wvu.edu. 
The Role of Institutional Structures, Interest Groups, and Framing in Explaining Occupational Road Safety Policy in the European Union and Member States: An Application of the Advocacy Coalition Framework and Multi-level Governance

\author{
Stephanie G. Pratt \\ Dissertation submitted to the \\ Eberly College of Arts and Sciences at \\ West Virginia University \\ in partial fulfillment of the requirements \\ for the degree of \\ Doctor of Philosophy \\ in \\ Political Science
}

Donley T. Studlar, Ph.D., Chair Christina Fattore, Ph.D. John Kilwein, Ph.D. Karleen West, Ph.D. Will Murray, Ph.D.

Department of Political Science Morgantown, West Virginia 2011

Keywords:

Road Safety; Occupational Safety; Advocacy Coalition Framework Copyright 2011 Stephanie G. Pratt 


\begin{abstract}
The Role of Institutional Structures, Interest Groups, and Framing in Explaining Occupational Road Safety Policy in the European Union and Member States: An Application of the Advocacy Coalition Framework and Multi-level Governance
\end{abstract}

\author{
Stephanie G. Pratt
}

In addition to being a leading cause of death in the general population, motor vehicle crashes are the leading cause of occupational fatalities in most high-income countries and regions, including the European Union (EU). The primary aims of this research were to: (1) assess the development of occupational road safety policy in the EU through the lens of the policy literature, focusing on the advocacy coalition framework (ACF) as a model of policy change, the role of interest groups, and multi-level governance (MLG); and (2) use the United Kingdom (UK), Sweden, and France as EU case studies to illustrate the contributions of EU-member state interactions vs. initiatives at the state level, with emphasis on transposition of relevant EU directives into state-level law. Assessment of the transposition of EU directives was guided by the findings of Falkner et al. (2005), which characterized transpositions of a number of employment directives as belonging to a "world of domestic politics" for the UK, a "world of law observance" for Sweden, and a "world of neglect" for France. The primary argument is that in the EU member states, the entrance of occupational road safety onto the policy agenda and the subsequent policies and regulatory regimes can be explained by institutional features and interest-group structures, mediated by prevailing policy ideas at domestic level. The methodology is largely qualitative. Primary sources of data are regulations, policy documents, guidance documents, the scholarly literature, and interviews with key informants.

Policy for occupational road safety remains essentially a domestic matter for the three EU member states. How it is managed in each of the three member states discussed here depends in part whether it is couched as a transport safety issue tied to business or industrial policy, as in the UK, or as a social welfare issue tied more closely to OSH policy, as in France and Sweden.

For this policy area, France is seen as more accurately placed in the "world of domestic politics" than in the "world of neglect." Here, it is statist France, not corporatist Sweden, that turns out to be the more corporatist of the two, and this may be attributed to the placement of occupational injury prevention functions within the social security agencies, where a corporatist approach is well-established. Another factor may be formal tripartite consultative mechanisms and collective bargaining for the road transport industry, which appear to be sector-specific exceptions to the conventional characterization of France as lacking corporatist institutions.

Sweden retains its corporatist tradition by allowing interest groups a formal role in the legislative process, but accords them surprisingly limited entrée to discussions about implementation. There is little evidence to support Sweden's placement anywhere but in the "world of law observance" with respect to its transposition of relevant EU directives. However, despite its 
overall high level of compliance with EU directives, Sweden took advantage of derogation opportunities to accommodate a state-level tradition of resolving certain issues through collective bargaining.

The UK's transposition of EU directives and its overall handling of occupational road safety policy support its placement in the "world of domestic politics." British transpositions of EU directives related to occupational road safety were found to be generally accurate, but were tempered by elements drawn from existing state-level legislation that do not hold employers to ensuring worker safety at all costs. The UK benefits from active epistemic communities, but its governance of occupational road safety lives up to expectations that risk management by employers will be framed as a business matter, not a social welfare issue.

For this particular policy area and for the three member states, the ACF provides a more complete account than does MLG. As described by Sabatier and colleagues, the ACF sees policymaking as taking place within a subsystem whose participants represent varied interests but tend to espouse shared beliefs at societal level and policy level. The ACF allows us to consider the stable features of the policymaking environment that are preconditions for any assessment of policy change, as well as the external forces that may "shock" the environment and create conditions under which a major policy change may occur.

Type I MLG, which focuses on delegation of governmental functions to sub-state units, is not especially salient for occupational road safety policy; few relevant functions have been passed to sub-state level in the three member states discussed here. Type II MLG does offer some insight into this policy area through its emphasis on interest groups and its distinction between "government" and "governance." However, the ACF, through its emphasis on policy subsystems made up of governmental and non-governmental actors, allows the discussion to extend to policy initiatives emanating from outside government.

This research offers some insight into the question of whether politics drives policies, or whether the reverse may in fact be true. The conventional "policy styles" approach holds that at state level, policymakers develop stable approaches to dealing with policy issues, which in turn lead to consistent policy. I argue that for occupational road safety policy in the UK, France, and Sweden, the "policy styles" framework is more appropriate, as the three states retain differences in policy instruments, institutional arrangements, and underlying societal beliefs. Despite the imposition of EU directives intended to create some level of consistency, all three member states have responded in ways that reflect state-level beliefs and approaches. 


\section{Acknowledgments}

First of all, I must thank my committee, especially my advisor and committee chair, Dr. Donley Studlar, for their valuable feedback and encouragement as I have developed my research prospectus and written my dissertation. As a dissertation advisor and as a professor, Dr. Studlar has always provided timely and constructive feedback and has given generously of his knowledge and experience. I also appreciate the contributions of the other committee members, Drs. Christina Fattore, John Kilwein, Karleen West, and Will Murray, for their constructive comments and feedback at the prospectus and dissertation stages. Special thanks to Dr. Will Murray, who has been a valued collaborator and friend for several years. More than anyone else, Will has helped me to grow into a useful member of the policy community for occupational road safety.

I also acknowledge the contributions of the many individuals from government, NGOs, and international organizations who were kind enough to take the time to talk with me about occupational road safety. Many of you have also been influential over a period of years in shaping how I look at road safety and the role of business and organizations in managing risk. I think you know who you are.

Thanks also to my managers at NIOSH - Nancy Stout, Tim Pizatella, Dawn Castillo, and Kara Perritt - for their willingness to put up with my absence from my regular job for 21 months so I could go back to school. I owe Kara a particular debt of gratitude for taking on my workload in addition to her own. Since my return to work, Kara has been extraordinarily patient and helpful, tolerating my occasional frustration as I've re-acclimated to work while writing a dissertation on evenings and weekends.

Valued colleagues and friends from the CDC and road safety communities have supported my return to school and have encouraged me along the way: Matts Belin, Christine Branche, Ann Dellinger, Bella Dinh-Zarr, Marilyn Fingerhut, Vik Kapil, Max Lum, Dave Melton, Andy Pearce, Ellen Townsend, and Jane Wilkins. By making me think and cheering me on, each of you has made my work better and the process less stressful.

Finally, I thank my family for their extraordinary support and patience during these past $3 \frac{1}{2}$ years, especially my husband, Alex Lubman, who has cheerfully borne the consequences of my grumpy moods, late nights studying, and lack of attention to household details. Only someone who loves me would have put up with me. I also thank my children, Jacob and Hannah Lubman, for their constant encouragement and faith in me. There is no way I could have accomplished this without having all three of you rooting for me. Other family members who are not in Morgantown have acted as cheerleaders from afar when I've needed a boost - my sister-in law Ilona Lubman and her daughter Alex, my mother Nina Pratt, my father-in-law Julius Lubman, and my sister Stacey Pratt. Finally, I dedicate this to three people who are not here to share my accomplishment but would be SO proud of me - my father James Pratt, my grandmother Miriam Braunger, and my mother-in-law Charlotte Lubman. 


\section{Table of Contents}

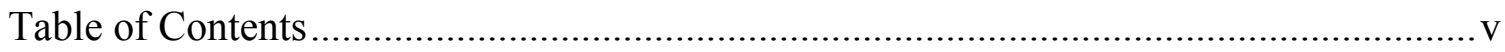

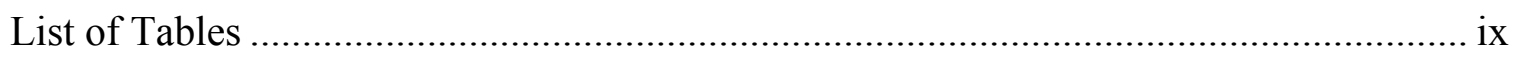

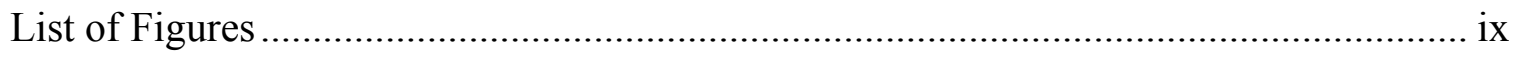

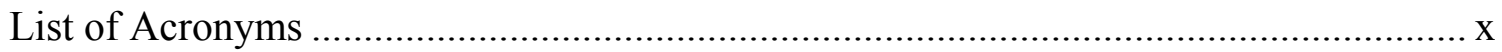

Chapter 1. Introduction: Occupational Road Safety as a Policy Issue ........................... 1

Occupational road safety in the European Union................................................. 3

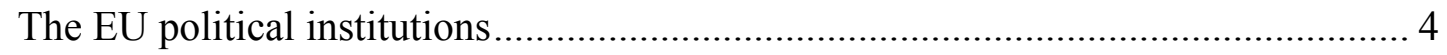

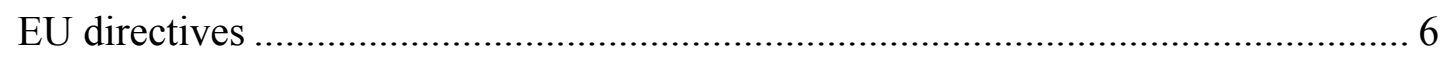

A brief history of transport policy in the EU................................................... 7

A brief history of occupational safety and health policy in the EU ....................... 12

European Union agencies with interest in occupational road safety ....................... 15

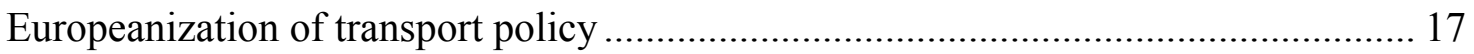

European Union member states: the United Kingdom, France, and Sweden .............. 18

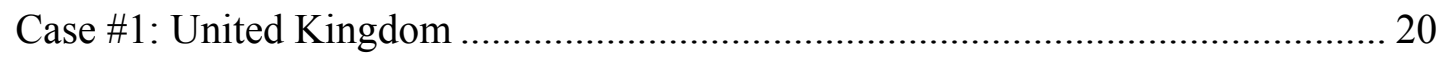

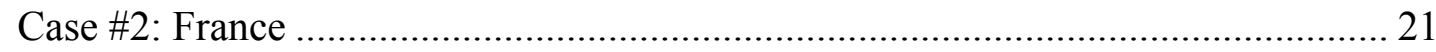

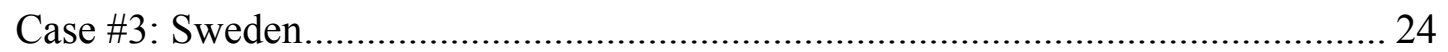

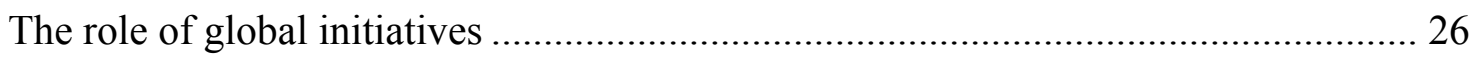

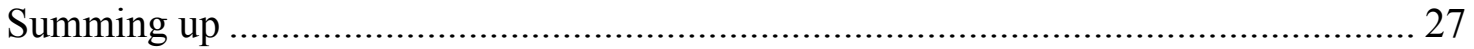

Chapter 2. Theoretical Framework, Research Questions, and Methodology ................. 29

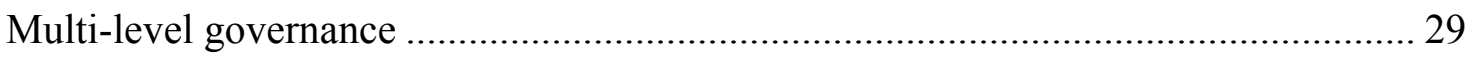

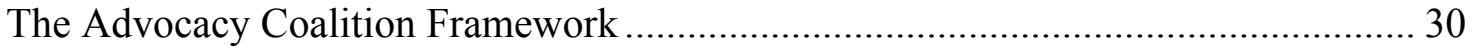

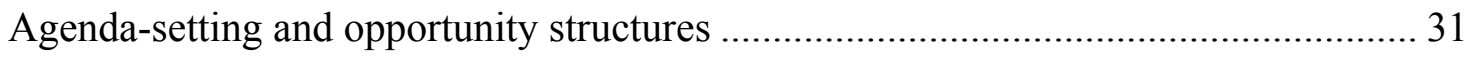

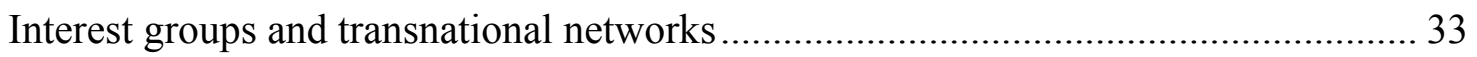

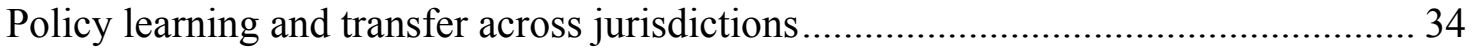

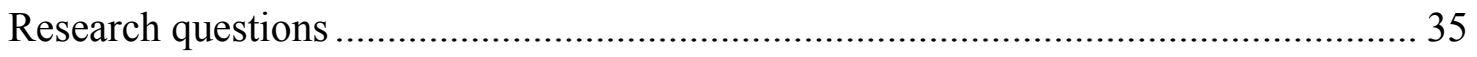

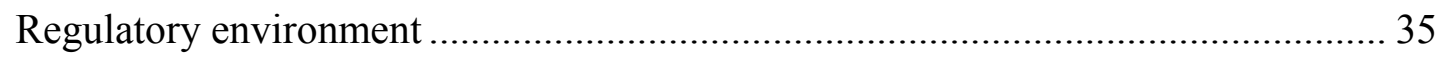

Applicability of the Advocacy Coalition Framework …........................................ 36

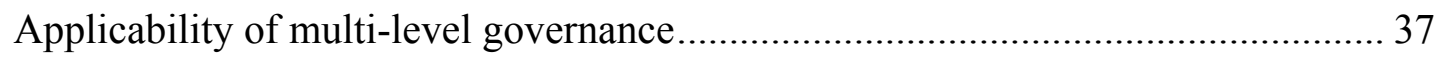




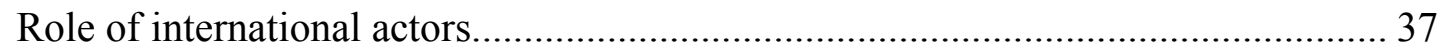

Key dependent and independent variables ........................................................... 38

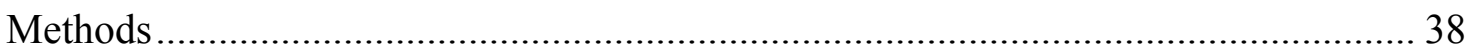

Framework for analyzing transposition of EU directives.......................................... 39

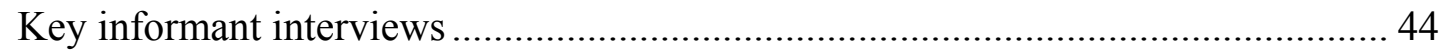

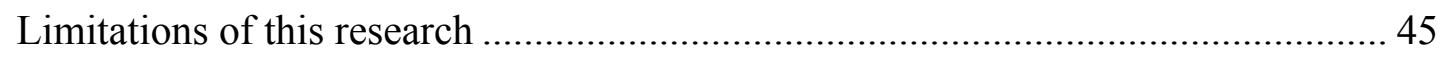

Chapter 3. The United Kingdom: Balancing Free Markets and Worker Safety .............. 47

Legislation and institutional structure .......................................................................... 47

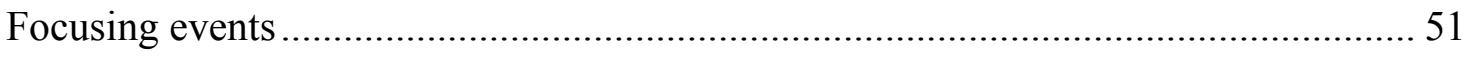

Actions by government, NGOs, researchers, and industry suppliers........................... 52

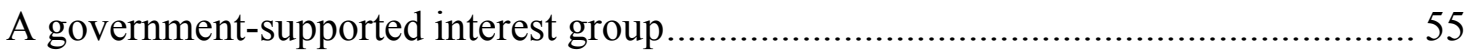

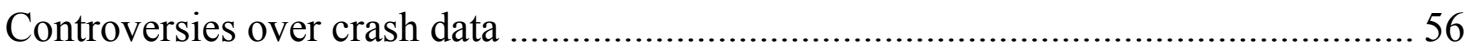

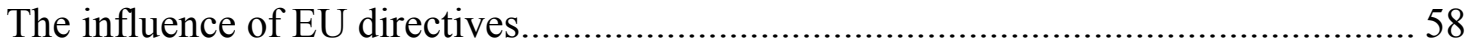

Policy learning through the European Union and multinational corporations.............. 58

British transposition of EU directives ....................................................................... 59

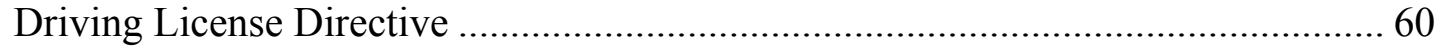

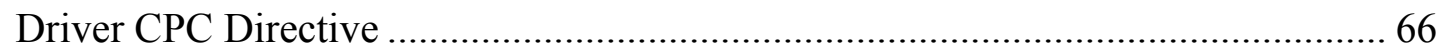

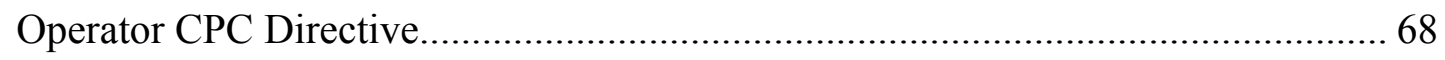

Road Transport Working Time Directive................................................................... 74

Working Time Directive ......................................................................................... 77

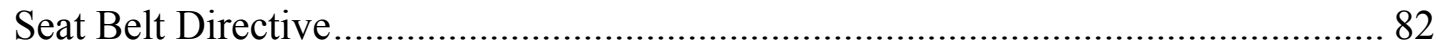

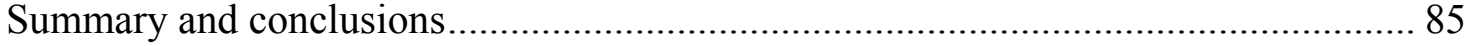

British transposition of EU directives .................................................................. 85

The ACF - Policy subsystem and framing ............................................................ 86

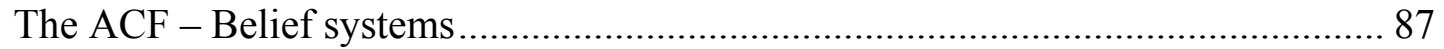

MLG - For the UK, less compelling than the ACF............................................... 88

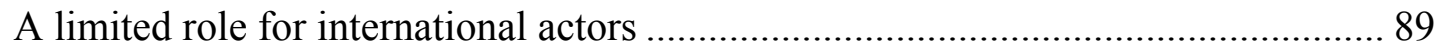

Chapter 4. France: Domestic Politics in a Surprisingly Corporatist Environment .......... 92

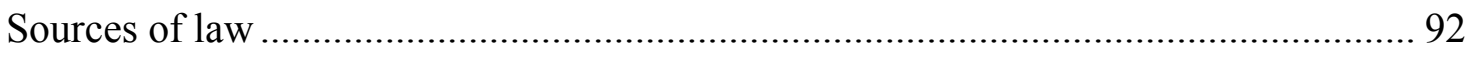

The Highway Code and institutional structure for transport........................................ 93

The Labor Code and occupational safety legislation .................................................... 96 


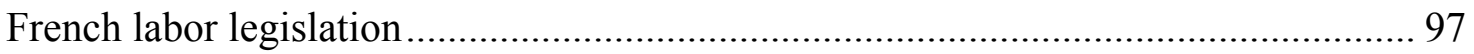

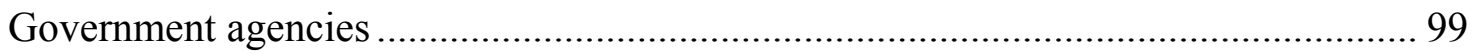

Interagency coordination through the Comité de pilotage ......................................... 100

French transposition of EU directives .................................................................... 102

Driving License Directive ...................................................................................... 103

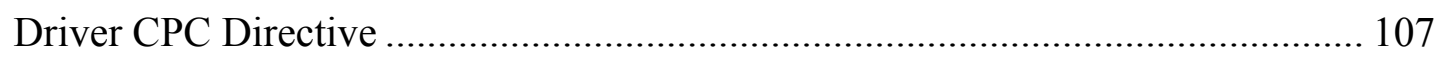

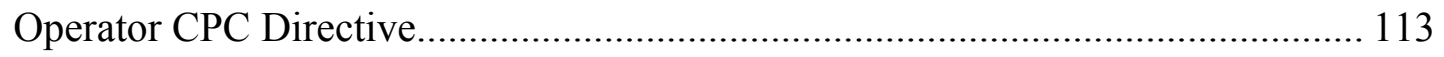

Road Transport Working Time Directive............................................................... 120

Working Time Directive ................................................................................. 125

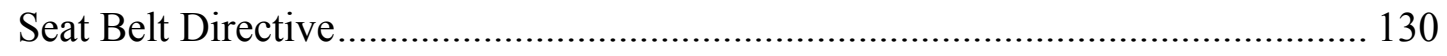

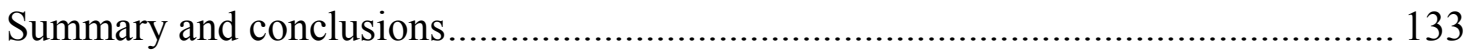

French transposition of EU directives ................................................................ 133

The primacy of domestic practices and politics .................................................... 134

Corporatist governance of occupational road safety ……........................................ 134

The ACF - Internal and external influences on policy........................................... 135

MLG - More a matter of governance than delegation to sub-state units ................. 136

Limits of diffusion of French policy and practices................................................... 137

Chapter 5. Sweden: Occupational Road Safety as Part of a Larger Vision for Society 142

Swedish legal instruments .................................................................................. 142

Legislation and institutional structure for road safety ............................................... 143

Vision Zero: A radical change in course ............................................................... 144

Legislation and institutional structure for occupational safety .................................. 147

Swedish transposition of EU directives ............................................................... 150

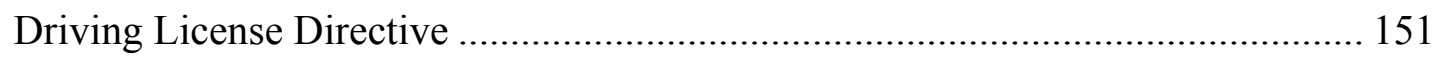

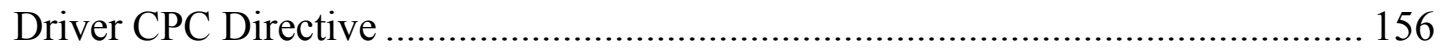

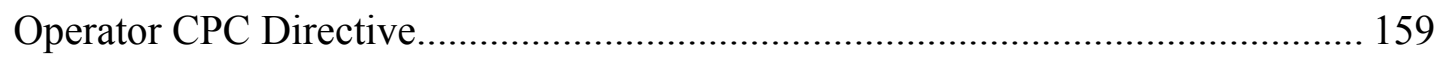

Road Transport Working Time Directive............................................................. 164

Working Time Directive .................................................................................. 168

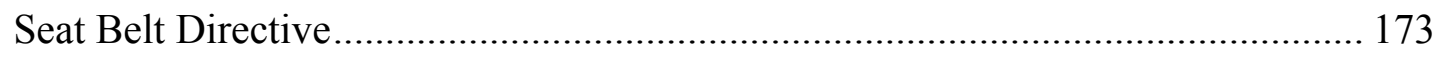

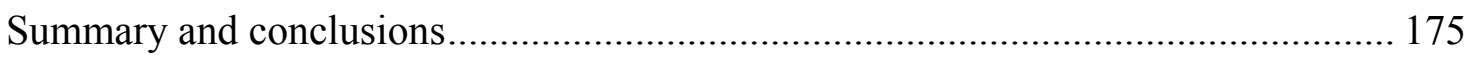

Swedish transposition of EU directives .............................................................. 175 
The ACF - A strong role for "deep core" beliefs.................................................... 176

Sweden's institutions and policymaking modes do matter ...................................... 177

Integration of road safety and occupational safety policy...................................... 178

Deviations from the "spirit" of EU law? ................................................................ 179

Bureaucratic discretion - a mixed record of success.............................................. 179

MLG - Greater applicability for Type II......................................................... 180

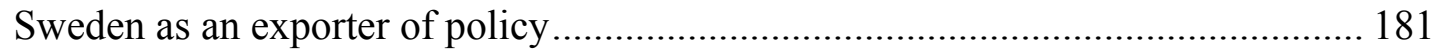

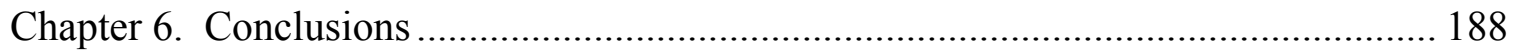

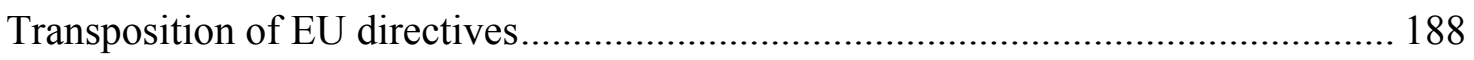

Applicability of the Advocacy Coalition Framework (ACF)...................................... 192

The ACF - Policy subsystems and belief systems ................................................ 192

The ACF - Epistemic communities and interest groups .......................................... 194

The ACF - Stable system parameters.................................................................. 196

The ACF - External systemic influences on policy ............................................... 198

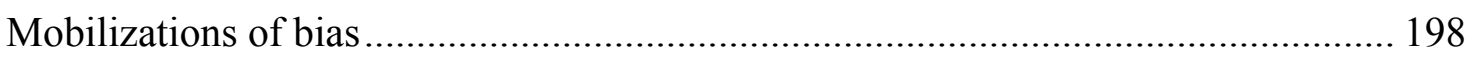

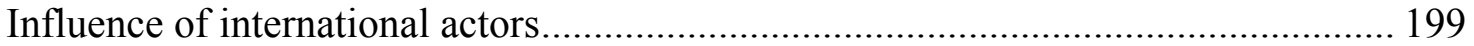

Applicability of multi-level governance (MLG) ………........................................... 202

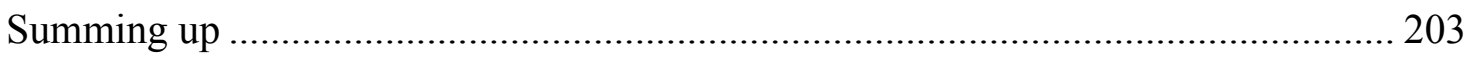

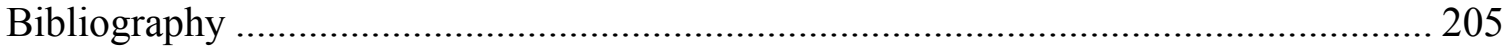

Appendix A. Key Informant Interviews .................................................................. 227

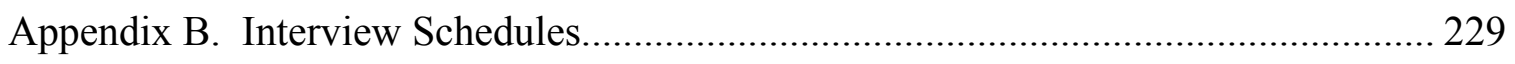

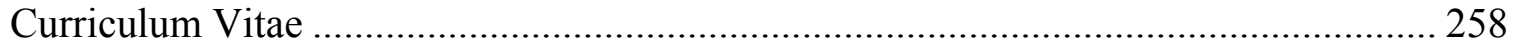




\section{List of Tables}

Table 1-1 Selected social and economic indicators for the EU-27 and selected member states

Table 2-1 EU directives included in transposition analysis or discussion

Table 3-1 British government agencies with responsibility for occupational road safety

Table 3-2 British transposition of Driving License Directive (91/439/EEC)

Table 3-3 United Kingdom transposition of Driver CPC Directive (2003/59/EC)

Table 3-4 British transposition of Operator CPC Directive (98/76/EC)

Table 3-5 British transposition of Road Transport Working Time Directive (2002/15/EC)

Table 3-6 British transposition of Working Time Directive (2003/88/EC)

Table 3-7 British transposition of Seat Belt Directive (2003/20/EC)

Table 3-8 British legislation and regulations related to transposition of selected EU directives for occupational road safety

Table 4-1 French government agencies with responsibility for occupational road safety

Table 4-2 French transposition of Driving License Directive (91/439/EEC)

Table 4-3 French transposition of Driver CPC Directive (2003/59/EC)

Table 4-4 French transposition of Operator CPC Directive (98/76/EC)

Table 4-5 French transposition of Road Transport Working Time Directive (2002/15/EC)

Table 4-6 French transposition of Working Time Directive (2003/88/EC)

Table 4-7 French transposition of Seat Belt Directive (2003/20/EC)

Table 4-8 French legislation and regulations related to transposition of selected EU directives for occupational road safety

Table 5-1 Swedish government bodies and sources of law related to occupational road safety

Table 5-2 Swedish transposition of Driving License Directive (91/439/EEC)

Table 5-3 Swedish transposition of Driver CPC Directive (2003/59/EC)

Table 5-4 Swedish transposition of Operator CPC Directive (98/76/EC)

Table 5-5 Swedish transposition of Road Transport Working Time Directive (2002/15/EC)

Table 5-6 Swedish transposition of Working Time Directive (2003/88/EC)

Table 5-7 Swedish transposition of Seat Belt Directive (2003/20/EC)

Table 5-8 Swedish legislation and regulations related to transposition of selected EU directives for occupational road safety

Table 6-1 Summary table: State-level transpositions of EU directives

\section{List of Figures}

Figure 1 Advocacy coalition framework

Figure 2 Standard vehicle classes used in the European Union 


\section{List of Acronyms}

\begin{tabular}{|c|c|}
\hline Acronym & Full name \\
\hline $\mathrm{ACF}$ & Advocacy Coalition Framework \\
\hline AETR & $\begin{array}{l}\text { Accord Européen sur les Transports Routiers [European Agreement on Road } \\
\text { Transport] }\end{array}$ \\
\hline AFS & $\begin{array}{l}\text { Arbetsmiljöverkets författningssamling [Statute Book of the Swedish Work } \\
\text { Environment Authority] }\end{array}$ \\
\hline CCMSA & $\begin{array}{l}\text { Caisse centrale de la mutualité sociale agricole [Social insurance fund for } \\
\text { agriculture] (France) }\end{array}$ \\
\hline CFDT & $\begin{array}{l}\text { Fédération nationale des transport routiers [National Road Transport Federation] } \\
\text { (France) }\end{array}$ \\
\hline CNAMTS & $\begin{array}{l}\text { Caisse nationale de l'assurance maladies des travailleurs salaries [National } \\
\text { Health Insurance Fund for Employees] (France) }\end{array}$ \\
\hline CNARCL & $\begin{array}{l}\text { Caisse nationale de retraites des agents des collectivités locales [Social insurance } \\
\text { fund for local government employees] (France) }\end{array}$ \\
\hline $\mathrm{CPC}$ & Certificate of Professional Competence \\
\hline CRAM & Caisse régionale d'assurance maladie [Regional health insurance fund (France) \\
\hline CTP & Common Transport Policy \\
\hline DfBB & Driving for Better Business (United Kingdom) \\
\hline DfT & Department for Transport (United Kingdom) \\
\hline DG & Directorate-General \\
\hline DG MOVE & Directorate-General Mobility \& Transport (European Union) \\
\hline DGTREN & Directorate-General Energy and Transport (European Union) \\
\hline DRP & Direction des risques professionnels [Directorate for Occupational Risks] (France) \\
\hline DSA & Driving Standards Agency (United Kingdom) \\
\hline DSCR & $\begin{array}{l}\text { Direction de la sécurité et de la circulation routières [Directorate of Road Safety } \\
\text { and Traffic] (France) }\end{array}$ \\
\hline DVLA & Driver and Vehicle Licensing Authority (United Kingdom) \\
\hline EC & European Community \\
\hline ECJ & European Court of Justice \\
\hline EEA & European Economic Area \\
\hline EEC & European Economic Community \\
\hline EP & European Parliament \\
\hline ETSC & European Transport Safety Council \\
\hline EU & European Union \\
\hline EU-OSHA & European Agency for Safety and Health at Work \\
\hline FMCSA & Federal Motor Carrier Safety Administration (United States) \\
\hline HMSO & Her Majesty's Stationery Office \\
\hline HSC & Health and Safety Commission (United Kingdom) \\
\hline HSE & Health and Safety Executive (United Kingdom) \\
\hline HSW Act & Health and Safety at Work Act (United Kingdom) \\
\hline ILO & International Labour Organization \\
\hline INRETS & $\begin{array}{l}\text { Institut national de recherche sur les transports et leurs sécurité [Institute for } \\
\text { Research on Transport and Transport Safety] (France) }\end{array}$ \\
\hline
\end{tabular}




\begin{tabular}{|c|c|}
\hline Acronym & Full name \\
\hline $\mathrm{IO}$ & International organization \\
\hline ISO & International Standards Organization \\
\hline JORF & $\begin{array}{l}\text { Journal Officiel de la République Française [Official Journal of the French } \\
\text { Republic] }\end{array}$ \\
\hline MLG & Multi-level governance \\
\hline MNC & Multi-national corporation \\
\hline MOU & Memorandum of understanding \\
\hline MVC & Motor vehicle crash \\
\hline NGO & Non-governmental organization \\
\hline NTF & $\begin{array}{l}\text { Nationalforeningen for Trafiksakerhetens Framjande (NTF) [National Society for } \\
\text { Road Safety] (Sweden) }\end{array}$ \\
\hline OECD & Organization for Economic Cooperation and Development \\
\hline OJ & Official Journal (of the European Community) \\
\hline OLV & Occupational light vehicle \\
\hline OMC & Open method of coordination (European Union) \\
\hline $\mathrm{OSH}$ & Occupational safety and health \\
\hline OSHA & Occupational Safety and Health Administration (United States) \\
\hline PPS & Purchasing Power Standard \\
\hline PRAISE & Preventing Road Accidents and Injuries for the Safety of Employees \\
\hline PSRE & $\begin{array}{l}\text { Promotion et suivi de la sécurité routière en enterprise [Promotion and monitoring } \\
\text { of work-related road safety] (France) }\end{array}$ \\
\hline QMV & Qualified-majority voting \\
\hline RIDDOR & $\begin{array}{l}\text { Reporting of Injury, Diseases, and Dangerous Occurrences Regulations (United } \\
\text { Kingdom) }\end{array}$ \\
\hline RSI & Régime social des indépendants [Social insurance for the self-employed] (France) \\
\hline RoSPA & Royal Society for the Prevention of Accidents (United Kingdom) \\
\hline RTA & Road Traffic Act (United Kingdom) \\
\hline SEA & Single European Act \\
\hline SFS & Svensk författningssamling [Swedish Code of Statutes] \\
\hline TSFS & Transportstyrelsens författningssamling [Swedish Transport Agency Regulations] \\
\hline UK & United Kingdom \\
\hline UN & United Nations \\
\hline UNECE & United Nations Economic Commission for Europe \\
\hline UNOSTRA & $\begin{array}{l}\text { Union national des organizations syndicales de transporteurs routiers } \\
\text { automobiles [National Union of Motor Carriers] (France) }\end{array}$ \\
\hline UNRSC & United Nations Road Safety Collaboration \\
\hline US & United States \\
\hline VOSA & Vehicle and Operator Services Agency (United Kingdom) \\
\hline VVFS & $\begin{array}{l}\text { Vägverkets författningssamling [Swedish National Road Administration Statute } \\
\text { Book] }\end{array}$ \\
\hline WEA & Work Environment Act (Sweden) \\
\hline
\end{tabular}




\section{Chapter 1. Introduction: Occupational Road Safety as a Policy Issue}

Road traffic crashes are a leading cause of death, injury, and disability throughout the world. In 2004, an estimated 1.27 million persons died as a result of road traffic injury, making it the ninth leading cause of death worldwide, and an estimated 20 to 50 million persons suffered non-fatal injuries (World Health Organization, 2009, pp. ix, 1-2). For children and for persons in their prime wage-earning years, the death toll is especially high, with road traffic injury among the three leading causes of death for persons aged 5 to 44 years (World Health Organization, 2009, p. 3). Moreover, the World Health Organization has projected that if strong interventions are not undertaken, road traffic injury will become the fifth leading cause of death worldwide by 2030, eclipsing communicable and chronic diseases such as HIV/AIDS, tuberculosis, diabetes, and lung cancer (World Health Organization, 2009, p. ix).

Because deaths or injuries of wage-earners affect the well-being of entire families, road traffic crashes adversely affect economic growth and development. Previous research has estimated that crashes cost governments from 1 to 3 percent of their gross national products. The effects are especially devastating for low- and middle-income countries, many of which incur costs from crashes in excess of the total amount of development assistance they receive (Jacobs, AeronThomas, \& Astrop, 2000, p. 10).

In addition to being a leading cause of death in the general population, motor vehicle crashes $(\mathrm{MVCs})^{1}$ are the leading cause of occupational fatalities in most high-income countries and regions, including the European Union (EU) and the United States (U.S.) (European Commission, 2009a, p. 23; U.S. Department of Labor, 2009, p. 2). Policy responses to occupational MVCs differ among EU member states. Some polities have instituted fairly aggressive governmental initiatives to manage occupational road risk. In others, despite the high human and economic toll of occupational MVCs, governments have taken limited action.

The primary aims of this research are to: (1) assess the development of occupational road safety policy in the EU through the lens of the policy literature, focusing on the advocacy coalition framework (ACF) as a model of policy change, the role of interest groups, and multi-level governance (MLG); and (2) use the United Kingdom (UK), Sweden, and France as EU case studies to illustrate the contributions of EU-member state interactions vs. initiatives at the state level, with emphasis on transposition of relevant EU directives into state-level law.

The primary argument is that in the EU member states, the entrance of occupational road safety onto the policy agenda and the subsequent policies and regulatory regimes can be explained by institutional features and interest-group structures, mediated by prevailing policy ideas at the domestic level. Further, these same factors have influenced policymakers at EU level.

\footnotetext{
${ }^{1}$ Hereafter, I will use the phrase "motor vehicle crashes" or "MVCs" because in the high-income regions that are the topic of this study, crashes generally involve motorized vehicles. The phrase "road traffic injury" is more frequently used in discussions of the global situation because it encompasses vulnerable road users such as pedestrians and persons in non-motorized vehicles (for example, bicycles and animal-drawn conveyances), who are disproportionately the victims of crashes in low-income countries.
} 
More specifically, this research addresses the following questions related to agenda-setting and problem definition surrounding occupational road safety:

What factors have influenced the placement of occupational road safety on the policy agenda in the UK, France, and Sweden?

- How has occupational road safety been framed as a policy issue in these polities?

- To what extent have the missions, design, and placement of responsible agencies influenced the policy instruments chosen and the way in which those policies have been implemented?

- To what extent has the fragmentation of occupational road safety across several substantive policy areas impeded progress in making policy? On the other hand, has fragmentation helped policymaking in any way, for example, by offering multiple venues for policy activism?

- What roles have international organizations, non-governmental organizations (NGOs), quasi-governmental agencies, and the private sector played in shaping occupational road safety policy?

With respect to regulatory environment, I assess the following:

- How have EU directives and policies influenced the progression of occupational road safety policy within the UK, France, and Sweden?

- How well have the UK, France, and Sweden transposed relevant EU directives into statelevel law?

Finally, applying the policy literature, I will examine the following questions:

- How well does the ACF model explain the development of occupational road safety policy in the EU and in the three member states?

- Does multi-level governance offer a plausible explanation of the policy climate for occupational road safety in the EU?

- To what degree have international actors influenced the spread of policy ideas within the three EU member states, and at EU level?

The methodology is primarily qualitative, supplemented by injury and fatality data and statistics on interest groups. Primary sources of data are regulations, policy documents, guidance documents, scientific literature, and interviews with key informants in government, international organizations, non-governmental organizations, and industry. These data enabled me to do the following for the EU and its three member states:

- More fully ascertain the governmental and governance infrastructure in which occupational road safety policy is made

- Compare and contrast the policy instruments that have been implemented to reduce occupational road risk in these polities, and the policy ideas behind these instruments

- Assess the "opportunity structure," interest group structure, and policy networks that surround the governmental policymaking bodies

- Identify EU directives and policy recommendations related to occupational road safety

- Assess the differential responses of the three EU member states to these directives 
This research contributes to the literature in several ways. Occupational road safety, in particular as it relates to employee drivers who are not operators of large commercial vehicles, has yet to be examined in comparative perspective. A recent global review of literature on the effectiveness of occupational road safety interventions found limited literature on the topic (Banks, Davey, Biggs, \& King, 2010). Comparison of policy and practices around the world has begun only recently, with initial conclusions emphasizing the need for country-wide crash data systems to identify work relationship, and for policy makers to integrate road safety into other aspects of occupational safety policy (Murray, Pratt, \& Watson, 2008).

Further, occupational road safety policy has not previously been assessed through the lens of the literatures on definition and framing of policy issues and the role of interest groups. Because interest groups are expected to play an important role in determining policy outcomes, I use the $\mathrm{ACF}$ as a general frame for analysis, and the EU-centered concept of multi-level governance to account for the dispersion of responsibility across various levels of government as well as the role of non-governmental actors.

This study applies theory of interest groups, political institutions, and agenda-setting to the policy area of occupational road safety. Application of these theories to a policy area that has received relatively little attention affords an opportunity to demonstrate their broader applicability. To date, the ACF has seen little application to transport policy, and its use therein has been limited to planning of road systems (Dudley \& Richardson, 1996; Greenaway \& Grantham, 2000).

In addition, the research explores EU responses to occupational road risk in comparative perspective, which to my knowledge has not been done. In this study, Sweden, France, and the UK are used as case studies to illustrate the relative contributions of EU policies compared with state-level initiatives, emphasizing the translation of relevant EU directives into state-level law.

\section{Occupational road safety in the European Union}

Across the European Union (EU), the problem of work-related MVCs is similar in magnitude to the U.S. In 2005, 40\% of the 5,720 workplace fatalities in the EU-27 were the result of an $\mathrm{MVC}^{2}$ (European Commission, 2009b, p. 142). Jurisdiction for occupational road safety at central-government level is split between transportation and labor agencies, with some coordination and support from public health agencies. In addition, there are marked differences between management of truck safety and management of other employees who drive, with the former handled through government regulation and the latter largely voluntary. I argue that this separation of policies stems from the linkage of freight transport activities and its associated safety implications to economic policy, and a failure to concurrently link other forms of occupational driving to any policy area.

\footnotetext{
${ }^{2}$ Eurostat, the EU statistical agency, uses a number of indicators to track the economic and social well-being of EU citizens. It is interesting to note that although the rate of occupational fatalities is one of these indicators, MVCs at work are excluded from the numerator (European Commission, 2009a, p. 23).
} 
In the EU, a quasi-federal polity, member states can each have a significant effect, and in some cases possibly an independent effect, on occupational road safety policy. The free movement of goods and labor that came with the completion of the single market has led to EU-level regulation of the trucking industry. However, the EU has no legislative imperative to regulate other employee drivers. Although the EU Directorate-General Mobility and Transport ${ }^{3}$ (DG MOVE) is the "home" agency for trucking policy, there is no "home" agency whose mission explicitly includes development of policy to promote the safety of other employee drivers.

\section{The EU political institutions}

Today, five major institutions within the EU set policy, enact legislation, and interpret law: the European Commission, the European Council, the Council of Ministers, the European Parliament, and the European Court of Justice. The Commission is the bureaucracy of the EU. Its functions include the exclusive right to propose legislation in areas of policy where the EU has competence, evaluating implementation of the primary treaty articles, issuing regulations and directives, managing the EU budget, and representing the EU in trade negotiations (Hix, 2005, p. 40). ${ }^{4}$ Its mission is to promote the welfare of the EU as a whole and not the interests of individual member states. As of February 2011, the Commission is divided into twenty-one directorates-general (DGs) with responsibility for individual policy areas; those directly relevant to occupational road safety are DG $\mathrm{MOVE}^{5}$ and the Directorate for Employment, Social Affairs, and Equal Opportunities. ${ }^{6}$

Staffing levels within the DGs are surprisingly modest; for example, the number of Commission staff dedicated to transport is far less than the number of staff employed at ministries of transport in individual member states (Stevens, 2004, p. 69). In 2003, the transport directorate, which at that time included energy, had 995 staff, and the employment directorate had 693 (Wallace, 2005, pp. 54-55). This has important implications for the way policy is made. Rather than relying on in-house expertise, Commission bureaucrats routinely draw on subject-matter experts from throughout the EU, including transnational actors, to obtain input for policy proposals (Zippel, 2004, p. 64).

The European Council is made up of chief political executives of member states and the President of the European Commission. Until 2009, it was chaired by the chief political executive of the member state that held the EU Presidency, which rotates among states every six

\footnotetext{
${ }^{3}$ Transport and energy policy functions within the European Commission, previously combined under the Directorate-General Energy and Transport (DGTREN), were split into two new DGs as of February 2010. The new DG responsible for transport is called the Directorate-General Mobility and Transport (DG MOVE).

${ }^{4}$ The word "Commission" is also used to refer to the body of 27 Commissioners (currently one from each member state) responsible for overall direction and decision-making for the EU bureaucracy.

${ }^{5}$ As of 2010, the Director-General of DG MOVE was Matthias Ruete of Germany, and the Commissioner whose portfolio includes transport was Siim Kallas of Estonia, who is also a vice-president of the College of Commissioners.

${ }^{6}$ As of 2010, the Director-General of the Employment directorate was Robert Verrue of France. The Commissioners whose portfolios encompass the activities of the employment directorate were László Andor of Hungary (employment, social affairs, and inclusion) and Viviane Reding of Luxembourg (gender equality and citizenship), who is also a vice-president of the College of Commissioners.
} 
months. It is now chaired by the President of the European Council, a new position created by the Treaty of Lisbon that is currently held by Herman Van Rompuy of Belgium. The European Council determines broad EU policy directions. For example, the decisions to proceed with European Monetary Union and to institute an aggressive program for accession of central and eastern European states came out of the European Council. The European Council also resolves issues that cannot be settled at lower levels (Wallace, 2005, p. 64). The member state holding the Presidency uses the position to promote a work program for the EU that typically emphasizes its state-level policy priorities.

The Council of Ministers is the main decision-making body of the EU. It meets in nine possible configurations depending on policy area, with one minister representing each member state. The minister from the member state that holds the EU Presidency chairs the Council of Ministers. Whereas the European Commission holds the right to propose legislation for core policy areas, the Council of Ministers shares with the European Parliament (EP) the power to enact legislation. Nearly all decisions made by the Council of Ministers once required unanimous approval by member states, but today most legislation can be passed by qualified-majority voting (QMV) in which each state is assigned a certain number of votes and passage requires roughly 70 percent of the votes. Configurations of the Council of Ministers relevant to this research are the Transport, Telecommunications, and Energy Council and the Employment, Social Policy, Health, and Consumer Affairs Council (Van Oudenaren, 2005, pp. 78-79).

The EP shares legislative responsibility with the Council of Ministers. It is unique among EU institutions in that members are directly elected by citizens of the member states. The 736 seats in the EP are allocated roughly proportional to member-state populations, but the states with the smallest populations are somewhat over-represented. Successive EU treaties have conferred more power on the EP. For example, the co-decision procedure requires the Council and Ministers and the EP to agree on legislation; if they do not, a commission must be formed to reconcile differences and agree on a text. The EP conducts much of its work through standing committees; among these are Regional Policy, Transport, and Tourism; and Employment and Social Affairs (Van Oudenaren, 2005, pp. 89-96).

Finally, the European Court of Justice (ECJ) is charged with adjudicating disputes stemming from interpretation of EU law. EU law is distinct from international law and from the legal systems of the member states. EU laws come from three sources. First are the treaties themselves and other high-level agreements between member states. Second are the various levels of executive and legislative actions: regulations, directives, decisions, recommendations, and opinions. Finally, ECJ decisions are informed by general legal principles derived in part from the EU treaties and in part from prevailing judicial philosophy at member-state level; these include upholding the "four freedoms" (free movement of goods, persons, services, and capital), fundamental human rights, political rights, and the right to a fair hearing (Hix, 2005, pp. 115117).

The ECJ is made up of one judge from each member state and eight advocates-general. It hears three types of cases: actions brought against member states for failure to adhere to obligations under the EU treaties or to EU regulations; judicial reviews of EU legislation and executive or administrative actions, and requests by state-level courts for preliminary rulings on cases related 
to EU law (Hix, 2005, pp. 119-120). In areas where the EU has competence, EU law takes precedence over member-state law if there is a conflict between the two. In addition, EU law is directly applicable to EU citizens, which means that the rights conferred upon individual citizens by EU law must be upheld by courts at member-state level, and that citizens have the right to bring cases directly to the ECJ (Hix, 2005, pp. 121-122).

\section{EU directives}

EU law is passed to the member states in various forms, with the intergovernmental treaties at the highest level, followed by regulations, directives, decisions, recommendations, and opinions. Regulations are directly applicable to member states, and provide no flexibility for adaptation or integration with state-level laws. Directives, on the other hand, are more performance-based, and are handed down to member states with the expectation that they will be "transposed" into state law within a certain time period. Decisions, like regulations, are binding on member states, but may also be addressed to private citizens or organizations. 7 Recommendations and opinions may be addressed to any entity, but do not bind the recipient (Hix, 2005, pp. 116-117; Van Oudenaren, 2005, pp. 105-107).

Not all directives are the same. Some leave considerable latitude to member states, while others such as food safety or environmental directives give technical or quantitative requirements that in fact leave little room for states to maneuver. The more technical directives reflect the socalled "precautionary principle" that underpins the EU approach to regulating substances or conditions which may reasonably be expected to pose high risks. This principle legitimates erring on the side of issuing regulations to cover potentially dangerous effects of a product or process, even in the absence of a body of conclusive evidence. The precautionary principle was incorporated into the Maastricht Treaty of 1992, and has been cited in numerous reports and resolutions of the EP since that time (Vogel, 2003, p. 566). However, the precautionary principle was only made explicit in Maastricht for environmental protections [Title XVI, Article 130r(2)] (European Community, July 29, 1992, pp. 28-29). The Commission later clarified that the principle was to be applied more broadly:

"...in practice, its scope is much wider, and specifically where preliminary objective scientific evaluation, indicates that there are reasonable grounds for concern that the potentially dangerous effects on the environment, human, animal or plant health may be inconsistent with the high level of protection chosen for the Community" (Commission of the European Communities, February 2, 2000, p. 3).

EU directives may also be distinguished by whether they address "product" characteristics that could result in non-tariff barriers to trade, or "process" directives related to manufacturing products or providing services (Sedelmeier, 2005, p. 416). Food safety directives again offer an

\footnotetext{
${ }^{7}$ Examples of decisions include determinations by the European Commission that proposed mergers such as Nestlé/Perrier were inconsistent with EU competition policy. The Commission also issued a decision that opposed the merger of Boeing and McDonnell Douglas, even though these were U.S. companies, on the grounds that it was harmful to EU markets (Wilks, 2005, pp. 115-116).
} 
example of "product" directives that may be linked to the European single market and unfair competition in the event they appear to favor one member state's agricultural products over another's.

The EU has generally been more successful in implementing product directives than process directives (Wallace, 2005, pp. 80-82). The reasons for this may be a clearer causal path to perceived risk for products than processes, and a more salient link to markets. Social and employment directives, which are generally more process-oriented, tend to allow member states more flexibility in transposition compared to product directives. By their very nature, they are less quantitative and therefore somewhat less prescriptive. Further, there is perhaps less of an imperative to ensure their uniform application, as they were intended not to create a "supranational welfare state" but to correct obvious market failures stemming from completion of the single European market (Rhodes, 2005, p. 285).

Overall, reliance on directives as the primary means of legislation that supports the EU treaties has its advantages and disadvantages. Compared to regulations, which are directly applicable, directives offer member states the opportunity to adapt EU-directed policy to state-level preferences. At domestic level, this arrangement may be more palatable politically than directly applicable directives in that it preserves state sovereignty to a greater degree. However, the widespread use of directives creates complications for the single market; businesses must deal with variability in state-level law across the countries in which they operate, at least in the case of the less prescriptive "process" directives. Further, from an administrative standpoint, a reliance on directives necessitates an extraordinarily complex system of monitoring for the European Commission bureaucracy (Van Oudenaren, 2005, pp. 105-107). Commission bureaucrats must monitor the timeliness and correctness of transposition of each directive by each member state. The Commission and other EU institutions may bring legal actions in the ECJ against member states for non-transposition of directives, with substantial financial penalties assessed in some instances (Wallace, 2005, p. 67).

\section{A brief history of transport policy in the EU}

The impetus for regulation of freight and passenger transport in the EU can be traced to related provisions in the Treaty of Rome ${ }^{8}$ (1957) which called for: "a common policy in the sphere of transport" [Article 3(1)(f)]; "an internal market characterised by the abolition, as between Member States, of obstacles to the free movement of goods, persons, services and capital" [Article 3(1)(c)]; and "a system ensuring that competition in the internal market is not distorted" [Article 3(1)(g)] (European Economic Community, 1957). Additional articles of the Treaty of Rome specific to transport charged the Council [of Ministers for Transport] with laying down "common rules applicable to international transport to or from the territory of a Member State or passing across the territory of one or more Member States" [Article 71(1)(a)] and "the conditions

\footnotetext{
${ }^{8}$ Originally titled the "Treaty establishing the European Economic Community," this was renamed the "Treaty establishing the European Community" by the Maastricht Treaty (1992) and again renamed the "Treaty on the functioning of the European Union" by the Treaty of Lisbon (2009).
} 
under which non-resident carriers may operate transport services within a Member State"9 [Article 71(1)(b)] (European Economic Community, 1957).

Article 70 of the Treaty of Rome stated: "The objectives of this Treaty shall, in matters governed by this Title, be pursued by Member States within the framework of a common transport policy" (European Economic Community, 1957). Stevens argues that this seemingly inconsequential provision was in fact significant because in linking the common transport policy (CTP) to the overarching objectives of the Treaty of Rome, which as laid out in Article 3 were essentially liberal economically, it ensured that the CTP that resulted would also be liberal (Stevens, 2004, p. 40). Here, the word "liberal" means that the guiding principles for the CTP would presumably support the removal of barriers that might prevent free access to markets in terms of the number of companies that could enter the market and the rates at which transport services could be offered.

Despite early efforts to set into motion a process for creating a CTP, its development was marked by false starts and philosophical differences. Kerwer and Teutsch summarize the dilemma as follows: "The nature of the debate regarding supranational decision making for road transport has always been a battle for opening of markets on the one hand and harmonization of competitive conditions between hauliers from different countries and among different modes of transport for the other" (Kerwer \& Teutsch, 2001b, p. 26). The early failure to progress may have been due to the lack of clear direction provided in the Treaty of Rome, likely a concession to divergent preferences at member-state level that were impossible to reconcile (Kerwer \& Teutsch, 2001b, p. 27; Stevens, 2004, p. 44). On the one hand, consistent with their domestic policy preferences, France, Germany, and Italy favored a model of state intervention in transport, which took two forms: quantitative restrictions much like those in force in the U.S. under economic regulation of trucking, that is, measures to limit the number of operating licenses for trucking companies and set prices for transport services; and qualitative restrictions which required companies to demonstrate a certain level of professional and financial qualification in order to operate (Kerwer \& Teutsch, 2001a, p. 126). On the other hand, the Netherlands favored a liberal approach to transport policy which would broaden market access and allow market forces to determine which companies would succeed and which would fail (Stevens, 2004, pp. 38-39).

It is important to note that the scope of the CTP extended to all modes of transportation, not just road transport. This was significant for countries such as France for which the rail system was a point of national pride and which were especially sensitive to the prospect that a CTP might cause them to lose control of rail infrastructure and policy. At the same time, there was a fear that liberalizing road transport across borders of member states might make freight transport via national rail systems less competitive (Héritier, 2001, p. 17; Kerwer \& Teutsch, 2001b, pp. 25, 27).

Another impediment to development of a CTP was that at the time the Treaty of Rome came into force, member states had set cross-border aspects of transport policy through bilateral and

${ }^{9}$ The access of foreign transport providers to foreign domestic markets is referred to as "cabotage" (Kerwer \& Teutsch, 2001b, p. 29). 
multilateral agreements and through mechanisms such as the European Conference of Ministers of Transport (Kerwer \& Teutsch, 2001b, p. 28). Because states had customarily handled transport policy through intergovernmental channels, a shift to the supranational approach prescribed by the Treaty of Rome may have been difficult for both practical and political reasons.

The first serious attempt to lay the foundation for a CTP came via the so-called "Schaus Memorandum" of 1961 spearheaded by Lambert Schaus, who was one of the signatories of the Treaty of Rome for Luxembourg, and the new European Economic Community's (EEC's) first Commissioner for Transport. The proposals in the Schaus Memorandum aspired to allow consumers of transport services free choice of modes and companies and to give transport operators freedom of action. ${ }^{10}$ Although Schaus was well-respected within the policy community, his detailed blueprint for a CTP failed to gain any traction within the Transport Council (Stevens, 2004, p. 48).

Throughout the remainder of the 1960s and into the 1970s, little progress was made in developing a CTP through either the Commission or the Transport Council. A 1971 decision by the ECJ, however, began to lay the groundwork for a supranational approach for the CTP. This decision, known as the AETR ${ }^{11}$ case (ECJ 22/70), nullified the European practice of negotiating bilateral and multilateral agreements in the intergovernmental arena, which had continued despite the affirmations in the Treaty of Rome that development of European policy was to proceed supranationally.

At issue was modification of a European agreement on the work of crews of vehicles engaged in international road transport. Although the AETR had been signed in 1962, it had yet to be implemented because not enough countries had ratified it. Negotiations resumed in 1967 under the auspices of the United Nations Economic Commission for Europe (UNECE) with the goal of developing a more widely acceptable version. Meanwhile, the Transport Council had agreed on a regulation (R543/69) harmonizing legislation within member states on points such as minimum rest periods and maximum driving hours. At the same time, it had decided to sign the amended AETR.

In bringing the AETR case before the ECJ, the Commission argued that the Transport Council had no authority to enter into intergovernmental agreements such as the AETR on behalf of the European Community. The ECJ judgment in the AETR case was critical, not just for future development of the CTP but to all EEC policy areas. It established the principle that once the EEC had established internal policy in a policy area, as the Transport Council had begun to do with regulation R543/69, the EEC also had competency in external relations in that area. This meant that member states no longer had the right to individually or collectively enter into agreements with third countries ${ }^{12}$ (Stevens, 2004, pp. 48-52).

\footnotetext{
${ }^{10}$ Two decades later, a Commission policy document noted that the Schaus Memorandum had indeed been written in accordance with the liberal frame of the Treaty of Rome (Commission of the European Communities, 1983, p. 3).

${ }^{11}$ From the Accord Européen sur les Transports Routiers (AETR) [European Agreement for Road Transport]

${ }^{12}$ For primarily procedural reasons, the ECJ actually found in favor of the Council in the AETR case. It chose, however, to use the AETR decision to establish the primacy of Community policy over intergovernmental agreements. Although the Commission lost its case, in reality the ECJ judgment significantly shifted the balance
} 
There followed shortly another attempt by the Commission to offer a framework for a CTP. This document ${ }^{13}$ showed a shift in strategy by the Commission, calling for integration of member state policies within an overarching Community policy rather than replacement of state policies with a single Community policy (Kerwer \& Teutsch, 2001b, pp. 27-28). A decade later, a Commission document on inland transport acknowledged that transport policy could not be pursued independently from other related policy areas, citing "the interdependence between transport and other Community policies for the attainment of better living and working conditions" (Commission of the European Communities, 1983, p. 5). Despite the concessions made in this document to member states concerned with maintaining some degree of state control over transport policy, the Transport Council again took no action in response (Stevens, 2004, p. 48).

The literature suggests that meaningful progress toward a CTP came about only after two key events: the European Parliament's 1983 suit against both the Transport Council and the Commission for their failure to develop a CTP, and a new push toward completion of a single European market. John Steele, the new Transport Commissioner and a key figure in promoting the Parliament's legal action, was guided by the liberal transport policies already in place in the UK, and hoped to transfer this approach to the European Economic Community (Stevens, 2004, p. 57). In its 1985 ruling on Parliament v. Council (Case 13/83), the ECJ did not find for infringement of the Treaty of Rome, but it did find that the Transport Council was in breach of specific obligations in Article 71(a) and (b) of the Treaty. ${ }^{14}$

The ECJ decision on the CTP was followed closely by the Commission's release of its White Paper on Completing the Internal Market. This report provided further political momentum for action on a CTP because it recognized that liberalizing transport markets was necessary to creating a single European market. The relevant text from this White Paper is worth quoting in its entirety:

The right to provide transport services freely throughout the Community is an important part of the Common Transport Policy set out in the Treaty. It should be noted that transport represents more than $7 \%$ of the Community's g.d.p., and that the development of a free market in this sector would have considerable economic consequences for industry and trade. The recent decision of the Court in the case brought by the European Parliament against the Council for failure to act in the field of the common transport policy (Case 13/83) highlights the necessity of making rapid progress in this area.

(Commission of the European Communities, 1985, p. 29)

toward supranational policymaking and confirmed the Commission's leadership in making proposals (Stevens, 2004, p. 51).

${ }^{13}$ Commission of the European Communities. (1973). Development of the Common Transport Policy, EC Bulletin Supplement 16/73. Cited in Stevens (2004), p. 48.

${ }^{14}$ These portions of Article 71 covered common rules governing transport across member state borders, and conditions under which transport companies based in one member state were permitted to operate in another member state ("cabotage"). 
The White Paper also stated that completion of the single European market would require the phasing out of quantitative restrictions (that is, quotas) in road transport markets, as well as defining of conditions under which transport firms from outside a member state could gain access to that state's transport markets ${ }^{15}$ (Commission of the European Communities, 1985, pp. 29-30). In order for the single market to be completed on schedule, these actions were to be taken by 1988. In 1988, the European Council did indeed formally decide to phase in the elimination of quantitative restrictions on road transport markets beginning in January, 1993. The plan was to increase the number of available licenses for road transport operators each year until July, 1998, by which time complete liberalization would be achieved (Kerwer \& Teutsch, 2001b, p. 29).

Beginning in the 1980s, changes to EEC treaties reinforced the linkage between transport policy and the single market, and linked transport policy to other emerging issues. First, Article 13 of the 1986 Single European Act (SEA), in defining the "four freedoms" upon which European integration was to rest, stated: "...the internal market shall comprise an area without internal frontiers in which the free movement of goods, persons, services, and capital is ensured in accordance with the provisions of this treaty" (European Economic Community, June 29, 1987, p. 7). In 1992, the Maastricht Treaty added new language to Article 75 (formerly Article 71), placing "measures to improve transport safety" within the competence of the newly constituted EU (European Community, July 29, 1992, p. 10). For road safety in general, this had wide implications, giving the EU the authority to regulate technical and behavioral aspects of road safety related to drivers, roadways, and vehicles. For occupational road safety in particular, the Maastricht Treaty supported the development of road safety regulations and directives for commercial transport to complement regulations that had already begun to develop under the EEC. Moreover, because it did not limit the scope of EU competence for transport safety to the transportation industry, the Maastricht Treaty also opened the door for EU legislation that went beyond the traditional scope of transport policy, that is, legislation that would apply to occupational drivers other than those engaged in transport of freight or passengers.

In the early 1970s, EEC member states began to develop action plans to address emerging environmental concerns such as climate change, pollution, waste management, and biodiversity (Hix, 2005, pp. 251-252). The SEA gave environmental policy greater stature by placing it fully under EEC competence, with implications for transport. The Maastricht Treaty added "a policy in the sphere of the environment" to the list of core EU activities in Article 2 (European Community, July 29, 1992, p. 5), and required further in the new Article 130r that "environmental protection requirements must be integrated into the definition and implementation of other Community policies" (European Community, July 29, 1992, p. 29). In addition, in calling for "sustainable and non-inflationary growth respecting the environment," (European Community, July 29, 1992, p. 5), the Maastricht Treaty placed environmental considerations above the economic imperatives that had heretofore driven development of the single European market. The EU had begun to recognize the negative externalities of transporting more goods by road, and of higher levels of road use in general - traffic congestion,

\footnotetext{
15 These two requirements were nothing new; in reality, they did nothing more than reaffirm Article 71 of the Treaty of Rome. Furthermore, the Treaty of Rome also alludes to the link between a common transport policy and the single market, with both these topics cited in Article 3.
} 
air pollution, climate change, reliance on fossil fuels, and increases in MVC-related deaths and injuries (Stevens, 2004, pp. 61-64).

\section{A brief history of occupational safety and health policy in the EU}

The Treaty of Rome (1957) left social policy, including working conditions and worker health and safety, largely in the hands of the member states (Falkner, Treib, Hartlapp, \& Leiber, 2005, p. 41; Majone, 1993, p. 154). Only in the 1980s when the full implications of the single market became clearer did European policymakers begin to realize that supranational coordination of economic and competition policy, coupled with member-state control of social policy, was ultimately untenable (Leibfried, 2005, p. 244). The single market project was essentially a deregulatory agenda that would dismantle all barriers to free movement of people, labor, capital, and goods (the "four freedoms"). However, if vast differences in social policy in member states remained, businesses across the EU could not compete on an equal footing, even if the single market were achieved, because the costs of complying with social regulations would be considerably higher in some states than in others.

The Treaty of Rome did give the EEC latitude in one particular area of social policy; Article 100 made an exception in the case of matters which "directly affect the functioning of the common market" (European Economic Community, 1957). Here, the Commission could propose measures which would then require unanimous approval in the Council of Ministers. The requirement for unanimity, however, practically limited the ability of the Community to pass this type of legislation.

The event that opened the door for EEC-level legislation of social policy was the passage of the SEA. Here, member states finally had to grapple with the essential incompatibility between supranational formation of economic policy and state-level formation of social policy. Although the SEA extended EEC competences in several areas, including environment, there remained resistance to ceding competence for social policy. Member states' employment regimes varied considerably, and were historically embedded in state-specific value systems, interest-group configurations, and labor market practices. States' labor policies fell into three groups: those with constitutional guarantees of workers' rights and substantial state intervention in labor markets, those in which the state has refrained from supporting comprehensive industrial codes and regulations, and those in which corporatist agreements between employers and unions generally take the place of government-imposed rules and regulations (Rhodes, 2005, p. 282). France belonged to the interventionist group, the UK to the non-interventionist group, and Sweden to the corporatist group. It is interesting to note that based on the literature, the French tendency toward interventionist, state-driven policies and the British tendency to let market forces prevail are consistent across both transport policy and labor policy (of which occupational safety is a component).

Despite member states' general reluctance to extend the EEC's competence into social policy, the SEA did contain a significant provision that placed occupational safety and health (OSH) under the purview of the EEC, and allowed relevant legislation to be approved by QMV. Specifically, the SEA amended the EEC treaty to state that "Member States shall pay particular attention to encouraging improvements, especially in the working environment, as regards the health and safety of workers, and shall set as their objective the harmonization of conditions in 
this area, while maintaining the improvements made" [Article 21 of the SEA, inserting new Article 118a(1) into the Treaty Establishing the European Economic Community] (European Economic Community, June 29, 1987, p. 9).

Two portions of the above text from the SEA are worthy of note. One is the introduction of the concept of the "working environment," which implied that the reach of OSH legislation by the Community might extend beyond the traditional boundaries of the physical workplace. Under the broad interpretation preferred by the EP (but not the Commission or Council of Ministers), Article 118a gave the EEC competence for legislation on matters such as hours of work, workrelated stress, ergonomics, and organization of the labor market (Majone, 1993, p. 155). Also significant is the last portion of this text, because it required existing state-level rules which might be more protective than future EEC rules to remain in place.

At the same time, however, the SEA contained provisions that set constraints on future social legislation by the EEC. One stipulated that small- and medium-sized firms should be protected from excessive regulatory burdens [Article 21 of the SEA, inserting new Article 118a(2) into the Treaty Establishing the European Economic Community] (European Economic Community, June 29, 1987, p. 9). In addition, although the new Article 100a no longer stipulated that any Community social legislation must be necessary to the functioning of a common market (as was the case in Article 100 of the Treaty of Rome) (Majone, 1993, p. 154), it did not extend QMV to provisions related to workers' rights and interests and to the free movement of persons. This qualification came at the insistence of the Thatcher government in the UK, which had been pursuing an aggressive deregulatory agenda domestically (European Economic Community, June 29, 1987, p. 8; Rhodes, 2005, p. 286).

Despite these limitations, however, the SEA provision that allows QMV for OSH legislation may be viewed as a meaningful first step, albeit a compromise for member states, because of the obvious urgency to achieving some degree of harmonization in labor standards as a condition for completing a single European market (Falkner, et al., 2005, p. 43). Moreover, the introduction of QMV was strengthened by language elsewhere in the SEA that set the standard of a high level of protection for future EEC regulation [Article 18 of the SEA, inserting new Article 100a(3) into the Treaty Establishing the European Economic Community] (European Economic Community, June 29, 1987, p. 8; Hix, 2005, p. 250; Leibfried, 2005, p. 249).

The first major OSH legislation after passage of the SEA was a 1989 directive on "measures to encourage improvements in the safety and health of workers at work," commonly referred to as the "Framework Directive." This directive (89/391/EEC) signaled a new approach for the management of occupational risk; instead of prescribing preventive measures targeted to specific sectors or hazards, it provided general guidelines with the expectation that more detailed “daughter directives" would follow ${ }^{16}$ (Baldwin, 1996, p. 95).

\footnotetext{
${ }^{16}$ An appendix to the directive specified that the "daughter directives" were to include but not be limited to the following topics: work places, work equipment, personal protective equipment, work with visual display units, handling of heavy loads involving risk of back injury, temporary or mobile work sites, and fisheries and agriculture (Commission of the European Communities, June 26, 1989).
} 
The Framework Directive applies to all enterprises in the public and private sectors, and obligates the employer to "take the measures necessary for the safety and health protection of workers, including prevention of occupational risks and provision of information and training, as well as provision of the necessary organization and means" [Article 6(1)]. It emphasizes the employer's responsibility to "evaluate the risks to the safety and health of workers, inter alia in the choice of work equipment, the chemical substances or preparations used, and the fitting-out of work places" [Article 6(3)a]. The employer is also required to "be in possession of an assessment of the risks to safety and health at work, including those facing groups of workers exposed to particular risks" [Article 9(1)a], and to inform workers, their representatives, and contract employees of "the safety and health risks and protective and preventive measures and activities in respect of both the undertaking and/or establishment in general and each type of workstation and/or job" [Article 10(1)a] (Commission of the European Communities, June 26, 1989).

The Framework Directive's scope and breadth admit the possibility that its requirements for risk assessment and worker information might apply to mobile work settings such as occupational vehicles, and raises the question of how individual member states may have interpreted the directive. (Article 118a of the EEC treaties as amended by the SEA raises similar questions because it introduced the idea of the "working environment" but then failed to define it.) No "daughter directives" to the Framework Directive have been formulated to address the specific issue of occupational road risk, yet taken at face value, the risk assessment provisions in the Framework Directive would seem to apply to all work situations, including driving. Nor does the Framework Directive explicitly state that transport activities are exempted from its scope. Therefore, the interpretation of this directive by member states, as it applies to occupational road risk, is of particular interest to this research.

EEC efforts to define a social dimension to the single-market program continued through the late 1980s, culminating with the approval in 1989 of the Charter on the Fundamental Social Rights of Workers (the "Social Charter") by all member states except for the UK. As negotiations leading to the Maastricht Treaty proceeded, the majority of member states wanted to incorporate the Social Charter into the new treaty and to institute QMV in most areas of social policy. However, the UK vetoed this proposal, so the remaining eleven states approved the new Social Protocol as an attachment to the Maastricht Treaty, with the UK opting out.

In essence, what the Social Protocol did for OSH policy was to enshrine the scope and aspirations of the Framework Directive within the EU treaties. Improved living and working conditions, improved social protections, and promotion of employment were now listed among the primary objectives of the EU and its member states [Article 1, Social Protocol]. In addition, the Community was bound to support member-state activities to promote improvement of the working environment, working conditions, and worker information and consultation [Article 2(1), Social Protocol]. Earlier provisions that directives should not discourage development of small- and medium-sized businesses were, however, retained [Article 2(2), Social Protocol] (European Community, July 29, 1992, p. 91).

One element of the Social Protocol gave peak employer and labor organizations (the "social partners") a greatly expanded role in policymaking for the Community. First, it gave the social 
partners the option to request that any EU directive be jointly implemented via collective agreement. Second, the Commission was now obliged to consult the social partners before submitting legislative proposals. In this situation, the social partners might submit recommendations to the Commission, or they might elect to negotiate the content of the Commission proposals amongst themselves with the goal of reaching a collective agreement, thereby bypassing the process of legislating through EU institutions [Articles 3-5, Social Protocol] (European Community, July 29, 1992, p. 92; Hix, 2005, p. 256; Rhodes, 2005, pp. 288289). Through this process, several framework agreements have been concluded on issues such as parental leave, part-time work, telework, work-related stress, harassment and violence at work, and fixed-term work (Commission of the European Communities, June 26, 2002, p. 27; European Foundation for the Improvement of Living and Working Conditions, 2010). The Treaty of Amsterdam (1997) coincided with a change in government in the UK, at which time the new Labour government reversed its previous opt-out of the Social Protocol, allowing the Protocol to be fully incorporated into the EU treaties. As a result, the extension of QMV to several new areas of social policy, already present in the Social Protocol, now became part of the formal EU treaties. This included provisions related to working conditions and worker information and consultation (Leibfried, 2005, p. 250).

The Treaty of Amsterdam broke little new ground with respect to social policy, but did signal changes in methods of coordination that continue today. In response to a Swedish initiative, the Treaty of Amsterdam added a new Title on employment, the provisions of which focused more on the exchange of reports and guidelines between member states than on the substance of policy or creation of new legal instruments (Leibfried, 2005, p. 254; Rhodes, 2005, p. 286). Similarly, the open method of coordination (OMC), applicable to employment, social policy, and many other areas, involves member states in collective monitoring of each other's domestic policies related to compliance with EU dictates (Hix, 2005, pp. 37-38).

The literature suggests that the EU has been quite successful in realizing its goal of setting a high standard for regulation, and that it has moved beyond product regulation tied to the single market project into the regulation of processes, as evidenced by its willingness to undertake social regulation (Hix, 2005, p. 250; Leibfried, 2005, p. 249). While these conclusions may be true for individual policy areas, there may well be challenges for the coordination of policy between institutions that are horizontally related. Because OSH policy is defined by the EU as social policy and is therefore handled primarily by the Directorate-General for Employment, Social Affairs, and Equal Opportunities, it cannot help but be influenced by policies specific to the relevant industrial sectors. For OSH policies related to road safety, the most obvious link is with the transport sector, for which DG MOVE is responsible. The possibility that health and safety regulations covering transport workers emanate from two different DGs creates clear potential for conflict in not only details of policies but in the values that underlay policies. Within the institutional structure of the EU there is, however, no mechanism for consultation of other Directorates-General in instances where policies applicable to specific industry sectors will have a direct bearing on labor policies (Keller, 2003, p. 44).

\section{European Union agencies with interest in occupational road safety}

Today, within the European Commission, DG MOVE focuses on professional drivers covered by EU directives. EU policy seems to be fragmented; that is, it is divided between "professional 
drivers" of large trucks and buses and all other employee drivers, with responsibility for the former explicitly with the transport agency and responsibility for the latter not clearly specified. Resources available from DG MOVE emphasize drivers of commercial vehicles and applicable regulations (European Commission Directorate-General Mobility and Transport, 2010a, 2010b). DG MOVE does, however, offer limited reference material and guidance that addresses occupational road safety more comprehensively (European Commission Directorate-General Mobility and Transport, 2010c). Some of the directives related to occupational road safety clearly fall under the purview of DG MOVE, while others may fall under the Directorate of Employment, Social Affairs, and Equal Opportunities.

The European Agency for Safety and Health at Work (EU-OSHA) ${ }^{17}$ is independent of the DGs, as its mission covers prevention of all types of occupational injury and illness and is therefore multi-sectoral. However, because its mission is most closely aligned with that of the Directorate of Employment, Social Affairs, and Equal Opportunities, it tends to identify and interact with that Directorate more regularly than with other Directorates for which occupational safety is not a central concern (European Agency for Safety and Health at Work, May 5, 2010).

Unlike the Occupational Safety and Health Administration (OSHA) in the U.S., EU-OSHA has no regulatory responsibility. Instead, like many of the other independent EU agencies, its core activities involve collecting and analyzing data in cooperation with partner agencies at memberstate level; coordinating exchange of information across transnational networks; and promoting dialogue between employers and unions (the "social partners") (Eberlein \& Grande, 2005, p. 153). EU-OSHA, like other EU "social regulatory" agencies, is relatively weak, as its effectiveness depends on the cooperation of the regulatory agencies and data providers at member-state level (Eberlein \& Grande, 2005, p. 154).

Through financial support and access to policy-making, the European Commission plays a role in determining which interest groups have the greatest potential to influence policy. Indeed, in some cases, the Commission itself is instrumental in setting up interest groups in policy areas it believes should be better-represented at the EU level; this model of interest representation has been referred to as "neo-pluralism" (Hix, 2005, pp. 210, 218-219).

One EU-sponsored interest group now taking action to promote occupational road safety is the European Transport Safety Council (ETSC), a non-profit organization based in Brussels and jointly funded by the European Commission and the private sector. ETSC has initiated a project called Preventing Road Accidents and Injuries for the Safety of Employees (PRAISE), which aims to increase awareness of the need for fleet safety management, to publicize relevant road safety standards of EU member states, and to advocate for this issue area at the EU level (European Transport Safety Council, 2010c). For example, ETSC has recently urged the Spanish Presidency of the EU to incorporate occupational road safety as a priority area in the EU action program for road safety, and to encourage EU institutional fleet managers and public sector fleets in EU member states to purchase vehicles meeting the highest safety standards (European Transport Safety Council, 2010a). ETSC advocacy has evidently met with some success, as Spain has committed to make work-related road safety a priority at domestic level and for its Presidency of the EU, and has included the topic on the agenda of the Transport Council

\footnotetext{
${ }^{17}$ http://osha.europa.eu/en
} 
(European Transport Safety Council, June 24, 2010). At the end of 2010, the conclusions of the Transport Council (that is, the document summarizing its deliberations) noted the importance of occupational road safety:

[The Council of the European Union] RECALLS that road safety is an issue of shared responsibility which requires that actions are undertaken at various levels within the public and private sectors; INVITES the Commission and the Member States to stimulate the development and use of safety management systems, in order to promote responsibility for road safety among all relevant stakeholders and ENCOURAGES employers to draft work related road safety action plans (Council of the European Union, December 2-3, 2010, p. 2).

\section{Europeanization of transport policy}

While EU regulations are implemented as written across all member states, directives require transposition into state law by each individual member state. However, responses to EU directives are not necessarily consistent across member states. Based on an examination of state responses to EU labor directives, Falkner et al. (2005) proposed that member states generally fall into one of three "worlds of compliance:" the "world of law observance," where compliance with EU directives is valued to the point where it overrides domestic concerns; the "world of domestic politics," in which EU directives are considered at the domestic level along with the priorities of the member-state government and interest groups; and the "world of neglect," where political will to adapt member-state law to EU directives may be limited and implementation may be poorly managed (Falkner, et al., 2005, pp. 321-326). With respect to compliance with labor law directives, Falkner and her colleagues characterized Sweden as falling within the "world of law observance" (Falkner, et al., 2005, pp. 331-333), the UK as within the "world of domestic politics" (Falkner, et al., 2005, p. 333), and France as within the "world of neglect" (Falkner, et al., 2005, pp. 338-339).

Héritier and her colleagues undertook a study of the effects of Europeanization on transport policy in five member states: France, Germany, Italy, the Netherlands, and the United Kingdom (Héritier, et al., 2001). Compared with the work of Falkner et al., this research was less centered on member states' responses to individual EU directives on transport policy; instead, it examined changing policies, administrative structures, and patterns of interest intermediation that resulted from European policymaking. The authors concluded that differences in reform policy output and structural adjustment are a function of three factors: the stage of transport policy liberalization achieved in a country at the time EU policies were implemented, the dominant belief system or problem-solving approach in that country, and reform capacity at member-state level (Héritier \& Knill, 2001).

Relevant to the discussion of belief systems by Héritier and her colleagues are two different European approaches to transport policy found in the literature. The first of these is the AngloSaxon approach promoted by the UK, which saw market mechanisms with minimal government regulation as the most efficient means of operating the transport network (Kerwer \& Teutsch, 2001b; Stevens, 2004, pp. 201-202). Although the UK did not join the EEC until 1973, its liberal philosophy had a disproportionate effect on the ultimate direction taken by transport 
policy in Europe. The strong push toward privatization, deregulation, and cutting back on government that was the hallmark of the Thatcher government may well have been influenced by similar developments that took place in the U.S. beginning in the 1970s, notably the deregulation of transport industries (Stevens, 2004, pp. 24, 43). The Thatcher program coincided temporally and philosophically with the growing recognition that achieving the "four freedoms" guaranteed by the SEA (including free movement of goods and labor) would require an open transport market (Knill, 2001, p. 58; Majone, 1994).

On the other hand, the Continental approach, popular in both France and West Germany, viewed transport as one of many public goods for which the state has the responsibility to intervene, for the purpose of meeting a variety of economic and social welfare objectives (Stevens, 2004, p. 2). Consequently, the Continental approach tends to accept a heavier regulatory burden than the Anglo-Saxon approach (Stevens, 2004, pp. 201-202). Underlying the more interventionist Continental approach was the desire of both the state and the strongly unionized workforce to protect domestic transport industries from competition from foreign transport firms and drivers (Kerwer \& Teutsch, 2001a, pp. 129-131; Stevens, 2004, pp. 32-33).

It is important to note that the literature discusses these policy characteristics only in the context of transport policy and the CTP. This means that although safety policy outcomes pertaining to transportation of freight and passengers have been linked to the Anglo-Saxon and Continental approaches, it is not necessarily the case that policy for occupational operation of lighter vehicles has been driven by the same belief systems or followed the same progression.

\section{European Union member states: the United Kingdom, France, and Sweden}

I assess occupational road safety policy in three EU member states which the literature suggests may be managing the issue somewhat differently: the United Kingdom (UK), France, and Sweden. Comparison of these three countries is appropriate for several reasons. For France and the UK in particular, the literature provides comparative accounts of transport policy that can serve as a foundation for comparison of occupational road safety policy (Douillet \& Lehmkuhl, 2001; Héritier, et al., 2001; Knill, 2001; Stevens, 2004). Other research addresses all three countries as having distinct policy styles: the UK as liberal and market-oriented, France as statecentered and interventionist, and Sweden as corporatist and consensual (Bovens, 't Hart, \& Peters, 2001; Hayward, 1982; Siaroff, 1999). Another study that examines transposition of EU directives related to employment and social protections characterizes the three countries as responding differently to EU directives, with Sweden generally compliant, the UK driven by domestic politics, and France lagging behind (Falkner, et al., 2005).

It is appropriate to choose member states that are reasonably similar on key economic and social indicators, and that have institutional and interest group structures that are stable enough and well-enough established to provide a basis for assessment. As Table 1-1 shows, the UK, France, and Sweden do not differ substantially from one another with respect to social indicators such as unemployment rate, gross domestic product (GDP) per capita, social expenditures, and life expectancy. All three are generally above the average for all $27 \mathrm{EU}$ member states for these measures, and show similar levels of progress in reducing the toll of serious workplace accidents since 1998. France's rate of traffic deaths per billion vehicle miles traveled is the median value 
among the 13 EU member states for which these data are available. Sweden and the UK have, respectively, the lowest and second-lowest rates; these are actually the two best road safety road safety outcomes worldwide ${ }^{18}$ (International Traffic Safety Data and Analysis Group, 2011, p. 13).

Table 1-1. Selected social and economic indicators for the EU-27 and selected member states

\begin{tabular}{|l|c|c|c|c|c|}
\hline Indicator & EU-27 & France & Sweden & $\begin{array}{c}\text { United } \\
\text { Kingdom }\end{array}$ & $\begin{array}{c}\text { Range for } \\
\text { EU-27 }\end{array}$ \\
\hline Unemployment rate, 2007 & 7.1 & 8.3 & 6.1 & 5.3 & $3.2-11.1$ \\
\hline GDP per capita, 2007 & 24,900 & 29,800 & 36,200 & 33,700 & $3,800-75,600$ \\
\hline $\begin{array}{l}\text { Expenditures on social protections } \\
\text { as \% of GDP* }\end{array}$ & 26.9 & 31.1 & 30.7 & 26.4 & $12.2-31.1$ \\
\hline Male life expectancy, 2006 & 75.2 & 77.3 & 78.8 & 77.1 & $65.4-78.8$ \\
\hline $\begin{array}{l}\text { Index of serious accidents at } \\
\text { work/100,000 employees, 2005 } \\
\text { (1998=100) }\end{array}$ & 78 & 87 & 84 & 86 & $48-131$ \\
\hline $\begin{array}{l}\text { Traffic deaths/billion vehicle miles } \\
\text { traveled** }\end{array}$ & -- & 7.8 & 4.4 & 4.6 & $4.4-19.4 * * *$ \\
\hline
\end{tabular}

Source for first five indicators: The social situation in the European Union 2008: New insights into social inclusion (European Commission, 2009b).

*Expressed in Purchasing Power Standard (PPS) units, which remove the effects of price differences across member states such that one euro=one PPS unit.

** IRTAD road safety 2010 annual report (International Traffic Safety Data and Analysis Group, 2011, p. 13).

***Covers 13 of the $27 \mathrm{EU}$ member states.

Inclusion of a new member state from the former Soviet bloc would have complicated the analysis. Compared with the more prosperous longstanding EU member states in western Europe, the newer member states from the former Soviet bloc have low income levels, high unemployment, poor population health status, and a less robust ethos of social protection and worker safety. To a lesser degree, this is also true of member states in southern Europe such as Greece and Portugal. For example, Romania's GDP per capita, at 3,800 PPS, is barely 15 percent of the EU-27 average. A finding that Romania's policy beliefs surrounding occupational road safety are dictated by economic imperatives would hardly be surprising. Further, the newer member states have undergone transitions from socialist to market economies with the last two decades. They lack the continuity in institutional structures and interest group structures found in western Europe, and are thus difficult to compare with the western European democracies on an equal footing.

The conditions under which EU directives were transposed would also be quite different for new and older member states. For the UK, France, and Sweden, transposition of most of the directives included in the analysis occurred while the country was already part of the EU, not as a condition of EU accession. Accession to the EU requires that a new member state accept all accumulated EU treaties, laws, directives, and regulations (Van Oudenaren, 2005, p. 148). Because a new member state would have to transpose all applicable directives within a

\footnotetext{
${ }^{18}$ Rates based on vehicle miles traveled are a better measure of road safety performance than are rates based on either population of numbers of registered motor vehicles because they take exposure to traffic into account.
} 
compressed time frame, and after other member states had done so, comparison with the transposition experience of an "old" member state such as France would be inappropriate. France, Sweden, and the UK may all be considered fairly advanced among EU member states in managing occupational road risk; however, their approaches reflect distinct national styles, including the different approaches to transport policy discussed above. For each, I begin with a general discussion of the governmental structure, political system, and policymaking environment, and follow with a closer examination of institutions, non-governmental actors, research, and policies that are relevant to occupational road safety.

\section{Case \#1: United Kingdom}

The United Kingdom (UK) is a constitutional monarchy in which the monarch is officially head of state. It has a parliamentary system of government in which the prime minister, the leader of the party that wins a legislative majority, is the chief political executive and has the power to appoint cabinet ministers (Gallagher, Laver, \& Mair, 2006, p. 39). In this system, the majority party is therefore guaranteed control of both the executive and legislative branches, thereby increasing the likelihood that the party's programs can be advanced, as well as the possibility that policy change may be drastic rather than incremental (Stevens, 2004, p. 24).

The UK is a unitary system with power concentrated in the central government. Exceptions are Scotland and Wales, which have achieved some degree of autonomy through directly elected assemblies, and in the case of Scotland, appointment of a cabinet and "first minister" (Gallagher, et al., 2006, pp. 171-173).

The British parliament consists of an upper house, the House of Lords, where membership is based on hereditary privilege or political appointment, and a lower house, the House of Commons, whose members are directly elected by simple plurality ("first-past-the-post") from single-member constituencies. In reality, the British parliament is nearly a unicameral system, with virtually all legislative power given to the House of Commons (Lijphart, 1999, pp. 15, 18). Politics in the UK are dominated by two major parties, Conservative and Labour, but there are a number of smaller parties distinguished by ideology or regional ties; these become prominent in political negotiations only if one of the major parties fails to gain a majority in parliamentary elections.

Although local governments in the UK carry out a number of functions, their right to do so is not constitutionally guaranteed, and they are dependent on the central government for funds. The UK has neither a written constitution nor judicial review; instead, parameters for functioning of the political system are based on a cumulating body of statutory and common law. The UK has a decidedly pluralist interest-group system which parallels the adversarial and competitive government-versus-opposition environment that prevails at central-government level (Lijphart, 1999, pp. 16-19).

UK central-government agencies with the greatest levels of involvement in occupational road safety are the Department for Transport (DfT) and the Health and Safety Executive (HSE), the occupational safety and health agency. Central government response has taken the form of "guidance" or "codes of practice" targeted at employers - not regulation. This approach is consistent with general characterizations of UK policy responses as influenced by market- 
oriented pressures (Bovens, et al., 2001, pp. 18-19), as well as descriptions of the liberal "AngloSaxon" approach to transport policy which sees transport as a service that is most efficiently and most appropriately provided by the market (Kerwer \& Teutsch, 2001b, p. 48; Knill, 2001, p. 69; Stevens, 2004, p. 2).

Like its counterpart OSHA in the U.S., the HSE does not exercise its jurisdiction over occupational MVCs. The Department for Transport does not offer specific guidance for workrelated driving, referring users to the RoadSafe Web site. Recently, however, a new legal remedy has become available to fill the gap in regulation. The 2007 Corporate Manslaughter and Homicide Act allows criminal negligence lawsuits against businesses when failure of management to exercise its duty of care results in death. The new law is intended to complement other legal remedies, including health and safety regulations, and is not limited to liability for MVCs. Lawsuits brought under this law are handled as criminal cases, not labor actions (Ministry of Justice (United Kingdom), 2007).

In the UK, epistemic communities made up of academics and NGOs have played a large role in pushing government action on occupational road safety, supported by research which has identified occupational crashes as comprising significant proportions of total road fatalities and recommended management interventions (Bibbings, 1997; Clarke, Ward, Bartle, \& Truman, 2009; Darby, Murray, \& Raeside, 2009; Dimmer \& Parker, 1999; C. Downs, Keigan, Maycock, \& Grayson, 1999; Grayson, 1999; Lynn \& Lockwood, 1999; Murray, 2000; Murray \& Watson, 2010). The most frequently cited estimate of the annual number of occupational crash fatalities in the UK is 800 , which represents about $25 \%$ of all road fatalities, and three times the number of occupational fatalities from all other causes (Murray, Pratt, Hingston, \& Dubens, 2009, p. 49). As of this writing, however, the true burden of work-related MVCs in the UK is not reflected in EU statistics. The UK crash data system only began to record work relationship in 2005, and these data do not yet appear to have been incorporated into EU statistics (European Commission, 2009a, p. 23). In the UK, as in the U.S., a crash is considered to be "occupational" only if it occurs during the course of work. The UK has no state-sponsored workers' compensation. Claims for occupational MVCs in employer-provided vehicles are typically paid by employerpurchased private insurance or, in larger organizations, via self-insurance or re-insurance programs. MVCs occurring on business in a worker's own vehicle or while commuting are typically compensable through the employee's private insurance.

A number of interest groups in the UK have taken on occupational road safety as at least part of their missions: the Royal Society for the Prevention of Accidents (RoSPA), which is similar to the National Safety Council in the U.S. and has undertaken an initiative called "Managing Occupational Road Risk" (Royal Society for the Prevention of Accidents, 2010); the Occupational Road Safety Alliance (Occupational Road Safety Alliance, 2010); the road safety charity Brake (Brake, 2010); and RoadSafe, which has undertaken a "Driving for Better Business" initiative (RoadSafe, 2010).

\section{Case \#2: France}

In France, the head of state is a president chosen by direct election for a five-year term. The president has formal power to appoint and dismiss the prime minister, who is chosen from the political party holding a majority in parliament and not necessarily from the president's party. 
The president can also dissolve parliament and call for new elections (Gallagher, et al., 2006, pp. 26-27). There is the possibility of divided government if a political party other than the president's party wins parliamentary elections. The primary political parties in France are the center-right Union for a Popular Movement (the political party of current president Nicolas Sarkozy) and the Socialists, with numerous minor parties representing ideological positions across the political spectrum (Bale, 2008, p. 147; Nordsieck, 2010a).

The upper house of the French parliament is the Senate, whose members are chosen by elected local government officials; this may result in a general bias toward the interests of rural areas and small municipalities (Lijphart, 1999, p. 210). The lower house is the Assemble Nationale [National Assembly], whose members are directly elected from single-member constituencies in two rounds of elections (Gallagher, et al., 2006, p. 348). France has one of the weaker parliaments in Europe; the central government exercises great influence over its agenda, and has a number of procedural options to limit the parliament's discretion. Further, many members maintain official roles in local governments in their constituencies and thus devote less attention to national affairs. While this situation may weaken the legislature at central-government level, it may also serve to strengthen the political voice of regions and municipalities (Bale, 2008, pp. $89,120)$.

France is divided into 26 administrative regions, 22 of which are located in the metropole. Regions are further divided into departments and communes. Although regions have no legislative authority, they are permitted to levy taxes and thus have some degree of discretion in spending.

In France, the government agency with responsibility for road safety is the Sécurité routière, a unit within the Ministère de l'écologie, de l'énergie, de développement durable et de la mer, and for occupational safety is the Direction générale du travail, a unit within the Ministère du travail, de la solidarité et de la fonction publique. In France, however, activities associated with prevention of occupational crashes appear to reside in a social security agency, the Caisse nationale de l'assurance maladies des travailleurs salaries (CNAMTS) [National Health Insurance Fund for Employees]. The reason for this may be that the Direction des risques professionnels (DRP) [Directorate for Occupational Risks] within CNAMTS provides workers' compensation for work-related crashes. Crash injuries that occur while commuting to and from work, as well as those occurring during the course of the work day, are compensated as occupational injuries in France (Eurogip, 2003, p. 4).

In 2008, motor vehicle crashes accounted for 465 occupational fatalities in France, 49 percent of the total. Of these 465 deaths, 132 occurred while driving during the course of the work day, and the remaining 333 while commuting (Eurogip, 2010, p. 11). For the 132 at-work fatalities, decedents were most likely to have been an occupant of a private car (44) or a truck weighing more than 3.5 tons (38). For the 333 commuting fatalities, the majority of decedents were occupants of a private car (163) or a motorized two-wheeled vehicle (90) (Eurogip, 2010, p. 13). Unlike the UK, where businesses dominate, the French interest group structure related to occupational road safety is centered on governmental and quasi-governmental entities. This structure is consistent with what the literature suggests is typical of the French policy climate: reliance on a centralized, technocratic bureaucracy with the central state as the primary 
governance mechanism (Bovens, et al., 2001, pp. 18-19; Hayward, 1982, p. 116). It is also consistent with a broad characterization of France as one of the least corporatist states in Europe, a designation based on low levels of participation from labor and the presence of only three of twenty-two factors said to be associated with the "ideal type" of corporatism: a centralized and powerful central state with some level of intervention in the economy, some blurring of the distinction between the public and private sectors, and high levels of social expenditures (Siaroff, 1999). Indeed, France is described as essentially a pluralist system, ${ }^{19}$ with pockets of corporatism found only in limited sectors, notably agriculture (Siaroff, 1999, p. 183).

Several research agencies supported by the French government include prevention of occupational road risk among their programs. The Institut national de recherche et de securité (INRS) [National Research and Safety Institute] focuses on reducing occupational risk, including road risk. Together, CNAMTS and INRS fund Eurogip, a public interest group that coordinates France's interactions with the EU in the area of occupational safety and health. Eurogip is governed jointly by trade unions and employers, suggesting the possibility of some deviation from a characterization of labor as playing a limited role within the pluralist French system (Siaroff, 1999, p. 182). On the transport side, the Institut national de recherche sur les transports et leurs sécurité (INRETS) [Institute for Research on Transport and Transport Safety], supervised jointly by the ministries of research and transport, has overarching responsibility for conducting or reviewing all aspects of road safety research and interacts with its counterpart agencies outside France (Eurogip, 2003, pp. 29-30).

In France, there appears to be recognition of the need for coordination of policies for occupational road safety across government ministries, as evidenced by the formation of the Comité de pilotage pour la prévention du risque routier professionnel [Steering Committee for the Prevention of Occupational Road Risk] in 2001. In addition to CNAMTS, INRS, and INRETS, members of this body currently represent three specialized social insurance funds, the Caisse centrale de la mutualité sociale agricole (CCMSA) (social insurance fund for agriculture), Régime social des indépendants (RSI) (social insurance for the self-employed), Caisse nationale de retraites des agents des collectivités locales (CNARCL) (social insurance fund for local government employees); and government agencies with responsibility for road safety (Sécurité routière [Road Safety], a unit within the Ministère de l'écologie, de l'énergie, de développement durable et de la mer) [Ministry of Ecology, Energy, Sustainable Development, and the Sea] and occupational safety (Direction générale du travail [Directorate General of Labor] a unit within the Ministère du travail, de la solidarité et de la fonction publique) [Ministry of Labor, Solidarity, and Civil Service] (Eurogip, 2009, p. 13; Ministère de l'écologie, de l'énergie, de développement durable et de la mer, Sécurité routière [Ministry of Ecology, Energy, Sustainable Development, and the Sea, Road Safety Unit], 2010). The French government also champions a non-profit organization of employers dedicated to promoting the safety of vehicle fleets, Promotion et suivi de la sécurité routière en enterprise (PSRE) [Promotion and monitoring of work-related road safety]. Although PSRE was founded by employers, membership is based on willingness to sign a road safety charter with the French government (Eurogip, 2003, p. 31).

\footnotetext{
${ }^{19}$ Pluralist systems are marked by interest groups having no formal role in allocation of resources and implementation of policy, an assumption that interest groups will be voluntary and self-generating, and that they will compete freely for access to the policy arena (Gallagher, et al., 2006, pp. 450-451).
} 
A description of France as an essentially pluralist system does not preclude the existence of peak associations for labor and industry with interest in occupational road safety. The most important employer organization, the Fédération nationale des transport routiers (FNTR) [National Road Transport Federation] represents 15,000 of a total of 36,000 haulage enterprises in France. Another group with some influence is the Union national des organizations syndicales de transporteurs routiers automobiles (UNOSTRA) [National Union of Motor Carriers], whose members tend to be smaller enterprises. On the union side, the Confédération française démocratique du travail [French Democratic Confederation of Labor], the French trade union with the largest membership overall, and Force ouvrière [Workers' Power] are involved in negotiating labor agreements with the peak associations FNTR, UNOSTRA, and others (Douillet \& Lehmkuhl, 2001, p. 113; European Foundation for the Improvement of Living and Working Conditions, 2009, p. 5). In addition, the history of economic regulation of the transport market resulted in formation of the tripartite bodies the Conseil supérieur des transports [High Council for Transport] and Comité national routier [National Road Committee], which provide some level of formal access to policymaking for labor and industry groups (Douillet \& Lehmkuhl, 2001, p. 113). Thus, the literature suggests that for the road transport industry in particular, the French system may possess certain corporatist characteristics such as unionization of blue-collar workers, grouping of both labor and employer groups into peak confederations, and centralized wage bargaining (Siaroff, 1999, pp. 177-178).

\section{Case \#3: Sweden}

Although the hereditary constitutional monarch is officially the head of state in Sweden, the monarch in fact has no role in the formation of the government. The prime minister, the political chief executive, is nominated by the chair of the parliament (the Riksdag) after consulting with leaders of all political parties represented in the parliament (Gallagher, et al., 2006, p. 39). The primary political parties in Sweden are the Social Democratic Workers' Party and the Moderate Rally Party, with a number of significant minor parties representing ideologies such as agrarianism, Euroskepticism, the Greens, and social liberalism (Nordsieck, 2010b). Representation in the single-chamber Riksdag is determined using a form of proportional representation referred to as "list PR." The country is divided into 28 multi-member constituencies, with voters choosing from among a list of candidates provided by each political party (Bale, 2008, p. 170; Gallagher, et al., 2006, pp. 349-350).

Sweden is a unitary state with a strong central government, but a number of public functions such as public works, elder care, and education are implemented by sub-state bodies. At regional level, Sweden is divided into 21 counties. Decision-making at this level is carried out by directly-elected county councils and by county administrative boards. The country is further divided into 290 municipalities which, similarly, have elected municipal councils and municipal boards that lead the work carried out locally (Swedish Institute, 2007).

Within the central government, Sweden's policy-making environment is strongly consensual. The overall governance of the country is strongly influenced by an ethos of corporatism, which has been defined as the "co-ordinated, co-operative, and systematic management of the national economy by the state, centralised unions, and employers (these latter two co-operating directly in industry), presumably to the relative benefit of all three actors" (Siaroff, 1999, p. 177).

Corporatist values dictate a search for consensus solutions and joint implementation of programs 
(Gallagher, et al., 2006, pp. 443-445) and in the occupational safety arena, this would suggest a cooperative rather than adversarial approach to risk management.

The consensual and corporatist Swedish approach to policy development is reflected in the work of government bureaucracy itself. The central government's policy decisions are not necessarily prepared solely by the ministries. On issues of major importance, the central government frequently appoints a commission or committee of inquiry, which thoroughly examines the issues at hand and then presents recommendations for changes in the laws or other reforms (Swedish Institute, 2007).

Three Swedish agencies at central-government level are involved in policy for occupational road safety. The Swedish Transport Administration, Trafikverket, is responsible for strategic planning for road safety, infrastructure planning and construction, and operational aspects of driver licensing. The Swedish Transport Agency, Transportstyrelsen, is responsible for the content of driving tests for regular and commercial driver licensing as well as regulations and penalties applicable to all kinds of road users. The Swedish Work Environment Authority, Arbetsmiljöverket (the Swedish equivalent of the U.S. OSHA) is housed in the Ministry of Employment. This agency has integrated road safety into occupational safety policy, determining that the roadway is part of the work environment and that employers bear some responsibility for minimizing road risk for employees, regardless of the ownership of the vehicle (Swedish Work Environment Authority, 2003/2004).

Sweden is the home of the widely-cited "Televerket study" published in 1996, which was the first and remains one of very few studies to apply an experimental research design to occupational road safety. This research applied four different fleet safety interventions to groups of approximately 900 drivers each who were employed by the Swedish telephone company Televerket, with a fifth group serving as a control. Each group received one of four treatments: driver training, group discussions, safety campaigns, and bonuses to reward crash-free driving. The researchers followed the five groups for a period of two years after the interventions were implemented. Only the driver training and group discussion interventions were found to have been associated with decreased crash rates and costs (Gregersen, Brehmer, \& Moren, 1996).

Overall, the incidence of occupational fatality in Sweden is quite low, but of the 59 deaths recorded in 2005, 20 (34\%) were due to MVCs (Scheresberg \& Marolda, 2009, p. 11). Sweden's overarching road safety program, "Vision Zero," reflects a commitment to eliminate all road fatalities, and has met with considerable success. Sweden has championed a "safe-systems" approach to road safety which combines human factors, vehicle design, and roadway design (Vägverket [Swedish Road Administration], 2008). Sweden's integrative approach to road safety policy is shown by the inclusion of private and public sector road users as key stakeholders in the safe-systems approach (Howard, 2009). This approach is consistent with widely held conceptions of Swedish policy as corporatist, consensual, and imbued with social engineering motivations (Bovens, et al., 2001, pp. 18-19).

Swedish policy makers have successfully exported the safe-systems model abroad through the Organization for Economic Cooperation and Development (OECD) (Joint Transport Research Centre of the OECD \& International Transport Forum, 2008); and through leadership in the 
development of an international standard, ISO (International Organization for Standardization) 39001/TC 241, Road traffic safety (RTS) management systems - Requirements with guidance for use. The UK is a full participant in development of ISO 39001; France is an official "observer" country, while the U.S. has elected not to participate (International Organization for Standardization (ISO), 2009).

Within Sweden, NGOs play some role in influencing occupational road safety policy. Quality III, partially funded by a labor union and partially by a non-profit organization, takes a holistic approach to promoting safe truck operations (Quality Three Organisation, 2005). In addition, the Nationalforeningen for Trafiksakerhetens Framjande (NTF) [National Society for Road Safety], an umbrella organization representing county road safety federations, professional associations, and advocacy groups, develops policy recommendations in support of Vision Zero goals. NTF notes that half of all traffic in Sweden is estimated to be either commercial or commuting traffic, therefore businesses leading by example to promote safe vehicle operations can have a substantial impact on public safety (Nationalforeningen for Trafiksakerhetens Framjande (NTF) [National Society for Road Safety], 2006).

\section{The role of global initiatives}

Advocacy for occupational road safety in the EU has benefited from interactions with global networks that include international organizations (IOs) and epistemic communities that include multi-national corporations (MNCs), country governments, NGOs, researchers, and academicians. A notable example is the United Nations Road Safety Collaboration (UNRSC), managed by the World Health Organization and made up of government agencies, MNCs, NGOs, and IOs. The UNRSC was the focal point for development of the landmark World Report on Road Traffic Injury Prevention and several other initiatives intended to help low- and middle-income countries build capacity for prevention of MVCs (Peden, et al., 2004). The UNRSC has also served to catalyze momentum for a new UN resolution on road safety and a UN Decade of Action for Road Safety, both of which were approved in the General Assembly early in 2010 (United Nations General Assembly, March 2, 2010).

Transnational actors have met with some success in attaching road safety imperatives to economic and human development goals. In turn, occupational road safety advocates have attached their issue to broader global initiatives that address road safety in the general population. Advocates work within bodies such as the UNRSC to raise the profile of occupational driving, emphasizing the substantial contributions of commercial traffic to total traffic volume and the toll of occupational MVCs on workers and other vulnerable road users. A multi-sectoral Work-related Road Safety Project Group has formed within the UNRSC, and a group of MNCs has organized a related Private Sector Road Safety Collaboration to enhance information exchange and coordination of road safety initiatives amongst themselves. All these structures provide opportunities for the repeated contacts between stakeholders that may increase the likelihood of policy learning and diffusion between countries and between the members of the various epistemic communities. 


\section{$\underline{\text { Summing up }}$}

In summary, then, the UK is a unitary system with a strong central government, with the majority party in the parliament guaranteed control of both the executive and legislative branches. For occupational road safety, the policy area of interest here, the most active UK government agencies are the Department for Transport and the Health and Safety Executive (the OSH agency). For the most part, central government response has taken the form of "guidance" or "codes of practice" targeted at employers, consistent with accounts of a liberal "Anglo-Saxon" orientation to transport policy, and a labor policy that is reluctant to intervene in business affairs (Kerwer \& Teutsch, 2001b, p. 48; Knill, 2001, p. 69; Rhodes, 2005, p. 282; Stevens, 2004, p. 2). The UK has a pluralist interest-group system, and in the area of occupational road safety, business interests and academics are quite actively pursuing initiatives outside government.

France has a strong central government, with power concentrated in the presidency. It also has a prime minister chosen from the majority party in the parliament. France has one of the weaker parliaments in Europe; not only does the executive branch exercise substantial control over the parliamentary agenda, but legislators tend to retain local or regional political offices and therefore may give less than full attention to the national parliament. The sub-state administrative regions can levy taxes and thus have some capacity for discretionary spending. Unlike the UK, where businesses dominate, the French interest group structure related to occupational road safety is centered on governmental and quasi-governmental entities. Also in contrast to the UK, in France the workers' compensation agency takes a lead role, with additional contributions from government-supported transport research agencies and advocacy groups. Of all the polities considered here, at face value France seems to most closely approximate having a "lead" agency for occupational road safety at central-government level.

A state-centered structure is consistent with the French policy style suggested in the literature: reliance on a centralized, technocratic bureaucracy with the central state as the primary governance mechanism (Bovens, et al., 2001, pp. 18-19; Hayward, 1982, p. 116). In contrast to the UK's liberal approach to both transport and labor policy, the French philosophy views transport as a public service open to state intervention, and labor policy is similarly marked by an acceptance of substantial state intervention as a policy instrument. The literature describes France as essentially a pluralist system, with formal access to the policymaking process for the social partners generally limited (Siaroff, 1999). However, the literature suggests that for the road transport industry, the French system may possess elements of corporatism, including tripartite consultative mechanisms and centralized labor agreements (Douillet \& Lehmkuhl, 2001).

Like the UK, Sweden is a unitary state with a strong central government. The political chief executive is the prime minister, who is chosen by the chair of the single-chamber parliament in consultation with leaders of other political parties. At the sub-state level, Sweden is divided into counties and further into municipalities, which each have administrative boards responsible for policy implementation at county or local level.

Swedish policymaking reflects a consensual and corporatist approach (Bovens, et al., 2001, pp. 18-19). Major government policy decisions often involve appointment of broad-based 
commissions to study issues and present recommendations (Swedish Institute, 2007). Swedish agencies at central-government level involved in policy for occupational road safety are the Swedish Transport Administration, Swedish Transport Agency, and the Swedish Work Environment Authority, which is the OSH agency. Sweden, however, is more like France than like the UK in its government's policy activism to promote road safety. Sweden's holistic, integrative concept of road safety policy is shown by its systems-based approach and by the formal inclusion of private and public sector road users as key stakeholders in the governmental planning process.

Overlaying the three states is the EU, which has a number of institutions and agencies whose activities may influence occupational road safety policy. Overall, the CTP and OSH policies appear to have developed rather independently of one another, despite the obvious link between both policy areas and the single market. The European Commission directorates with interest in occupational road safety policy are DG MOVE and the Directorate-General for Employment, Social Affairs, and Equal Opportunities; the extent to which these two directorates have cooperated on occupational road safety policy remains to be seen. Other EU institutions linked to the Commission are EU-OSHA, a research and information agency with close links to the social dialogue process promoted largely through the employment directorate, and the ETSC, a quasi-governmental research and advocacy group supported in part by the Commission and more closely linked to DG MOVE than to the employment directorate.

The ECJ has historically played a pivotal role in development of the CTP and thus in the development of the EU's policies vis-à-vis truck safety, less so for labor policy that affects other occupational drivers. EP committees on transport and employment consult with the Commission and respond to legislative proposals, and member states that hold the rotating EU presidency have the option of including occupational road safety in transport or labor policy initiatives they may choose to promote. 


\section{Chapter 2. Theoretical Framework, Research Questions, and Methodology}

Two complementary theoretical frameworks inform this research. The first is multi-level governance (MLG), which was originally formulated to account for the multiple and flexible levels of government emerging in the EU and the growing role of non-governmental actors in EU governance. Some scholars are, however, beginning to apply MLG to analysis of federal systems outside Europe (Asare, Cairney, \& Studlar, 2009; M. Stein \& Turkewitsch, 2010; M. B. Stein \& Turkewitsch, 2008). The second is the advocacy coalition framework (ACF), which was first applied to policy development in the U.S. but has been used increasingly in other parts of the world. Central to the ACF is the assumption that policy is made within subsystems, and that epistemic communities, belief systems, and opportunity structures are all important inputs to policy development and change (P. Sabatier, 1998; P. Sabatier \& Weible, 2007; P. A. Sabatier \& Jenkins-Smith, 1999).

Both frameworks are appropriate for a consideration of policy for occupational road safety, the ACF because of its emphasis on subsystems and ideological foundations of policy, and MLG because of its allowance for multiple interwoven levels of governance and its recognition that governance goes beyond the functions of organized political units. Finally, both frameworks see interest groups, including epistemic communities, as instrumental in the policy process. In the sections that follow, I review the literature on MLG and the ACF. I then discuss agendasetting, opportunity structures, interest groups, and mechanisms for policy learning within and across jurisdictions, all of which are to some degree considered by both MLG and the ACF. The chapter ends with a detailed discussion of research questions, methodology, and limitations of this research.

\section{Multi-level governance}

The concept of multi-level governance (MLG) refers to a system in which "supranational, national, regional, and local governments are enmeshed in territorially overarching policy networks" (Marks, 1993, p. 402). The original formulation of MLG, put forth to describe the emerging regional aspects of EU structural funding, seems to have been limited to interactions between governmental units. Later, however, MLG was divided into two types to account for the growing role of non-governmental actors in European governance. Type I MLG is essentially as proposed in Marks (1993); it emphasizes the federal nature of the EU polity and the interactions between the EU, central governments of the member states, and sub-national governments. The Type I structure assumes distinct, non-intersecting governmental units, a limited number of levels, and a stable system (Hooghe \& Marks, 2003; Marks \& Hooghe, 2004, pp. 236-237). Type II MLG, on the other hand, allows for jurisdictions to operate at numerous territorial levels, and sees jurisdictions as both flexible and task-specific, that is, as "public service industries" rather than general-purpose (Hooghe \& Marks, 2003, pp. 237-239; Marks \& Hooghe, 2004, pp. 20-21).

For this research, Type II MLG is a more appropriate framework than Type I MLG because Type I is particularly concerned with sub-state governments, which the literature suggests are not strongly influential in the development of occupational road safety policy. The use of the word "governance" is particularly salient to Type II MLG and to occupational road safety policy in 
that it accounts for the increasing interdependence between governments and non-governmental actors at various levels of government, along with a "steering" role for international organizations such as the World Bank (Bache \& Flinders, 2004, pp. 3-4). Further, a description of Type II MLG as including "dispersed self-rule on the part of diverse voluntary groups" (Marks \& Hooghe, 2004, p. 22) implies that this type of governance is not limited to rule by state entities. This point seems particularly relevant for occupational road safety, where nongovernmental actors and quasi-governmental agencies have stepped in to fill a policy vacuum where governments are constrained from intervening or have elected not to. Further, the flexibility inherent in MLG allows multiple points of access for interest groups to push their preferred policy positions. Central governments of member states are by no means the only voices in the EU policy arena, and they may in fact be at a disadvantage compared to interest groups with pan-European reach and access to information through multiple networks (Hooghe \& Marks, 2001, p. 28).

\section{The Advocacy Coalition Framework}

A second policy framework which has been applied to both the U.S. and European settings is the advocacy coalition framework (ACF) formulated and described by Sabatier and colleagues (P. Sabatier, 1998; P. Sabatier \& Weible, 2007; P. A. Sabatier \& Jenkins-Smith, 1999). See Figure 1 below for a schematic of the ACF (P. Sabatier, 1998, p. 102). The defining feature of the ACF is the policy subsystem, an aggregation of large numbers of actors representing different institutions and levels of government - actors who share a set of normative and causative beliefs about the content and instruments of policy in a given area (P. A. Sabatier \& Jenkins-Smith, 1999, p. 154). In contrast with the traditional "iron triangle" of U.S. policy-making, the ACF model sees a strong role for institutional actors and epistemic communities, whose policy positions are influenced by broad societal and economic forces (P. Sabatier \& Weible, 2007, p. 191). Several features of the ACF seem particularly relevant to occupational road safety policy: the assumption of policy subsystems as the main drivers of policy, and the role of epistemic communities within those subsystems; the role of belief systems in determining policy and the possibility for policy change; and the role of opportunity structures in creating a venue and climate for policy change.

The ACF first acknowledges that there are relatively stable features of a policy environment which often militate against change. These include existing legislation and regulation, the distribution of resources available to address the policy issue, and the societal values underpinning the current policy environment. The ACF sees two sets of forces by which policy may change: "policy-oriented learning" and external shocks (P. Sabatier \& Weible, 2007, pp. 198-199). For example, in occupational road safety, policy-oriented learning might take the form of an emerging body of evidence that the use of mobile devices while driving increases crash risks, prompting government to institute bans on the use of certain devices while driving, with the possibility of stricter bans for drivers providing public transport services. An example of an external shock is a series of high-profile crashes that leads to calls for government action from advocates or the public.

The most recent formulation of the ACF introduces two sets of variables that mediate policy change. This appears to be an effort to make the ACF more broadly applicable beyond the U.S. 
setting. The first of these is long-term coalition opportunity structures, defined as "relatively enduring features of a polity that affect the resources and constraints of subsystem actors" (P. Sabatier \& Weible, 2007, p. 200). Other discussions of opportunity structures emphasize institutional arrangements within the EU that affect the ability of outside groups to influence policy (Princen \& Kerremans, 2008, p. 1130). In the ACF, opportunity structures are operationalized along two dimensions: the degree of consensus needed for major change in policy, and the openness of the political system, that is, the number and accessibility of venues in which decisions are made. The second set of mediating variables involves short-term constraints and resource issues affecting subsystem actors. For both sets of mediating variables, there may well be distinctions that can be drawn between Sweden, France, and the UK.

Figure 1. Advocacy Coalition Framework

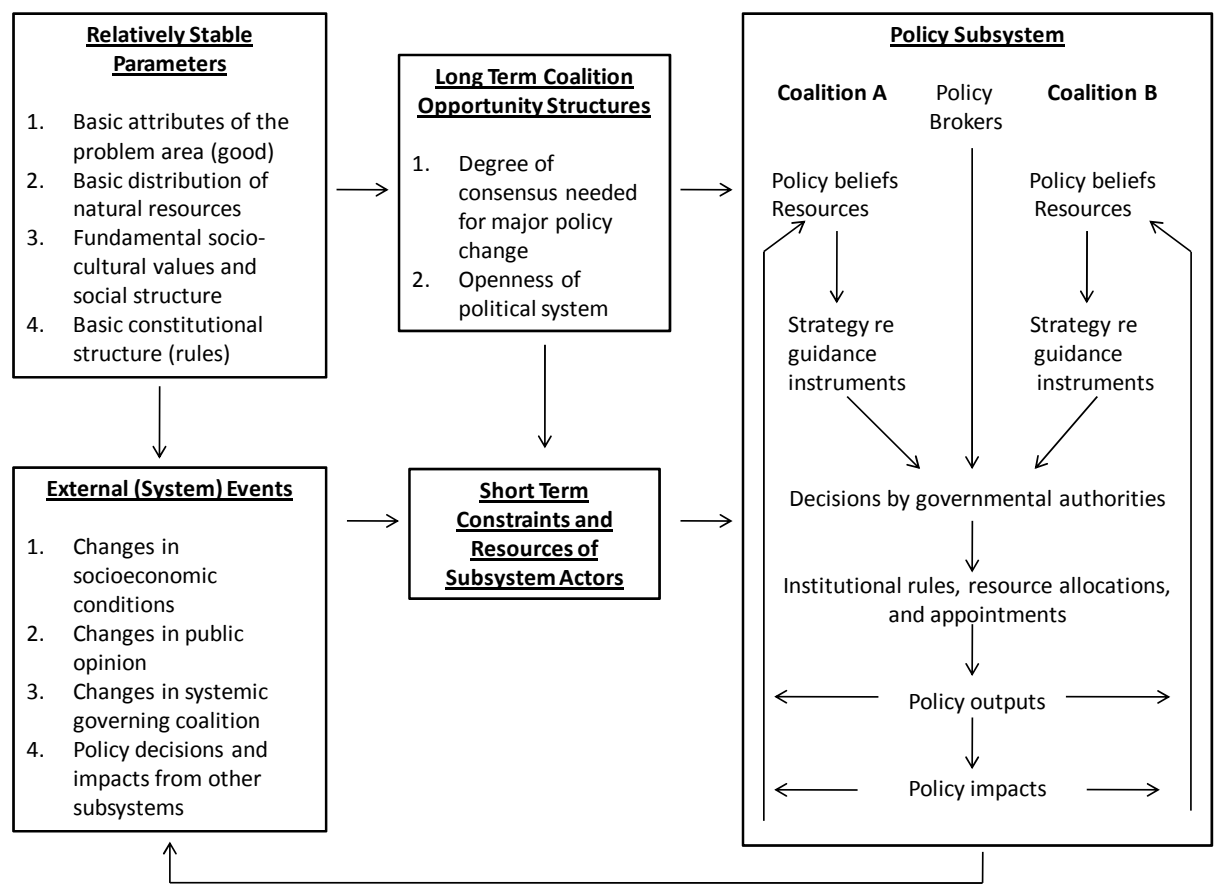

$\underline{\text { Agenda-setting and opportunity structures }}$

In most policy areas, numerous interests from inside and outside government compete to influence the course of policy. In the case of occupational road safety, where regulation may be spotty and jurisdictions fragmented, voluntary initiatives may play a particularly important role, in some cases taking the place of formal governmental intervention. Several strands of literature are relevant here, and I see all as applicable in some way to occupational road safety policy in the EU and its member states. I will discuss literature on agenda-setting and opportunity structures, interest groups, and transnational networks.

Literature from both sides of the Atlantic on problem definition, agenda-setting, and framing of issues is relevant to this research. Of interest here are the ways the issue is defined and framed 
for purposes of its advancement through the policymaking process, and the kind of institutional structure, if any, created to manage the issue.

How an issue is conceptualized and framed is critical to whether it comes to the attention of legislators and policy makers and how it will be received once it reaches the government's agenda (Baumgartner, Green-Pedersen, \& Jones, 2006; Baumgartner \& Jones, 1993; Princen, 2009). In both the U.S. and the EU, trucking policy was initially framed as economic policy, in the U.S. as a means of regulating competition and ensuring access to trucking services (Belzer, 2000), and in the EU, as part of the project to complete the single European market (Commission of the European Communities, 1985; Hilal, 2008, pp. e19-e20).

In contrast, occupational road safety (outside of truck safety) has been framed in a variety of ways: as a public health and safety problem, as a worker safety problem, as a compensable occupational risk, as a risk to be managed at employers' discretion, or as part of a comprehensive transport policy. Different actors may subscribe to different definitions of the problem, or use "causal stories" to argue for the need for government intervention or for certain forms of intervention (D. A. Stone, 1989). The result is that across jurisdictions, occupational road safety has variously been handled within transport, health, social insurance systems, and labor, but not necessarily in a coordinated fashion. Alternatively, it may remain completely outside the purview of government.

The dispersion of an issue across policy competency areas may have positive or negative results. More positively, it provides multiple access points for policy initiatives from inside or outside government (Varone, Rothmayr, \& Montpetit, 2007, p. 19). Scholars of MLG cite the multiple access points afforded by multiple levels of government and flexible forms of governance (Beyers, Eising, \& Maloney, 2008, p. 1112; George, 2004, pp. 113-114; Hooghe \& Marks, 2001, p. 28; 2003). U.S. and European scholars cite the concept of "venue shopping," which entails the marketing of policy ideas to a variety of groups in the hope that someone will be receptive (Baumgartner \& Jones, 1993; Keck \& Sikkink, 1998; Mahoney \& Baumgartner, 2008, p. 1261; Princen \& Kerremans, 2008). "Venue shopping" may also take the form of efforts to keep an issue off the government's agenda altogether (Mahoney \& Baumgartner, 2008, p. 1263). On the other hand, the presence of multiple venues in which to put forward an issue also implies the presence of multiple "veto players" positioned to push back against policy proposals to address that issue (Tsebelis, 1995). Further, fragmentation of responsibility across a number of agencies, or placement of the responsible unit at a low level of government, may decrease the likelihood of there being an authoritative and coordinated response (McCubbins, 1985, pp. 725-728; McCubbins, Noll, \& Weingast, 1987, p. 244).

The literature suggests that once an institutional structure is created to manage a policy area, activity in that area will continue regardless of whether the issue continues to receive close attention from legislators, the media, or the public (Baumgartner \& Jones, 1993, pp. 87-88; A. Downs, 1972, pp. 40-41). Creation of a government agency to address a particular problem is likely to be accompanied by the creation of interest groups associated with that same issue (Baumgartner \& Jones, 1993, p. 191; Mahoney, 2004, p. 461; Mahoney \& Baumgartner, 2008, p. 1260). For example, a long history of managing economic and safety aspects of truck and bus transport through regulation makes it all the more likely that this set of policy instruments will 
continue to be used. In the case of other forms of occupational driving, a decision to regulate would represent a major shift in policy direction; such shifts, the literature suggests, occur through "external shocks" (P. Sabatier \& Weible, 2007; P. A. Sabatier \& Jenkins-Smith, 1999); or through either positive or negative mobilizations from policy makers, interest groups, or the public (Baumgartner \& Jones, 1993, pp. 88-89).

\section{$\underline{\text { Interest groups and transnational networks }}$}

In virtually all policy areas, groups representing business, social movements, membership organizations, and all manner of other interests seek to influence the course of public policy. The mechanisms by which this occurs may differ between the highest levels of government (here, EU-level) and lower levels (here, EU member states and sub-state units). Hix (2005) observes that with the proliferation of private lobbying at the EU level, Brussels is starting to look more like pluralist Washington, D.C. than like the state capitals of Europe (Hix, 2005, p. 222). Mahoney and Baumgartner (2008) argue that globalization has contributed to a growing convergence of interest-group politics in the U.S. and the EU, as MNCs, international NGOs, and international lobbying firms are increasingly active in Brussels in much the same way as in Washington (Mahoney \& Baumgartner, 2008, p. 1255). The increase in EU-level lobbying by MNCs may reflect a venue shift from domestic-level bargaining with trade unions and memberstate governments, characteristic of the corporatist structure common to much of continental Europe, to a broader focus on lobbying EU-level regulators and legislators to adopt neoliberal and anti-regulatory policies (Hix, 2005, p. 225). Activity at the EU level may also place MNCs in a better position to participate in transnational standards-setting and harmonization initiatives $^{20}$ (Mahoney \& Baumgartner, 2008, p. 1255). Princen extends the discussion further, noting that not only does a unified EU-level voice lead to influence on international bodies, but that international standards or consensus can also affect policymaking at EU level (Princen, 2009, pp. 162-163).

One way by which governments engage with interest groups to further mutual policy goals is through public-private partnerships. Börzel and Risse (2005) argue that in the EU, such arrangements do not necessarily replace state authority, but rather may increase the legitimacy and effectiveness of transnational governance (T. Börzel \& Risse, 2005, p. 196). In some policy areas, it is possible that partnerships may facilitate non-governmental solutions to issues that have not yet reached the public policy agenda. Participation in standards-setting and rulemaking is one function of public-private partnerships suggested in the literature, along with implementation and monitoring of compliance with international rules and the provision of services (T. Börzel \& Risse, 2005, p. 199). Public-private partnerships have been examined in the context of road safety, focusing on the Global Road Safety Partnership, which has engaged MNCs in supporting road safety initiatives as a component of business operations or as a philanthropic gesture. For MNCs, support of road safety activities demonstrates "corporate social responsibility," which can reap public relations benefits in addition to reducing operating costs (Bekefi, 2006).

\footnotetext{
${ }^{20}$ EU-level activity in standards-setting does not necessarily preclude involvement of member-state governments, however, as individual countries generally remain the negotiating units. The ISO 39001 road safety management standard is a case in point.
} 
Interest-group activity of all kinds frequently extends beyond state borders. Interactions between domestic-level interest groups from different EU member states, as well as activities of panEuropean interest groups and peak associations, certainly fall into this category. In addition, EUbased entities engage in formal and informal interactions with colleagues overseas across multiple policy areas, including road safety. The phrase "transnational advocacy networks," suggested by Keck and Sikkink (1998), describes the linkages of all kinds of societal actors who work toward shared policy goals - NGOs, foundations, academics, journalists, and parts of IOs and NGOs and governments. Members of such networks benefit from information exchange and shared resources. More specifically, where domestic-level groups are unable to effect a desired policy change, pressure from international networks can be brought to bear on national governments (Keck \& Sikkink, 1998).

Zippel (2004) argues that transnational advocacy networks can play an especially strong role in the EU compared with other polities because of the EU's institutional structure. She observes that the EU's bureaucratic model of policy making, with the European Commission playing a pivotal role, results in greater reliance on transnational expertise than on public opinion (Zippel, 2004). Similarly, Princen (2009) links the bureaucratic structure at EU level with the so-called "democratic deficit," which is marked by limited accountability to EU citizens on the part of EU bureaucrats (Princen, 2009, p. 163). The EU bureaucratic model contrasts with domestic-level policy making, in which political parties and governments dominate the process. ${ }^{21}$ The exchanges between EU bureaucrats and transnational networks stand to benefit both groups. Network members gain access to the policy arena, and Commission staff benefits from information originating in member states or pan-European venues to which it might not otherwise have access.

Another example of the role of the EU bureaucracy in shaping policy debates is its support and funding for the creation of EU-level interest groups seen as necessary for balancing the interestgroup landscape. One example in this policy is the ETSC, discussed earlier, which is funded partly by the European Commission and partly by MNCs, and has "member" organizations from government, NGOs, research, and academia. This sort of activism on the part of the Commission, however, runs the risk of marginalizing other groups which have not been included but which may more legitimately represent the interest of EU citizens (Hix, 2005, p. 219). Similarly, Mahoney emphasizes the "demand-side" nature of interest-group formation within the EU, and notes also that allocation of seats on various consultative committees are another means by which the bureaucracy influences interest-group access (Mahoney, 2004, p. 444).

\section{$\underline{\text { Policy learning and transfer across jurisdictions }}$}

Several threads of the discussion thus far have alluded to the various mechanisms by which policies or policy ideas are transferred from one level of government to another. The ACF sees "policy-oriented learning" as a primary contributor to policy change (P. Sabatier, 1998; P. Sabatier \& Weible, 2007; P. A. Sabatier \& Jenkins-Smith, 1999). For Sabatier and his co-

\footnotetext{
${ }^{21}$ Along these same lines, Hooghe and Marks (2001) note: "While national representatives preside at Council meetings, the Commission sits in to clarify, redraft, and finalize the proposal; in short, it holds the pen." (Hooghe \& Marks, 2001, p. 21).
} 
authors, the dependent variable is policy change within a particular jurisdiction, and the flow of information that feeds that policy change is of greatest interest. It is important to consider, however, that this process is more complex than transfer of policies from a higher to lower level of government.

Börzel (2002) argues that in addition to being the recipients of EU dictates, member states may attempt to "upload" policies from domestic to EU level, a process that might be motivated by a desire to minimize the amount of domestic adjustment required to absorb EU policies (T. A. Börzel, 2002, p. 194). I would suggest that a member state might also have altruistic motives. If a particular approach has worked well domestically, or if the state has an idea for a creative interpretation of an existing EU policy, a state's motive may be as simple as the desire to share its success with other member states.

Nor is policy transfer necessarily voluntary. While it may often occur through joint participation of member states in transnational organizations or networks or through one-to-one exchange of information between policymakers or technical staff in member states, it may also occur through what is essentially coercion, as in the mandatory application of EU regulations and directives to member states. What gets transferred also varies. In some instances, it may simply be the ideas used to justify the need for a policy, but in other cases, policy transfer may entail the exporting of an entire program, including its specific content, mode of delivery, and institutions as well as its ideological underpinnings (Dolowitz \& Marsh, 2000; Wolman, 1992, p. 41).

With respect to policy learning and transfer, then, at issue are the direction in which information flows (upward, downward, or horizontally), who is transferring the information and where they are positioned vis-à-vis the recipient, whether the transfer is coercive or voluntary, and the content of the learning or transfer (the technical content, and its location on a continuum ranging from the germ of an idea to a full-blown program). Given the complexity of the EU's governance structure and the multi-sectoral nature of occupational road safety policy, it is likely that for the first two of these elements (direction of information flow, and sources of information that is learned or transferred), multiple flows of information and multiple actors will be present. These points are consistent with the aspects of MLG theory that emphasize the emergence of flexible jurisdictions and the flows of information between networks which represent varied interests and are active at different levels of government.

\section{$\underline{\text { Research questions }}$}

This research addresses the following questions:

\section{Regulatory environment}

- How have EU directives and policies influenced the progression of occupational road safety policy within the UK, France, and Sweden?

- How well have the UK, France, and Sweden transposed relevant EU directives into statelevel law? 
Hypothesis 1: Following Falkner et al. (2005), policy responses to EU directives related to occupational road risk will generally mirror the "world of domestic politics" for the UK, the "world of law observance" for Sweden, and the "world of neglect" for France.

Hypothesis 2: Where there are no EU directives to dictate policy content, state-level policy approaches as described in the literature will apply: UK policy responses as influenced by market-oriented pressures; Swedish responses as reflecting a corporatist, consensual, and holistic approach; and French responses as relying on a technocratic bureaucracy within the central state.

In addressing these questions, I describe the scope and content of relevant EU directives. I also discuss policy areas in which there are gaps in the EU's regulatory reach due to a lack of EU competence or for other reasons. I expect to find that transposition of directives relevant to occupational road safety will follow a pattern similar to that reported by Falkner et al. (2005) regarding transposition of EU labor directives. Although occupational road safety cuts across a number of policy areas, it has a strong social policy component, so we would expect memberstate governments to handle it in similar fashion as the labor directives studied by Falkner et al. However, a finding of relative "neglect" of EU directives by France, or predominance of domestic concerns in the UK, does not necessarily mean that these two polities have not addressed occupational road risk outside the scope of EU directives. Where no EU directives exist, I expect that policy instruments and content related to occupational road safety will reflect general state-level styles of policymaking as well as belief systems related to the role of transport in society, that is, the Anglo-Saxon and Continental approaches discussed above.

\section{Applicability of the Advocacy Coalition Framework}

- How well does the advocacy coalition framework (ACF) model explain the development of occupational road safety policy in the EU and in the three member states?

0 What factors have influenced the placement of occupational road safety on the policy agenda in the UK, France, and Sweden?

o How has occupational road safety been framed as a policy issue in these polities?

o To what extent have the missions, design, and placement of responsible agencies influenced the policy instruments chosen and the way in which those policies have been implemented?

o To what extent has the fragmentation of occupational road safety across several substantive policy areas impeded progress in making policy? On the other hand, has fragmentation helped policymaking in any way, for example, by offering multiple venues for policy activism?

o Have policies generally been "downloaded" from the EU to member states, or have member states also attempted to "upload" policy for wider implementation across the EU?

o What roles have international organizations, NGOs, quasi-governmental agencies, and the private sector played in shaping occupational road safety policy?

Hypothesis 3: Beliefs held by policy makers and interest groups, specifically those concerned with the extent to which government should dictate the behavior of the private sector, will play an important role in shaping policy responses in the three EU member states. 
I expect to find that the ACF will be broadly applicable to the development of occupational road safety policy in the EU and the three EU member states. Of particular relevance are the framing of the problem in various venues, the importance of belief systems, the pivotal role of interest groups (the private sector, policy experts, and safety advocates), and the role of institutional structures in mediating access to the policy arena.

The implications of differences in institutional structures are that there may be separate agencies with responsibility for different types of occupational driving (for example, large trucks versus lighter work vehicles) or different kinds of policy (for example, transport policy, where the worker is seen as a specific kind of road user, versus labor policy, where the worker is a client to be protected from road risks by OSH regulations and compensated in the event of injury). In addition, "policy learning" and "external shocks" may lead to shifts in policy content and policy instruments that range from incremental adjustment to sweeping change.

Applicability of multi-level governance

- Does the multi-level governance (MLG) framework offer a plausible explanation of the policy climate for occupational road safety in the EU?

Hypothesis 4: The multiple levels of government at which policy for occupational road safety is formulated and implemented, the opportunities for policy entrepreneurship by a range of actors at the various levels of government, and the degree to which governance takes place outside formal governmental structures will confirm the applicability of MLG to this policy area.

I expect to find that occupational road safety policy in the EU and the three member states will align well with the proposals of MLG. Further, MLG's consideration of non-governmental actors is particularly relevant to occupational road safety policy. Within the EU, not only is there opportunity for policymaking in multiple venues and levels, but the flexibility inherent in the EU system allows for a combination of coercive and collegial interactions within the policy community. In addition, I expect that policy learning and transfer will occur both vertically (upward as well as downward) and horizontally.

\section{Role of international actors}

- To what degree have international actors influenced the spread of policy ideas within the three EU member states, and at EU level?

Hypothesis 5: International actors such as NGOs and international organizations and less formal networks of policy experts will be shown to have a substantial influence on occupational road safety policy at EU and member-state levels.

Here I explore the possible influence of transnational actors other than the EU, and the EU may be seen as a potential recipient. The literature suggests that transnational actors, be they informal networks or international organizations, can be instrumental in helping domestic actors promote policies that might otherwise be difficult to enact, and that they are also sources of policy learning (Keck \& Sikkink, 1998; Zippel, 2004). Because numerous groups representing diverse 
interests are engaged in advancing road safety globally, I expect to find some evidence of substantive influence on EU and member-state policies for occupational road safety.

\section{Key dependent and independent variables}

In addressing the above questions, this research will assess the following dependent variables:

- State-level translation of EU directives related to occupational road safety by the UK, France, and Sweden: the degree and accuracy to which each was transposed

- The adoption of other state-level policy instruments prior to the formulation of EU directives, or as supplements to EU directives

- The degree to which policy responses to occupational road safety are fragmented

Relevant independent variables are as follows:

- The occurrence of "external shocks:" these may include events such as creation of new agencies or treaties at EU level, sentinel events such as multiple-fatality crashes, or economic shocks

- "Policy learning" by government policy makers through communication and advocacy by interest groups at various levels, both domestic and international

- The opportunity structure for occupational road safety policy:

o The number, variety, and governmental level of venues where policy making and related advocacy takes place. This information will aid in assessing the level of fragmentation in the institutional structure surrounding policymaking for occupational road safety.

o The role of domestic, pan-European, and international non-state actors such as MNCs, international organizations, standards organizations, organized labor, and EU-supported quasi-governmental interest groups such as ETSC

- The framing of policy for occupational road safety, that is, how arguments in favor of policy action are constructed, and how they may be attached to related policy issues to appeal to new or broader audiences of policymakers or end users

\section{$\underline{\text { Methods }}$}

The methodology is primarily qualitative, supplemented by data on injuries, fatalities, and interest groups. Primary sources of data are regulations, policy documents, guidance documents, the scholarly literature, and interviews with key informants. With these data, I do the following for the EU and its three member states:

- More fully ascertain the governmental and governance infrastructure in which occupational road safety policy is made

- Compare and contrast the policy instruments that have been implemented to reduce occupational road risk in these polities, and the policy ideas behind these instruments

- Assess the "opportunity structure," interest group structure, and policy networks that surround the governmental policymaking bodies

- Identify EU directives and policy recommendations related to occupational road safety

- Assess the differential responses of the three EU member states to these directives 


\section{Framework for analyzing transposition of EU directives}

Of particular interest to this research is the degree to which transposition of directives applicable to occupational driving is consistent with the findings of Falkner and her colleagues (Falkner, et al., 2005). In her assessment of compliance with six EU social policy directives, Falkner states that non-compliance may take any of three forms: non-transposition through delay in transposition or incorrect transposition, non-enforcement through inadequate monitoring or failure to impose sanctions for violations, or non-application. Falkner also offers possible explanations for non-compliance by member states based on intentionality. Opposition to a directive by a member state may be divided into three broad categories: (1) opposition to specific contents or potential effects of the directive; (2) opposition to the decision mode used by the EU; or (3) domestic political conditions such as parliamentary or ministerial conflicts, or interestgroup opposition. Non-compliance may also be unintentional, in other words, attributable to the inability of the member state to follow through with transposition or implementation. Inability to transpose may be due to: (1) the member state interpreting the directive differently than the EU intended; (2) administrative constraints or inefficiencies at member-state level; or (3) political instability (Falkner, et al., 2005, pp. 11-14).

The present research concentrates on assessing the transposition of selected EU directives using Falkner's criteria of timeliness and accuracy. For the directives considered in this research, we can assess quality of transposition based on the nature of the standard itself. Where there are quantitative requirements, such as maximum numbers of hours in the work day, the member state should be held to the "letter" of the directive. On the other hand, where the requirements are more qualitative, (for example, in the case of stipulations that driver testing must address general subject areas), we can only hold the member state to transposition of the "spirit" of the directive. In many instances, following Falkner, data from the literature and from key informant interviews provided insights as to whether non-transposition was based on opposition to the directive or inability to transpose.

The approach taken here is not to comprehensively assess the transposition of each provision of each directive; rather, the focus is on assessing only those individual provisions with direct application to occupational road safety. The same pre-selected provisions were assessed for all three member states.

Review of the literature and discussions with key informants based in EU agencies yielded eighteen directives and regulations of possible relevance (Caisse nationale de l'assurance maladies des travailleurs salariés - Direction des Risques professionnels (CNAMTS-DRP), April 28, 2010; European Agency for Safety and Health at Work, May 5, 2010; European Transport Safety Council, May 7, 2010). These directives cover topics such as working time and rest breaks, assessment of occupational risk, certification of competence as a road transport operator, and safety belt use. The complete listing of these directives and regulations appears in Table 2$1 .^{22}$

\footnotetext{
${ }^{22}$ There are additional EU directives which pertain to standards for manufacture and testing of motor vehicles intended for the EU market. See (Freund, 2007, pp. 17-22) for a detailed discussion of these directives. Although these have implications for road safety, and some are even specific to commercial motor vehicles, I do not include
} 
The primary source of information on EU directives was the EUR-lex database of European law found at http://eur-lex.europa.eu/en/index.htm. In addition to providing full text of directives, EUR-lex offers other documentation which may include a history of amendments, Commission proposals to further amend the directive, proceedings against member states for failure to comply with the directive, and references to member-state laws reported to have incorporated the directive. The completeness of this supporting documentation varies greatly by directive and by member state. The information available in EUR-lex was occasionally supplemented by administrative reports that discussed implementation of a directive within a single member state or across member states.

Table 2-1 divides the directives and regulations into four groups. The first group, labeled "Analysis of Transposition," consists of six directives for which it was possible to perform an assessment of transposition by EU member states France, Sweden, and the UK. The topics of these directives are: professional competence to operate a road transport business, working time for workers engaged in road transport, professional competence for drivers of large trucks and buses, driving licenses, seat belts, and working time for workers other than those engaged in road transport. The first three are specific to workers engaged in the transportation of goods and passengers, while the others apply more broadly to workers engaged in other kinds of workrelated driving.

One of the directives in the latter group, the "Working Time Directive" (2003/88/EC), merits further discussion. Mobile workers, defined as "any worker employed as a member of travelling or flying personnel by an undertaking which operates transport services for passengers or goods by road, air or inland waterway," are exempted from provisions related to daily rest, rest breaks, weekly rest periods, and night work [Article 20(1)]; (Commission of the European Communities, November 18, 2003, p. 14). Thus, the reference to "transport services" in Article 20 would exempt those companies whose primary business is transporting goods and passengers, as well as those entities transporting goods in support of their primary business, which might be manufacturing, distribution, or retail trade. The directive specifies further that "standards laid down in other Community instruments ...for certain categories of workers should take precedence over the provisions of this Directive" [Preamble (14)] (Commission of the European Communities, November 18, 2003, p. 10). One such example of a parallel sector-specific directive is the "Road Transport Working Time Directive" (2002/15/EC). Other categories of workers other than road transport workers are similarly exempted from the provisions related to rest breaks and night work; these include many workers who would be likely to drive regularly for work purposes: for example, ambulance workers, postal workers, refuse collection workers, telecommunications workers, and utility workers [Article 17(3)] (Commission of the European Communities, November 18, 2003, p. 13).

One of the most important provisions in the Working Time Directive is the stipulation that the average work week, including overtime, is not to exceed 48 hours [Article 6(b)] (Commission of the European Communities, November 18, 2003, p. 11). The directive allows member states to create exemptions from maximum work week rules for certain categories of workers: managers and executives, family workers, and religious workers [Article 17(1)], and doctors in training

them because they are linked more closely to product specification and harmonization than to the operational and policy dimensions of occupational road safety which are central to this research. 
[Article 17(5)]. However, these derogations were to be eliminated within five years of the directive going into effect (Commission of the European Communities, November 18, 2003, pp. 12-13). Despite the various exemptions provided, on its face this directive does not necessarily exclude other workers engaged in driving other than that which involves transport of goods and passengers, or workers other than those allowed special exemptions. For this reason, it is worth addressing its transposition by the three member states.

Assessing the transposition of the Driving License Directive (91/439/EEC) is complicated by the fact that it has been amended several times since 1991. The version used for analysis is a consolidated version that incorporates amendments as of 2007, but does not yet include provisions of the Revised Driving License Directive 2006/126/EC not yet in force (Commission of the European Communities, January 1, 2007). The rationale for this approach is that the consolidated version offers the best basis for comparison with information currently available on member-state licensing laws.

Directives in the "Discussion Only" group are discussed in the following chapters in the context of questions of their broad applicability to occupational driving, but they are not subjected to detailed analysis of their transposition into member-state law. The Framework Directive for OSH (89/391/EEC) has no provisions specific to occupational driving, yet does not exempt any transport-related activities from its reach. Among other responsibilities, employers are charged with providing a safe work environment, risk assessment, training, and risk notification, all of which may be applied to driving for work. Here, the question is not so much how well each member state has transposed the provisions of the Framework Directive and its "daughter directives," but how each state has interpreted its applicability to occupational driving. (Moreover, the majority of the "daughter directives" have no relationship at all to driving.) The situation is similar for the original "Working Equipment Directive" (89/655/EEC) and the "Revised Working Equipment Directive" (2009/104/EC) for which transposition is still in progress. In this case, the question is whether the vehicle is to be considered a piece of working equipment in the same way that one would view a piece of machinery in a fixed workplace. The final directive in this group, the "Revised Driving License Directive" (2006/126/EC) is relevant to occupational road safety because it speaks to harmonization of licensing and testing standards across member states. Drivers of large trucks and buses are covered by the "Driver CPC Directive" (2003/59/EC); Directive 2006/126/EC is similar in scope and purpose, but covers all other motorists, including occupational drivers of lighter vehicles. However, Directive 2006/126/EC does not take effect until January 2013, and transposition continues into 2011. Therefore, this research assesses transposition of the original "Driving License Directive" (91/439/EEC).

The three items shown under "Regulation" [the "Willi Betz Directive" (484/2002/EC), the "Driving Rest Time Directive" (561/2006/EC), and the "Data Directive" (1338/2008/EC)] are in fact EU regulations and therefore directly applicable legislation. Therefore, there is no basis for assessing how well member states have transposed them.

Finally, five directives are excluded for other reasons. The "Workplaces Directive" (89/654/EEC) specifically excludes vehicles from its definition of a workplace: "This Directive shall not apply to: (a) means of transport used outside the undertaking and/or the establishment, 
or workplaces inside means of transport; [or] (b) temporary or mobile work sites" (Commission of the European Communities, November 30, 1989). This exclusion of transport vehicles seems legitimate given that the provisions of the directive address features that would be associated with a stationary facility, including ventilation, lighting, showers, and escalators. The "Temporary Workers' Directive" (91/383/EEC) and the "Part-time Worker Directive" (97/81/EC) are excluded because while there may be certain safety management challenges associated with these worker populations, neither directive explicitly addresses risk factors for MVCs. Directive 2006/22/EC focuses on procedures for roadside checks for compliance with commercial motor vehicle regulations, and is excluded because of its indirect relationship to road safety. Transposition is still in progress for Directive 2009/5/EC, which deals with harmonization of penalties for infringement of transport-related social legislation across member states.

Table 2-1. EU directives included in transposition analysis or discussion

\begin{tabular}{|c|c|c|c|}
\hline Directive & Short Title & Source & Comments \\
\hline \multicolumn{4}{|l|}{ Analysis of transposition } \\
\hline $\begin{array}{l}\text { Council Directive 91/439/EEC of } 29 \text { July } \\
1991 \text { on driving licences }\end{array}$ & $\begin{array}{l}\text { Driving License } \\
\text { Directive }\end{array}$ & $\begin{array}{l}\text { OJ No. L 237, } \\
24.08 .91, \text { p. } 1 \\
\text { Consolidated } \\
\text { version of } \\
2007\end{array}$ & $\begin{array}{l}\text { Amended by Dir. 94/72/EC, } \\
\text { 96/47/EC, } 97 / 26 / \mathrm{EC}, \\
\text { 2000/56/EC, 2003/59/EC, } \\
\text { 2006/103/EC, and Reg. } \\
\text { 1882/2003 } \\
\text { To be replaced by Dir. } \\
\text { 2006/126/EC as of } 2013\end{array}$ \\
\hline $\begin{array}{l}\text { Council Directive } 98 / 76 / \text { EC of } 1 \text { October } \\
1998 \text { amending Directive } 96 / 26 / \text { EC on } \\
\text { admission to the occupation of road haulage } \\
\text { operator and road passenger transport } \\
\text { operator and mutual recognition of diplomas, } \\
\text { certificates and other evidence of formal } \\
\text { qualifications intended to facilitate for these } \\
\text { operators the right to freedom of } \\
\text { establishment in national and international } \\
\text { transport operations. }\end{array}$ & $\begin{array}{l}\text { Operator CPC } \\
\text { [Certificate of } \\
\text { Professional } \\
\text { Competence] } \\
\text { Directive }\end{array}$ & $\begin{array}{l}\text { OJ No. L } 277 \\
14.10 .98, \text { p. } 17\end{array}$ & $\begin{array}{l}\text { Amends Dir. 96/26/EC [OJ } \\
\text { No. L 124, 23.5.96, p. 1] } \\
\begin{array}{l}\text { Combined for analysis with } \\
\text { original directive } 96 / 26 / \mathrm{EC}\end{array}\end{array}$ \\
\hline $\begin{array}{l}\text { Directive } 2002 / 15 / \mathrm{EC} \text { of the European } \\
\text { Parliament and of the Council of } 11 \text { March } \\
2002 \text { on the organisation of the working time } \\
\text { of persons performing mobile road transport } \\
\text { activities }\end{array}$ & $\begin{array}{l}\text { Road Transport } \\
\text { Working Time } \\
\text { Directive }\end{array}$ & $\begin{array}{l}\text { OJ No. L 80, } \\
23.3 .2002, p \text {. } \\
35\end{array}$ & \\
\hline $\begin{array}{l}\text { Directive } 2003 / 20 / \text { EC of the European } \\
\text { Parliament and of the Council of } 8 \text { April } \\
2003 \text { amending Council Directive } \\
91 / 671 / \text { EEC on the approximation of the } \\
\text { laws of the Member States relating to } \\
\text { compulsory use of safety belts in vehicles of } \\
\text { less than } 3,5 \text { tonnes }\end{array}$ & Seat Belt Directive & $\begin{array}{l}\text { OJ L 115, } \\
9.5 .2003, \text { p. } 63\end{array}$ & Amends Dir. 91/671/EC \\
\hline $\begin{array}{l}\text { Directive 2003/59/EC of the European } \\
\text { Parliament and of the Council of } 15 \text { July } \\
2003 \text { on the initial qualification and periodic } \\
\text { training of drivers of certain road vehicles for } \\
\text { the carriage of goods or passengers, }\end{array}$ & $\begin{array}{l}\text { Driver CPC } \\
\text { Directive }\end{array}$ & $\begin{array}{l}\text { OJ No. L 226, } \\
\text { 10.9.2003, p. } 4\end{array}$ & $\begin{array}{l}\text { Amends Reg. (EEC) No } \\
\text { 3820/85 and Dir. 91/439/EEC }\end{array}$ \\
\hline
\end{tabular}




\begin{tabular}{|c|c|c|c|}
\hline $\begin{array}{l}\text { amending Council Regulation (EEC) No } \\
\text { 3820/85 and Council Directive 91/439/EEC } \\
\text { and repealing Council Directive 76/914/EEC }\end{array}$ & & & \\
\hline $\begin{array}{l}\text { Directive 2003/88/EC of the European } \\
\text { Parliament and of the Council of } 4 \text { November } \\
2003 \text { concerning certain aspects of the } \\
\text { organisation of working time }\end{array}$ & $\begin{array}{l}\text { Working Time } \\
\text { Directive }\end{array}$ & $\begin{array}{l}\text { OJ No. L 299, } \\
18.11 .2003, p \\
9\end{array}$ & $\begin{array}{l}\text { Consolidates Dir. 93/104/EC } \\
\text { and its amending Dir. } \\
\text { 2000/34/EC }\end{array}$ \\
\hline \multicolumn{4}{|l|}{ Discussion only } \\
\hline $\begin{array}{l}\text { Council Directive } 89 / 391 / \mathrm{EEC} \text { of } 12 \text { June } \\
1989 \text { on the introduction of measures to } \\
\text { encourage improvements in the safety and } \\
\text { health of workers at work }\end{array}$ & $\begin{array}{l}\text { Framework } \\
\text { Directive for OSH }\end{array}$ & $\begin{array}{l}\text { OJ No. L } 183 \\
29.6 .89, \text { p. } 1\end{array}$ & $\begin{array}{l}\text { Amended by Reg. 1882/2003 } \\
\text { and Dir. 2007/30/EC }\end{array}$ \\
\hline $\begin{array}{l}\text { Council Directive } 89 / 655 / \mathrm{EEC} \text { of } 30 \\
\text { November } 1989 \text { concerning the minimum } \\
\text { safety and health requirements for the use of } \\
\text { work equipment by workers at work (second } \\
\text { individual Directive within the meaning of } \\
\text { Article } 16 \text { (1) of Directive } 89 / 391 / \mathrm{EEC} \text { ) }\end{array}$ & $\begin{array}{l}\text { Working } \\
\text { Equipment } \\
\text { Directive }\end{array}$ & $\begin{array}{l}\text { OJ No. L 393, } \\
30.12 .1989, \mathrm{p} \\
1\end{array}$ & $\begin{array}{l}\text { Amended by Dir. } 95 / 63 / \mathrm{EC} \text {, } \\
\text { Dir. 2001/45/EC, and } \\
\text { Dir. 2007/30/EC } \\
\text { Original directive and } \\
\text { amendments repealed and } \\
\text { superseded by Dir. } \\
\text { 2009/14/EC }\end{array}$ \\
\hline $\begin{array}{l}\text { Directive 2006/126/EC of the European } \\
\text { Parliament and of the Council of } 20 \\
\text { December } 2006 \text { on driving licences (Recast) }\end{array}$ & $\begin{array}{l}\text { Revised Driving } \\
\text { License Directive }\end{array}$ & $\begin{array}{l}\text { OJ No. L 403, } \\
12.30 .2006, p \text {. } \\
18\end{array}$ & $\begin{array}{l}\text { Repeals and supersedes Dir. } \\
\text { 91/439/EEC and its amending } \\
\text { directives 94/72/EC, } \\
\text { 96/47/EC, 97/26/EC, and } \\
\text { 2000/56/EC, along with } \\
\text { portions of Dir. 2003/59/EC } \\
\text { (Article 10, paragraph 2) and } \\
\text { Reg. 1882/2003 (Annex II, } \\
\text { point 24) } \\
\text { Transposition still in progress }\end{array}$ \\
\hline $\begin{array}{l}\text { Directive } 2009 / 104 / \mathrm{EC} \text { of the European } \\
\text { Parliament and of the Council of } 16 \\
\text { September } 2009 \text { concerning the minimum } \\
\text { safety and health requirements for the use of } \\
\text { working equipment by workers at work } \\
\text { (second individual directive within the } \\
\text { meaning of Article 16(1) of Directive } \\
\text { 89/391/EEC }\end{array}$ & $\begin{array}{l}\text { Revised Working } \\
\text { Equipment } \\
\text { Directive }\end{array}$ & \begin{tabular}{|l} 
OJ No. L260, \\
3.10 .2009$, p. 5
\end{tabular} & Transposition still in progress \\
\hline \multicolumn{4}{|l|}{ Regulations } \\
\hline $\begin{array}{l}\text { Regulation (EC) No } 484 / 2002 \text { of the } \\
\text { European Parliament and of the Council of } 1 \\
\text { March } 2002 \text { amending Council Regulations } \\
\text { (EEC) No } 881 / 92 \text { and (EEC) No } 3118 / 93 \text { for } \\
\text { the purposes of establishing a driver } \\
\text { attestation }\end{array}$ & $\begin{array}{l}\text { Willi Betz } \\
\text { Directive }\end{array}$ & \begin{tabular}{|l} 
OJ No. L 76, \\
19.3.2002, p. 1
\end{tabular} & $\begin{array}{l}\text { No need for member state } \\
\text { transposition }\end{array}$ \\
\hline $\begin{array}{l}\text { Regulation (EC) No } 561 / 2006 \text { of the } \\
\text { European Parliament and of the Council of } \\
15 \text { March } 2006 \text { on the harmonisation of } \\
\text { certain social legislation relating to road } \\
\text { transport and amending Council Regulations } \\
\text { (EEC) No } 3821 / 85 \text { and (EC) No } 2135 / 98 \text { and } \\
\text { repealing Council Regulation (EEC) No } \\
3820 / 85\end{array}$ & $\begin{array}{l}\text { Driving Rest Time } \\
\text { Directive }\end{array}$ & \begin{tabular}{|l|} 
OJ No. L 102, \\
11.4.2006, p. 1
\end{tabular} & $\begin{array}{l}\text { No need for member state } \\
\text { transposition }\end{array}$ \\
\hline Regulation (EC) No $1338 / 2008$ of the & Data Directive & OJ No. L 354, & No need for member state \\
\hline
\end{tabular}




\begin{tabular}{|c|c|c|c|}
\hline $\begin{array}{l}\text { European Parliament and of the Council of } \\
16 \text { December } 2008 \text { on Community statistics } \\
\text { on public health and health and safety at } \\
\text { work. Official Journal of the European } \\
\text { Communities, L354, } 70-81 \text {. }\end{array}$ & & $\begin{array}{l}31.12 .2008, \mathrm{p} \\
70\end{array}$ & transposition \\
\hline \multicolumn{4}{|l|}{ Excluded for other reasons } \\
\hline $\begin{array}{l}\text { Council Directive } 89 / 654 / \mathrm{EEC} \text { of } 30 \\
\text { November } 1989 \text { concerning the minimum } \\
\text { safety and health requirements for the } \\
\text { workplace (first individual directive within } \\
\text { the meaning of Article 16(1) of Directive } \\
\text { 89/391/EEC) }\end{array}$ & $\begin{array}{l}\text { Workplaces } \\
\text { Directive }\end{array}$ & $\begin{array}{l}\text { OJ No. L 393, } \\
30.12 .1989, \text { p. } \\
170\end{array}$ & $\begin{array}{l}\text { Amended by Dir. 2007/30/EC } \\
\text { Exempts "means of transport } \\
\text { used outside the undertaking" } \\
\text { [Article } 1(2)]\end{array}$ \\
\hline $\begin{array}{l}\text { Council Directive 91/383/EEC of } 25 \text { June } \\
1991 \text { supplementing the measures to } \\
\text { encourage improvements in the safety and } \\
\text { health at work of workers with a fixed- } \\
\text { duration employment relationship or a } \\
\text { temporary employment relationship }\end{array}$ & $\begin{array}{l}\text { Temporary } \\
\text { Workers' Directive }\end{array}$ & \begin{tabular}{|l} 
OJ No. L 206, \\
29.7.91, p. 19
\end{tabular} & $\begin{array}{l}\text { No content directly related to } \\
\text { occupational driving }\end{array}$ \\
\hline $\begin{array}{l}\text { Council Directive } 97 / 81 / \text { EC of } 15 \text { December } \\
1997 \text { concerning the Framework Agreement } \\
\text { on part-time work concluded by UNICE, } \\
\text { CEEP and the ETUC }\end{array}$ & $\begin{array}{l}\text { Part-time Work } \\
\text { Directive }\end{array}$ & \begin{tabular}{|l} 
OJ No. L 14 \\
20.1 .98$, p. 9
\end{tabular} & $\begin{array}{l}\text { No content directly related to } \\
\text { occupational driving }\end{array}$ \\
\hline $\begin{array}{l}\text { Directive 2006/22/EC of the European } \\
\text { Parliament and of the Council of } 15 \text { March } \\
2006 \text { on minimum conditions for the } \\
\text { implementation of Council Regulations } \\
\text { (EEC) No } 3820 / 85 \text { and (EEC) No } 3821 / 85 \\
\text { concerning social legislation relating to road } \\
\text { transport activities and repealing Council } \\
\text { Directive } 88 / 599 / \text { EEC }\end{array}$ & $\begin{array}{l}\text { Minimum } \\
\text { conditions for } \\
\text { roadside checks to } \\
\text { ensure compliance } \\
\text { with driving time } \\
\text { regulations }\end{array}$ & $\begin{array}{l}\text { OJ No. L 102, } \\
\text { 11.4.2006, p. } \\
35\end{array}$ & Administrative in nature \\
\hline $\begin{array}{l}\text { Commission Directive } 2009 / 5 / \mathrm{EC} \text { of } 30 \\
\text { January } 2009 \text { amending Annex III to } \\
\text { Directive } 2006 / 22 / \mathrm{EC} \text { of the European } \\
\text { Parliament and of the Council on minimum } \\
\text { conditions for the implementation of Council } \\
\text { Regulations (EEC) Nos } 3820 / 85 \text { and } 3821 / 85 \\
\text { concerning social legislation relating to road } \\
\text { transport activities }\end{array}$ & $\begin{array}{l}\text { Harmonized } \\
\text { categorization of } \\
\text { infringements for } \\
\text { use in enforcing } \\
\text { social legislation } \\
\text { relating to road } \\
\text { transport activities }\end{array}$ & $\begin{array}{l}\text { OJ No. L 29, } \\
\text { 31.1.2009, p. } \\
45\end{array}$ & $\begin{array}{l}\text { Amends a portion of Dir. } \\
\text { 2006/22/EC } \\
\text { Transposition still in progress }\end{array}$ \\
\hline
\end{tabular}

\section{Key informant interviews}

Interviews with key informants based in government, international organizations, NGOs, and private industry are used to confirm, disconfirm, or otherwise qualify the research hypotheses. Interviews are an especially useful tool for addressing research questions such as those addressed here, several of which consider the prevailing policy ideas underpinning state-level policy responses and the sentinel events or "external shocks" that bring an issue to policymakers' attention. Linkages between events are often not apparent if inquiry is limited to review of official documents, and the insights provided by key informants can fill in missing information or correct misperceptions. Conversely, interviews can reveal that events which on the surface appear to be linked may in fact be unrelated, or that forces that appear to be influential may in fact be of little consequence. 
Interview schedules were prepared in accordance with accepted criteria for constructing openended questions that are neutral, singular, and clear (Patton, 2005, pp. 353-366). Here, "neutrality" means taking care not to introduce project the interviewer's personal opinion about a program or policy into the content of a question, and not to construct a "leading question" that steers the interviewee down a particular path in responding to the question. An example of a non-neutral question pertinent to this study might be: "Why have international organizations failed to influence the French government's policy responses for occupational road safety?" The construction of "singular" questions refers to ensuring that the respondent is asked one question at a time. If a question is "double-barreled," the interviewee may be confused as to which component of a question he or she is expected to answer. An example of a "double-barreled" question that might have been used for this research is: "To what extent do you understand and agree with the rules found in the EU's directives on maximum working time?" Finally, clarity is important for the obvious reasons that it reduces the possibility that questions will confuse or alienate the interviewee. For this research, it was important to be explicit about names of organizations, governmental units, and directives, avoiding acronyms and jargon. Lack of clarity in interview questions can also threaten validity in that the interviewee may be responding to a question other than the question the researcher meant to ask, a fact that may escape both the researcher and the interviewee.

For this research, interviews were conducted with individuals from a variety of organizations: EU member-state governments, international organizations, NGOs, and the European Commission. Details of organizations and interviewees are provided in Appendix A. Points of discussion for each interview necessarily varied by interviewee; for example, although I asked informants from state-level governments to discuss the role of domestic government agencies in managing occupational road risk, I asked representatives of international organizations to comment more broadly on their relationships with the EU and member state governments vis-àvis occupational road safety. Some questions were quite broad, eliciting background information about the history of occupational road safety as a policy issue; others were much more specific and intended to resolve questions raised by review of literature and policy documents. The interviews were of value in: (1) identifying the circumstances to the entry of occupational road safety onto the policy agenda, or the barriers to that entry; (2) identifying regulations or policy directives relevant to occupational road safety that my literature searches did not reveal; (3) for the three EU member states, assessing the quality of response to EU directives relevant to occupational road safety; and (4) assessing the relative roles of interest groups, epistemic communities, and government officials in formulating and advocating for policy change. Complete interview schedules are shown in Appendix B.

\section{Limitations of this research}

This research is subject to a number of limitations. First, the use of interview data admits the possibility that the interviewee may not have understood all the questions or may not have been fully informed about the topic. My ability to conduct personal interviews in all but two instances (as opposed to telephone interviews or written queries) made it possible to gauge the interviewee's level of understanding and better assess whether the interviewee was an authoritative source on a particular topic. In one case, the interviewee was unfamiliar with one line of questioning and referred me to a subject-matter expert who was able to provide definitive answers. I made every effort to cross-check statements by interviewees against official 
documents or to obtain clarification directly from interviewees as questions arose during preparation of this document.

Second, it is important to note that language and translation issues undoubtedly had an effect on my ability to identify and interpret key sources written in French and Swedish. Although key informants were helpful in steering me to useful sources of information for each of these countries, it is possible that I either failed to locate other important sources or failed to recognize them as such.

I relied heavily on Internet-based translation engines to identify relevant regulations and other policy documents. A fair reading knowledge of French made it possible for me to consider French-language documents and translations side by side, evaluate the accuracy of translations, and adjust where necessary. I believe that I have accurately traced transposition of EU directives, but I have undoubtedly missed agency reports that might have allowed me to present a more complete accounting of occupational road safety policy in France.

For the Swedish-language materials, it was extraordinarily helpful that the Swedish government provides official translations of major legislation such as the Work Environment Act, and publishes the top levels of its government Web pages in English. In addition, Swedish road safety researchers publish widely in English-language journals, and the individuals I interviewed are quite fluent in spoken English. Based on the variety of reliable English-language sources available for Swedish law and policy, I am reasonably confident that my conclusions reflect the scope and content of Swedish policy. 


\section{Chapter 3. The United Kingdom: Balancing Free Markets and Worker Safety}

The chapter begins with a review of the major OSH and transport legislation and agency roles and responsibilities that have influenced the development of occupational road safety policy in the UK, incorporating data from interviews of key informants. This is followed by a discussion of events that focused the attention of policymakers and the public on the hazards of occupational driving, and which led to calls for government action by interest groups. Next, I discuss the government's response to interest group pressures, and persistent points of contention regarding the framing of occupational road safety in the UK. The first section of the chapter closes with presentation of evidence from interviews about the influence of EU directives on domestic policies, and the extent to which the UK has participated in policy transfer or learning related to occupational road safety.

Next, I review the UK's transposition of EU directives on driver licensing, certificates of professional competence for road transport operators and drivers, working time, and seat belts. In general, I find accurate transpositions which are, however, tempered by domestic policy slants that do not necessarily reflect the EU approach to risk management. The chapter concludes with a discussion of the evidence for and against the research hypotheses. I conclude that the ACF is a more compelling framework for explaining occupational road safety policy in the UK than is MLG. Two features of the ACF - a robust policy subsystem whose actors represent diverse interests, and a strong role for policy beliefs - are especially salient for the UK.

\section{$\underline{\text { Legislation and institutional structure }}$}

In the UK, two bodies of domestic legislation and regulation, one related to transport and the other to OSH, have had the greatest impact on the development of occupational road safety. For the most part, the basic legislation in both policy areas pre-dates relevant EU directives. The first major transport legislation was the Transport Act of 1968, which had direct effect on occupational road safety through its provisions on working hours for drivers in road transport of freight and passengers. The purpose of these provisions was "protecting the public against the risks which arise in cases where the drivers of motor vehicles are suffering from fatigue" [Part VI, Section 95(1)] (HMSO, 1968). The 1968 legislation covered maximum permitted hours of driving during a shift, during a work week, and between breaks. After the UK joined the EU, the Transport Act was amended to incorporate EU rules for on-board electronic recording of driving hours.

On the employer side, the Transport Act of 1968 required any concern operating heavy-goods vehicles to hold an operator's license contingent upon established experience and reputation in the industry, adequate financial standing, resources to maintain vehicles, and compliance with regulations on driving hours and vehicle weights [Part V, Section 62] (HMSO, 1968). Although freight transport in the UK remained state-run under the National Freight Corporation, these provisions nonetheless changed the focus of British regulation from a quantitative to a qualitative approach (Lawton-Smith, 1995, p. 141). The shift to provision of quality services as the 
criterion for entry into the freight transport industry created a competition-oriented operating environment consistent with deregulation, which was finally accomplished in 1982.

The second major piece of transport legislation was the Road Traffic Act (RTA) of 1988, which was broader in scope than the Transport Act of 1968, covering general motoring and road user behavior rather than exclusively the transport industry. RTA provisions covered driver licensing, driving instruction, vehicle manufacturing standards, safety belt use, impaired driving, reckless driving, rules for cyclists, vehicle inspections, vehicle insurance, physical fitness to drive, the powers given to law enforcement officers, and penalties for traffic violations. It also contained sections specific to loading and maintenance of goods vehicles and special licensing provisions for heavy-goods vehicle drivers.

In addition to provisions targeted to the road transport sector, the RTA contains language that holds employers and other parties partially responsible for certain road infractions. All the UK interviewees, in noting HSE's lack of jurisdiction over employee driving on public roadways, cited "cause or permit" provisions of the RTA as offering some protections for employees driving for work (Department for Transport (United Kingdom), April 30, 2010; Health and Safety Executive, April 30, 2010; RoadSafe, May 6, 2010; Royal Society for the Prevention of Accidents, April 29, 2010). An example of one such provision is: "It is an offence for a person to cause or permit another person to drive a heavy goods vehicle of any class on a road if that other person is not so licensed to drive a heavy goods vehicle of that class" [Section 110(2)]. "Cause or permit" provisions also cover "Leaving vehicles in dangerous positions" [Section 22], "Vehicles not to be sold in unroadworthy condition or altered so as to be unroadworthy" [Section 75], "Offences in connection with unfit or overloaded goods vehicles" [Section 71], and "Drivers of motor vehicles to have driving licences" [Section 87] (HMSO, 1988). However, "cause or permit" provisions are by no means all-inclusive, and even those that seem quite specific to occupational road safety do not explicitly confer any particular responsibilities on employers. One interviewee concluded that "road safety law is quite silent as to what employers must do" (Royal Society for the Prevention of Accidents, April 29, 2010). In practice, though, the RTA has become the UK's de facto source of law for occupational driving, with an HSE interviewee affirming that the agency's "...official position is that as long as you are satisfying road traffic requirements, ${ }^{23}$ you are doing what needs to be done to manage occupational road risk" (Health and Safety Executive, April 30, 2010).

Through the RTA, laws covering the road transport sector were integrated into the legislation covering all motoring. To a large degree, functions for monitoring the road transport sector were also integrated into the agencies that covered these areas for the general motoring public. ${ }^{24}$ All the relevant transport agencies are located within the DfT and operate at central-government level, with a single set of standards for England, Scotland, and Wales. Although administered separately, standards for Northern Ireland are generally nearly identical in substance to British standards.

\footnotetext{
${ }^{23}$ In other words, holding a valid driving license and complying with general rules of the road such as speed limits.

${ }^{24}$ This is in direct contrast to the U.S., where government management of safety for the transport sector is handled by a dedicated agency, the Federal Motor Carrier Safety Administration (FMCSA), which is housed directly under the Secretary of Transportation and is situated parallel to other road safety agencies.
} 
The Driving Standards Agency (DSA) is responsible for setting driver testing standards, conducting and scoring written and on-road driving tests at several hundred locations around the UK, and regulating driving instructors and trainers. The Driver and Vehicle Licensing Authority (DVLA) issues driving licenses and vehicle registrations, including special endorsements and qualifications for certain types of licenses, and is the agency to which licensed drivers must report medical conditions affecting their ability to drive. The scope and activities of both the DSA and DVLA are relevant to any individual seeking to obtain and maintain a driving license in the UK, and would, by extension, be relevant to persons driving a personal or company-owned or leased vehicle for work purposes. As licensing information from the DVLA becomes more readily accessible in an electronic format, organizations are increasingly using it to ensure that their drivers are legally compliant and to manage any risks identified.

The Vehicle and Operator Services Agency (VOSA) has more specialized responsibilities pertaining to companies and drivers in the road transport sector. VOSA enforces safety standards for large-goods vehicles ${ }^{25}$ related to topics such as hours of service and weight limitations, and reviews and issues certifications that allow companies to maintain authorization to operate a road transport operation and drivers to work in passenger or freight transport. However, VOSA also has responsibilities for monitoring the quality of the general vehicle fleet in the UK. VOSA administers vehicle manufacturing standards and regulations, operates mandatory vehicle inspection programs for all types of vehicles, investigates vehicle defects, and issues vehicle recalls.

The UK's first comprehensive OSH legislation was the Health and Safety at Work (HSW) Act of 1974. It remains the framework for all subsequent regulations. Before the HSW Act, the UK's OSH regime was quite fragmented, with rules codified in nine separate groups of statutes administered by five different central-government departments and enforced by seven separate inspectorates. The HSW Act was enacted in response to pressure on government from labor unions (notably the Trades Union Congress) and others to reduce the growing toll of occupational injuries; fragmentation of the existing OSH regime was seen as a barrier to employer awareness and compliance.

The basis for the HSW Act was the 1972 report of a committee led by Lord Robens, which recommended a single "framework" statute that would both reduce the number of rules and extend OSH regulation to all types of workplaces. The primary ideas underlying the Robens report were that OSH regulation should provide an environment in which self-regulation could flourish, and that OSH initiatives should be carried out by employers in concert with employees and the organizations representing their interests (Baldwin, 1996, p. 84). The HSW Act, passed by Parliament in 1974, took the form of a framework statute as recommended by the Robens report. The "duty of care" provision in the HSW Act is of particular importance, as it became an underlying principle for all subsequent OSH legislation: "It shall be the duty of every employer to ensure, so far as is reasonably practicable, the health, safety and welfare at work of all his employees" [Section 2(1)] (HMSO, 1974).

Two new agencies were created by the HSW Act: the Health and Safety Commission (HSC), which was to be the policymaking body for OSH, and the HSE, which was tasked with

\footnotetext{
${ }^{25}$ Referred to in earlier legislation such as the Transport Act of 1968 as "heavy-goods vehicles"
} 
enforcement functions. The rationale for creation of two separate agencies was that the HSE's enforcement activities would be viewed as more impartial if HSE were to be functionally independent of the HSC (Baldwin, 1996, p. 85). The HSC, a tripartite body made up of government, employer, and labor representatives, is surprisingly corporatist (for the UK). An executive communication that coincided with passage of the HSW Act was quite important to the future course of the UK's policy for occupational road safety. Michael Foot was one of the political architects of the HSW Act and the Secretary of State for Employment in the Labour government. For Foot, passage of the HSW Act raised fundamental questions about the implications of the Act for policy areas where other ministries or agencies might be seen to already have some jurisdiction. In 1975, he crafted the so-called "Foot letter" to the HSC, delineating the relationships between the HSC, himself, and other ministers. Although the "Foot letter" had no basis in law, it nonetheless established that where existing law covered a particular area of risk for employees, that law would be enforced, not the general "duty of care" that was a pillar of the HSW Act. For occupational road safety, this distinction meant that the HSE would enforce regulations in fixed workplaces, whereas police would enforce road safety law (Royal Society for the Prevention of Accidents, April 29, 2010; Russell, 2001).

Although transport and OSH laws and regulations are generally set and enforced from centralgovernment level, there is some allowance for sub-state initiatives based on local priorities. This is mandatory in some cases and discretionary in others. On the transport side, the RTA charges local authorities (defined as a county or metropolitan council in England and Wales, and as a regional council in Scotland) to "carry out studies into accidents arising out of the use of vehicles on roads or parts of roads, other than trunk roads, within their area, and... in the light of those studies, take such measures as appear to the authority to be appropriate to prevent such accidents" [Section 39 (3) (a and b)] (HMSO, 1988).

Within the HSE, although implementation strategies are transferred from central authorities to regional and local level, some deviations within local work plans are allowed, and it is possible for initiatives to originate at local level. However, these are more at the program implementation level than the policymaking level. There is also some evidence of inter-agency cooperation through a memorandum of understanding (MOU) between the HSE and the Police, with guidance added to the Police Road Death Investigation Manual (Association of Chief Police Officers, 2001, pp. 181-186). The HSE and the Metropolitan Police in London have implemented the MOU whereby if in the investigation of a crash involving an occupational vehicle the police suspect that some management failure may have been a contributing factor, the police are authorized by the HSE to go into workplaces and ask employers to demonstrate that road risk is managed appropriately. This program covers any type of vehicle driven for "commercial purposes," not just large trucks and buses (Health and Safety Executive, April 30, 2010). The London program is noteworthy as an activity in which the HSE functions as if risk assessment for driving is part of the regulations, in a way circumventing its own policy position on the limits of its jurisdiction.

Table 3-1 below shows how the UK government agencies with a role in occupational road safety are situated institutionally, and summarizes their areas of responsibility. 
Table 3-1. British government agencies with responsibility for occupational road safety

\begin{tabular}{|c|c|c|}
\hline Agency & Ministry & Notes \\
\hline \multicolumn{3}{|l|}{ Transport Agencies } \\
\hline $\begin{array}{l}\text { Department for } \\
\text { Transport (DfT) }\end{array}$ & & DSA, DVLA, and VOSA are each placed under DfT \\
\hline $\begin{array}{l}\text { Driving Standards } \\
\text { Agency (DSA) }\end{array}$ & $\begin{array}{l}\text { Department for } \\
\text { Transport }\end{array}$ & $\begin{array}{l}\text { - Sets driver testing standards, including those for Driver CPC } \\
\text { - } \quad \text { Conducts written and on-road driving tests } \\
\text { - } \quad \text { Regulates driving instructors }\end{array}$ \\
\hline $\begin{array}{l}\text { Driver and Vehicle } \\
\text { Licensing Agency } \\
\text { (DVLA) }\end{array}$ & $\begin{array}{l}\text { Department for } \\
\text { Transport }\end{array}$ & $\begin{array}{l}\text { - Issues driving licenses and vehicle registrations } \\
\text { - Agency to which licensed drivers must report medical } \\
\text { conditions affecting their ability to drive }\end{array}$ \\
\hline $\begin{array}{l}\text { Vehicle and Operator } \\
\text { Services Agency } \\
\text { (VOSA) }\end{array}$ & $\begin{array}{l}\text { Department for } \\
\text { Transport }\end{array}$ & $\begin{array}{l}\text { Enforces safety standards for large-goods vehicles and } \\
\text { passenger-transport vehicles } \\
\text { - Supports work of regional Traffic Commissioners, who } \\
\text { review applications and issue Operator CPCs for passenger } \\
\text { or freight transport } \\
\text { - For all types of vehicles: } \\
\text { o Oversees vehicle inspection programs and enforcement } \\
\text { of manufacturing standards } \\
\text { o Investigates vehicle defects and issues recalls }\end{array}$ \\
\hline \multicolumn{3}{|l|}{ OSH Agencies } \\
\hline $\begin{array}{l}\text { Health and Safety } \\
\text { Commission (HSC) }\end{array}$ & $\begin{array}{l}\text { Independent } \\
\text { commission }\end{array}$ & Sets policy for OSH \\
\hline $\begin{array}{l}\text { Health and Safety } \\
\text { Executive (HSE) }\end{array}$ & $\begin{array}{l}\text { Not attached to a } \\
\text { ministry }\end{array}$ & $\begin{array}{l}\text { - Implements and enforces OSH regulations } \\
\text { - Investigates occupational injuries on employer premises } \\
\text { - } \quad \text { Functionally independent of HSC }\end{array}$ \\
\hline
\end{tabular}

\section{$\underline{\text { Focusing events }}$}

Several high-profile transportation disasters drew attention of UK policymakers and the public to occupational transport issues (Stevens, 2004, p. 110). This is corroborated by media accounts and by several key informants interviewed for this study. The first of these incidents, although not a roadway crash, influenced the course of policy because it established the idea that corporations could be held criminally responsible for unsafe actions of employees (Royal Society for the Prevention of Accidents, April 29, 2010). This was the capsizing of a car ferry off the coast of Zeebrugge, Belgium in March of 1987, in which over 190 people died. The bow doors of the ferry were left open after departure, causing the decks to flood. The ferry operator and seven employees were subsequently charged with manslaughter by the Crown Prosecution Service. Although the coroner's inquest laid blame on individual employees and not the ferry operator, the case set a precedent for corporate manslaughter to be legally admissible as an offense in English courts, laying the groundwork for the 2007 Corporate Manslaughter Act (BBC News, 2010).

In the 1990s, two motor vehicle crashes with multiple fatalities focused attention on occupational driving, resulting in calls for government intervention (Health and Safety Executive, April 30, 2010; Royal Society for the Prevention of Accidents, April 29, 2010). The first of these occurred at Sowerby Bridge, West Yorkshire in September of 1993. In this incident, a truck described as 
an "eight-wheeler tipper lorry" (in the U.S., a dump truck) collided with a British Telecom van, pushing the van into a post-office building and killing three women and a child. Investigators concluded that the truck (driven by a contract worker) had lost its brakes; four of the brake shoes were found to be worn down to the rivets, and all eight brake drums showed excessive wear (Palmer, September 7, 1993; The Independent (UK), February 25, 1994).

In the second crash, a school minibus returning music students from a concert in London plowed into the back of a stopped maintenance vehicle on the M40 motorway in Warwickshire. The teacher driving the minibus and eleven children were killed, and three children were injured. An inquest found no mechanical cause for the crash, but suggested that a directional sign on the maintenance vehicle may have been obscured, making it difficult for the teacher to discern the position of the maintenance vehicle (Boggan, November 19, 1993). Fatigue and long work hours, followed by a long drive home after the concert, were also discussed as risk factors. In both incidents, the workers involved in the crash were killed: in the Sowerby Bridge crash, the truck driver and a British Telecom engineer, and in the M40 crash, the teacher driving the minibus. However, the focus of public concern was not so much on the safety of the workers operating the vehicles, but on the impact of worker-operated vehicles on public safety (Royal Society for the Prevention of Accidents, April 29, 2010).

The Sowerby Bridge crash in particular led to campaigns in the media at regional level by the Yorkshire Post and also in the national media by The Independent. Here, the press expanded the discussion to blame management failures motivated by cost-cutting pressures, and to draw attention to dangers posed by hazardous materials transport (Bennetto, October 10, 1993; Furbisher, October 15, 1994; Murray \& Whiteing, 1995, pp. 23-24; The Independent (UK), February 25, 1994). The tone of the press coverage was important here in that it shifted attention from the actions of individual drivers to argue for greater accountability on the part of the employer, setting the stage for the debate among stakeholders that was to follow. Local politicians in the Yorkshire area took advantage of the advocacy in the press to urge action at higher levels of government.

The Sowerby Bridge incident led to the emergence of the West Yorkshire-based road safety charity, Brake, which has since campaigned for research and policy change for work-related road safety. It also prompted the local University of Huddersfield to begin research in this area, which helped to inform arguments for changes in government policy and organizational practices (McCorry \& Murray, 1993; Murray \& Whiteing, 1995).

Actions by government, NGOs, researchers, and industry suppliers

At the same time that concerns about occupational road safety were beginning to resonate with the public, the research community, and policymakers, organizations in the UK whose employees were doing extensive work-related driving generally provided some form of driver training. However, in most instances, driver training was not carried out within a framework of health and safety management that viewed driving at work as an occupational risk to be managed in the same way as on-premises risks such as work at elevations or hazardous chemicals (Royal Society for the Prevention of Accidents, April 29, 2010). 
The situation began to change in the mid-1990s with increasing stakeholder engagement and new applied research on occupational road safety. Well-attended conferences were hosted at the University of Huddersfield in 1995 and 1998, bringing together researchers, industry suppliers, NGOs, and safety practitioners. These were the catalyst for important research on topics such as collision reporting and benchmarking, driver assessment and monitoring, the role and safety of contract/and temporary workers in the transport sector, and road safety culture and company policy. Over 500 managers from industry and government also attended workshops on workrelated road safety at the University of Huddersfield. At the same time, the Transport Research Laboratory (originally wholly government-owned but privatized in 1996) began to receive government and other support for research on work-related road safety.

In 1996 and 1997, RoSPA organized stakeholder meetings around the question of whether employer "duty of care" under the HSW Act should extend to occupational driving. Reportedly, arguments in favor of employers taking responsibility for managing occupational road risk were bolstered by the EU Framework Directive for OSH (89/391/EC). The main points cited were the requirement that employers to conduct comprehensive risk assessments, and the fact that the Framework Directive did not exclude driving or transport activities. The RoSPA-sponsored meetings, which attracted over 40 participants from industry, government, the Trades Union Congress, and NGOs, led to a consensus that businesses ought to institute policies and procedures to manage road risk. ${ }^{26}$ A declaration to that effect was signed by all participants except for the HSE, which declined to sign because its jurisdiction "ended when the vehicle left the gates" (Royal Society for the Prevention of Accidents, April 29, 2010). HSE's action is not surprising, given that a government agency would be highly unlikely to make any such commitment that might push the agency to take on responsibilities beyond its current scope of activity. Resource limitations are also a critical issue for HSE, as including MVCs in its scope could more than triple the number of fatalities it might be charged with investigating each year. ${ }^{27}$ Despite HSE's reluctance to publicly support the need for employers to include road risk among their OSH responsibilities, advocates were successful in promoting government engagement at a broader level, and the structure of the bureaucracy at the time made this easier to achieve. In the late 1990s, at the time of the RoSPA meeting declaration was issued, the Parliamentary UnderSecretary of State for the Department of the Environment, Transport and the Regions was Larry Whitty, who was at one time a labor union representative. ${ }^{28}$ Thus, occupational road safety advocates had the advantage of being able to reach out to a high-level transport policymaker with experience in occupational health and safety, who evidently recognized the relationship between occupational road safety and the policy areas in his charge.

\footnotetext{
${ }^{26}$ It is worth noting that although RoSPA's motivation clearly centered on safety promotion, it also had a material interest in encouraging broad acceptance of the need to manage occupational road risk. Like its U.S. counterpart the National Safety Council, RoSPA is a vendor of driver training services and also offers risk management consultation.

${ }^{27}$ This statement is based on expert estimates of 600 to 800 fatal at-work MVCs per year, as compared to 152 workplace fatalities from all other causes as reported by the HSE for data year 2009/2010 (Health and Safety Executive, 2010, p. 8).

${ }^{28}$ Whitty was the official who signed several major transport regulations, including the Goods Vehicle Operators (Qualifications) Regulations and the Motor Vehicles (Driving Licences) Regulations (both 1999).
} 
Under-Secretary Whitty responded to the advocates' overtures by convening a governmentsponsored committee headed by Richard Dykes which included representatives from industry, regional government units, HSE, the Driving Standards Agency, RoSPA, trade unions, law enforcement, insurance, and NGOs. The product of this committee, the "Dykes Report," recommended that employers should manage at-work road risk within the framework that should already be in place for managing all other occupational health and safety risks. In addition, the Dykes Report recommended the risk management approach laid down in the HSW Act 1974 and the Management of Health and Safety at Work Regulations 1999 as the best framework for employers to use (Work-related Road Safety Task Group, 2001). The latter are the revised version of one UK response to the EU Framework Directive for Occupational Safety and Health (89/391/EEC), thus, they cover employer responsibility for occupational risk assessment across all industries and for all occupational hazards.

Little substantive change came as a result of the Dykes Report. Its recommendations were referred back to the HSE, but it was unclear what the HSE might do because its own policy still dictated that the majority of on-road work-related collisions were outside its jurisdiction. Ultimately, however, HSE collaborated with the DfT to issue a joint guidance document called Driving at Work: Managing Work-related Road Safety (Health and Safety Executive, 2003). This document is an example of the "practical guidance" to employers promoted through the HSW Act. While it lacked the force of regulation, and thus offered no possibility for civil or criminal penalties to be imposed on employers should they fail to comply, it was much easier to push through the approval chain. Such a document required only the approval of the departmental Secretary of State (Baldwin, 1996, p. 85). Although Driving at Work was not backed by the force of regulation, it was nonetheless symbolically important because it represented an official entrance into the occupational road safety policy area by HSE. Further, it has come to be accepted as setting core requirements to be followed by companies and organizations. Driving at Work cited domestic law and regulations, the latter a transposition of an EU directive, as the basis for its conclusions:

The Health and Safety at Work Act 1974 requires you to ensure, so far as is reasonably practicable, the health and safety of all employees while at work. You also have a responsibility to ensure that others are not put at risk by your workrelated driving activities.

Under the Management of Health and Safety at Work Regulations 1999, you have a responsibility to manage health and safety effectively. You need to carry out an assessment of the risks to the health and safety of your employees, while they are at work, and to other people who may be affected by their work activities. The Regulations require you to periodically review your risk assessment so that it remains appropriate. (Health and Safety Executive, 2003, p. 3)

Today, HSE's primary responsibility remains the enforcement of OSH regulations and investigation of occupational injuries occurring on employer premises. In a few instances, HSE chooses to take the lead on incidents that occur on or near a road. For example, HSE will investigate the death of a highway worker working on the side of a road (which falls under construction industry regulations), the on-road death of a refuse collector, and any incident 
involving hazardous materials. The rule of thumb is that if the work activity normally occurs on the road, and is not inherently a driving activity, HSE will be the lead investigative agency. If, however, the incident involves transport of goods or passengers, or any other type of workrelated driving, the traffic police have jurisdiction and the RTA and related rules are the first-line body of applicable law (Health and Safety Executive, April 30, 2010).

Two pieces of recent legislation may affect the likelihood and consequences of legal action against employers for failing to exercise duty of care in protecting workers from road risk. The first of these, the Corporate Manslaughter and Corporate Homicide Act of 2007, allows an organization to be held criminally liable if "the way in which its activities are managed or organised causes a person's death, and amounts to a gross breach of a relevant duty of care owed by the organisation to the deceased" [Section 1(1)(a and b)] (HMSO, 2007). The law applies to public and private sector organizations. Here, the "duty of care" is cast broadly as an organization's "duty owed to its employees or to other persons working for the organisation or performing services for it" [Section 2(1)(a)] (HMSO, 2007). This legislation represented a material change in British law, changing precedents established under common law that had made it practically impossible to prosecute a corporation for gross negligence leading to death (Barrett, 2009, pp. 7-8). Moreover, because the Corporate Manslaughter and Corporate Homicide Act is criminal law and therefore not tied to the HSW Act, there is no basis for excluding road risk from its scope.

In 2008, the Health and Safety (Offences) Act strengthened penalties for violations of the HSW Act, allowing for fines, imprisonment, or both. However, although this legislation signaled greater concern from Parliament for enforcement of OSH law, it was practically less relevant to occupational road safety. Because it is linked to enforcement of the HSW Act, the interpretation of the HSW Act that excludes MVCs from HSE jurisdiction limits the application of the Health and Safety (Offences) Act to road risk (Barrett, 2009, p. 7).

\section{A government-supported interest group}

Around the time HSE and DfT released the Driving at Work guidance, both agencies took further action by sponsoring several research contracts and programs covering collision reporting, safety culture, good practice for businesses, and fuel-efficient driving. In addition, DfT created a government-supported interest group, Driving for Better Business (DfBB), which would allow businesses to work amongst themselves to improve occupational road safety. ${ }^{29}$ The genesis of DfBB was a "Motorists' Forum" sponsored by DfT, which was the government's response to public perceptions that it was "anti-motorist," largely because of increased fuel taxes and reduced speed limits. Concerns about the impact of work-related driving on public safety also came out during the Motorists' Forum, in the wake of a 2004 truck crash which had resulted in six fatalities. One idea that emerged from the Motorists' Forum was that instead of government foisting additional guidance on businesses to encourage them to better manage road risk, businesses might be instead be more readily "persuadable by each other" (Department for Transport (United Kingdom), April 30, 2010). This idea was put into practice through DfBB.

\footnotetext{
${ }^{29} \mathrm{http}: / /$ www.drivingforbetterbusiness.com/
} 
The DfT funds DfBB through the RoadSafe NGO, which recruits business community "champions" who have successfully managed road risk among their employees, and assists them in spreading safety messages to other businesses. In addition to encouraging high-level discussions among business leaders, DfBB also emphasizes opportunities for public and private sector organizations to move intervention and cultural change down the supply chain by imposing risk assessment requirements on subcontractors or suppliers (Health and Safety Executive, April 30, 2010). DfBB thus represents a government-supported interest group created to fill a perceived need, similar to EU-level groups described by Hix (2005). However, unlike some groups developed through the European Commission, DfBB was not created to ensure that previously unheard voices would be mobilized to contribute to public discourse about a policy area. Rather, DfBB allowed the DfT to show interest and concern about occupational road safety yet in a manner that would not be viewed by business as heavy-handed, supporting the "general policy position of DfT...that occupational road safety can be improved through campaigns such as Driving for Better Business, not through additional legislation" (Department for Transport (United Kingdom), April 30, 2010).

The distribution of DfBB "champions" reflects several ideas that define occupational road safety as a broad policy issue. First, membership ranges from the British Library, which operates only a handful of company-owned vehicles, to British Telecommunications and the Royal Mail, each of which operates over 30,000 vehicles. Second, the issue of occupational road safety is framed as being equally important for private and public sector agencies; there are a number of county councils, city governments, and public institutions such as the fire services and the British Library among the DfBB "champions." Finally, the recruitment of "champions" from among MNCs, in addition to solely UK-based companies, brings in information about "best practices" and management innovations from other European countries and beyond.

\section{Controversies over crash data}

A major point of contention in the UK between road safety researchers and advocates and the government is the absence of government data to determine the contribution of work-related crashes to the overall toll of road crashes or the overall toll of occupational injuries. There are two relevant data systems: the HSE data system for occupational injuries (the Reporting of Injury, Diseases, and Dangerous Occurrences Regulations [RIDDOR]); and the DfT system for road crashes based on police reports (Stats19). Based on intense lobbying by NGOs and researchers and the DfT's own research, in 2005 an item was added to the standard crash reporting form for Stats19 to ascertain whether persons involved in the crash were driving for work. However, the inclusion of an item on the crash reporting form does not guarantee that law enforcement officers will be trained and encouraged to capture the data. Results from Stats 19 thus far are not encouraging, with approximately 70 percent of collisions still assigned a value of "unknown" for the "purpose of journey" variable (Department for Transport (United Kingdom), April 30, 2010; Health and Safety Executive, April 30, 2010).

Advocates are concerned not only about the slow transition to capturing complete data on occupational crashes through Stats 19, but about the omission of on-road MVCs from RIDDOR. The HSE interviewee explained that the reason for excluding MVCs is that HSE has no jurisdiction over them through its enforcement and investigative responsibilities: "HSE is not 
going to follow up, so there is no point in capturing them" (Health and Safety Executive, April 30, 2010). According to the HSE informant, RIDDOR was not designed to collect data on incidents occurring "outside the workplace," and adding a type of incident that might make up one-third of all occupational fatalities would over-burden the system. Further, companies would oppose additional reporting requirements, and the mandatory inclusion of MVCs in standard reporting to shareholders might give the appearance of poor health and safety outcomes (Health and Safety Executive, April 30, 2010).

The possibility of adding work-related road crashes to RIDDOR was proposed at HSC level several times over the last decade, but was rejected because of HSE's lack of jurisdiction and because of limitations in RIDDOR reporting procedures. ${ }^{30}$ Key players for HSE, DfT, RoSPA, Brake, and others are well aware of one another's positions regarding the addition of workrelated MVCs to RIDDOR, but at this time it appears that there are no clear prospects for change. Within HSE, the RIDDOR database is clearly defined as being aligned with the scope of the agency's program of OSH enforcement: it was not designed to provide an accounting of all occupational injuries in the UK (Health and Safety Executive, April 30, 2010). Although the separation of HSC's policymaking function and the HSE's enforcement function may have been a prudent policy decision, the designation of HSE as both the OSH enforcement agency and OSH data collector was an unfortunate outcome. The use of RIDDOR as a tool for monitoring progress in reducing all types of occupational injuries should therefore be viewed thus far as a missed opportunity.

The DfT informant interviewed for this research saw little added value to his department if onroad crashes were to be added to RIDDOR, stating that the inclusion of MVCs would contravene the purpose for which RIDDOR was developed, which was to require employers to report serious injuries on their own premises. Echoing comments from HSE, the DfT interviewee also noted potential problems of under-reporting work-related MVCs, additional burdens on the RIDDOR system, and likely opposition from employers. Finally, he stated that the addition of MVCs to RIDDOR would not cause MVCs to become more visible as an OSH problem in need of attention through regulation or other means. He argued that the problem of work-related crashes is well-enough recognized in the UK, and that more data would contribute little to the discussion (Department for Transport (United Kingdom), April 30, 2010).

Of the UK interviewees, only the RoSPA representative provided a strong voice in favor of adding MVCs to the RIDDOR system. His primary argument was that if no data are collected, it is much easier for policymakers to ignore an issue. This informant stated that the inclusion of work-related MVCs in RIDDOR would be "psychologically important," conferring greater urgency on the need to manage occupational road risk by allowing it to be viewed on an equal footing with other OSH hazards (Royal Society for the Prevention of Accidents, April 29, 2010).

\footnotetext{
${ }^{30}$ At this time, the UK and Ireland are the only EU member states that do not report work-related MVCs as part of the data set submitted to Eurostat, the EU statistical agency, for publication in statistical abstracts of occupational injuries and illnesses.
} 


\section{The influence of EU directives}

Overall, interviewees in the UK indicated that EU directives related to occupational road safety had not required substantial changes in state-level regulations, nor had they strongly influenced how government or employers managed road risk for employees. As one respondent put it: "The UK is a leader - this is not a situation where UK agencies have had to make changes in national law based on EU action" (RoadSafe, May 6, 2010). However, informants from UK government agencies did note a few instances in which EU directives had made a difference, either by reinforcing the government's preferred policy direction or by requiring changes in regulations. The HSE informant, speaking from an OSH perspective, said that the Framework Directive (89/391/EEC) had been quite influential, leading to new UK regulations addressing occupational hazards specified in the Directive (not including road safety). In addition, the Framework Directive helped to bolster the HSE's case for routine application of risk assessment processes to work-related driving, as articulated in the 2003 Driving at Work guidance document (Health and Safety Executive, 2003, April 30, 2010). From the standpoint of the DfT, the most influential EU directives pertinent to occupational road safety have been those addressing the content and standards for driving licenses (91/439/EEC and its successor EC/2006/126, which is still undergoing transposition), and those addressing the mutual recognition of licenses and diplomas (again, the driving license directives, as well as those pertaining to certificates of professional competence (CPCs) for both road transport operators and drivers [96/26/EC, 98/76/EC and 2003/88/EC]) (Department for Transport (United Kingdom), April 30, 2010).

\section{Policy learning through the European Union and multinational corporations}

According to UK informants, EU directives have led to limited changes in policy for occupational road safety in the UK. Several interviewees, especially those engaged in consultation or advocacy, emphasized the role of non-governmental actors, many of them transnational, in influencing the UK's largely voluntary business-centered approach to managing occupational road risk. One informant cited the ETSC's PRAISE project and the networking and guidance structure it has created as influencing UK organizations that operate vehicles (Health and Safety Executive, April 30,2010). Another noted that MNCs are the primary conduit through which EU-wide policy learning between companies is taking place (RoadSafe, May 6, 2010). Another mentioned the presence of MNCs in groups such as the UN Road Safety Collaboration as important to incorporating occupational road safety into global policy debates (Royal Society for the Prevention of Accidents, April 29, 2010).

Two countries were mentioned as having exerted some influence on occupational road safety in the UK. One individual noted that a great deal of information has flowed from Australia to the UK because of a common language and because of considerable movement of scholars and consultants between the two countries. She cited Australia's strong governmental support for occupational road safety as an influence on the DfT's decision to support the DfBB program. In addition, this interviewee noted that Sweden's emphasis on technology and safe systems has served as a model for businesses in the UK (RoadSafe, May 6, 2010). 
Overall, based on the views expressed by key informants based elsewhere in Europe and by individuals from the UK itself, the UK is one of the European leaders in occupational road safety (European Commission Directorate-General Mobility and Transport, May 6, 2010; European Transport Safety Council, May 7, 2010; Global Road Safety Partnership, May 4, 2010; RoadSafe, May 6, 2010; World Health Organization, Department of Public Health and Environment, May 4, 2010). The interviewee from the RoadSafe NGO cited one shortcoming of the UK's business-centered approach: that there is so much information available and so many commercial providers of fleet management and consultation services as to be confusing to the uninitiated. In addition, this informant noted that government support of a "softer" approach to road safety management, which rests on promoting dialogue between businesses through initiatives such as DfBB, could also be construed as the government's "washing its hands of the problem" (RoadSafe, May 6, 2010).

\section{$\underline{\text { British transposition of EU directives }}$}

The primary sources used to identify the British legislation that transposed EU directives were the UK Statute Law Database maintained by the Office of Public Sector Information (www.statutelaw.gov.uk) and the www.legislation.gov.uk site maintained by the National Archives. In some instances, clarifying information emerged through implementation reports produced by the British government, reports examining transposition of selected directives across EU member states, and personal interviews. For each of the six directives assessed, transposing legislation and regulations are identified, followed by a table that displays the preselected text of the EU directive adjacent to relevant text from British legal instruments. Each assessment ends with a commentary that ties the transposition to the policy literature and interview results. Table 3-8 at the end of this chapter provides full citations for all the transposing laws and regulations for the UK identified through this research.

Some of the laws discussed here are Acts of Parliament (statutes). Acts give the Secretary of State for Transport, a prime-ministerial appointee in the Cabinet, the power to issue regulations for the purpose of carrying out Parliament's legislative intent. The Regulations are referred to as Statutory Instruments (Lowe, 2007, p. 217). ${ }^{31}$

All but one of the six directives discussed below were transposed twice, resulting in one set of regulations for Great Britain only (England, Scotland, and Wales) and another for Northern Ireland. The agencies responsible for transposition and implementation for Great Britain are the central-government DfT and subordinate agencies (for those regulations related to the transport sector) and HSE (for the Working Time Directive) (Department for Transport (United Kingdom), 2008). For Northern Ireland, legislation is enacted by the Northern Ireland Assembly. The agencies responsible for transposition and implementation for Northern Ireland are the Department of the Environment (for those regulations related to the transport sector) and the Department of Economic Development (for the Working Time Directive).

\footnotetext{
${ }^{31}$ The Secretary of State may also issue Orders to implement provisions found in Acts (although no Orders are discussed in the present study).
} 
The only regulations with direct applicability to Northern Ireland are those related to transposition of the Driver CPC Directive. One exception in these regulations is a provision that amends driver licensing regulations. The reason for the exception is that the driver licensing regulations for Northern Ireland are issued separately from those for Great Britain, so any change to these would have to be accomplished outside of this regulation that applies to the whole of the UK.

In general, the transpositions for Great Britain and Northern Ireland barely differ from one another. Clearly, the substance of Acts and Regulations emanating from central-government level provide the blueprint for legislative and regulatory action in Northern Ireland; often, the only points of differences between documents applicable to the two jurisdictions are legal citations and the names of agencies. Therefore, for the sake of simplifying an already complex task, this research will cite only British regulations. For the six directives assessed here, Northern Ireland regulations were found to differ in substance from British regulations on a single point pertaining to use of seat belts. The discrepancy is noted below in the discussion of the transposition of the Seat Belt Directive.

\section{Driving License Directive}

\section{Council Directive 91/439/EEC of 29 July 1991 on driving licences [consolidated version of January 1, 2007]}

Assessing British transposition of the Driving License Directive was complicated by the fact that the basic transpositions, the 1996 Motor Vehicles (Driving Licences) Road Traffic Regulations and its 1999 revision, were not self-contained documents. They are understood only in the context of the 1988 and 1991 versions of the Road Traffic Act which they amend. Therefore, to evaluate each topic, it was necessary to begin with the 1996 regulations to determine if the topic had been incorporated, moving back to the 1988 and 1991 Road Traffic Acts to determine if there was already conformance to the letter of the EU directive, and moving forward to the 1999 Motor Vehicles (Driving Licences) Road Traffic Regulations and other regulations to see if the topic was incorporated there.

Table 3-2. British transposition of Driving License Directive (91/439/EEC)

\begin{tabular}{|c|c|}
\hline EU Directive & British Regulation \\
\hline $\begin{array}{l}\text { Article 1(2): Driving licences issued by Member States } \\
\text { shall be mutually recognized. }\end{array}$ & $\begin{array}{l}\text { Motor Vehicles (Community Driving Licence) Regulations } \\
1996 \\
\text { [Amending the Road Traffic Act of 1988] } \\
\text { 9. After section } 99 \text { there shall be inserted- } \\
\text { "Community licence holders } \\
\text { Authorisation to drive in Great Britain. } \\
\text { 99A.- (1) A Community licence holder may drive, and } \\
\text { a person may cause or permit a Community licence holder } \\
\text { to drive, in Great Britain, a motor vehicle of any class } \\
\text { which- } \\
\text { (a)he is authorised by his Community licence to drive, and } \\
\text { (b)he is not disqualified for holding or obtaining a licence } \\
\text { under this Part of this Act to drive, }\end{array}$ \\
\hline
\end{tabular}




\begin{tabular}{|c|c|c|}
\hline & \multicolumn{2}{|c|}{$\begin{array}{l}\text { notwithstanding that he is not the holder of } \\
\text { a licence under this Part of this Act. } \\
\text { (2) Subsections (3) and (4) below apply to a } \\
\text { Community licence holder who is normally resident in } \\
\text { Great Britain. } \\
\text { (3) In a case where the Community licence holder is } \\
\text { authorised by his Community licence to drive motor } \\
\text { vehicles of classes other than any prescribed class of } \\
\text { goods vehicle or any prescribed class of passenger- } \\
\text { carrying vehicle, he shall cease to be authorised by virtue } \\
\text { of subsection (1) above to drive in Great Britain any such } \\
\text { classes of motor vehicle from- } \\
\text { (a)the date on which he attains the age of seventy years, or } \\
\text { (b)the expiry of the period of three years beginning with } \\
\text { the relevant date, } \\
\text { whichever is the later. }\end{array}$} \\
\hline $\begin{array}{l}\text { Article 3(1): The driving licence provided for in Article1 } \\
\text { shall authorize the driving of vehicles in the following } \\
\text { categories: [See Figure } 2 \text { for a graphic showing standard } \\
\text { vehicle classes.] }\end{array}$ & \multicolumn{2}{|c|}{$\begin{array}{l}\text { Motor Vehicles (Driving Licences) Road Traffic } \\
\text { Regulations } 1996 \\
\text { Schedule } 2 \text { reproduces standard vehicle categories found } \\
\text { in the EU directive. }\end{array}$} \\
\hline $\begin{array}{l}\text { Article 4(1): Driving licences shall state the conditions on } \\
\text { which the driver is authorized to drive. [Annex I (added } \\
\text { by } 2000 / 56 / E C \text { ) provides a list of harmonized } \\
\text { Community codes to be used on member-state licenses. } \\
\text { These address restrictions based on need for corrective } \\
\text { lenses, vehicle adaptations such as modified control } \\
\text { layouts or assistive devices, and a Certificate of } \\
\text { Professional Competence (CPC) to operate a commercial } \\
\text { motor vehicle (this last provision added by 2003/59/EC).] }\end{array}$ & \multicolumn{2}{|c|}{$\begin{array}{l}\text { No evidence of transposition into law through either } 1996 \\
\text { or } 1999 \text { Motor Vehicles (Driving Licences) Road Traffic } \\
\text { Regulations, or in any of the many subsequent } \\
\text { amendments of these regulations through } 2010 .\end{array}$} \\
\hline $\begin{array}{l}\text { Article 6(1): The minimum age conditions for the issue of } \\
\text { driving licences shall be as follows: } \\
\text { (a) } 16 \text { years: } \\
\text { - for subcategory A1; } \\
\text { - for subcategory B1; } \\
\text { (b) } 18 \text { years: } \\
\text { - for category A... } \\
\text { - for categories B, B + E; } \\
\text { - for categories C, C + E and subcategories C1, C1 + } \\
\text { E... } \\
\text { (c) } 21 \text { years: }\end{array}$ & \multicolumn{2}{|c|}{$\begin{array}{l}\text { Motor Vehicles (Driving Licences) Road Traffic } \\
\text { Regulations } 1999 \\
\text { Regulation 9: Minimum ages for holding or obtaining } \\
\text { licences } \\
\text { 9. - (1) Subsection (1) of section } 101 \text { of the Traffic Act* } \\
\text { shall have effect as if for the classes of vehicle and the } \\
\text { ages specified in the Table in that subsection there were } \\
\text { substituted classes of vehicle and ages in accordance with } \\
\text { the following provisions of this regulation [goes on to } \\
\text { specify certain exceptions to limits shown in Table below, } \\
\text { e.g., lowering age limit for (3) from } 17 \text { to } 16 \text { in certain } \\
\text { cases, as allowed by EU directive] }\end{array}$} \\
\hline [various derogations and exceptions permitted] & \multicolumn{2}{|c|}{$\begin{array}{l}\text { *Road Traffic Act } 1988 \\
\text { Section 101: Disqualification of persons under age } \\
\text { (1) A person is disqualified for holding or obtaining a } \\
\text { licence to drive a motor vehicle of a class specified in the } \\
\text { following Table if he is under the age specified in relation } \\
\text { to it in the second column of the Table. } \\
\text { TABLE }\end{array}$} \\
\hline & Class of motor vehicle & $\begin{array}{l}\text { Age (in } \\
\text { years) }\end{array}$ \\
\hline & 1. Invalid carriage & 16 \\
\hline & 2. Motor cycle & 16 \\
\hline & 3. Small passenger vehicle or small goods & 17 \\
\hline
\end{tabular}




\begin{tabular}{|c|c|}
\hline & $\begin{array}{ll}\text { vehicle } & \\
\text { 4. Agricultural tractor } & 17 \\
\text { 5. Medium-sized goods vehicle } & 18 \\
\text { 6. Other motor vehicles } & 21\end{array}$ \\
\hline $\begin{array}{l}\text { Article 7(1): Driving licences shall, moreover, be issued } \\
\text { only to those applicants: (a) who have passed a test of } \\
\text { skills and behaviour and a theoretical test and who meet } \\
\text { medical standards, in accordance with the provisions } \\
\text { of Annexes II and III; }\end{array}$ & $\begin{array}{l}\text { Motor Vehicles (Driving Licences) Road Traffic } \\
\text { Regulations } 1996 \\
\text { Regulation } 36 \text { : “... the test for a licence authorising the } \\
\text { driving of a motor vehicle of a class included in category } \\
\text { A, B, C, D, or P shall be conducted in two parts, namely- } \\
\text { (a) a theoretical test, and (b) a practical test of driving } \\
\text { skills and behaviour, and a person taking such a test must } \\
\text { pass both parts.” }\end{array}$ \\
\hline $\begin{array}{l}\text { ANNEX II } \\
\text { I. MINIMUM REQUIREMENTS FOR DRIVING } \\
\text { TESTS } \\
\text { 2. Content of the theory test concerning all vehicle } \\
\text { categories } \\
2.1 \text {. Questions must be asked on each of the points listed } \\
\text { below, the content and form of the questions being left to } \\
\text { the discretion of each Member state: } \\
\text { [Followed by list of topics under these headings: Road } \\
\text { traffic regulations, The driver, The road, Other road users, } \\
\text { General rules and regulations and other matters, } \\
\text { Precautions necessary when alighting from the vehicle, } \\
\text { Mechanical aspects with a bearing on road safety, Vehicle } \\
\text { safety equipment, and Rules regarding vehicle use in } \\
\text { relation to the environment ] }\end{array}$ & $\begin{array}{l}\text { Motor Vehicles (Driving Licences) Road Traffic } \\
\text { Regulations } 1996 \\
\text { Schedule 7: Reproduces topics for theory tests nearly } \\
\text { verbatim from the EU directive. }\end{array}$ \\
\hline $\begin{array}{l}\text { Annex II } \\
\text { II. KNOWLEDGE, SKILL AND BEHAVIOUR FOR } \\
\text { DRIVING A POWER-DRIVEN VEHICLE } \\
\text { Specific provisions concerning categories C, C+E, C1, } \\
\text { C1+E, D, D+E, D1 and D1+E }\end{array}$ & $\begin{array}{l}\text { Motor Vehicles (Driving Licences) Road Traffic } \\
\text { Regulations } 1996 \\
\text { Regulation 36, Schedule 8, Parts } 3 \text { and 4: Provide for } \\
\text { separate testing criteria for persons seeking licensure to } \\
\text { drive heavier vehicles (those in classes C, D, and E). }\end{array}$ \\
\hline $\begin{array}{l}\text { ANNEX III } \\
\text { MINIMUM STANDARDS OF PHYSICAL AND } \\
\text { MENTAL FITNESS FOR DRIVING A POWER- } \\
\text { DRIVEN VEHICLE [covers sight, hearing, CVD, } \\
\text { diabetes, alcohol, mental illness, drugs and medications] }\end{array}$ & $\begin{array}{l}\text { Motor Vehicles (Driving Licences) Road Traffic } \\
\text { Regulations } 1999 \\
\text { Regulation 71: Disabilities prescribed in respect of } \\
\text { Group } 1 \text { and } 2 \text { licences } \\
\text { 71.--(1) The following disabilities are prescribed for the } \\
\text { purposes of section 92(2) of the Traffic Act as relevant } \\
\text { disabilities* in relation to an applicant for, or a person who } \\
\text { holds, a Group } 1 \text { or Group } 2 \text { licence-- } \\
\text { (a) epilepsy; } \\
\text { (b) severe mental disorder; } \\
\text { (c) liability to sudden attacks of disabling giddiness or } \\
\text { fainting which are caused by any disorder or defect of the } \\
\text { heart as a result of which the applicant for the licence or, } \\
\text { as the case may be, the holder of the licence has a device } \\
\text { implanted in his body, being a device which, by operating } \\
\text { on the heart so as to regulate its action, is designed to }\end{array}$ \\
\hline
\end{tabular}

\footnotetext{
${ }^{32}$ These vehicle classes are typically used for carrying freight and passengers. Because of their function, weight, and configuration, they are singled out for special consideration by regulations. See Figure 2 for a graphic displaying all the standard vehicle classes used in the EU.
} 


\begin{tabular}{|c|c|c|}
\hline & & $\begin{array}{l}\text { correct the disorder or defect; } \\
\text { (d) liability to sudden attacks of disabling giddiness or } \\
\text { fainting, other than attacks falling within paragraph (1)(c); } \\
\text { and } \\
\text { (e) persistent misuse of drugs or alcohol, whether or not } \\
\text { such misuse amounts to dependency. } \\
\\
\text { *Road Traffic Act } 1988 \\
\text { Section 92: Requirements as to physical fitness of } \\
\text { drivers } \\
\text { (1) An application for the grant of a licence must include a } \\
\text { declaration by the applicant, in such form as the Secretary } \\
\text { of State [for Transport] may require, stating whether he is } \\
\text { suffering or has at any time (or, if a period is prescribed } \\
\text { for the purposes of this subsection, has during that period) } \\
\text { suffered from any relevant disability or any prospective } \\
\text { disability. (2) In this Part of this Act- "disability" } \\
\text { includes disease... }\end{array}$ \\
\hline
\end{tabular}


Figure 2. Standard vehicle classes used in the European Union

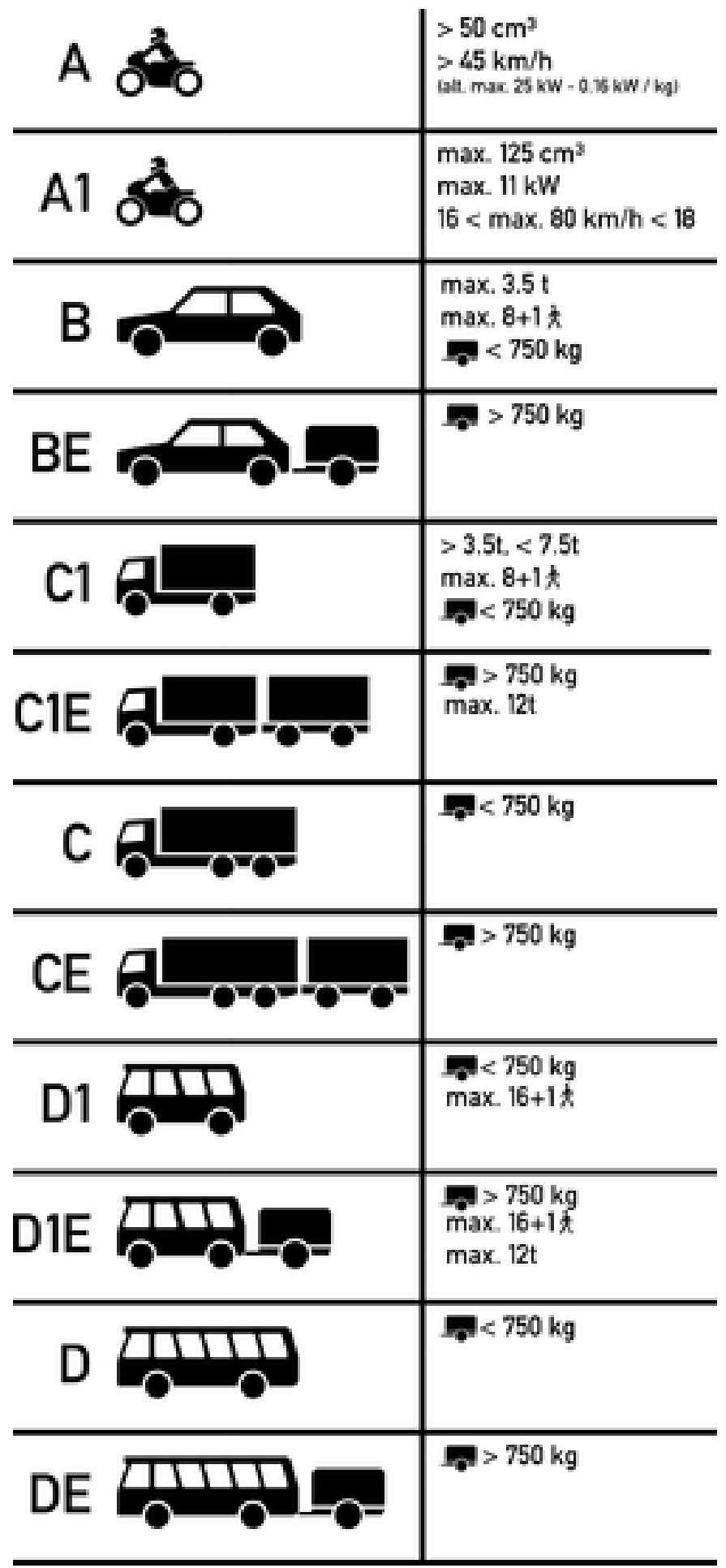


Great Britain did not meet the June 30, 1994 deadline for transposition of the EU Driving License Directive. The British response to this directive is found primarily in the 1996 and 1999 versions of the Motor Vehicles (Driving Licences) Road Traffic Regulations, with measures related to mutual recognition of licenses handled in the 1996 Motor Vehicles (Community Driving Licence) Regulations. Of the eight provisions in the EU directive considered here, only five were transposed essentially correctly by the two 1996 British regulations.

It is noteworthy that Great Britain was correct in its initial, albeit late, transposition of Article 1(2) of the Driving License Directive, which pertains to member states' mutual recognition of driving licenses. Mutual recognition has two components that are especially relevant to occupational driving. The first relates to the ability of workers to operate a vehicle in a member state other than which they are a permanent resident without having to obtain special permissions, and to exchange their original license for a new license should they choose to change their official residency to a different member state. The second component relates to the recognition by Great Britain that an individual authorized to drive certain classes of vehicles via endorsements on a license issued by another EU member state may drive those classes of vehicles within Great Britain. Clearly, these elements of British law reinforce the free movement of persons and services provided for by the SEA. This includes permissions for drivers with special endorsements such as those for large-goods vehicles and buses to drive in Great Britain as non-residents or permanent residents.

Two of the provisions considered here were transposed in the 1999 version of the Motor Vehicles (Driving Licences) Road Traffic Regulations. One of these added requirements from Annex III of the EU directive related to medical qualifications of drivers, but there appears to have been no list of disqualifying conditions incorporated into British regulations before that time. ${ }^{33}$ The 1999 version of the Motor Vehicles (Driving Licences) Road Traffic Regulations also made minor changes to age standards for driver licensing. For the most part, the age limits for British licensing found in the Road Traffic Act of 1988 were already in conformance with requirements of the EU directive; the 1999 revision to the British licensing regulation simply took advantage of a few opportunities to lower age limits as provided for in the EU directive. There is no evidence that one element of the EU Driving License Directive was directly incorporated into British law or regulations via the major 1996 or 1999 versions of the Motor Vehicles (Driving Licences) Road Traffic Regulation, or in any of the many amendments that have followed. This is the harmonized list of operator restriction codes provided for by Article 4(1) and Annex I of the EU Driving License Directive. A UK government public information Web site provides a current list of restriction codes used on British licenses. This list does not conform to the list shown in Annex I of the Driving License Directive, nor does it include the code related to the CPC requirement (Directgov (United Kingdom), 2010). Of note, compliance with the list provided in Annex I was mandatory for member states (Commission of the European Communities, January 1, 2007, p. 12).

\footnotetext{
${ }^{33}$ Prior to 1999, the relevant language was found in the Road Traffic Act of 1988, which required licensees to report diseases or disabilities that could affect their ability to drive. Currently, the Driver and Vehicle Licensing Agency within DfT relies on periodically updated administrative guidance to advise medical professionals as to conditions under which individuals can be disqualified from operating a motor vehicle on medical grounds (http://www.dft.gov.uk/dvla/medical/ataglance.aspx).
} 
The UK was evidently not the only EU member state that encountered challenges in transposing the Driving License Directive. As late as 2002, the European Commission was still reminding member states of failed transpositions of the Driving License Directive, citing ECJ decisions, identifying non-compliant member states, and offering interpretive guidance based on hypothetical situations (Commission of the European Communities, March 28, 2002).

\section{Driver CPC Directive}

\section{Directive 2003/59/EC of the European Parliament and of the Council of $15 \mathrm{July}$ 2003 on the initial qualification and periodic training of drivers of certain road vehicles for the carriage of goods or passengers, amending Council Regulation (EEC) No 3820/85 and Council Directive 91/439/EEC and repealing Council Directive 76/914/EEC}

The "Driver CPC Directive" covers requirements for qualification and training of drivers of C, $\mathrm{D}$, and $\mathrm{E}$ category vehicles. Licensing requirements for these drivers are handled separately within the Driving License Directive; qualification and training requirements are handled by Directive 2003/59/EC. Within a given member state, the requirements apply to nationals of that state, as well as third-country nationals employed by a business based in another member state [Article 1]. This directive requires member states to implement systems for initial qualification that will lead to a Certificate of Professional Competence (CPC) for individual drivers. Member states may elect to qualify drivers through tests only (written and on-the-road), or through class attendance combined with tests [Article 3] (Commission of the European Communities, September 10, 2003). For the initial qualification, the UK selected the first option involving tests only. Of interest here is how successfully the UK has transposed the requirements related to training centers and course content, as these are more closely linked to safety outcomes than are requirements that pertain mainly to administration and recordkeeping.

Table 3-3. United Kingdom transposition of Driver CPC Directive (2003/59/EC)

\section{EU Directive}

Article 6: CPC certifying the initial qualification

1.CPC certifying an initial qualification

(a) CPC awarded on the basis of course attendance and a test:

In accordance with Article 3(1)(a)(i), Member States shall require trainee drivers to attend courses in a training centre approved by the competent authorities in accordance with section 5 of Annex I,* hereinafter referred to as 'approved training centre'. These courses shall cover all the subjects referred to in section 1 of Annex I.**

(b) CPC awarded on the basis of tests: In accordance with Article 3(1)(a)(ii), Member States shall require trainee drivers to pass the theoretical and practical tests referred to in section 2(2.2) of Annex I.***

\section{United Kingdom Regulation}

Vehicle Drivers (Certificates of Professional Competence) Regulations 2007

Regulation 4: Persons who must take initial CPC test 4. - (1) Except where paragraph (5) or (9) applies and subject to paragraph (7), a person to whom these Regulations apply is not permitted to drive a relevant vehicle on a road on or after the date specified in paragraph (3) unless he has successfully completed the appropriate initial CPC test.

(2) For the purposes of this regulation-

(a) the appropriate initial CPC test is the test relating to vehicles of the category into which that particular relevant vehicle falls;

(b) where Article 5(5) of the Directive applies, the appropriate initial CPC test must comply with the last paragraph of Section 2.2 of Annex I* to the Directive.

Regulation 5: Initial CPC test

5.-(1) The initial CPC test may be organised by the 


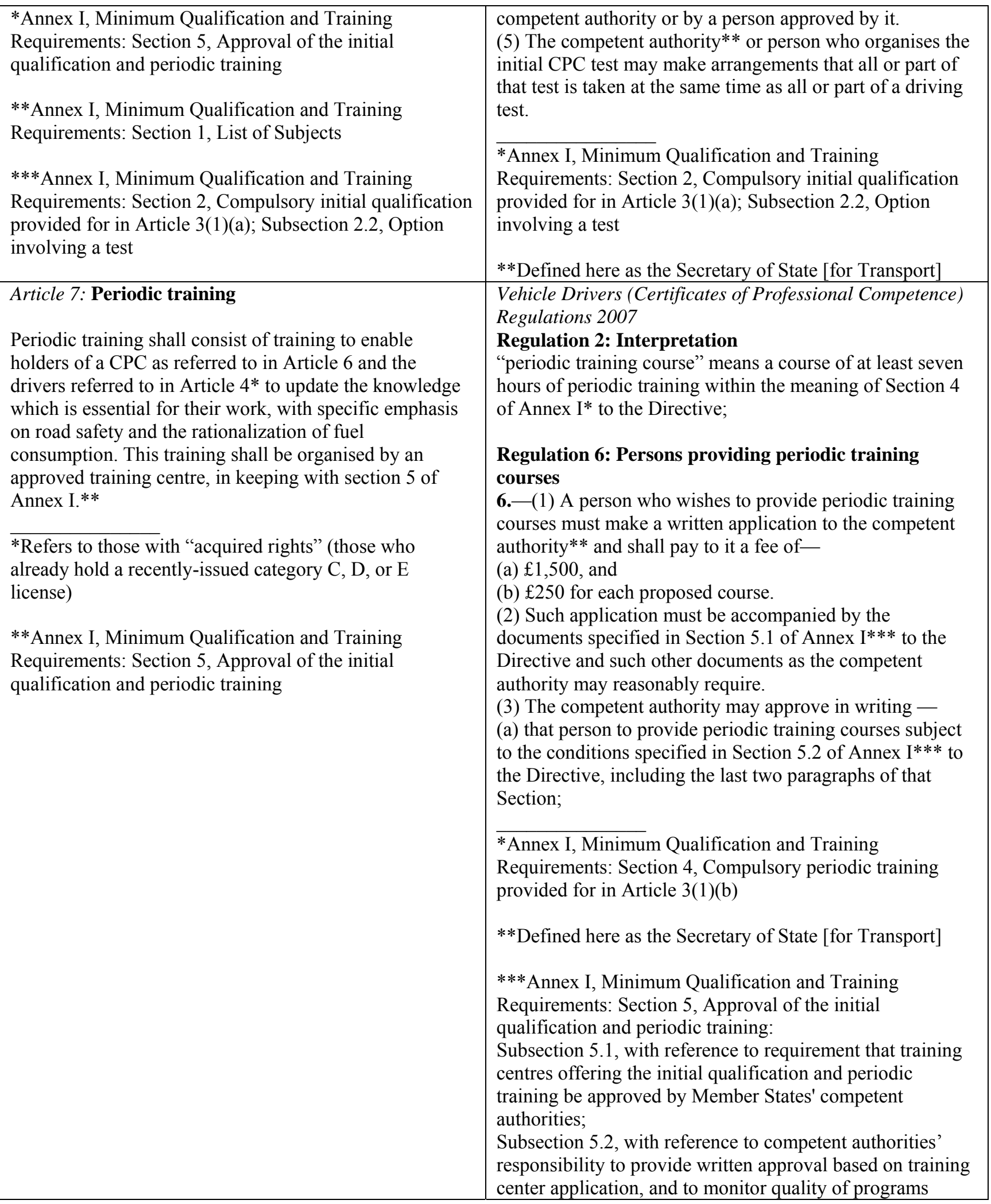


The UK was several months late in transposing the Driver CPC Directive. The transposition deadline was September 9, 2006, but the UK's Vehicle Drivers (Certificates of Professional Competence) Regulations were not enacted until February of 2007. Because of certain features of the UK's state-level regulatory structure for driver licensing, its transposition of Directive 2003/59/EC is somewhat difficult to follow. In the UK, a single set of regulations covers licensing for all kinds of drivers; these are the Motor Vehicles (Driving Licences) Regulations discussed above in connection with the EU Driving License Directive 91/439/EEC. The strategy chosen for implementation was to develop a new regulation laying out content and procedures for individual drivers to acquire the new CPC. At the same time, the EU directive made it necessary to modify the Motor Vehicles (Driving Licences) Regulations because requirements for commercial drivers were incorporated there along with requirements for the general motoring public. Thus, the new UK regulation is by no means a stand-alone document; to make sense of provisions affecting the Motor Vehicles (Driving Licences) Regulations, the reader must refer back to those regulations, and to make sense of the transposition of the EU directive, the reader must have access to the directive itself.

Directive 2003/59/EC is unusually detailed in its provision of course topics, training objectives, and knowledge and skills to be evaluated through written and on-road tests, addressing all these points in the four-page Annex I. Interpretation of the new UK regulation is complicated by the fact that throughout, it incorporates relevant sections of Annex I by reference. Among EU member states, the UK is not unusual in its incorporation of various portions of Annex I into its state-level regulation; a recent report on implementation of 2003/59/EC found that this practice was the rule among member states (Commission Internationale des Examens de Conduite Automobile (CIECA), 2010).

Because the new UK regulation essentially incorporates by reference the vast majority of the substance of 2003/59/EC, it may be concluded that the UK has successfully transposed it. Questions of the training's effectiveness, the competency of the training centers, and the quality of enforcement are beyond the scope of this study. ${ }^{34}$

\section{Operator CPC Directive}

\section{Council Directive 98/76/EC of 1 October 1998 amending Directive 96/26/EC on admission to the occupation of road haulage operator and road passenger transport operator and mutual recognition of diplomas, certificates and other evidence of formal qualifications intended to facilitate for these operators the right to freedom of establishment in national and international transport operations.}

Table 3-4. British transposition of Operator CPC Directive (98/76/EC)

\begin{tabular}{|l|l|}
\hline EU Directive & British Legislation and Regulation \\
\hline Article 1(2) & Goods Vehicles (Licensing of Operators) Act 1995 \\
1. This Directive shall not apply to undertakings & Operators' Licenses \\
engaged in the occupation of road haulage operator by & 2.-(2) Subsection (1)* does not apply to-_ \\
\hline
\end{tabular}

\footnotetext{
${ }^{34}$ In any event, it is too early to evaluate these issues, as the requirements for buses became effective in 2008 and for trucks in 2009.
} 
means of motor vehicles or combinations of vehicles the maximum authorised weight of which does not exceed 3,5 tonnes. Member States may, however, lower this limit for all or some categories of transport operations. 2a. Member States may, after consulting the Commission, exempt from the application of all or some of the provisions of this Directive road haulage undertakings engaged exclusively in national transport operations having only a minor impact on the transport market because of:

- the nature of the goods carried, or

- the short distance involved. (a) the use of a small goods vehicle within the meaning given in Schedule $1 * *$;

4.-(1) A traffic commissioner may, for the purpose of-

(a) enabling an emergency to be dealt with, or

(b) enabling some other special need to be met, by notice in writing grant to any person falling within subsection (2) a temporary exemption from any requirement to hold a standard licence which would otherwise be imposed on him by sections 2 and $3 \ldots$ (2) A person falls within this subsection if he is engaged exclusively in national transport operations which have only a minor impact on the transport market because of the nature of the goods carried or the short distances over which goods are carried.

*That is, the requirement to have an operating license. **Schedule 1. Meaning of "Small Goods Vehicle" 2. A goods vehicle falls within this paragraph if it does not form part of a vehicle combination and-

(a) has a relevant plated weight not exceeding 3.5 tonnes, or

(b) if it does not have a relevant plated weight, has an unladen weight not exceeding 1525 kilograms.

Article 3(1): Undertakings wishing to engage in the occupation of road transport operator shall:
(a) be of good repute;
(b) be of appropriate financial standing;
(c) satisfy the condition as to professional competence.

\section{Transport Act 1968}

Section 62. Applications for Operators' Licences (2) A person applying for an operator's licence shall give to the licensing authority a statement giving such particulars as the authority may require of the motor vehicles proposed to be used under the licence which-

(a) belong to the applicant, or

(b) are in his possession under an agreement for hire purchase, hire or loan, or

(c) he intends, if the application is granted, to acquire, or to obtain possession of under such an agreement, and also stating the number and type of any trailers proposed to be so used.

(4) A person applying for an operator's licence shall give to the licensing authority...

(a) such particulars as he may require with respect to the purposes for which the vehicles referred to in the statement under subsection (2) of this section are proposed to be used;

(b) particulars of the arrangements for securing that Part VI of this Act...will be complied with in the case of those vehicles, and for securing that those vehicles are not overloaded;

(c) particulars of the facilities and arrangements for securing that those vehicles will be maintained in a fit and serviceable condition;

(d) particulars of any activities carried on, at any time before the making of the application, by-

(i) the applicant,

(ii) any company of which the applicant is or has been a director; 


\begin{tabular}{|c|c|}
\hline & $\begin{array}{l}\text { (iii) where the applicant is a company, any } \\
\text { person who is a director of the company; } \\
\text { (iv) where the applicant proposes to operate } \\
\text { the said vehicles in partnership with other } \\
\text { persons, any of those other persons ; } \\
\text { (v) any company of which any such person as } \\
\text { is mentioned in sub-paragraph (iii) or (iv) of } \\
\text { this paragraph is or has been a director ; } \\
\text { (vi) any company of which the applicant is a } \\
\text { subsidiary, } \\
\text { being activities in carrying on any trade or business in } \\
\text { the course of which vehicles of a ny description are } \\
\text { operated, or as a person employed for the purposes of } \\
\text { any such trade or busi ness, or as a dire ctor of a } \\
\text { company carrying on any such trade or business; } \\
\text { (e) particulars of any convictions during the five years } \\
\text { preceding the making of the application- } \\
\text { (i) of the applicant; and } \\
\text { (ii) of any other person as to whose activities } \\
\text { particulars may be required to be given under } \\
\text { paragraph (d) of this subsection... } \\
\text { (f) particulars of the financial resources which are or } \\
\text { are likely to be available to the applicant; } \\
\text { Goods Vehicles (Licensing of Operators) Act 1995 } \\
\text { Determination of Applications } \\
\text { 13.-(3) For the requirements of this subsection to be } \\
\text { satisfied the traffic commissioner must be satisfied that } \\
\text { the applicant fulfils the following requirements, } \\
\text { namely-- } \\
\text { (a) that he is of good repute, } \\
\text { (b) that he is of the appropriate financial standing, and } \\
\text { (c) that he is professionally competent; } \\
\text { and the traffic commissioner shall determine whether } \\
\text { or not that is the case in accordance with Schedule } 3 \text {. }\end{array}$ \\
\hline $\begin{array}{l}\text { Article 3(2): Member States shall determine the } \\
\text { conditions which must be fulfilled by undertakings } \\
\text { established within their territory in order to satisfy the } \\
\text { good-repute requirement. They shall provide that this } \\
\text { requirement is not satisfied, or is no longer satisfied, if } \\
\text { the natural person or persons who are deemed to satisfy } \\
\text { this condition under paragraph 1: } \\
\text { (a) have been convicted of serious criminal offences, } \\
\text { including offences of a commercial nature, } \\
\text { (b) have been declared unfit to pursue the occupation of } \\
\text { road transport operator under any rules in force, } \\
\text { (c) have been convicted of serious offences } \\
\text { against the rules in force concerning: } \\
\text { - the pay and employment conditions in the } \\
\text { profession, or } \\
\text { - road haulage or road passenger transport, as } \\
\text { appropriate, in particular the rules relating to drivers' } \\
\text { driving and rest periods, the weights and dimensions of } \\
\text { commercial vehicles, road safety and vehicle safety, the } \\
\text { protection of the environment and the other rules } \\
\text { concerning professional liability. }\end{array}$ & $\begin{array}{l}\text { Goods Vehicles (Licensing of Operators) Act } 1995 \\
\text { Schedule 3, Qualifications for standard licence } \\
\text { Good repute: } \\
\text { 1. (1) In determining whether an individual is of good } \\
\text { repute, a traffic commissioner may have regard to any } \\
\text { matter but shall, in particular, have regard to-- } \\
\text { (a) any relevant convictions of the individual or of his } \\
\text { servants or agents; and } \\
\text { (b) any other information in his possession which } \\
\text { appears to him to relate to the individual's fitness to } \\
\text { hold a licence. } \\
\text { 2. Without prejudice to the generality of a traffic } \\
\text { commissioner's power under paragraph } 1 \text { to determine } \\
\text { that a person is not of good repute, a commissioner } \\
\text { shall determine that an individual is not of good repute } \\
\text { if that individual-- } \\
\text { (a) has more than one conviction of a serious offence; } \\
\text { or } \\
\text { (b) has repeatedly been convicted of road transport } \\
\text { offences. } \\
\text { 4. "Road transport offence" means- }\end{array}$ \\
\hline
\end{tabular}


Article 3(4)(a): The condition relating to professional competence shall consist in the possession of knowledge corresponding to the level of training provided for in Annex I* in the subjects listed therein. It shall be established by means of a compulsory written examination which may be supplemented by an oral examination organised in the form set out in Annex I** by the authority or body designated for that purpose by the Member State.

*Required knowledge covers civil, commercial, social, and fiscal law; business and financial management; rules governing market access; technical standards for operation; and road safety.

**Compulsory 4-hour written exam (multiple choice/short answer and essay/case studies), with optional oral exam

Article 10(1): As from 1 January 1990, Member States shall recognize as sufficient proof of professional competence certificates as referred to in the fourth subparagraph of Article 3 (4) which are issued by another Member State. (a) an offence under the law of any part of the United Kingdom relating to road transport including, in particular, offences relating to-

(i) drivers' hours of work and rest periods;

(ii) the weights and dimensions of commercial vehicles; and

(iii) road and vehicle safety; or

(b) any corresponding offence under the law of a country or territory outside the United Kingdom.

Goods Vehicles Operators (Qualifications) Regulations 1999

Regulation 2: Good repute

(2) [Amends Schedule 3, paragraph 4 of Goods Vehicles (Licensing of Operators) Act 1995]

Road transport offence" means-

(a) an offence under the law of any part of the United Kingdom relating to road transport including, in particular-

(i) an offence relating to drivers' hours of work or rest periods, the weights or dimensions of commercial vehicles, road or vehicle safety or the protection of the environment; and

(ii) any other offence concerning professional liability; or

(b) any corresponding offence under the law of a country or territory outside the United Kingdom. Goods Vehicles Operators (Qualifications) Regulations 1999

Regulation 4: Professional competence

4. - (1) For sub-paragraph (2) of paragraph 13 of that Schedule [3] there shall be substituted the following sub-paragraph-

"(2) The written examination mentioned in subparagraph (1)(a) may be supplemented by an oral examination organised by the approved body in the form set out in Annex I to Council Directive No. 96/26/EC."

(2) In sub-paragraph (3) of that paragraph-

(b) for the definition of "the requisite skills" there shall be substituted the following definition-

"the requisite skills" means knowledge corresponding to the level of training, for either national or international transport operations as the case may be, provided for in Annex I to that Directive [96/26/EC] in the subjects there listed."

No reference to such a provision is found in either the 1995 Goods Vehicles (Licensing of Operators) Act or 1999 Goods Vehicles Operators (Qualifications) Regulations. See, however, the following provisions in earlier regulations: 


\begin{tabular}{|c|c|}
\hline & $\begin{array}{l}\text { Goods Vehicles (Community Authorisations) } \\
\text { Regulations } 1992^{35} \\
\text { Regulation 5: Entitlement to the issue of } \\
\text { Community authorisation } \\
\text { 5.-(1) A person shall be entitled to be issued with } \\
\text { a Community authorisation under Article } 3.2 \text { of the } \\
\text { Council Regulation if- } \\
\text { (a) in the case of a person established as a haulier in } \\
\text { Great Britain, he holds a standard operator's licence } \\
\text { covering international transport operations; or } \\
\text { (b) in the case of a person established as a haulier in } \\
\text { Northern Ireland, he holds an operator's licence } \\
\text { covering international transport operations. } \\
\text { Regulation 3: Use of goods vehicle without } \\
\text { Community authorisation } \\
\text { 3. A person who uses a vehicle in the United } \\
\text { Kingdom in contravention of Article } 3.1 \text { of the Council } \\
\text { Regulation shall be guilty of an offence and liable on } \\
\text { summary conviction to a fine not exceeding level } 4 \text { on } \\
\text { the standard scale. }\end{array}$ \\
\hline $\begin{array}{l}\text { Article 10a: Member States shall provide for systems of } \\
\text { penalties for infringements of the national provisions } \\
\text { adopted in accordance with this Directive and shall take } \\
\text { all the measures necessary to ensure that those penalties } \\
\text { are applied. The penalties thus provided for shall be } \\
\text { effective, proportionate and dissuasive. }\end{array}$ & $\begin{array}{l}\text { Goods Vehicles Operators (Qualifications)Regulations } \\
1999 \\
\text { Regulation 2: Good repute } \\
\text { 2._(1) For paragraph } 2 \text { of Schedule } 3 \text { to the Act } \\
\text { (qualifications for standard licence) there } \\
\text { shall be substituted the following paragraph- } \\
\text { " } 2 \text {. Without prejudice to the generality of a traffic } \\
\text { commissioner's power under paragraph } 1 \text { to determine } \\
\text { that a person is not of good repute, a commissioner } \\
\text { shall determine that an individual is not of good repute } \\
\text { if that individual has- } \\
\text { (a) more than one conviction of a serious offence; or } \\
\text { (b) been convicted of road transport offences."* } \\
\text { Goods Vehicles (Licensing of Operators) Act } 1995 \\
\text { Schedule 3: Qualifications for standard licence } \\
3 \text { (1) A person has a conviction of a "serious offence" } \\
\text { if- } \\
\text { (a) he has been convicted of any offence under the law }\end{array}$ \\
\hline
\end{tabular}

35 This legislation is the British implementation of Regulation 92/881/EEC on "access to the market in the carriage of goods by road within the Community to or from the territory of a Member State or passing across the territory of one or more Member States." Article 3(2) reads as follows:

Community authorization shall be issued by a Member State, in accordance with Article 5 and 7, to any haulier carrying goods by road for hire or reward who:

— is established in a Member State, hereinafter referred to as the 'Member State of establishment' in accordance with the legislation of that Member State,

— is entitled in that Member State, in accordance with the legislation of the Community and of that State concerning admission to the occupation of road haulage operator to carry out the international carriage of goods by road (Commission of the European Communities, April 9, 1992, p. 4). 


\begin{tabular}{|l|l|}
\hline & $\begin{array}{l}\text { of any part of the United Kingdom or under the law of } \\
\text { a country or territory outside the United Kingdom, and } \\
\text { (b) on such conviction there was imposed on him for } \\
\text { that offence a punishment falling within sub-paragraph } \\
\text { (2). } \\
\text { (2) The punishments are- } \\
\text { (a) a sentence of imprisonment for a term exceeding } \\
\text { three months; } \\
\text { (b) a fine exceeding level } 4 \text { on the standard scale; } \\
\text { (c) a community service order requiring him to perform } \\
\text { work for more than 60 hours; and } \\
\text { (d) in the case of an offence committed under the law } \\
\text { of a country or territory outside the United Kingdom, } \\
\text { any punishment corresponding to those mentioned in } \\
\text { paragraphs (a) to (c). }\end{array}$ \\
$\begin{array}{l}\text { *See UK response to Article 3(2) above for a definition } \\
\text { of "road transport offence." }\end{array}$ \\
\hline
\end{tabular}

When Directive 98/76/EC and its predecessor 96/26/EC were enacted, British law was already substantially in compliance with their requirements; therefore, minimal changes in British regulations were required as the result of EU legislation. In fact, the underpinnings of the concepts "good repute," "appropriate financial standing," and "professional competence," central to Operator CPC directives 96/26 and 98/76, were part of British law as early as the Transport Act of 1968. Although the 1968 law did not use the exact wording found in later EU directives, it did require prospective operators to present a statement certifying the size and nature of the fleet they intended to operate, past experience in operating a road transport entity, availability of material and financial resources needed to maintain those vehicles, and ability to comply with relevant vehicle and safety regulations. Arguably, these provisions demonstrate the essence if not the letter of the EU directives that came almost three decades later.

Because existing British law already covered most of its provisions, the passage of Directive 98/76/EC required minimal changes when the Goods Vehicles Operators (Qualifications) Regulations were put in place in 1999. One change was the addition of offenses related to "protection of the environment" to the list of "road transport offences" that endangered an operator's "good repute" (HMSO, 1999). Another was the addition of the option for the CPC exam to include an oral component. Finally, the 1999 Regulations incorporated by reference the comprehensive list of topics in which prospective CPC holders were to be proficient (found in Annex I of the EU directive). Curiously, the 1999 Regulations referenced the list found in Annex I of 96/26/EC, not the considerably updated list found in 98/76/EC.

The British implementation of mutual recognition of operator CPCs (Article 10(1) of 98/76/EC) presents an interesting case. There is no indication that the principle of mutual recognition was incorporated into the British legal instruments that represent the primary implementation of the Operator CPC Directive (the Goods Vehicles (Licensing of Operators) Act of 1995 and the Goods Vehicles Operators (Qualifications) Regulations of 1999). However, in this instance, it is possible that the matter may have been settled by regulations that were associated more with the single European market than with trucking operations per se. These were the Goods Vehicles (Community Authorisations) Regulations 1992, the British implementation of an EU directive 
pertaining to removal of quotas for cross-border access to markets by truck (92/881/EEC). ${ }^{36}$ Directive 92/881/EEC and the British regulation that followed it are clearly applicable to the transport operator, not the individual driver, so are more akin to the operator CPC than the driver CPC. However, even if we assume that the implicit acceptance of "Community authorisations" from other member states is tantamount to acceptance of non-UK operator CPCs implemented several years later, the 1992 British regulation and later transpositions of the CPC directives fall somewhat short of assuring non-UK operators that their CPCs will be recognized by British authorities. ${ }^{37}$

In Great Britain, responsibility for granting operator CPCs and monitoring continuing fitness to operate has been delegated to eight sub-state jurisdictions called "Traffic Areas" managed by Traffic Commissioners appointed by the Secretary of State for Transport (HMSO, 1968, 1995). The Commissioners are independent quasi-judicial authorities with statutory power to grant or refuse licenses to operate road transport concerns, to place restrictions on operators based on safety or environmental infringements, and to impose penalties (Lowe, 2007, p. 194). This arrangement is a clear example of MLG. Traffic Areas are administrative jurisdictions that are not aggregates of sub-state governmental units. Rather, they are purpose-built jurisdictions responsible for conducting the operator CPC program and other functions related to traffic safety. Thus, they possess attributes of MLG noted in the literature: operation at different territorial levels, and flexible, task-specific "public service industries" functioning outside traditional comprehensive governmental units (Hooghe \& Marks, 2003, pp. 237-239; Marks \& Hooghe, 2004, pp. 20-21).

\section{Road Transport Working Time Directive}

\section{Directive 2002/15/EC of the European Parliament and of the Council of 11 March 2002 on the organisation of the working time of persons performing mobile road transport activities}

Table 3-5. British transposition of Road Transport Working Time Directive (2002/15/EC)

\begin{tabular}{|c|c|}
\hline EU Directive & British Legislation and Regulation \\
\hline $\begin{array}{l}\text { Article 4: Maximum weekly working time } \\
\text { Member States shall take the measures necessary to } \\
\text { ensure that: } \\
\text { (a) the average weekly working time may not exceed } \\
48 \text { hours. The maximum weekly working time may be } \\
\text { extended to } 60 \text { hours only if, over four months, an } \\
\text { average of } 48 \text { hours a week is not exceeded. }\end{array}$ & $\begin{array}{l}\text { The Road Transport (Working Time) Regulations } 2005 \\
\text { Regulation 4: Working time } \\
\text { 4. - (1) Subject to paragraph (2) below, the working } \\
\text { time, including overtime, of a mobile worker shall not } \\
\text { exceed } 60 \text { hours in a week. } \\
\text { (2) In any reference period which is applicable to his } \\
\text { case, a mobile worker's working time shall not exceed an } \\
\text { average of } 48 \text { hours for each week. }\end{array}$ \\
\hline $\begin{array}{l}\text { Article } 5: \text { Breaks } \\
\text { 1. Member States shall take the measures necessary to } \\
\text { ensure that, without prejudice to the level of } \\
\text { protection provided by Regulation (EEC) No } 3820 / 85\end{array}$ & $\begin{array}{l}\text { Transport Act } 1968 \\
\text { Section 96. Permitted driving time and periods of } \\
\text { duty } \\
\text { (2)Subject to the provisions of this section, if on any }\end{array}$ \\
\hline
\end{tabular}

\footnotetext{
${ }^{36}$ See Table 3-4 and footnote 35 for relevant text from both documents.

${ }^{37}$ It is possible, however, that recognition of Operator CPCs from other member states has been incorporated into bureaucratic procedures without explicit transposition into state law.
} 
or, failing that, by the AETR Agreement, persons performing mobile road transport activities, without prejudice to Article 2(1), in no circumstances work for more than six consecutive hours without a break. Working time shall be interrupted by a break of at least 30 minutes, if working hours total between six and nine hours, and of at least 45 minutes, if working hours total more than nine hours.

\section{Article 7: Night work}

1. Member States shall take the measures necessary to ensure that:

- if night work is performed, the daily working time does not exceed ten hours in each 24 [hour] period, - compensation for night work is given in accordance with national legislative measures, collective agreements, agreements between the two sides of industry and/or national practice, on condition that such compensation is not liable to endanger road safety.

\section{Article 11: Penalties}

Member States shall lay down a system of penalties for breaches of the national provisions adopted pursuant to this Directive and shall take all the measures necessary to ensure that these penalties are applied. The penalties thus provided for shall be effective, proportional and dissuasive. working day a driver has been on duty for a period of, or for periods amounting in the aggregate to, five and a half hours and-

(a)there has not been during that period, or during or between any of those periods, an interval of not less than half an hour in which he was able to obtain rest and refreshment; and

(b)the end of that period, or of the last of those periods, does not mark the end of that working day, there shall at the end of that period, or of the last of those periods, be such an interval as aforesaid.

\section{The Road Transport (Working Time) Regulations 2005 Regulation 7: Breaks}

7. - (1) No mobile worker shall work for more than six hours without a break.

(2) Where a mobile worker's working time exceeds six hours but does not exceed nine hours, the worker shall be entitled to a break lasting at least 30 minutes and interrupting that time.

(3) Where a mobile worker's working time exceeds nine hours, the worker shall be entitled to a break lasting at least 45 minutes and interrupting that period.

(4) Each break may be made up of separate periods of not less than 15 minutes each.

The Road Transport (Working Time) Regulations 2005

\section{Regulation 9: Night work}

9. - (1) The working time of a mobile worker, who performs night work in any period of 24 hours, shall not exceed 10 hours during that period.

(2) The period of 10 hours may be extended in relation to particular mobile workers or groups of mobile workers for objective or technical reasons or reasons concerning the organisation of work, by a collective agreement or a workforce agreement.

(3) Compensation for night work shall not be given to a mobile worker in any manner which is liable to endanger road safety.

The Road Transport (Working Time) Regulations 2005

Regulation 17: Enforcement

(3) It is an offence for a person -

(a) to contravene any requirement imposed by an inspector under paragraph 2 of Schedule 2;

(b) to prevent or attempt to prevent any other person from appearing before an inspector or from answering any question to which an inspector may...require an answer; (c) to contravene any requirement or prohibition imposed by an improvement notice or a prohibition notice;

(d) intentionally to obstruct an inspector in the exercise or performance of his powers;

Regulation 18: Offences due to fault of other person

18. Where the commission by any person of an offence is due to the act or default of some other person, that other person shall be guilty of the offence, and a 
person may be charged with the conviction of the offence by virtue of this regulation whether or not proceedings are taken against the first-mentioned person.

\section{Regulation 19: Offences by bodies corporate}

19. - (1) Where an offence committed by a body corporate is proved to have been committed with the consent or connivance of, or to have been attributable to any neglect on the part of, any director, manager, secretary or other similar officer of the body corporate or a person who was purporting to act in any such capacity, he as well as the body corporate shall be guilty of that offence and shall be liable to be proceeded against and punished accordingly.

The technical content of the British transposition of this directive, the Road Transport (Working Time) Regulation of 2005, is consistent with the EU directive. In fact, the UK Transport Act of 1968 was already substantially in compliance with the provision on breaks found in the $2002 \mathrm{EU}$ directive, requiring a break after $5 \frac{1}{2}$ hours of work, compared to 6 hours in the EU directive. Although the 2005 transposition revised the language of the Transport Act of 1968 to be more consistent with the Road Transport Working Time Directive, no substantial changes were required.

A qualifying provision attached to many of the articles in the Road Transport (Working Time) Regulations of 2005 reflects a distinct "policy core belief" as described in the ACF (P. Sabatier $\&$ Weible, 2007, pp. 194-195). This is the idea that worker protection is not an absolute to be achieved by the employer at any cost, but rather, that the employer is not to be faulted if all reasonable precautions to protect worker safety are taken. The concept finds it origins in the Health and Safety at Work Act and thus permeates subsequent regulations in the UK. In the British transposition of the Road Transport Working Time Directive, the relevant text is: "An employer shall take all reasonable steps, in keeping with the need to protect the health and safety of the mobile worker, to ensure that the limits specified above are complied with in the case of each mobile worker employed by him" (HMSO, 2005). In contrast, provisions in the corresponding EU directive are introduced as follows: "Member States shall take the measures necessary to ensure that..." (Commission of the European Communities, March 23, 2002). The EU directive provides no guidance as to the lengths to which employers are to go in order to ensure worker safety.

As shown in Table 3-4 above, the British transposition of Article 11 reflects a policy belief that an individual other than the person directly violating the regulation may be held responsible for the violation, and in the same way, that a corporate body may ultimately be found to be at fault. This is consistent with the shift in beliefs about corporate culpability which reportedly began after the Zeebrugge ferry disaster, and which was also reflected in the passage of the Corporate Manslaughter Act of 2007 (Royal Society for the Prevention of Accidents, April 29, 2010). This provides some evidence of policy learning, as suggested by the ACF. In this case, despite a dominant belief that the private sector is best-equipped to manage occupational road risk, legislators and regulators were willing to allow for corporations to be held responsible for management failures with consequences for worker safety. 
The British regulation includes a provision not found in the EU directive to clarify that an employer is responsible for contract employees' working time in the same way he or she is responsible for direct-hire employees. The British text reads as follows: "This regulation applies in any case where an individual ("the agency worker") - (a) is supplied by a person ("the agent") to do the work of a mobile worker for another ("the principal") under a contract or other arrangements made between the agent and the principal..." (HMSO, 2005).

\section{Working Time Directive}

\section{Directive 2003/88/EC of the European Parliament and of the Council of 4 November 2003 concerning certain aspects of the organisation of working time}

The Working Time Directive (2003/88/EC) consolidates requirements of an earlier comprehensive EU directive on working time (93/104/EC) and its amending directive 2000/34/EC. The assessment presented here touches on the history of the British response to EU directives on working time, ending with Great Britain's 2003 amendment. It is not limited to transposition of the original Working Time Directive (93/104/EC) because that topic has been addressed by earlier research, although in a somewhat different fashion (Falkner, et al., 2005, pp. 94-117). Moreover, the revised 2000 EU directive and Great Britain's subsequent 2003 amendment make some attempts to clarify the status of "mobile workers," a point of considerable interest to this research.

Table 3-6. British transposition of Working Time Directive (2003/88/EC)

\begin{tabular}{|c|c|}
\hline EU Directive & British Regulation \\
\hline $\begin{array}{l}\text { Article 1: Purpose and scope } \\
\text { 3. This Directive shall apply to all sectors of activity, both } \\
\text { public and private, within the meaning of Article } 2 \text { of } \\
\text { Directive } 89 / 391 / \mathrm{EEC},{ }^{*} \text { without prejudice to Articles } 14 \text {, } \\
17,18 \text { and } 19 \text { of this Directive. }\end{array}$ & $\begin{array}{l}\text { Although the Working Time Regulations and their } 2003 \\
\text { revision reproduce lists of derogations allowed by the EU } \\
\text { directive, neither version contains a statement affirming } \\
\text { the application of the regulations across all sectors. }\end{array}$ \\
\hline $\begin{array}{l}\text { *Article 2(1). This Directive shall apply to all sectors of } \\
\text { activity, both public and private (industrial, agricultural, } \\
\text { commercial, administrative, service, educational, cultural, } \\
\text { leisure, etc.) (Commission of the European Communities, } \\
\text { June 26, 1989). }\end{array}$ & \\
\hline $\begin{array}{l}\text { Article 3: Daily rest } \\
\text { Member States shall take the measures necessary to ensure } \\
\text { that every worker is entitled to a minimum daily rest period } \\
\text { of } 11 \text { consecutive hours per } 24 \text {-hour period. }\end{array}$ & $\begin{array}{l}\text { Working Time Regulations } 1998 \\
\text { Regulation 10: Daily rest } \\
\text { 10. - (1) An adult worker is entitled to a rest period of } \\
\text { not less than eleven consecutive hours in each 24-hour } \\
\text { period during which he works for his employer. }\end{array}$ \\
\hline $\begin{array}{l}\text { Article 4: Breaks } \\
\text { Member States shall take the measures necessary to ensure } \\
\text { that, where the working day is longer than six hours, every } \\
\text { worker is entitled to a rest break, the details of which, } \\
\text { including duration and the terms on which it is granted, } \\
\text { shall be laid down in collective agreements or agreements } \\
\text { between the two sides of industry or, failing that, by } \\
\text { national legislation. }\end{array}$ & $\begin{array}{l}\text { Working Time Regulations } 1998 \\
\text { Regulation 12: Rest breaks } \\
\text { 12. - (1) Where an adult worker's daily working time is } \\
\text { more than six hours, he is entitled to a rest break. } \\
\text { (2) The details of the rest break to which an adult worker } \\
\text { is entitled under paragraph (1), including its duration and } \\
\text { the terms on which it is granted, shall be in accordance } \\
\text { with any provisions for the purposes of this regulation } \\
\text { which are contained in a collective agreement or a }\end{array}$ \\
\hline
\end{tabular}




\section{Article 5: Weekly rest period}

Member States shall take the measures necessary to ensure that, per each seven-day period, every worker is entitled to a minimum uninterrupted rest period of 24 hours plus the 11 hours' daily rest referred to in Article 3.

workforce agreement.

(3) Subject to the provisions of any applicable collective agreement or workforce agreement, the rest break provided for in paragraph (1) is an uninterrupted period of not less than 20 minutes, and the worker is entitled to spend it away from his workstation if he has one.

\section{Working Time Regulations 1998}

\section{Regulation 11: Weekly rest period}

11. - (1) Subject to paragraph (2), an adult worker is entitled to an uninterrupted rest period of not less than 24 hours in each seven-day period during which he works for his employer.

(2) If his employer so determines, an adult worker shall be entitled to either -

(a) two uninterrupted rest periods each of not less than 24 hours in each 14-day period during which he works for his employer; or

(b) one uninterrupted rest period of not less than 48 hours in each such 14-day period,

in place of the entitlement provided for in paragraph (1).

[Not revised by the Working Time (Amendment) Regulations 2003]

Article 6: Maximum weekly working time

Member States shall take the measures necessary to ensure that, in keeping with the need to protect the safety and health of workers:

(a) the period of weekly working time is limited by means of laws, regulations and administrative provisions or by collective agreements or agreements between the two sides of industry;

(b) the average working time for each seven-day period, including overtime, does not exceed 48 hours.

\section{Article 8: Length of night work}

Member States shall take the measures necessary to ensure that:

(a) normal hours of work for night workers do not exceed an average of eight hours in any 24-hour period;

(b) night workers whose work involves special hazards or heavy physical or mental strain do not work more than eight hours in any period of 24 hours during which they perform night work.

\section{Article 20}

\section{Mobile workers and offshore work}

1. Articles 3, 4, 5 and 8 shall not apply to mobile workers.* Member States shall, however, take the necessary measures

\section{Working Time Regulations 1998}

\section{Regulation 4: Maximum weekly working time}

4. - (1) Subject to regulation 5, a worker's working time, including overtime, in any reference period which is applicable in his case shall not exceed an average of 48 hours for each seven days.

\section{Regulation 23. Collective and workforce agreements}

23. A collective agreem ent or a workforce agreem ent may-

(a)modify or exclude the application of regulations 6(1) to (3) and (7), 10(1), 11(1) and (2) and 12(1), and (b)for objective or technical reasons or reasons concerning the organization of work, modify the application of regulation 4(3) and (4) by the substitution, for each reference to 17 weeks, of a different period, being a period not exceeding 52 weeks, in relation to particular workers or groups of workers.

\section{Working Time Regulations 1998}

\section{Regulation 6: Length of night work}

6. - (1) A night worker's normal hours of work in any reference period which is applicable in his case shall not exceed an average of eight hours for each 24 hours. (7) An employer shall ensure that no night worker employed by him whose work involves special hazards or heavy physical or mental strain works for more than eight hours in any 24-hour period during which the night worker performs night work.

\section{Working Time Regulations 1998}

These fail to define "mobile workers." The 2003 revision remedies this, except that it excludes "inland waterway" from the definition. 
to ensure that such mobile workers are entitled to adequate rest, except in the circumstances laid down in Article $17(3)(\mathrm{f})$ and $(\mathrm{g}) . * *$

*defined as "any worker employed as a member of travelling or flying personnel by an undertaking which operates transport services for passengers or goods by road, air or inland waterway" [Article 2(7)]

**(f) in the circumstances described in Article 5(4) of Directive 89/391/EEC [This Directive shall not restrict the option of Member States to provide for the exclusion or the limitation of employers' responsibility where occurrences are due to unusual and unforeseeable circumstances, beyond the employers' control, or to exceptional events, the consequences of which could not have been avoided despite the exercise of all due care (Commission of the European Communities, June 26, 1989).]

(g) in cases of accident or imminent risk of accident.

\section{Regulation 18: Excluded sectors}

18. Regulations 4(1) and (2), 6(1), (2) and (7), 7(1), and (6), 8, 10(1), 11(1) and (2), 12(1), 13 and 16 do not apply -

(a) to the following sectors of activity -

(i) air, rail, road, sea, inland waterway and lake transport;

Working Time (Amendment) Regulations 2003

Regulation 6: Mobile workers [amending Regulation 24 of the 1998 regulations]

24A. - (1) Regulations 6(1), (2) and (7), 10(1), 11(1) and (2) and 12(1) do not apply to a mobile worker in relation to whom the application of those regulations is not excluded by any provision of regulation 18 .

(2) A mobile worker, to whom paragraph (1) applies, is entitled to adequate rest, except where the worker's activities are affected by any of the matters referred to in regulation 21(e).

(3) For the purposes of this regulation, "adequate rest" means that a worker has regular rest periods, the duration of which are expressed in units of time and which are sufficiently long and continuous to ensure that, as a result of fatigue or other irregular working patterns, he does not cause injury to himself, to fellow workers or to others and that he does not damage his health, either in the short term or in the longer term."

\section{Working Time Regulations 1998}

Regulation 5: Agreement to exclude the maximum

5. - (1) The limit specified in regulation 4(1) shall not apply in relation to a worker who has agreed with his employer in writing that it should not apply in his case, provided that the employer complies with the requirements of paragraph (4).

[Amending the 1996 Employment Rights Act] Regulation 31: Right not to suffer detriment 31. - (1) After section 45 of the 1996 Act there shall be inserted -

Working time cases.

45A. - (1) A worker has the right not to be subjected to any detriment by any act, or any deliberate failure to act, by his employer done on the ground that the worker (a) refused (or proposed to refuse) to comply with a requirement which the employer imposed (or proposed to impose) in contravention of the Working Time Regulations 1998,

(b) refused (or proposed to refuse) to forgo a right conferred on him by those Regulations,

(c) failed to sign a workforce agreement for the purposes of those Regulations, or to enter into, or agree to vary or extend, any other agreement with his employer which is provided for in those Regulations 
The UK's adoption of EU directives on working time was not a smooth process. The UK was the only EU member state with no statutory restrictions on working time at the time the first EU directive (93/104/EC) was enacted (Falkner, et al., 2005, p. 113), and the UK strongly opposed any attempt by the EU to issue directives on this topic. Opposition was based not just on "policy core beliefs" within the occupational health and safety policy subsystem in the UK (specifically, a culture that accepted long hours of work), but on "deep core beliefs" founded on neo-liberal economic thinking and concerns about EU interference in domestic affairs (Falkner, et al., 2005, pp. 97-99; P. Sabatier \& Weible, 2007, pp. 194-196). The latter set of "deep core beliefs" founded on neo-liberal beliefs and "Euroskepticism" did not necessarily represent the position of all players in the British government. These beliefs in fact reflected the position of the Conservative government then in power; however, given the fusion of power in the government and the Parliament characteristic of the UK system, the partisan beliefs of the Conservatives effectively became the position of the UK as a state.

The UK, recognizing the potential economic impact of limiting work hours, was instrumental in pushing forward the controversial "individual opt-out" provision, which allowed individual workers to voluntarily choose to work more than the permitted maximum 48 hours per week on average. (This is described in Article 22 of Directive 2003/88/EC, shown above in Table 3-5.) Despite inclusion of the "individual opt-out," the UK abstained when the final vote was taken in the Council of Ministers, but the abstention did not prevent Directive 93/104/EC from being approved.

In 1994, the UK brought a case in the ECJ contending that the Working Time Directive should be set aside, arguing that working time was not a matter of occupational health and safety under Article 118a of the SEA (thereby allowing passage of related EU legislation by QMV), but an employment matter requiring unanimity. This line of argument is what Rhodes (1995) refers to as the "treaty-base game" wherein the European Commission or a member state argues that an issue should be handled one way or the other based on differing interpretations of how the EU treaties classify that issue (Rhodes, 1995). Falkner et al. (2005) claim that in the case of the Working Time Directive, the European Commission played the "treaty-base game" in anticipation of the UK's opposition (Falkner, et al., 2005, pp. 97-99), but it is also true that the UK's responding challenge in the ECJ reflects the same strategy. The ECJ's judgment, handed down less than two weeks before the deadline for member-state transposition of the Working Time Directive, found in favor of the European Commission on all counts except for a minor non-binding provision (European Court of Justice, November 12, 1996).

Despite the unfavorable ECJ judgment, domestic partisan politics in the UK led to continued flouting of the Working Time Directive. The Conservative government then in power demanded that the EU convene an Intergovernmental Conference at which the EU treaty would be revised to allow the UK to derogate from the Working Time Directive. The Intergovernmental Conference failed to materialize, but the Conservative government continued to delay transposition of the Directive until its term in office ended in mid-1997 (Falkner, et al., 2005, p. $105)$.

Great Britain's initial Working Time Regulations were finally put in place in 1998 under the Blair Labour government, correctly transposing the EU's quantitative requirements associated 
with daily rest, maximum weekly working time, breaks, and length of night work. ${ }^{38}$ The requirements for weekly rest periods were also consistent with the EU directive, but gave employers discretion to spread the required rest periods over a two-week period, an option not given in the EU directive. This particular provision remained when the Working Time Regulations were revised in 2003.

Neither the 1998 Working Time Regulations nor their 2003 amendment include a statement similar to that found in Article 1(3) of 2003/88/EC, which affirms the applicability of the regulations to all sectors of activity (see Table 3-6 above, column 1, for exact wording). This omission may create some confusion in application of the regulations. Whereas the EU directive begins with an assurance of applicability across all sectors and proceeds to cite permitted derogations in Articles 17 through 22, Great Britain's transposition focuses on derogations without first defining the universe of workers to whom the regulations apply. The derogations made by Great Britain are, however, consistent with those allowed by the EU directive. ${ }^{39}$

Consistent with 2003/88/EC, Great Britain's 2003 amendment of the Working Time Regulations exempts "mobile workers" from provisions addressing daily rest, breaks, weekly rest periods, and length of night work. (Relevant text appears in, respectively, Articles 3, 4, 5, and 8 in 2003/88/EC and Regulations 10, 12, 11, and 6 of the original 1998 Working Time Regulations for Great Britain.) However, consistent with the EU directive, Great Britain's 2003 Working Time Regulations do state that these exempted workers are entitled to adequate rest, and they also provide guidance as to what that would entail.

It is important to note that the exemptions for mobile workers found in the EU directive and British regulations do not cover the important issue of maximum weekly work hours. It is true that the optional derogations in 2003/88/EC may include maximum weekly work hours in the case of certain groups of workers (for example, managing executives, public safety and utility workers, and fishers), but there are clearly large numbers of workers for whom there would be no apparent possibility of derogation from the Working Time Directive. These would include (1) "mobile workers" other than those cited in the derogations; and (2) any other persons who drive for work, but do not fit within the definition of a "mobile worker," in other words, those who are driving to make sales calls, attend conferences, or perform services on a customer's premises. This said, the UK did take advantage of the option to offer modification or exemption from the EU requirements based on collective bargaining agreements. However, union membership within the UK's workforce is among the lowest in the EU, estimated at 20 to 29 percent compared with over 80 percent for Belgium, Sweden, and Finland (European Foundation for the Improvement of Living and Working Conditions, 2009, p. 23). Therefore, the potential impact of such derogations may be less in the UK than in other member states where labor union density is much greater.

Comments made by individuals working in different parts of the EU bureaucracy show inconsistent understanding of the applicability of the Working Time Directive to occupational

\footnotetext{
${ }^{38}$ Unlike the other five EU directives discussed here, transposition of the Working Time Directive in the UK was the responsibility of the Department of Trade and Industry, with enforcement carried out by the HSE.

${ }^{39}$ However, as of 2000, the UK and Greece were the only member states incorporating the full range of permissible derogations into their state law (Commission of the European Communities, December 1, 2000, p. 5).
} 
driving. Key informants from EU-OSHA, while recognizing the Road Transport Working Time Directive's coverage of working time restrictions for a certain group of drivers, stated that the Working Time Directive "excludes the vehicle as a workplace" where other occupational drivers are concerned (European Agency for Safety and Health at Work, May 5, 2010). However, an individual from the Directorate for Employment, Social Affairs, and Equal Opportunities indicated that the Working Time Directive would "theoretically" cover occupational drivers of lighter vehicles (European Commission Directorate-General for Employment, May 5, 2010). In addition, an interviewee based in the UK noted that a recent prosecution of a work-related crash in the UK was argued on the basis of the employer's failure to exercise "reasonable duty of care" under the HSW Act, not under the Working Time Regulations, despite the fact that working time was a factor in the incident (Health and Safety Executive, April 30, 2010).

In summary, although Great Britain's transposition of the Road Transport Working Time Directive is clear enough in its statement of scope, its transposition of the Working Time Directive does not resolve the question of whether the restrictions therein apply to workers who are driving, but not transporting goods or passengers. However, the lack of clarity in the British regulations may be at least partly attributable to the lack of clarity in the EU directives on which they are based.

\section{Seat Belt Directive}

\section{Directive 2003/20/EC of the European Parliament and of the Council of 8 April 2003 amending Council Directive 91/671/EEC on the approximation of the laws of the Member States relating to compulsory use of safety belts in vehicles of less than 3,5 tonnes}

Table 3-7. British transposition of Seat Belt Directive (2003/20/EC)

\begin{tabular}{|l|l|}
\hline EU Directive & British Regulation \\
\hline $\begin{array}{l}\text { Article 2(1)(a)(i): M1, N1, N2 and N3 vehicles: for M1, NI, } \\
\text { N2 and N3 }{ }^{40} \text { vehicles, Member States shall require that all } \\
\text { occupants of vehicles in use shall use the safety systems } \\
\text { provided. }\end{array}$ & $\begin{array}{l}\text { Motor Vehicles (Wearing of Seat Belts) (Amendment) } \\
\text { Regulations 2006: } \\
\text { Regulation 12, amending Motor Vehicles (Wearing } \\
\text { of Seat Belts) Regulations 1993: In regulation 5 for } \\
\text { paragraph (1) substitute- } \\
\text { (1) Subject to the following provisions of these } \\
\text { Regulations, every person- } \\
\text { (a) driving a motor vehicle (other than a two-wheeled } \\
\text { motor cycle with or without a sidecar), or } \\
\text { (b) riding in a front or rear seat of a motor vehicle } \\
\text { (other than a two-wheeled motor cycle with or without } \\
\text { a sidecar), shall wear an adult belt." } \\
\text { Regulation 10, amending Motor Vehicles (Wearing }\end{array}$ \\
&
\end{tabular}

\footnotetext{
40 These categories refer to an old system of categorizing motor vehicles which was supplanted by the system now used for EU driving licenses. Essentially, $\mathrm{M}$ and $\mathrm{N}$ vehicles comprise vehicles of any size and weight which are intended to carry goods or passengers and are used primarily on public roadways (Commission of the European Communities, February 23, 1970).
} 


\begin{tabular}{|l|l|}
\hline & $\begin{array}{l}\text { of Seat Belts) Regulations 1993: } \\
\text { (8) For the purposes of these Regulations, a seat belt is } \\
\text { appropriate- } \\
\text { (c) in relation to a person aged 14 years or more, if it is } \\
\text { an adult belt. }\end{array}$ \\
$\begin{array}{l}\text { Article 2(2)(a): M2 and M3 vehicles: Member States shall } \\
\text { require that all occupants aged three and over of M2 and M3 } \\
\text { vehicles [buses] in use shall use the safety systems provided } \\
\text { while they are seated. }\end{array}$ & $\begin{array}{l}\text { Regulations 2006 } \\
\text { Regulation 13, amending Motor Vehicles (Wearing } \\
\text { of Seat Belts) Regulations 1993: The requirements } \\
\text { [for belt use specified in Regulation 12] do not apply to } \\
\text { a person riding in a small or large bus- } \\
\text { (a) which is being used to provide a local service } \\
\text { (within the meaning of the Transport Act 1985) in a } \\
\text { built-up area, or } \\
\text { (b) which is constructed or adapted for the carriage of } \\
\text { standing passengers and on which the operator permits } \\
\text { standing. }\end{array}$ \\
\hline $\begin{array}{l}\text { Article 2(2)(b): passengers in M2 and M3 vehicles [buses] } \\
\text { shall be informed of the requirement to wear safety belts } \\
\text { whenever they are seated and the vehicle is in motion. }\end{array}$ & $\begin{array}{l}\text { Motor Vehicles (Wearing of Seat Belts) (Amendment) } \\
\text { Regulations 2006 } \\
\text { Regulation 4, amending Road Traffic Act 1988: } \\
\text { Requirement to notify bus passengers to wear seat } \\
\text { belts } \\
\text {-1) ... the operator of a bus in which any of the } \\
\text { passenger seats are equipped with seat belts shall take } \\
\text { all reasonable steps to ensure that every passenger is } \\
\text { notified that he is required to wear a seat belt at all } \\
\text { times when- } \\
\text { (a) he is in a seat equipped with a seat belt, and } \\
\text { (b) the bus is in motion. }\end{array}$ \\
& \\
\hline
\end{tabular}

The British transposition of the Seat Belt Directive deviates somewhat in its use of age 14 as the threshold for wearing an adult seat belt. The EU directive defines this threshold in terms of height and weight, not age, but in the context of optional requirements for use of an adult belt as opposed to a child restraint [Articles 2(1)(a)(ii) and 1(3)(e)] (Commission of the European Communities, May 9, 2003, pp. 64-65). However, for this research, the important point is that Great Britain successfully transposed EU requirements for wearing of seat belts by adults in all seating positions within the vehicle.

The Road Traffic Act of 1988 had permitted exceptions to seat belt regulations for one important group of employee drivers: "the users of vehicles constructed or adapted for the delivery of goods or mail to consumers or addresses, as the case may be, while engaged in making local rounds of deliveries" (HMSO, 1988). Later, the Motor Vehicles (Wearing of Seat Belts in Rear Seats by Adults) Regulations 1991, in making belt use compulsory for rear-seat passengers, provided a long list of situations in which occupants of rear seats could be exempted. These included a number of occupational settings such as the fire service and local delivery or collection [Regulation 5] (HMSO, 1991). However, Great Britain's 2006 transposition of the EU directive replaced Regulation 5 with new text requiring mandatory belt use for all vehicle 
occupants, as shown above in Table 3-7. ${ }^{41}$ Thus, this transposition of the Seat Belt Directive had significant effects on worker safety; the inclusion of such a point in state law also reinforces beltuse policies that may be established by employers.

The seat belt regulations for Northern Ireland provide an example wherein transposition of an EU directive by Great Britain and Northern Ireland differs in substance. Northern Ireland's 1993 Motor Vehicles (Wearing of Seat Belts) Regulations did not require drivers or passengers to wear a seat belt if they were engaged in making local deliveries, collecting goods or mail, or supervising learner drivers. The 2008 amendment largely closed this loophole, substituting for the delivery driver exception an exception for the driver or passenger in a goods vehicle while on a journey of less than 50 meters for purposes of delivery or collection (HMSO, 2008). The Northern Ireland transposition is not incorrect; it simply took advantage of an exemption offered by the EU directive, whereas Great Britain no longer did so. However, this situation does illustrate that when an EU policy is downloaded to a member state, delegation of regulatory responsibility to sub-state levels of government can result in different policies, even in a (mostly) unitary state like the UK.

With respect to the requirement for belt use in buses (where belts are provided), the British transposition is somewhat less faithful than the transposition for belt use in lighter vehicles. It makes an exception for passengers on buses where standing is permitted, a topic not addressed in the EU directive, which says only that belts are to be used while seated. While the British provision does not directly contradict the EU directive, it appears on the surface more lenient than the EU directive in its exemption for standing passengers. In addition, the British regulation invokes other state-level legislation to maintain an exception for local bus services in built-up areas.

The regulation pertaining to bus drivers notifying passengers of the requirement to wear seat belts requires the driver to take "all reasonable steps" to communicate this information. Note that the same issue was identified above in connection with the transposition of the Road Transport Working Time Directive. Here, the technical content of the British transposition of this directive is consistent with the EU directive; however, the British regulation again does not require that the driver "shall" see that the intent of the EU directive is met at all costs. In this instance, there is further evidence for a distinct "policy core belief" as described in the ACF (P. Sabatier \& Weible, 2007, pp. 194-195). What is particularly interesting here is the apparent breadth to which the concept of taking "all reasonable steps" permeates British regulatory philosophy: it has been identified within basic occupational safety legislation, within road transport regulations for heavy-goods vehicle operation, and now within transport regulations aimed primarily at the general public. The concept is not explicit in EU directives, yet it is used as a qualifying concept in British transpositions of those EU directives.

\footnotetext{
${ }^{41}$ Of note, the EU Seat Belt Directive still permits member states to maintain exemptions to " allow certain types of occupation to be carried out effectively," and "to ensure that the police, security or emergency services can perform their duties properly" [Article 6] (Commission of the European Communities, May 9, 2003, p. 65).
} 


\section{$\underline{\text { Summary and conclusions }}$}

\section{British transposition of EU directives}

For the transposition of EU directives on occupational road safety, there is strong evidence that for the UK, the "world of domestic politics" prevails, as suggested by Falkner et al. in their analysis of British transpositions related to employment policy (Falkner, et al., 2005). Evidence from interviews, regulations, and government documents indicate that EU directives related to occupational road safety did not require substantial changes in state-level regulations, nor did they exert much influence on how government or employers managed road risk for employees. There are two exceptions to this conclusion.

First, the initial Working Time Directive (93/104/EC) did require substantial change to British law because the UK lacked state-level law in this area, and because its provisions ran counter to state-level policy preferences. This particular transposition had a distinct element of partisan politics not apparent in any of the other transpositions; the Conservative government in power at the time the first Working Time Directive was enacted strongly opposed the directive and brought suit against the European Commission in the ECJ in an effort to invalidate it. Only when the Labour Party came to power in 1997 did the environment change such that transposition eventually became politically possible.

Second, in certain cases in which an EU directive imposed quantitative requirements, the UK had little choice but to directly transpose these points of the directive. The Road Transport Working Time Directive is a good example of this; although it offers member states some flexibility in derogations for certain groups, there is no deviating from maximum hours of work or minimum hours of rest for workers to whom the regulation applies.

There is evidence that UK domestic practices may have influenced some elements of EU policy. The Operator CPC Directive (98/76/EC), with its predecessor 96/26/EC, appears to have "uploaded" at least one element of policy from the UK to the EU. The central criteria for professional competence, "good repute," "appropriate financial standing," and "professional competence," were present in British legislation dating from 1968 (the Transport Act) (LawtonSmith, 1995, p. 141), and were carried through all subsequent legislation. These three criteria are also found in the EU professional competence directive that preceded the two directives whose transpositions are assessed here.

EU directives do not preclude a member state creating regulations that offer stronger worker protections than those contained in the directives. This research did not identify instances in which the UK went noticeably beyond EU directives in transposing them, or created additional regulations to fill gaps in EU regulation. Transposition of the Framework Directive offered the HSE an opportunity to specify in British regulations that occupational risk assessment must extend to occupational driving, despite the fact that HSE does not exercise jurisdiction in this area. Nearly fifteen years later, the HSE in cooperation with DfT released its Driving at Work guidance (invoking the Management of Safety and Health at Work Regulations, a British transposition of the Framework Directive), but only after intense pressure from interest groups and a government-convened task force. 
There is some support for the hypothesis that where there are no EU directives to dictate policy content, the UK's policy response will reflect market-oriented pressures. Outside EU directives, the government's general approach has been to encourage businesses to voluntarily implement best practices for managing road safety. Arguments cited in favor of the continued exclusion of MVCs from the RIDDOR data system reflect a pro-business bias: concerns about imposing new reporting burdens on business, and concerns about disrupting the way in which businesses have customarily reported occupational injuries. Consistent with the Anglo-Saxon approach to transport cited in the literature, there is no evidence that government agencies look at road transport services as worthy of special government intervention or protection. While it is true that the UK has had to tailor its system for certifying companies and drivers to EU specifications, road transport is otherwise a business like any other business. Finally, the UK's protracted opposition to the Working Time Directive showed policy preferences that favored minimizing perceived economic harm to business over protecting workers from long hours that might lead to negative health and safety outcomes.

\section{The ACF - Policy subsystem and framing}

A number of elements in the ACF are useful in explaining the development of the UK's policies for occupational road safety. First, there is undoubtedly a policy subsystem operating in the UK around occupational road safety. Actors within the subsystem represent a wide range of stakeholders: government, business, unions, NGOs, risk management, consultants, and researchers. Many of the major actors within the UK subsystem are long-term players who know and understand each other's positions quite well. Representatives of MNCs, the European Union and its agencies, and other institutions outside the UK are welcome visitors to the subsystem. The university-based research community is a strong force within the subsystem and has built a strong case for the need for businesses to manage road risk for employees. A growing body of research, some of it performed on government contracts, has established unique risk factors associated with driving for work, the importance of identifying high-risk drivers, and the value of a comprehensive fleet management program in reducing occupational crash rates (Darby, et al., 2009; Dimmer \& Parker, 1999; C. Downs, et al., 1999; Grayson, 1999; Lynn \& Lockwood, 1999; McCorry \& Murray, 1993; Murray, Ison, Gallemore, \& Nijjar, 2009; Murray \& Whiteing, 1995). Despite the apparent lack of political will at higher levels to obtain a full accounting of occupational MVCs through government data systems, decision-makers within the bureaucracy have nonetheless exercised their discretion to steer research funds toward work-related road safety (Broughton, Baughan, Pearce, Smith, \& Buckle, 2003; Department for Transport (United Kingdom), 2004; Lancaster \& Ward, 2002). This has allowed the government to be indirectly involved in building the knowledge base to promote better management of employee drivers, without imposing new government mandates.

Based on an examination of the structure of relevant laws, regulations, and institutions, and on the assessments of key informants, it must be concluded that occupational road safety in the UK is framed as a matter to be handled by transport agencies. The institutions through which most government functions related to occupational road safety are handled reside within the DfT, and the HSE has elected not to take jurisdiction over occupational driving. Another aspect of framing is the distinction between policies for large trucks and buses and policies for other vehicles. The UK, like other high-income countries, has historically had a separate regulatory 
regime for large trucks and buses without a parallel regulatory regime for lighter occupational vehicles. The EU makes a similar distinction, developing specialized regulations for large trucks and buses and associated businesses, thereby reinforcing that this particular operating environment needs strict rules to operate safely while other occupational driving environments do not.

These distinctions by vehicle type and size, reinforced by the DfT's management of large trucks and buses and the HSE's limited attention to other occupational vehicles, are the primary way in which the UK's policy for occupational road safety is fragmented. This raises the question of whether institutional fragmentation led to policy fragmentation, or the reverse. I argue that fragmentation in policy (formulated domestically and reinforced by the EU) has led to the existing distribution of functions and programs across agencies. It makes more sense theoretically that ideas would drive creation of institutions - not that the ideas would adapt to fit the existing institutional structure.

However, despite the fact that there are a number of UK government agencies with some statutory or assumed responsibility for occupational road safety, the associated policy subsystem seems well-coordinated and closely knit. Part of the reason may be that policy direction is generally set at central-government level, so that even though there are several agencies involved, there is a single peak agency for Great Britain to which interest groups can direct their attention. Another reason may be that the strong influence of interest groups and researchers on the policy subsystem provides additional "glue," engaging government to a substantial degree and pushing it to be more open and communicative than it might otherwise be.

\section{The ACF - Belief systems}

There is a great deal in the UK case to support the hypothesis that the belief systems of policymakers and interest groups have influenced the course of policy. The neo-liberal belief that the business community should to the extent possible function without government intervention does extend to occupational road safety policy in the UK. Several points can be raised in support of this argument. First, OSH legislation for the UK is founded on the principle that employers are to ensure safe conditions "so far as is reasonably practicable" (HMSO, 1974). This implies that businesses are not to be held to an unattainable absolute standard of worker protection. Moreover, this principle qualifies several British transpositions of EU directives. Second, where EU directives allowed latitude for British regulators to find a direct application to occupational road safety (notably, for the Framework Directive, and also the Working Time Directive), no such determination was made. Third, government informants interviewed for this research suggested that it would be unlikely that the UK would initiate regulatory action on its own to require more rigorous management of occupational road safety. Fourth, in implementing DfBB, the DfT provided funding but in large measure stepped away to let businesses work out the program details. However, these pro-business and pro-market measures are balanced by other policy elements that hold companies accountable for their employees' actions on the road: the "cause or permit" provisions in the RTA, and the corporate manslaughter legislation. Thus, within a business-oriented world, businesses do have responsibilities for their employees' conduct on the roads, and this principle is at least implicit in a range of British legislation and regulation that covers OSH, transport, corporate regulations, and civil liability. 
Belief systems also played a role in the relatively few instances in which Great Britain lagged in its transposition of EU directives relevant to occupational road safety. In general, the problems identified were not specific to road safety policy, but extended to conflicts regarding broader social policy beliefs. For example, the UK strongly opposed the Working Time Directive on two levels: on the basis of "policy core beliefs" within the OSH policy subsystem that condoned long hours of work, and because of "deep core beliefs" that viewed restrictions on work hours as an unwarranted EU interference in domestic affairs (Falkner, et al., 2005, pp. 97-99; P. Sabatier \& Weible, 2007, pp. 194-196).

As the ACF suggests, "external shocks," here in the form of occupational crashes resulting in multiple fatalities to members of the public, were important in spurring British government responses related to occupational road safety. In response to high-profile truck crashes, the government convened the task force that produced the Dykes Report, which led to the Driving at Work publication that stands today as the joint HSE/DfT policy guidance to employers. In convening the task force and producing the HSE/DfT guidance, the government acted within the framework of its existing policy positions and its usual response modes, but it eventually did respond in some fashion. Here, it is worth noting that in the case of the HSE, the agency felt sufficient pressure to issue guidance in an area that officially fell outside its jurisdiction. There is evidence that advocates for occupational road safety used opportunities to influence government policymakers across agencies, generally at central-government level. The task force for the Dykes Report, taking advantage of the opportunity structure as understood by participants, targeted multiple agencies and stakeholders with its recommendations. In addition to calling on the HSE to issue guidance to employers on managing occupational road risk, it recommended broader application of OSH law to occupational driving, the inclusion of road crashes in RIDDOR, and the addition of a question on work relationship on the Stats19 data collection form (Work-related Road Safety Task Group, 2001).

\section{$M L G-F o r$ the UK, less compelling than the ACF}

Compared with the ACF, MLG offers a less compelling and comprehensive account of the UK's handling of occupational road safety. However, there is some evidence that in the UK, the issue is managed at different levels of government, and using several modes of governance. Three examples may be cited in support of Type I MLG, which focuses on delegation of government functions to sub-state levels of government (Hooghe \& Marks, 2003; Marks \& Hooghe, 2004, pp. 236-237). First, although the British Parliament enacts the primary legislation and the executive agencies set policy directions at central-government level, Northern Ireland typically enacts parallel legislation and writes its own regulations. For the regulations examined for this research, however, the distinction is largely a formality; here, Northern Ireland's autonomy has not resulted in materially different policy.

A second example of Type I MLG operating within the UK is the independent structures of Traffic Areas and Traffic Commissioners through which applications for operator CPCs are evaluated and monitored (among many other road-related governance functions). The Traffic Commissioners have statutory power to grant licenses to operate road transport undertakings and to restrict or withdraw those licenses based on operator performance. As is suggested by the literature on MLG, this governance structure is based on jurisdictions established for a special 
purpose which function apart from general-purpose governmental units and are not coterminous with those traditional governmental units.

Another layer of governance established by statute is the charge to local authorities to take some responsibility for road safety. The RTA gives local authorities (primarily county councils) the task of examining road safety within their jurisdictions and implementing programs to address local problems. Although this function does not involve the establishment of new jurisdictions, it does demonstrate some shifting of responsibility from the central government to local level. In addition, several local authorities have developed their own fleet safety programs as well as initiatives with local organizations.

On the other hand, the government-sponsored interest group DfBB and indeed, the broader engagement of government with epistemic communities, are examples of Type II MLG at work. One might expect government to take on the task of regulating a recognized workplace hazard, or to at least implement voluntary compliance programs. Instead, the British government has in a sense passed this inherently governmental function off to the organizations it might otherwise regulate, promoting a forum for organizations to convince each other of the economic and societal value of managing road risk. In the case of DfBB, "government" is replaced by "governance" in the form of a public-private partnership (T. Börzel \& Risse, 2005, p. 196). The government's actions here are similar to what has been described as characteristic of the UK's response to tobacco policy, where government involvement has taken the form of participation in professional networks for the purpose of sharing best practices (Asare, et al., 2009, p. 94).

In the UK, then, although the central government has its hand in occupational road safety through legislation, regulations (some EU-driven, some not), and non-regulatory guidance, there is also a good deal of complementary governance that takes place at sub-state level or through interest groups. At sub-state level, this ranges from programmatic flexibility (as in the case of local road safety authorities or HSE units) to true delegation of authority (as in the case of the Traffic Commissioners). On the interest-group side, DfBB is an example of government intervention to encourage private and public sector organizations to manage an occupational and transport safety issue through peer consultation and education, and NGOs and the research community are also regular contributors to the discussion.

\section{A limited role for international actors}

There is little evidence to support the hypothesis that international actors have influenced the way in which the UK's policy for occupational road safety has developed. There is no evidence that road safety advocates from within the UK have looked to international organizations or epistemic communities to help push policy changes that were difficult to achieve domestically. It could be argued that the EU, through activities such as PRAISE, has created venues for interaction which did not necessarily exist earlier. The UN Road Safety Collaboration also offers opportunity for information exchange between EU member states and their counterparts from around the world. However, in these venues, participants from the UK are generally in a position of communicating lessons learned and best practices rather than receiving information that will be applied at home. 


\section{Conclusions}

In summary, worker protection is an important policy matter for the UK, with relevant legislation pre-dating EU entry into this policy area. Provisions in basic transport and OSH legislation hold employers responsible for negligence but at the same time stop short of mandating worker protection at all costs. The UK has generally been compliant in transposition of EU directives related to occupational road safety, but resulting UK regulations nonetheless borrow policy ideas found in existing state-level legislation, lending some support to the hypothesis that domestic politics will be central to the UK's response. In areas where the EU has not issued directives, notably driving of lighter occupational vehicles for purposes other than transporting passengers or freight, the UK has chosen a cooperative, non-regulatory approach that engages businesses in developing risk management strategies. Interest groups, particularly academics, NGOs, and suppliers of training and risk management services, have been vocal in keeping occupational road safety on the policy agenda, and continue to be engaged with business in these cooperative activities.

There are some examples of MLG at work within the UK structure for managing occupational road safety with respect to delegations of authority to sub-state authorities and the development of governance mechanisms outside formal political units. However, the ACF, with its emphases on beliefs, policy subsystems, and mechanisms of policy change, seems to offer a more complete model for assessing the development of UK policy.

Table 3-8. British legislation and regulations related to transposition of selected EU directives for occupational road safety

\begin{tabular}{|c|c|}
\hline British legislation or regulation & Source \\
\hline \multicolumn{2}{|l|}{ Driving License Directive (91/439/EEC) } \\
\hline $\begin{array}{l}\text { The Motor Vehicles (Community Driving Licence) } \\
\text { Regulations } 1996 \text { (S.I. } n^{\circ} 1974 \text { of 1996). }\end{array}$ & $\begin{array}{l}\text { Her Majesty's Stationery Office (HMSO) (1996). London: } \\
\text { HMSO. http://www.legislation.gov.uk/uksi/1996/1974/made }\end{array}$ \\
\hline $\begin{array}{l}\text { The Motor Vehicles (Driving Licences) Road } \\
\text { Traffic Regulations } 1996 \text { (S.I. } n^{\circ} 2824 \text { of 1996). }\end{array}$ & $\begin{array}{l}\text { HMSO (1996). London: HMSO. } \\
\text { http://www.opsi.gov.uk/si/si1996/Uksi } 19962824 \text { en 1.htm }\end{array}$ \\
\hline $\begin{array}{l}\text { The Motor Vehicles (Driving Licences) Road } \\
\text { Traffic Regulations } 1999 \text { (S.I. }{ }^{\circ} 2864 \text { of 1999). }\end{array}$ & $\begin{array}{l}\text { HMSO (1999). London: HMSO. } \\
\mathrm{http} / / / \text { ww.opsi.gov.uk/si/si1999/uksi } 19992864 \text { en.pdf }\end{array}$ \\
\hline Road Traffic Act 1988 (1988 Chapter 52). & $\begin{array}{l}\text { HMSO (1988). London: HMSO. } \\
\mathrm{http} / / / \text { ww.opsi.gov.uk/acts/acts1988/ukpga } 19880052 \text { en } 1\end{array}$ \\
\hline \multicolumn{2}{|l|}{ Driver CPC Directive (2003/59/EC) } \\
\hline $\begin{array}{l}\text { Road traffic: The Vehicle Drivers (Certificates of } \\
\text { Professional Competence) Regulations } 2007 \text { (S.I. } \\
\mathrm{n}^{\circ} 605 \text { of 2007). }\end{array}$ & $\begin{array}{l}\text { HMSO. (2007). London: HMSO. } \\
\text { http://www.opsi.gov.uk/si/si2007/uksi_20070605_en_1 }\end{array}$ \\
\hline $\begin{array}{l}\text { Road traffic: The Motor Vehicles (Driving } \\
\text { Licences) Regulations } 1999 \text { (S.I. n } 2864 \text { of 1999). }\end{array}$ & $\begin{array}{l}\text { HMSO. (1999). London: HMSO. } \\
\text { http://www.opsi.gov.uk/si/si1999/uksi_19992864_en.pdf }\end{array}$ \\
\hline \multicolumn{2}{|l|}{ Operator CPC Directive (98/76/EC) } \\
\hline Transport Act (Chapter 73). & $\begin{array}{l}\text { HMSO (1968). London: HMSO. } \\
\text { http://www.legislation.gov.uk/ukpga/1968/73/enacted }\end{array}$ \\
\hline $\begin{array}{l}\text { Goods Vehicles (Community Authorisations) } \\
\text { Regulations } 1992 \text { (S.I. }{ }^{\circ} 3077 \text { of 1992). }\end{array}$ & $\begin{array}{l}\text { HMSO (1992). London: HMSO. } \\
\mathrm{http} / / \text { www.opsi.gov.uk/si/si1992/Uksi_19923077_en_1.htm }\end{array}$ \\
\hline $\begin{array}{l}\text { Goods Vehicles (Licensing of Operators) Act } 1995 \\
\text { (Chapter 23). }\end{array}$ & $\begin{array}{l}\text { HMSO (1995). London: HMSO. } \\
\text { http://www.opsi.gov.uk/acts/acts1995/pdf/ukpga } 19950023 \text { e }\end{array}$ \\
\hline
\end{tabular}




\begin{tabular}{|c|c|}
\hline & n.pdf. \\
\hline $\begin{array}{l}\text { Goods Vehicles (Licensing of Operators) } \\
\text { Regulations } 1995 \text { (S.I. }{ }^{\circ} 2869 \text { of 1995). }{ }^{42}\end{array}$ & $\begin{array}{l}\text { HMSO (1995). London: HMSO. } \\
\text { http://www.opsi.gov.uk/si/si1995/Uksi } 19952869 \text { en 1.htm }\end{array}$ \\
\hline $\begin{array}{l}\text { Goods Vehicles Operators (Qualifications) } \\
\text { Regulations } 1999 \text { (S.I. n² } 2430 \text { of 1999). }\end{array}$ & $\begin{array}{l}\text { HMSO (1999). London: HMSO. } \\
\text { http://www.opsi.gov.uk/si/si1999/uksi } 19992430 \text { en.pdf }\end{array}$ \\
\hline \multicolumn{2}{|c|}{ Road Transport Working Time Directive (2002/15/EC) } \\
\hline Transport Act (Chapter 73). & $\begin{array}{l}\text { HMSO (1968). London: HMSO. } \\
\text { http://www.legislation.gov.uk/ukpga/1968/73/enacted }\end{array}$ \\
\hline $\begin{array}{l}\text { The road transport (working time) regulations } 2005 \\
\left(\text { S.I. } n^{\circ} 639 \text { of } 2005\right) .\end{array}$ & $\begin{array}{l}\text { HMSO. (2005). London: HMSO. } \\
\text { http://www.opsi.gov.uk/si/si2005/20050639.htm }\end{array}$ \\
\hline \multicolumn{2}{|l|}{ Working Time Directive (2003/88/EC) } \\
\hline $\begin{array}{l}\text { The Working Time Regulations } 1998 \text { (S.I. } \mathrm{n}^{\circ} 1833 \\
\text { of 1998). }\end{array}$ & $\begin{array}{l}\text { HMSO (1998). London: HMSO. } \\
\text { http://www.opsi.gov.uk/si/si1998/19981833.htm }\end{array}$ \\
\hline $\begin{array}{l}\text { The Working Time (Amendment) Regulations } \\
2003 \text { (S.I. } n^{\circ} 1684 \text { of } 2003 \text { ). }\end{array}$ & $\begin{array}{l}\text { HMSO (2003). London: HMSO. } \\
\text { http://www.opsi.gov.uk/si/si2003/20031684.htm }\end{array}$ \\
\hline \multicolumn{2}{|l|}{ Seat Belt Directive (2003/20/EC) } \\
\hline $\begin{array}{l}\text { The Motor Vehicles (Wearing of Seat Belts) } \\
\text { (Amendment) Regulations } 2006 \text { (S.I. } n^{\circ} 1892 \text { of } \\
\text { 2006). }\end{array}$ & $\begin{array}{l}\text { HMSO (2006). London: HMSO. } \\
\text { http://www.opsi.gov.uk/si/si2006/20061892.htm }\end{array}$ \\
\hline Road Traffic Act 1988 (Chapter 52). & $\begin{array}{l}\text { HMSO (1988). London: HMSO. } \\
\text { http://www.opsi.gov.uk/acts/acts1988/ukpga } 19880052 \text { en } 1\end{array}$ \\
\hline $\begin{array}{l}\text { The Motor Vehicles (Wearing of Seat Belts in Rear } \\
\text { Seats by Adults) Regulations } 1991 \text { (S.I. n }{ }^{\circ} 1255 \text { of } \\
\text { 1991). }\end{array}$ & $\begin{array}{l}\text { HMSO (1991). London: HMSO. } \\
\text { http://www.statutelaw.gov.uk } / \text { content.asp } \text { ?LegType }=\text { All }+ \text { Le } \\
\text { gislation\&title }=\text { wearing }+ \text { of }+ \text { seat }+ \text { belts\&searchEnacted }=0 \& \text { ex } \\
\text { tentMatchOnly }=0 \& \text { confersPower }=0 \& \text { blanketAmendment }=0 \& \\
\text { sortAlpha }=0 \& T Y P E=Q S \& \text { PageNumber }=1 \& \text { NavFrom }=0 \& \text { par } \\
\text { entActiveTextDocId }=3268979 \& \text { ActiveTextDocId }=3268979 \& \\
\text { filesize }=22124\end{array}$ \\
\hline $\begin{array}{l}\text { The Motor Vehicles (Wearing of Seat Belts) } \\
\text { Regulations } 1993 \text { (S.I. } n^{\circ} 176 \text { of 1993). }\end{array}$ & $\begin{array}{l}\text { HMSO (1993). London: HMSO. } \\
\text { http://www.opsi.gov.uk/si/si1993/uksi } 19930176 \text { en 1.htm }\end{array}$ \\
\hline
\end{tabular}

${ }^{42}$ This is the regulation based on the Goods Vehicles (Licensing of Operators) Act 1995. The Act contains more substance than the Regulations, notably Schedule 3 of the Act, which details requirements for obtaining the Operator CPC. The Regulations are cited for the sake of completeness, but the assessment of the UK's transposition of the Operator CPC Directive is based on the Act, not the Regulations that followed. 


\section{Chapter 4. France: Domestic Politics in a Surprisingly Corporatist Environment}

The chapter begins with a review of the sources of French law, including a discussion of the relationship between the various legislative and regulatory instruments and the codes of law. Following is a discussion of the major highway and labor legislation in France, the institutions supporting its implementation, and an inter-ministerial steering committee formed to address occupational road safety. The course of French policy in this area has been strongly influenced by the social insurance funds that have assumed a non-regulatory consultative role with employers, with active participation of the social partners.

Next, I review French transpositions of EU directives on driver licensing, certificates of professional competence for road transport operators and drivers, working time, and seat belts. With the exception of the directive on driver licensing, I find that France's transpositions were generally accurate and timely. Transpositions were often complicated by domestic processes or priorities, and France generally chose not to sacrifice those priorities in the name of swift transposition. Therefore, I conclude that for this group of EU directives France does not belong within the "world of neglect" as described by Falkner and her colleagues. The chapter concludes with a discussion of the evidence for and against the research hypotheses. There is some evidence that authority for implementation of occupational road safety policy has been delegated to sub-state levels, although no special jurisdictions have been defined for this purpose. Further, contrary to the conventional characterization of French policy as interventionist and dictated from central-government level, the management of occupational road safety instead takes a corporatist tack, with government and the social partners engaged in cooperative prevention activities.

\section{$\underline{\text { Sources of law }}$}

The French legal and regulatory instruments fall into a hierarchy of lois [statutes, which are primary legislation], followed by ordonnances [ordinances], décrets [decrees that establish regulations], and arrêtés [orders]. Lois are passed by the bicameral Parliament, and have particular constitutional significance because they are seen as expressing the will of the people through their elected representatives (Pollard, 1998, p. xxiii).

Ordonnances are a special case. The development of an ordonnance by the executive branch is authorized by Parliament through a "habilitation law," which defines its scope. Although Parliament has the option to deny ratification, ordonnances are approved in most cases. Because they are authorized by Parliament, they have the force of primary legislation (Pollard, 1998, pp. xxiv-xxv; Weston, 1991, pp. 60-61).

Under the French Constitution, lois cover criminal offenses and basic principles associated with property, contracts, and torts. All other aspects of law are covered by regulations, primarily décrets and arrêtés. Décrets are regulations signed by the prime minister and countersigned by other relevant ministers. Arrêtés are second-tier regulations issued by ministers, their subordinates, or local authorities. The power of an entity to issue arrêtés is limited to its area of 
responsibility as designated by primary legislation (European Commission, European Judicial Network in Civil and Commercial Matters, 2005; Weston, 1991, pp. 60, 64). Finally, administrative circulaires [circulars] are frequently issued at agency level. Circulaires containing instructions to civil servants are generally viewed by the Conseil d'État [Council of State $^{43}$ as having the status of regulations (Weston, 1991, p. 65).

A distinguishing feature of French law is codification, an ongoing process through which existing laws and regulations on a particular topic are brought together under a single code. Legislation (lois, décrets, and ordonnances) may directly amend a code by adding new provisions or modifying existing ones. When a legislative act or regulation is codified, it may be edited for the sake of consistency or comprehension, but it is not fundamentally altered. Of greatest relevance to this research are the Code de la Route [Highway Code] and Code du Travail [Labor Code]. Codes are generally divided into two parts: la partie législative [legislative part], derived from lois and whose entries have the prefix "L", and la partie réglementaire [regulatory part], derived from décrets and whose entries have the prefix "R." Some codes also incorporate arrêtés using the prefix "A;" however, Legifrance provides only the "L" and "R" sections in its online database (Legifrance, 2010).

\section{The Highway Code and institutional structure for transport}

Created in 1921, the Highway Code is the repository for French rules of the road, and is continuously updated as pertinent legislation is enacted, amended, or repealed. The Code applies to all drivers on roads in France and its overseas possessions, and it applies to all aspects of occupational driving unless other transport or OSH regulations impose stricter requirements or additional requirements. The Highway Code is divided into legislative and regulatory parts, each of which follows the same outline. Provisions are not necessarily present at every entry in the outline; for example, there may be legislation on a particular topic, but no regulations. Each part of the Highway Code follows the same basic outline:

\section{Book 1: General provisions}

Titles: Definitions, Responsibility, Research and recording violations, Provisions related to overseas

\section{Book 2: The driver}

Titles: Teaching driving and road safety, Driver's license, Driver behavior, Provisions related to overseas

\section{Book 3: The vehicle}

Titles: Technical provisions, Administrative arrangements, Recording and reporting of information relating to the movement of vehicles, Provisions related to overseas

\section{Book 4: The use of methods}

Titles: General provisions, Additional provisions applicable on certain routes, Additional provisions applicable to certain vehicles, Provisions related to overseas

\footnotetext{
${ }^{43}$ The literal translation for Conseil d'État is somewhat misleading, as this body has nothing to do with foreign affairs and serves a judicial function. It is both France's chief advisory body to the government on legislation, and the supreme administrative court (Pollard, 1998, pp. xvi-xvii; Weston, 1991, pp. 86-87).
} 
In the legislative part, there are within each title are several chapters, and within each chapter are articles (in some cases as many as ten or fifteen). In the regulatory part, which has considerably more provisions than the legislative, there are again several chapters, but these are further subdivided into sections, which consist of articles. Books 2 and 3, those related to the driver and the vehicle, contain laws and regulations related to general motoring that would also be relevant to occupational driving. Some of the provisions, particularly in Book 3, are in fact specific to driving for work because they focus on technical standards for heavy vehicles such as coupling trailers, use of tachographs to record working time, and vehicle weight limits. However, the Highway Code in its current form is by no means a comprehensive guide for French laws and regulations for work-related road safety. First, France has not yet incorporated into the Highway Code the ministry-level arrêtés that articulate a good deal of French policy in this area. In addition, because occupational road safety policy tends to be split between multiple agencies, one would not expect to find all applicable measures within a single body of law.

A 1958 ordinance enacted under the auspices of the transport and labor ministries essentially defined occupational driving in France for purposes of government regulation, and this ordinance was still cited in new regulations almost 50 years later. ${ }^{44}$ The points from Article 1 (the statement of the ordinance's scope) that are most relevant to this research are:

To ensure the safety of traffic, the conduct and operation of all road vehicles transporting goods or passengers, public or private, are subject to obligations relating to:

$1^{\circ}$ Hours of work and in particular the distribution of work periods and rest;

$2^{\circ}$ Special conditions of work, including the number of drivers as well as specific rules on hygiene and safety;

$3{ }^{\circ}$ Control methods, materials and devices to be used;

$4^{\circ}$ Initial and continuing vocational training of drivers: these obligations apply to drivers of vehicles transporting goods whose gross vehicle weight exceeds 3.5 tonnes and passenger vehicles comprising more than eight seats in addition to the driver, with the exception of drivers of:

(g) Vehicles carrying material or equipment for use in the profession of the driver, provided that driving the vehicle is not the driver's main activity

(Ministère de travaux publics, December 25, 1958)

This ordinance implied that, with the exception of training requirements, future regulations applicable to occupational driving would be limited to vehicles engaged in transport of goods or passengers. Training requirements were specific to operation of heavy-goods vehicles or large passenger transport vehicles, and explicitly excluded drivers who transported materials and equipment as part of their job, but whose main job entailed something else. However points 1, 2, and 3 from Article 1 above do not restrict the scope of occupational health and safety rules for drivers to those who drive large vehicles. What is not entirely clear in this ordinance is whether occupational drivers whose primary work activity is something other than transporting goods or passengers are in fact within its scope.

44 This ordonnance was repealed on December 1, 2010. 
The statement of training aims found in the 1958 ordinance is worth noting in that it reflects a surprisingly integrative view of occupational road risk for the time. Training was expected to lead to understanding of road safety rules as well as regulations on working time and driving time and rest; to develop defensive driving skills that would enable drivers to anticipate road hazards and be aware of other road users; and to streamline fuel consumption of their vehicle. Here, the recognition that the occupational drivers are subject to the rules of the road and to OSH rules is telling. The fact that the ministries of transport and labor were both signatories to this ordinance supports this point. ${ }^{45}$

France's first major road safety initiative came in 1972 after strong media pressure and initiative from within the government led to a proposal by Prime Minister Jacques Chaban-Delmas to create a position called the "National Delegate for Road Safety." Under the resulting decree, this individual was tasked with organizing and coordinating a new Interministerial Committee for Road Safety, made up of twelve government ministers and chaired by the Prime Minister (Président de la République Française, July 8, 1972). Of note, the labor minister (at the time Joseph Fontanet, who held the title Minister of Labor, Employment, and Population) was not among the ministers who were party to the decree and would serve on the Interministerial Committee. The exclusion of worker interests from this important governmental initiative is quite remarkable, as some of the ministries that were in fact included would seem to be only loosely linked to the topic of road safety: the ministry of postal service and telecommunications, for example.

The Interministerial Committee's overarching function was to define government policy for road safety and ensure that it was successfully applied. This was to be achieved by preparing draft legislation in support of policy decisions, and by monitoring levels of investment in road safety as a proportion of relevant ministerial budgets. In addition, appointment of the National Delegate for Road Safety generated publicity such that the incumbent was able to exploit opportunities to campaign for road safety through media outlets (Gerondeau, 2006, pp. 10-11).

Between the early 1970s and the present, France enacted numerous changes to its road safety laws and regulations, addressing speed, seat belts, alcohol, helmets, licensing, commercial motor vehicles, and other topics. The mechanism for this has generally been to enact specific arrêtés or décrets at ministerial level amending the Highway Code. In a few instances in which there has not been previous state-level law, higher-level legislation in the form of a loi has been required in order to set a general direction for more specific regulations that will follow. There have been no comprehensive lois enacted that have signaled a radical shift in policy direction for general road safety or occupational road safety. Nor has there been legislation for the purpose of consolidating existing legislation; the Highway Code serves that purpose.

From the 1970s into the late 1980s, French laws that affected occupational road safety were primarily responses to state-level policy initiatives, as the EU had not yet issued large bodies of directives in either the realm of transport or OSH. More recently, French legislative and regulatory actions have had to be responsive to EU requirements; therefore, like its fellow member states, France has had to balance its state-level policy preferences with EU priorities.

\footnotetext{
${ }^{45}$ The reference to reduced fuel consumption is interesting, and ahead of its time. Whether this was motivated by economic or environmental concerns is anyone's guess.
} 
Historically, the institutional structure under which France's transport policy function is placed has shifted with changes in government. The position of Secretary of State for Transport is a cabinet-level position, yet there is usually no separate Ministry of Transport. Instead, the agency responsible for transport is combined with other agencies into a large multi-purpose ministry. In the past, transport has been combined with public works or infrastructure, housing, tourism, and development. Today, the transport agency called Transports et sécurité routière [Transport and road safety] is a part of the Ministère de l'écologie, de l'énergie, de développement durable et de la mer [Ministry of Ecology, Energy, Sustainable Development, and the Sea].

The Labor Code and occupational safety legislation

Like the Highway Code, the Labor Code is divided into legislative and regulatory parts, each of which follows the same basic outline: a series of books, under which there are numerous titles, chapters, sections, sub-sections, and articles. The regulatory part of the Labor Code is divided into two sections. The first consists of décrets for which the Conseil d'État has issued an opinion. The second consists of décrets simples [simple decrees] issued under the authority of the Prime Minister through the powers invested in him or her by the Constitution. As of May 2008, the overall structure of Labor Code put in place in 1973 was revised substantially and all the articles re-numbered. The older version of the Labor Code that existed prior to this restructuring and re-numbering was used for this research, as virtually all the provisions discussed here in connection with transposition of EU directives were enacted before 2008. Below is the general outline of each part in the version in force before May 1, 2008.

\section{Book 1: Labor conventions}

Titles: Social dialogue, Apprentice contract, Employment contract, Collective labor agreements, Salary, Penalties

\section{Book 2: Employment regulations}

Titles: Conditions of work; Rest and leave; Health, safety, and working conditions; Occupational health services; Social services; Penalties

\section{Book 3: Hiring and employment}

Titles: Placement, Employment, High Council of equality between men and women, Foreign labor and transnational posting of workers, Unemployed workers, Penalties

Book 4: Professional groups, employee representation, profit-sharing and savings plans Titles: Trade unions; Employee representatives; Work committees; Profit-sharing and savings plans; Economic, social, and trade union education; Workers' right to freedom of expression; Wage fund; Penalties

\section{Book 5: Labor disputes}

Titles: Individual conflicts - the industrial tribunals, Disputes, Penalties

\section{Book 6: Monitoring and enforcement of labor regulations}

Titles: Control services, Obligations of employers, Penalties

\section{Book 7: Provisions specific to certain professions}

Titles: Energy and mining; Processing industries; Buildings and public works; Transportation and telecommunications; Traveling representatives and canvassers; Journalists, artists, models; Janitorial staff, housekeepers, child minders and caregivers, educators and tutors, teachers at youth centers and residential facilities; Provisions related to certain categories of workers and enterprises; Penalties 


\section{Book 8: Special provisions for overseas}

Titles: Labor conventions, Investment and employment, Labor disputes, Penalties

\section{Book 9: Continuing vocational training throughout life}

Titles: Institutions of vocational training, Rights and duties of training organizations, Individual rights and collective rights of employees in training, Contribution of the State and the regions, Employer involvement in the development of continuing vocational training, Financial aid awarded to students of vocational training and their social protection, Provisions on the continuing professional training of public officials, Contracts and periods of professionalization, Control of continuing vocational training Miscellaneous - Penalties

Within the legislative part of the Labor Code, the portion focusing on occupational safety is Book II (Employment Regulations), Title III (Health, Safety, and Working Conditions), Chapter III (Safety).

\section{French labor legislation}

In 1973, France passed legislation that articulated the country's approach to workplace safety promotion as a cooperative effort between labor and industry, with responsibilities on each side. Under this legislation, enterprises with 300 or more employees were required to establish works committees whose function would be to research solutions to problems related to the duration and hours of work (including night work), logistics, environmental factors, and physical characteristics of the work. The employer was required to consult the works committee before introducing any new methods of work organization, before making changes to equipment or labor practices that might result in major changes for workers, before changing wage rates or standards for productivity, or before making any change that might significantly affect the physical environment or workplace safety [Article 1] (Président de la République Française, December 30, 1973). Ongoing responsibilities for the employer included submitting a report to the works committee at least annually on activities related to OSH during the previous year and submitting a work plan for the following year. The works committee would then issue a formal opinion on the report and request remediation or future action by the employer if it chose [Article 2]. Under the works committee system, all employees were required to report any situation posing imminent danger to safety and health. If the employer chose not to cease work in response, he or she was required to send a justification to the Labour Inspectorate within 24 hours [Article 13] (Président de la République Française, December 30, 1973).

The 1973 legislation also created an agency for the improvement of working conditions. The new agency, to be housed in the labor ministry, was charged with conducting research on occupational injuries and circulating information on means of preventing them, and coordinating with stakeholder within France, foreign governments, and international organizations [Articles 6 and 7] (Président de la République Française, December 30, 1973). The agency was to be managed by a board consisting of equal numbers of members from the national employer associations, trade unions, and relevant government ministries, with representatives of Parliamentary committees on employment and social affairs acting in an advisory capacity [Article 8] (Président de la République Française, December 30, 1973). Attached to this 
legislation were provisions on working time and the organization of health and safety committees.

During the remainder of the 1970s and the 1980s, France passed considerable labor legislation modifying the terms of engagement between employers and works committees. It also enacted detailed provisions to protect workers against specific occupational risks. However, France's approach to OSH as a shared responsibility between the social partners was not fundamentally altered until the Framework Directive for OSH (89/391/EEC). The Framework Directive required France to adjust its conception of worker protection to be more consistent with the EU formulation, which placed the greatest responsibility on the employer. This was accomplished through legislation (Loi $\mathrm{n}^{\mathrm{o}}$ 91-1414) that directly amended the Labor Code to add the following:

The employer shall take the measures necessary to ensure safety and protect the health of workers at the facility, including temporary workers. These measures include prevention of occupational risks, information and training, and the establishment of an organization and appropriate resources. The employer will ensure the adaptation of these measures to take account of changing circumstances and aim to improve the existing situation [Title I, Article 1] (Président de la République Française, January 7, 1992).

This French legislation also lays out general principles for risk assessment and injury prevention, specifying measures such as eliminating risks at their source and adapting workstations and work equipment to limit potential negative impact on safety and health. Occupational injury prevention is framed holistically; the employer must "plan for prevention by integrating technology, work organization, working conditions, social relationships and the influence of environmental factors." Further, injury prevention measures are to focus on achieving collective benefits, which are given priority over protective measures advantageous to certain individuals [Title I, Article 1] (Président de la République Française, January 7, 1992).

However, this initial transposition of the Framework Directive appears to have been focused on traditional fixed workplaces, referring to "the facility," "work equipment," and "workstations," leaving little room for its application to occupational driving. Moreover, the legislation lacks a statement of scope that might facilitate its extension to mobile workplaces and occupational driving.

Other than the transposition of the Framework Directive, the legislative portion of the Labor Code contains few provisions that can be linked in any way to occupational driving. An exception is legislation on work and rest; provisions specific to portions of the transport sector are consolidated in Book II (Employment Regulations), Title I (Conditions of work), Chapters II and III (Hours of work and Night work).

As would be expected, the more detailed regulations enacted through arrêtés (and in some cases, décrets) are found in the regulatory part of the Labor Code. These cover the full range of occupational hazards that might be present in a fixed workplace: fall hazards, chemical exposures, machinery, noise, repetitive motion, explosive materials, and many others. As noted earlier, however, the Labor Code is silent on operation of motor vehicles outside industrial 
premises. The regulatory portion of the Labor Code contains extensive provisions on work equipment, but no list of covered work equipment is provided. Based on the content of the provisions, work equipment is implicitly defined as fixed machinery. Discussion of hazards associated with mobile machinery or equipment is limited to driver licensing for operators of truck-mounted hoisting devices, and for mobile equipment in incidental operation on public roads (or in work zones) to travel at safe speed and in accordance with the road configuration [Book II, Title III, Chapter III, Section I, Subsections 4 and 5, Articles R. 233-13-16 and R. 23313-19] (République Française, March 2008).

\section{Government agencies}

France has a dual system for preventing occupational injuries, with responsibility shared between the labor ministry and the social security ministry and its associated social insurance funds. The ministry of labor is charged with developing and implementing state-level public policy for preventing occupational injuries. Within this ministry, the Direction des relations du travail [Directorate for Labor Relations] develops and implements occupational safety regulations. A broad-based commission, however, plays an important consultative role. The Conseil supérieur de la prévention des risques professionnels [High Council for the Prevention of Occupational Risks] made up of representatives from the government, employers, labor, and independent experts assists the labor ministry in setting policy direction. The Conseil supérieur can propose any kind of prevention measure for the workplace, and must be consulted on all proposed legislation or draft regulations related to occupational risk prevention (Institut national de recherche et de securité (INRS) [National Research and Safety Institute], 2010). The Labour Inspectorate, also within the labor ministry, is responsible for workplace inspections and enforcement of OSH regulations, and has a consulting and information-sharing role in priority areas not covered by OSH regulations. The state-level Labour Inspectorate is subdivided into regional inspectorates.

The French social security system plays a substantial role in the prevention of occupational injuries, including MVCs, not only by providing compensation for injuries that do occur but by developing and disseminating non-regulatory strategies to prevent MVCs. The present system has been in place since 1945. Under the French system, an occupational injury is defined as "any accident resulting from work or occurring during work," and also includes "accidents occurring during the journey to or from work, or between the workplace and the place where the individual usually has their lunch" (Centre des Liaisons Européennes et Internationales de Sécurite Sociale (CLEISS) [Center for European and International Social Security], 2010). Injured workers are therefore compensated for crash injuries sustained while commuting. Because the French system includes commuting-related crashes in its occupational injury definition, these crashes are also included in national statistics on occupational injuries (Caisse nationale de l'assurance maladies des travailleurs salariés - Direction des Risques professionnels (CNAMTS-DRP), April 28, 2010).

Within the social security system, the largest fund (and the most active in addressing occupational risk) is the Caisse nationale d'assurance maladies des travailleurs salaries, 
(CNAMTS) [National Health Insurance Fund for Salaried Employees]. ${ }^{46}$ CNAMTS operates under the dual authority of the social security ministry and the economy and finance ministry. The CNAMTS Direction des risques professionnels (DRP) [Directorate for Occupational Risks] oversees occupational injury prevention activities at state level and develops recommendations and resources for nationwide distribution. Although CNAMTS operates under government authority, it is in fact managed by the "social partners:" the peak employer associations and labor unions (Caisse nationale de l'assurance maladies des travailleurs salariés - Direction des Risques professionnels (CNAMTS-DRP), April 28, 2010; Institut national de recherche et de securité (INRS) [National Research and Safety Institute], 2010). Across all functions of CNAMTS, the social partners work closely with CNAMTS to develop policy recommendations. Although the recommendations that come out of this consultative process do not have the force of law, they may be used to support the development of regulations (Caisse nationale de l'assurance maladies des travailleurs salariés - Direction des Risques professionnels (CNAMTS-DRP), April 28, 2010). The CNAMTS emphasis on informal, consultative activities with a goal of voluntary adoption by employers is distinct from the operating principles of the Labour Inspectorate, which acts almost solely on the basis of regulations (Institut national de recherche et de securite (INRS) [National Research and Safety Institute], 2010).

Below state level, CNAMTS operates as sixteen semi-autonomous regional funds called Caisses régionales d'assurance maladie (CRAMs) [Regional health insurance funds], which work directly with employers and workers to implement injury prevention programs. CRAMs receive programmatic guidance from CNAMTS but also have some latitude in developing their own programs to address local priorities. For example, the CRAM that covers the Paris region has instituted a special emphasis program to promote safe operation of motorcycles in the occupational setting (Caisse regionale de l'assurance maladie (CRAM), April 28, 2010). Throughout France, the work of the CRAMs is coordinated with the work of the regional Labour Inspectorates via regional coordinating committees (Institut national de recherche et de securité (INRS) [National Research and Safety Institute], 2010).

Interagency coordination through the Comité de pilotage

In 1999, CNAMTS and the government (specifically, the Direction de la sécurité et de la circulation routières (DSCR) [Directorate of Road Safety and Traffic], a unit within the transport agency) reached a landmark agreement that the risk assessment principles of the EU Framework Directive for OSH would be applied to driving for work. The agreement was driven by the idea that regardless of whether the driver is employed as a "professional" driver, everything done by the worker with or in the vehicle in the course of the workday should be classified as work. The rationale is that because the road is ruled by the state, the state has the authority to interpret the directive as it chooses (Caisse nationale de l'assurance maladies des travailleurs salariés Direction des Risques professionnels (CNAMTS-DRP), April 28, 2010).

In 2001, a formal steering committee was established to develop a broad and coordinated response to the problem of occupational MVCs. The Comité de pilotage pour la prevention du risque routier professionnel [Steering Committee for the Prevention of Occupational Road Risk]

\footnotetext{
${ }^{46}$ Other funds cover employees of local authorities, agricultural workers, and the self-employed.
} 
was formed by an arrêté issued jointly by the ministries of transport and labor. Its role was to make proposals to the government related to improvement of occupational road safety, develop a work plan coordinated between the two ministries, and report to the government on development and progress of collaborative projects. The chair of the Comité de pilotage was to be the head of the Directorate for Occupational Risk in CNAMTS, and the vice-chair was the head of the Directorate of Road Safety and Traffic in the transport ministry. Each of the two agencies was empowered to nominate eight delegates for three-year terms (Ministre de l'équipement, April 27, 2001). In 2006, the Comité de pilotage was enlarged by an inter-ministerial arrêté that expanded its scope to include the social insurance funds for agriculture and local government employees ${ }^{47}$ and increased its membership to 24 persons (Ministre des transports, June 10. 2006).

Because regulations from the transport ministry govern the operation of vehicles weighing more than 3.5 tonnes, the Comite de pilotage concluded that its focus should be occupational light vehicles (OLVs) not covered by existing regulations. Although OLVs are covered by the Highway Code along with all other types of on-road vehicles, they are never mentioned in the Labor Code (Fassenot, 2010).

The primary policy instrument available to the Comité de pilotage is the development and regional dissemination through the CRAMs of resource materials for voluntary use by employers and organizations (Caisse nationale de l'assurance maladies des travailleurs salariés - Direction des Risques professionnels (CNAMTS-DRP), April 28, 2010; Caisse regionale de l'assurance maladie (CRAM), April 28, 2010). However, the Comité has in recent years become more active within the government in promoting policy positions. In 2007, after consulting widely with its stakeholders from labor and industry, it published a White Paper consisting of twelve proposals to promote the safety of OLVs, identifying key agents for change in each instance. The White Paper emphasized the need for occupational safety managers to assess road risk, citing the Framework Directive for OSH. It recommended improvements in design and selection of OLVs, noting the substantial wear and tear on such vehicles as compared with ordinary passenger vehicles. The White Paper also advocated refresher training for drivers of OLVs along the same lines as that required for drivers of heavier vehicles by the Driver CPC Directive (Comité de pilotage pour la prevention du risque routier professionnel [Steering Committee for the Prevention of Occupational Road Risk], 2007; Eurogip, 2009, p. 13).

More recently, the Comité de pilotage played a role in formulating an innovative proposal to the European Commission regarding application of a directive: the newest Working Equipment Directive (2009/104/EC), which is still in the process of being transposed by member states. Based on advocacy of the Comité de pilotage, France in March 2010 proposed to the EU Directorate for Employment, Social Affairs, and Equal Opportunities that OLVs should be classified as "working equipment" under the new directive. The argument was that if the EU would not recognize OLVs as covered under risk assessment provisions of the EU Framework Directive for OSH (89/391/EEC), the Working Equipment Directive offered a viable and more current alternative (Caisse nationale de l'assurance maladies des travailleurs salariés - Direction des Risques professionnels (CNAMTS-DRP), April 28, 2010). The Comité also identified two

\footnotetext{
47 These were, respectively, the Caisse centrale de la mutualité sociale agricole (CCMSA), and the Caisse nationale de retraites des agents des collectivités locales (CNRACL).
} 
other DGs as appropriate venues for advocacy on OLVs: DG MOVE because of its responsibility for vehicle safety standards, and DG Enterprise because of its oversight of manufacturing of vehicles and after-market devices that may be installed in them (Fassenot, 2010).

Table 4-1 below summarizes the institutional placement and roles of the French government agencies that share responsibility for developing and implementing policy for occupational road safety.

Table 4-1. French government agencies with responsibility for occupational road safety

\begin{tabular}{|c|c|c|c|}
\hline French name & English name & Ministry & Notes \\
\hline \multicolumn{4}{|l|}{ Transport Agency } \\
\hline $\begin{array}{l}\text { Transports et sécurité } \\
\text { routière }\end{array}$ & $\begin{array}{l}\text { Transportation and } \\
\text { Road Safety }\end{array}$ & $\begin{array}{l}\text { Ecology, Energy, Sustainable } \\
\text { Development, and the Sea }\end{array}$ & $\begin{array}{l}\text { Develops and enforces } \\
\text { transport regulations }\end{array}$ \\
\hline \multicolumn{4}{|l|}{ OSH agency } \\
\hline $\begin{array}{l}\text { Direction des } \\
\text { relations du travail }\end{array}$ & $\begin{array}{l}\text { Directorate of Labor } \\
\text { Relations }\end{array}$ & Labor & $\begin{array}{l}\text { Develops and enforces OSH } \\
\text { regulations - limited } \\
\text { consultative role }\end{array}$ \\
\hline \multicolumn{4}{|c|}{ Social security agencies } \\
\hline $\begin{array}{l}\text { Caisse nationale } \\
\text { d'assurance maladies } \\
\text { des travailleurs } \\
\text { salaries (CNAMTS) }\end{array}$ & $\begin{array}{l}\text { National Health } \\
\text { Insurance Fund for } \\
\text { Salaried Employees }\end{array}$ & $\begin{array}{l}\text { Joint governance by social } \\
\text { security ministry and } \\
\text { economy/finance ministry }\end{array}$ & $\begin{array}{l}\text { Works with social partners to } \\
\text { develop voluntary } \\
\text { occupational injury prevention } \\
\text { initiatives }\end{array}$ \\
\hline $\begin{array}{l}\text { Caisses régionales } \\
\text { d'assurance maladie } \\
\text { (CRAMs) }\end{array}$ & $\begin{array}{l}\text { Regional health } \\
\text { insurance funds }\end{array}$ & & $\begin{array}{l}\text { Work with social partners to } \\
\text { implement voluntary } \\
\text { occupational injury prevention } \\
\text { initiatives }\end{array}$ \\
\hline
\end{tabular}

\section{French transposition of EU directives}

The primary source of information on French legislation and regulations was the Legifrance database, which may be searched by date, subject, and number. Most of the materials relevant to this research were found in the Journal Officiel de la République Française (JORF) [the Official Journal of the French Republic], ${ }^{48}$ which records official government actions in much the same way as the Federal Register in the U.S.

Legislation and regulations related to occupational road safety are predominantly arrêtés issued by the ministries of transport or labor. Although many of these documents are published in the JORF, some appear only in the Bulletins Officiel [Official Gazettes] of the relevant ministries.

Use of the Highway and Labor Codes available through Legifrance presented some challenges for this research. While versions of the Labor Code are available on Legifrance as early as January 1974, earlier versions of the Highway Code date only to January 2008. Individual provisions within a code may be re-numbered periodically as the code is updated. To better assess timeliness of transposition, this research relied on original versions of legislation as a rule

\footnotetext{
${ }^{48}$ http://www.legifrance.gouv.fr/
} 
of thumb. It was therefore difficult in some cases, for a given provision of a code referred to in legislation, to follow back to the same provision in the version of the code available as of this writing. Moreover, once a law or regulation is codified, its original source is not necessarily cited in the code into which it has been incorporated. Therefore, a provision in a code may constitute an accurate transposition of an article, but it is not possible to assess the timeliness of that transposition.

Results from French government sources were supplemented by NATLEX, the database of national labor, social security, and related human rights legislation maintained by the ILO's International Labour Standards Department. Records in NATLEX provide abstracts of legislation and relevant citation information, and may be searched by country and subject. ${ }^{49}$ In addition to basic labor law such as annual leave and working time, NATLEX covers laws affecting specific industry sectors; therefore, much of the legislation covering the road transport industry is included. Of the six EU directives considered in this research, only the Driving License Directive falls outside the scope of NATLEX.

Table 4-8 at the end of this chapter provides full citations for all the transposing laws and regulations for France identified through this research.

\section{Driving License Directive}

\section{Council Directive 91/439/EEC of 29 July 1991 on driving licences [consolidated version of January 1, 2007]}

Table 4-2. French transposition of Driving License Directive (91/439/EEC)

\begin{tabular}{|l|l|}
\hline EU Directive & French Regulation \\
\hline $\begin{array}{l}\text { Article 1(2): Driving licences issued by Member States shall } \\
\text { be mutually recognized. }\end{array}$ & $\begin{array}{l}\text { Driver's License Decree 1998 } \\
\text { Article 1 } \\
\text { [Amending R. 123-1 of the Highway Code] } \\
\text { I. - All domestic driving licenses issued to persons with } \\
\text { normal residence in France by a State belonging to the } \\
\text { European Union or European Economic Area, valid in } \\
\text { this State, are recognized in France provided that the } \\
\text { holder satisfies the conditions laid down by order of the } \\
\text { Minister for Transport, after consulting the Minister of } \\
\text { Interior and Minister of Foreign Affairs. These } \\
\text { conditions relate to the period of validity, medical } \\
\text { checks, the information essential for managing the } \\
\text { license and the restrictive measures that affect the } \\
\text { license. } \\
\text { II. - Any person having his normal residence in France } \\
\text { and holding a national driver's license issued by a state } \\
\text { belonging to the European Union or European }\end{array}$ \\
\hline
\end{tabular}

${ }^{49}$ http://www.ilo.org/dyn/natlex/natlex browse.home?p_lang=en 


\begin{tabular}{|c|c|}
\hline & $\begin{array}{l}\text { Economic Area in force in that State may, without } \\
\text { being required to undergo examinations under the } \\
\text { second paragraph of Article R. 123, exchange it for a } \\
\text { French driving license in the manner determined by } \\
\text { order of the Minister for Transport, after consulting the } \\
\text { Minister of Justice, the Interior Minister and the } \\
\text { Minister of Foreign Affairs. }\end{array}$ \\
\hline $\begin{array}{l}\text { Article 3(1): The driving licence provided for in Article } 1 \\
\text { shall authorize the driving of vehicles in the following } \\
\text { categories: [See Figure } 2 \text { above for a graphic showing } \\
\text { standard vehicle classes.] }\end{array}$ & $\begin{array}{l}\text { Driver's License Decree } 1998 \\
\text { Article } 2 \text { reproduces the vehicle categories specified in } \\
\text { the EU directive. }\end{array}$ \\
\hline $\begin{array}{l}\text { Article 4(1): Driving licences shall state the conditions on } \\
\text { which the driver is authorized to drive. [Annex I (added by } \\
2000 / 56 / E C) \text { provides a list of harmonized Community codes } \\
\text { to be used on member-state licenses. These address } \\
\text { restrictions based on need for corrective lenses, vehicle } \\
\text { adaptations such as modified control layouts or assistive } \\
\text { devices, and a Certificate of Professional Competence (CPC) } \\
\text { to operate a commercial motor vehicle (this last provision } \\
\text { added by 2003/59/EC).] }\end{array}$ & $\begin{array}{l}\text { Driver's License Order } 1999 \\
\text { Article } 12 \text { lists license codes effective as of December } \\
10,2010, \text { which are generally similar to the codes } \\
\text { shown in } 2000 / 56 / \text { EC but have several significant } \\
\text { omissions. }\end{array}$ \\
\hline $\begin{array}{l}\text { Article 6(1): The minimum age conditions for the issue of } \\
\text { driving licences shall be as follows: } \\
\text { (a) } 16 \text { years: } \\
\text { - for subcategory A1; } \\
\text { - for subcategory B1; } \\
\text { (b) } 18 \text { years: } \\
\text { - for category A... } \\
\text { - for categories B, B + E; } \\
\text { - for categories C, C + E and subcategories C1, C1 + E... } \\
\text { (c) } 21 \text { years: } \\
\text { - for the categories D and D + E and subcategories D1, D1 } \\
\text { + E... } \\
\text { [various derogations and exceptions permitted] }\end{array}$ & $\begin{array}{l}\text { Driver's License Decree } 1998 \\
\text { Article } 3 \\
\text { [Amending R. 124-1 of the Highway Code] } \\
\text { The minimum requirements for obtaining a driver's } \\
\text { license....are as follows: } \\
1 \text { Age (e): } \\
\text { a) sixteen years of age for subcategories A } 1 \text { and B 1; } \\
\text { b) eighteen years of age for categories A, B, C, E (B) } \\
\text { and E (C); } \\
\text { c) From twenty-one years for categories D and E (D). }\end{array}$ \\
\hline $\begin{array}{l}\text { Article 7(1): Driving licences shall, moreover, be issued only } \\
\text { to those applicants: (a) who have passed a test of skills and } \\
\text { behaviour and a theoretical test and who meet medical } \\
\text { standards, in accordance with the provisions } \\
\text { of Annexes II and III; }\end{array}$ & $\begin{array}{l}\text { Driver's License Order } 1999 \\
\text { Article } 8 \\
\text { 8.1. Candidates for the license must undergo testing, } \\
\text { approved by the minister of transport, by an inspector } \\
\text { of driver licensing and road safety and in accordance } \\
\text { with the provisions of Article R. } 123 \text { of the Highway } \\
\text { Code, a technical exam including: } \\
\text { 8.1.1. A theoretical test of general knowledge on their } \\
\text { understanding of traffic regulations, operation of the } \\
\text { vehicle, and driver behavior. } \\
\text { 8.1.2. A practical test to assess their ability to drive and } \\
\text { maneuver a vehicle in the category for which the } \\
\text { license is sought, and to assess their driving behavior. } \\
\text { Applicant can only undergo this practical test after } \\
\text { having passed the general theory test defined in } \\
\text { paragraph } 8.1 .1 \text {. } \\
\text { Article } 15 \\
\text { 15. The practical terms of driving licenses in sub- } \\
\text { category A1 and category A are set in Schedule } 2 \text { of } \\
\text { the present order. The practical terms of driving } \\
\text { licenses in category E (B) are set in Schedule } 3 \text { of the } \\
\text { present order. The practical terms of driving licenses in }\end{array}$ \\
\hline
\end{tabular}




\begin{tabular}{|c|c|}
\hline & $\begin{array}{l}\text { categories C, D, E (C) and E (D) are set in Schedule } 4 \\
\text { of the present order. } \\
\text { Footnote: Schedules 2, } 3 \text { and } 4 \text { will each be a separate } \\
\text { document in the Official Gazette of the Ministry of } \\
\text { Infrastructure, Transport and Housing. }\end{array}$ \\
\hline $\begin{array}{l}\text { ANNEX II } \\
\text { I. MINIMUM REQUIREMENTS FOR DRIVING TESTS } \\
\text { 2. Content of the theory test concerning all vehicle } \\
\text { categories } \\
\text { 2.1. Questions must be asked on each of the points listed } \\
\text { below, the content and form of the questions being left to the } \\
\text { discretion of each Member state: } \\
\text { [Followed by list of topics under these headings: Road traffic } \\
\text { regulations, The driver, The road, Other road users, General } \\
\text { rules and regulations and other matters, Precautions } \\
\text { necessary when alighting from the vehicle, Mechanical } \\
\text { aspects with a bearing on road safety, Vehicle safety } \\
\text { equipment, and Rules regarding vehicle use in relation to the } \\
\text { environment ] }\end{array}$ & $\begin{array}{l}\text { No indication of transposition into French law. } \\
\text { However, this item appears to have been incorporated } \\
\text { by at least } 2003 \text { or } 2004 \text { through administrative } \\
\text { processes (see discussion below). }\end{array}$ \\
\hline $\begin{array}{l}\text { Annex II } \\
\text { II. KNOWLEDGE, SKILL AND BEHAVIOUR FOR } \\
\text { DRIVING A POWER-DRIVEN VEHICLE } \\
\text { Specific provisions concerning categories C, C+E, C1, } \\
\text { C1+E, D, D+E, D1 and D1+E }\end{array}$ & $\begin{array}{l}\text { Driver's License Order } 1999 \\
\text { Schedule 4. [no date] } \\
\text { Contains detailed instructions for written and on-road } \\
\text { testing for drivers of vehicles in these categories. }\end{array}$ \\
\hline $\begin{array}{l}\text { ANNEX III } \\
\text { MINIMUM STANDARDS OF PHYSICAL AND MENTAL } \\
\text { FITNESS FOR DRIVING A POWER-DRIVEN VEHICLE } \\
\text { [includes sight, hearing, CVD, diabetes, alcohol, mental } \\
\text { illness, drugs and medications] }\end{array}$ & $\begin{array}{l}\text { Medical Conditions Order } 2005 \\
\text { Appendix } \\
\text { INTRODUCED BY ORDER OF December 21, } 2005 \\
\text { ESTABLISHING THE LIST OF MEDICAL } \\
\text { CONDITIONS INCONSISTENT WITH OBTAINING } \\
\text { OR MAINTAINING THE DRIVER'S LICENSE OR } \\
\text { THAT MAY GIVE RISE TO THE LICENSING OF } \\
\text { DRIVERS OF LIMITED DURATION } \\
\text { The drivers of category A, A1, B, B } 1 \text { and EB belong } \\
\text { to the light group (group 1). } \\
\text { Applicants or drivers of category C, D, EC and ED are } \\
\text { physical standards required for the heavy group (group } \\
\text { 2). Additional risks associated with driving in the } \\
\text { heavy vehicles group, especially among professional } \\
\text { drivers, will be considered with extreme caution. } \\
\text { [List of prohibited conditions:] } \\
\text { Class I. Cardiovascular disease } \\
\text { Class II. Visual impairment } \\
\text { Class III. Oto-rhino-laryngology - pulmonology } \\
\text { Class IV. Addictive practices - Neurology - Psychiatry } \\
\text { Class V. Musculoskeletal } \\
\text { Class VI. Metabolic diseases and transplantation }\end{array}$ \\
\hline
\end{tabular}

France does not appear to have transposed any elements of the Driving License Directive by the EU deadline of June 30, 1994, and it is questionable whether certain provisions have yet been

\footnotetext{
${ }^{50}$ These vehicle classes are typically used for carrying freight and passengers. Because of their function, weight, and configuration, they are singled out for special consideration by regulations. See Figure 2 for a graphic displaying all the standard vehicle classes used in the EU.
} 
fully transposed as of this writing. For the provisions considered in this research, the earliest evidence of transposition into French law is in 1998 and 1999 for the principle of mutual recognition [Article 1(2)], age requirements [Article 6(1)], vehicle categories [Article 3(1)], and separate testing for applicants seeking licenses for class $C$ and D vehicles [Annex II]. Also in 1999, France partially transposed Article 4(1) through its Driver's License Order, correctly transposing most of the license codes specified in the EU directive. Notable omissions were the special code noting that the driver must use a hearing aid, and the special code for the CPC for a commercial motor vehicle driver. The current version of the legislation available through the Legifrance database does not indicate that either of these codes has yet been incorporated into French licensing law.

Another partial transposition was Article 7(1), where in 1999 France enacted the Driver's License Order stipulating that obtaining a driving license was contingent on passing a written theory test and an on-road skills test. However, the French law made no direct reference to Annex II or III of the EU directive, nor did it specify the content of either test. Instead, it indicated that the details of testing standards for the various classes of vehicles would be developed at ministry level as three separate schedules and published in the Bulletin officiel du ministère de l'équipement, des transports et du logement [Official Gazette of the Ministry of Infrastructure, Transport, and Housing].

Based on a keyword search of this Bulletin Officiel from 1999 to the present, using "permis de conduire" ["driver's license"] as the search term, none of these schedules has been published in electronic format by the French government. A Schedule 4 containing standards for the on-road skills test for Class C and D licenses (but with no date of publication or attribution) was located on an external site. Although this was a generally accurate transposition for the on-road test, it offered no guidance for the content of the written theory test (Lepermis.com [License.com], 2010). Arrêtés from 1999, 2000, 2002, and 2004 amended the three schedules that followed the Driver's License Order of 1999, but it is not possible to determine from these documents whether France correctly transposed the minimum requirements for written theory tests found in Annex II of the EU directive. ${ }^{51}$

In 2002, a case was successfully brought against France in the ECJ (ECJ C-85/02) for failure to correctly transpose one element of Article 7(1)(a) related to on-road tests of driving skills (see Table 4-2 above). At issue was the following provision in Annex II of the EU directive:

\section{Length of the test}

The length of the test and the distance travelled must be sufficient to assess the skills and behaviour laid down in paragraph B of this Annex. In no circumstances should the time spent driving on the road be less than 25 minutes for categories $\mathrm{A}, \mathrm{A} 1, \mathrm{~B}, \mathrm{~B} 1$ and $\mathrm{B}+\mathrm{E}$ and 45 minutes for the other categories [Annex II (B)(10)] (Commission of the European Communities, January 1, 2007, p. 37).

\footnotetext{
${ }^{51}$ These are arrêtés of December 16, 1999 amending Schedule 2, April 28, 2000 amending Schedule 4, April 23, 2002 amending Schedules 2 and 3, and December 29, 2004 amending Schedules 3 and 4.
} 
The basis for the action was that the average duration of the on-road test in France for obtaining a category B license was 22 minutes. In response to a reasoned opinion sent by the Commission in January 2001, France stated that it intended to implement the provisions of the Directive as soon as possible, but that it needed to hire additional driving examiners in order to fully comply. In its ruling, the ECJ cited its precedent that "the Court has repeatedly held that a Member State may not rely on provisions, practices or circumstances in its own legal order to justify failure to implement a directive within the prescribed period" (European Court of Justice, 2003, p. 1700). France responded to the ECJ judgment by publishing a unit-level order from the Director of Security and Road Traffic which subsequently appeared in the JORF. This order stipulated that the duration of the on-road skills test was set at 35 minutes, and under no circumstances was it to be less than 25 minutes (Ministère de l'équipement, des transports, du logement, du tourisme et de la mer [Ministry of Infrastructure, Transport, Housing, Tourism, and the Sea], June 5, 2003).

As is evident from the discussion thus far, the issue of the brevity of the on-road skills test was only a small part of the transposition problem. Further, administrative documents provide further evidence that French officials recognized their country's substantial delays in transposing the Driving License Directive. A 2002 letter from an official in the transport ministry referred to a new written driving theory test introduced in 2001 that was in the process of being implemented throughout France. ${ }^{52}$ A subsequent communication refers to a "major overhaul" of the theory test implemented throughout the country as of mid-2003 (Ministère de l'équipement, des transports et du logement, October 6, 2003). In addition, a 2004 French government Web site describes the new driving theory test in detail. The topics covered by the questions are consistent with the requirements of Annex II of the EU Driving License Directive regarding minimum requirements for written driving tests (Ministère de l'écologie, de l'énergie, de développement durable et de la mer [Ministry of Ecology, Energy, Sustainable Development, and the Sea], 2004). Thus, whether implemented by administrative processes or published in official records of government actions, it appears that France finally implemented Article 7(1) of the EU directive by at least 2004.

The 2002 letter mentioned above also refers to initiation of a process to develop a new "practical" test of on-road driving skills, enlisting the assistance of driver training officials at département level. In doing so, the official states: "This reform will also be an opportunity for France to finally transpose the EU Directive 91/439/EEC of 29 July 1991 on driving licenses, as amended by Commission Directive 2000/56/EC of 14 September 2000" (Battle, October 18, 2002). At the time of this letter, case C-85/02 against France had been introduced in the ECJ, although the ruling did not come until March of 2003. However, based on this letter it is clear that within the French government, transposition of the Driving License Directive was seen as not yet completed.

\section{Driver CPC Directive}

\section{Directive 2003/59/EC of the European Parliament and of the Council of $15 \mathrm{July}$ 2003 on the initial qualification and periodic training of drivers of certain road}

\footnotetext{
${ }^{52}$ Presumably, the content of this new theory test was documented in the three elusive Annexes that were to follow publication of the Driver's License Order of 1999.
} 


\section{vehicles for the carriage of goods or passengers, amending Council Regulation (EEC) No 3820/85 and Council Directive 91/439/EEC and repealing Council Directive 76/914/EEC}

The "Driver CPC Directive" covers requirements for qualification and training of drivers of C, $\mathrm{D}$, and $\mathrm{E}$ category vehicles. Licensing requirements for these drivers are handled separately within the Driving License Directive, while qualification and training requirements are handled by Directive 2003/59/EC. Within a given member state, the requirements apply to nationals of that state, as well as third-country nationals employed by a business based in another member state [Article 1]. This directive requires member states to implement systems for initial qualification that will lead to a Certificate of Professional Competence (CPC) for individual drivers. Member states may elect to qualify drivers through tests only (written and on-the-road), or through class attendance combined with tests [Article 3] (Commission of the European Communities, September 10, 2003).

Table 4-3. French transposition of Driver CPC Directive (2003/59/EC)

\begin{tabular}{|c|c|}
\hline EU & ions \\
\hline $\begin{array}{l}\text { ) CPC awarded on the basis of course attendance and a test: } \\
\text { accordance with Article } 3(1) \text { (a)(i), Member States shall } \\
\text { equire trainee drivers to attend courses in a training centre } \\
\text { pproved by the competent authorities in accordance with } \\
\text { ection } 5 \text { of Annex I,* hereinafter referred to as 'approved } \\
\text { aining centre'. These courses shall cover all the subjects } \\
\text { ferred to in section } 1 \text { of Annex I.** } \\
\text { ) CPC awarded on the basis of tests: In accordance with } \\
\text { rticle } 3(1)(\text { a)(ii), Member States shall require trainee drivers } \\
\text { pass the theoretical and practical tests referred to in section }\end{array}$ & $\begin{array}{l}\text { Driver Training Decree } 2007 \\
\text { Chapter } 1 \text {. Provisions on the initial qualification } \\
\text { Article } 1 \\
\text { Every driver mentioned in item } 4 \text { of Article } 1 \text { of the } \\
\text { Ordinance of } 23 \text { December } 1958^{53} \text { referred to above } \\
\text { must satisfy, prior to entering the profession, the } \\
\text { requirement for initial qualification training, which } \\
\text { includes attendance at a compulsory course and is } \\
\text { sanctioned by passing a final exam. This training can } \\
\text { be long or accelerated. } \\
\text { Article } 2 \\
\text { The initial qualification can be obtained after a long } \\
\text { training, } 280 \text { hours at least, leading to a professional } \\
\text { road driving certificate issued by the Minister for } \\
\text { Employment. } \\
\text { Article } 4 \\
\text { The initial qualification can also be obtained after a } \\
\text { training course called accelerated mandatory minimum } \\
\text { training. This training is for a period of } 140 \text { hours at } \\
\text { least. It is delivered on four consecutive mandatory } \\
\text { weeks except when performed as part of a professional } \\
\text { contract. } \\
\text { Chapter III. Common provisions } \\
\text { Article } 13 \\
\text { The agenda and modalities of implementation of } \\
\text { vocational training in the first paragraph of Article } 2 \\
\text { shall be fixed by order of the Minister for Employment. }\end{array}$ \\
\hline
\end{tabular}

\footnotetext{
${ }^{53}$ This ordinance applied primarily to "drivers of vehicles transporting goods whose gross vehicle weight exceeds 3.5 tonnes and passenger vehicles comprising more than eight seats, in addition to the driver" [Article 1(4)]. It exempted a number of categories such as the military, emergency vehicles, and personal-use vehicles, as well as "vehicles carrying material or equipment for use in the profession of their driver, provided that driving the vehicle is not the driver's main activity" [Article 1(4)(g)] (Ministère de travaux publics, December 25, 1958).
} 


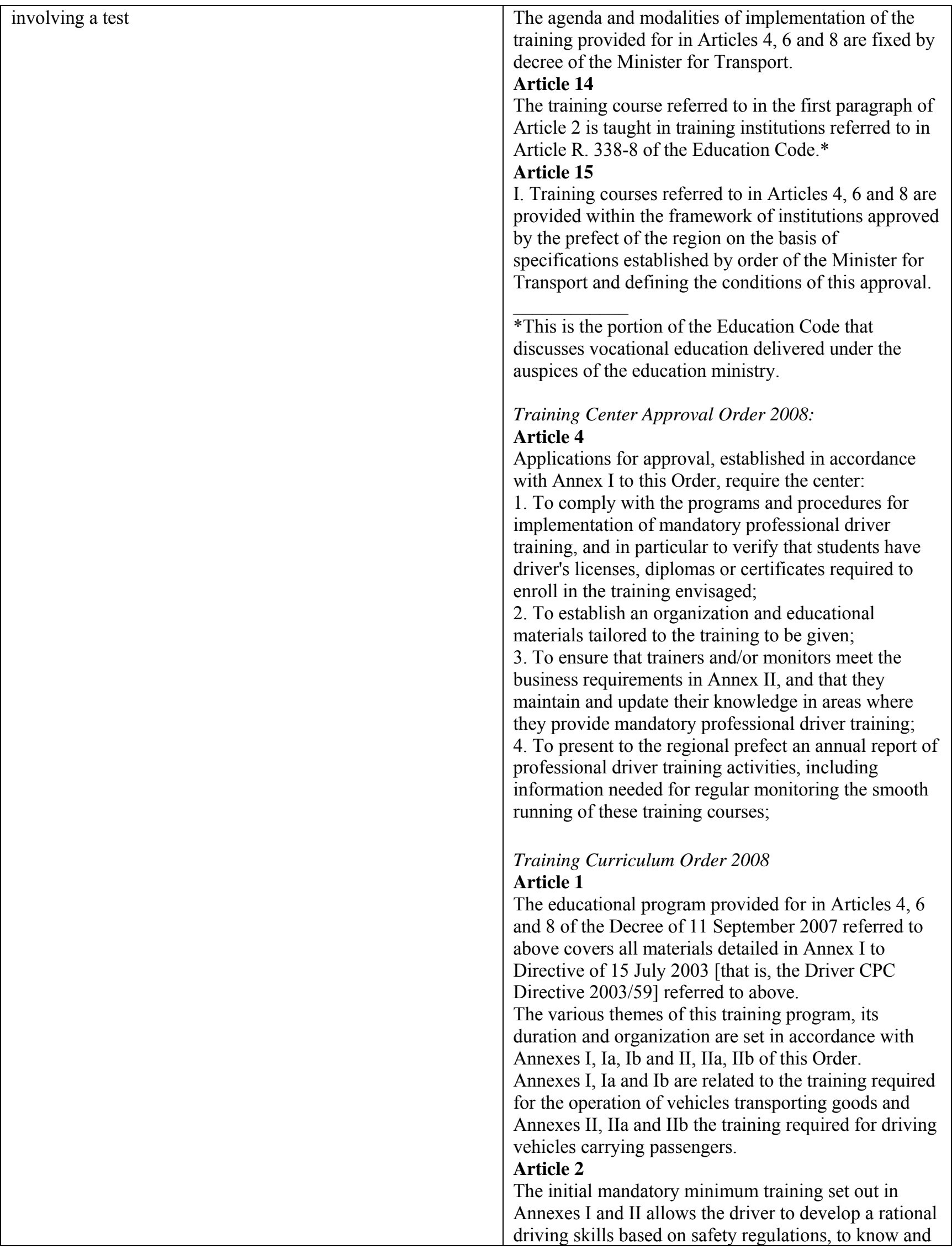




\begin{tabular}{|c|c|}
\hline & $\begin{array}{l}\text { observe the transport regulations and the rules relating } \\
\text { to health, road safety, environmental safety, service } \\
\text { and logistics. } \\
\text { Training Recognition Order } 2008 \\
\text { Article } 1 \\
\text { The list of professional credentials leading to level V } \\
\text { certification as a road driver referred to in Article } 2 \text { of } \\
\text { Decree of } 11 \text { September } 2007 \text { referred to above is } \\
\text { annexed hereto. } \\
\text { APPENDIX } \\
\text { I. For transport of goods: } \\
\text { - Certificate of Professional Aptitude (CAP) road } \\
\text { freight operator; } \\
\text { - Vocational studies certificate (BEP) for driving and } \\
\text { services in road transport; } \\
\text { - Professional Title (TP) as road driver on all vehicles } \\
\text { (CTRMV) issued by the Minister for Employment and } \\
\text { Vocational Training; } \\
\text { - Professional Title (TP) as road freight driver } \\
\text { (CTRMP) issued by the Minister for Employment and } \\
\text { Vocational Training. } \\
\text { II. - For transport of passengers: } \\
\text { - Certificate of Professional Aptitude (CAP) for road } \\
\text { passenger transport; } \\
\text { - Professional Title (TP) for road driving and } \\
\text { interurban passenger transport (CTRIV) issued by the } \\
\text { Minister for Employment and Vocational Training; } \\
\text { - Professional Title (TP) of commercial agent and } \\
\text { driver for urban road transport of passengers } \\
\text { (ACCTRUV) issued by the Minister for Employment } \\
\text { and Vocational Training. }\end{array}$ \\
\hline $\begin{array}{l}\text { Article 7: Periodic training } \\
\text { Periodic training shall consist of training to enable holders of } \\
\text { a CPC as referred to in Article } 6 \text { and the drivers referred to in } \\
\text { Article } 4 * \text { to update the knowledge which is essential for their } \\
\text { work, with specific emphasis on road safety and the } \\
\text { rationalization of fuel consumption. This training shall be } \\
\text { organised by an approved training centre, in keeping with } \\
\text { section } 5 \text { of Annex I.** } \\
\text { *Refers to those with "acquired rights" (those who already } \\
\text { hold a recently-issued category C, D, or E license) } \\
\text { **Annex I, Minimum Qualification and Training } \\
\text { Requirements: Section 5, Approval of the initial qualification } \\
\text { and periodic training }\end{array}$ & $\begin{array}{l}\text { Driver Training Decree } 2007 \\
\text { Chapter II. Provisions related to continuing } \\
\text { education } \\
\text { Article } 8 \\
\text { Every driver mentioned in Article } 1 \text { must complete a } \\
\text { period of mandatory continuing education every five } \\
\text { years, the first stage taking place five years after } \\
\text { obtaining the initial qualification. } \\
\text { Chapter III. Common provisions } \\
\text { Article } 15 \\
\text { I. Training courses referred to in Articles } 4,6 \text { and } 8 \text { are } \\
\text { provided within the framework of institutions approved } \\
\text { by the prefect of the region on the basis of } \\
\text { specifications established by order of the Minister for } \\
\text { Transport and defining the conditions of this approval. } \\
\text { Training Curriculum Order } 2008 \\
\text { Article } 3 \\
\text { Mandatory continuing education stipulated in Annexes } \\
\text { I and IIA allows the driver to start from existing } \\
\text { knowledge and skills to further develop rational driving } \\
\text { skills based on safety rules, and to update his } \\
\text { knowledge of regulation of transport and health, road } \\
\text { safety, environmental safety, service and logistics to }\end{array}$ \\
\hline
\end{tabular}




\begin{tabular}{|l|l|}
\hline & improve his performance in these areas. \\
& Article 4 \\
Additional "bridge" training mentioned in Article 6 of \\
Decree of 11 September 2007 referred to above is \\
defined in Annex Ib and IIb. It allows the driver to \\
acquire or supplement the knowledge and skills \\
necessary for access to the transport sector of \\
passengers or goods by improving rational driving \\
skills based on safety, knowledge, application and \\
compliance with transport regulations and rules \\
relating to health, road safety, environmental and \\
economic organization of the market in the transport \\
sector.
\end{tabular}

France did not meet the EU deadline of September 9, 2006 for transposing the Driver CPC Directive. Its main transposition, the Driver Training Decree of 2007, was enacted slightly more than a year after the EU deadline. Three clarifying arrêtés were issued at ministry level in January and February of 2008. Overall, the French transposition was correct, and exercised the stricter option in Article 6(1) of the Driver CPC Directive that calls for mandatory course attendance following by theoretical and practical driving tests.

France's transposition of the Driver CPC Directive illustrates how an EU directive may be transposed essentially correctly without abandoning an established state-level policy approach. Historically, France's approach to training and certifying professional drivers was distinguished by separate training regimes for work in the goods transport sector and work in the passenger transport sector. Generally, before the Driver CPC Directive came into force, France had issued separate decrees and orders for drivers in each of these sectors. Further, the initial qualification of drivers through the standard 280-hour course was framed as a vocational training matter, with the Education Code referred to in the preamble to the Driver Training Decree of 2007, and was thus housed within the employment ministry rather than the transport ministry. "Refresher" training of currently employed drivers, re-training of drivers to work in a different transport sector, and the accelerated 140-hour initial training course were framed as concerns for the transport industry, and were thus placed under the transport ministry.

In response to requirements to transpose the Driver CPC Directive, France consolidated the training requirements for drivers engaged in goods transport and passenger transport into a single umbrella decree. However, it maintained the two distinct training programs for goods and passenger transport, and it also maintained the historical approach to framing initial training as primarily a matter of vocational training and workplace development, and refresher training as a matter of maintaining skills of current transport industry employees. The Driver Training Decree of 2007 and the arrêtés that followed it consistently segment drivers and their training requirements into four distinct groups, based on the training regimes defined by Articles 2, 4, 6 , and 8 , of that decree:

Under employment ministry:

- Article 2 training: Training of 280 hours duration through which an individual driver obtains initial qualification as a professional driver, and receives a professional road driving certificate after having completed an approved training course and passing an 
exam. This training is delivered through the system of vocational education at lycées des métiers [trades high schools], most of which are publicly-funded and region-based. The student may earn one of a number of certifications that qualify him or her to work in either freight or passenger transport (Ministère de l'éducation nationale, 2010).

\section{Under transport ministry:}

- Article 4 training: Accelerated mandatory minimum training leading to initial qualification of 140 hours duration over hour consecutive weeks, with the same testing procedures as for Article 2 above. Unlike the Article 2 training described above, which takes place in educational institutions, this course is typically taught at a for-profit or company-based training center.

- Article 6: Drivers who have obtained the professional road driving certificate for goods transport may obtain a certificate for passenger transport as long as they can obtain the necessary Class D driving license and attend a 35-hour training course. The same is true for drivers holding a certificate for passenger transport; they may obtain a certificate for goods transport as long as they can obtain a Class $\mathrm{C}$ driving license and attend the appropriate course.

- Article 8: All drivers holding a professional road driving certificate must complete mandatory refresher training of 35 hours duration five years after acquiring the initial qualification.

A limitation of this assessment of the French transposition is that details of the training curricula as implemented were not accessible. The 2008 Training Curriculum Order refers to numerous annexes which provide details of training covered under articles 4,6 , and 8 of the Driver Training Decree of 2007. However, neither the Legifrance database version of the Training Curriculum Order nor the ministry-specific Bulletin Officiel version contains the relevant annexes. The Training Curriculum Order does state that "the educational program provided for in Articles 4, 6 and 8 of the Decree of 11 September 2007 referred to above covers all materials detailed in Annex I to Directive of 15 July 2003 [that is, the Driver CPC Directive 2003/59/EC] referred to above" [Article 1] (Ministère de l'écologie, January 29, 2008). Therefore, it may be concluded that the specific training topics are at least incorporated into French law by reference.

A similar situation exists for the training elements related to Article 2 training, that is, the initial training for professional drivers conducted through the vocational education system. The Driver Training Decree of 2007 charges the employment ministry with implementation of the training agenda and format, but this research yielded no confirmation that the training elements specified in the EU directive have been explicitly transposed into French law. However, it is clear that such training is ongoing, as education ministry sources list vocational schools throughout France that offer this training (Ministère de l'éducation nationale, 2010), and the Training Recognition Order of 2008 lists the various forms of certification that are recognized as meeting the requirements for the initial training discussed in Article 2 of the Driver Training Decree (Ministère de l'écologie, March 29, 2008). In this case, it is again clear that the Driver CPC Directive has been implemented in some fashion, but this research could not assess the quality of the implementation of the training elements specified in Annex I of the EU directive. 


\section{Council Directive 98/76/EC of 1 October 1998 amending Directive 96/26/EC on admission to the occupation of road haulage operator and road passenger transport operator and mutual recognition of diplomas, certificates and other evidence of formal qualifications intended to facilitate for these operators the right to freedom of establishment in national and international transport operations}

Table 4-4. French transposition of Operator CPC Directive (98/76/EC)

\begin{tabular}{|l|}
\hline EU Directive \\
\hline Article 1(2) \\
1. This Directive shall not apply to undertakings \\
engaged in the occupation of road haulage operator by \\
means of motor vehicles or combinations of vehicles the \\
maximum authorised weight of which does not exceed \\
3,5 tonnes. Member States may, however, lower this \\
limit for all or some categories of transport operations. \\
2a. Member States may, after consulting the \\
Commission, exempt from the application of all or some \\
of the provisions of this Directive road haulage \\
undertakings engaged exclusively in national transport \\
operations having only a minor impact on the transport \\
market because of: \\
- the nature of the goods carried, or \\
- the short distance involved.
\end{tabular}

\section{French Regulation}

Goods Transport Operator Decree 1999

TITLE II. OPERATING CERTIFICATES ${ }^{54}$ AND TRANSPORT DOCUMENTS

Article 10

The registration gives rise to the issuance by the regional prefect of one of two types of operating certificates:

a) A Community certificate for vehicles whose permissible maximum weight exceeds 6 tons or whose permissible payload, including the trailer, exceeds 3.5 tonnes;

b) An operating certificate for domestic transport when vehicles do not exceed any of these limits. When the company uses only vehicles that do not exceed 3.5 tonnes maximum permitted weight, the operating certificate for domestic transport shall include the following statement: "transport activity or lease provided exclusively by vehicles that do not exceed 3.5 tonnes maximum permitted weight. » "

\section{TITLE IV. EXEMPTIONS}

Article 17

The provisions of Title I and Title II are not applicable to the following:

1o Transport performed by companies whose transportation is not the main activity and are linked by a contract for the execution of joint work, or sharing a portion of their business under the following conditions:

a) Vehicles owned by these companies or hired by them;

b) The goods transported are the property of either party to the contract;

c) The transportation is necessary to the processing, repair, commission or sales activities of one or the other Contracting Parties ;

d) The transportation is incidental to the

\footnotetext{
54 The original French version reads "titres administratifs" ["administrative titles"]. To eliminate potential confusion, I have chosen to translate this as "operating certificate," since it is clear that this is referring to the certification required to operate a road transport entity.
} 


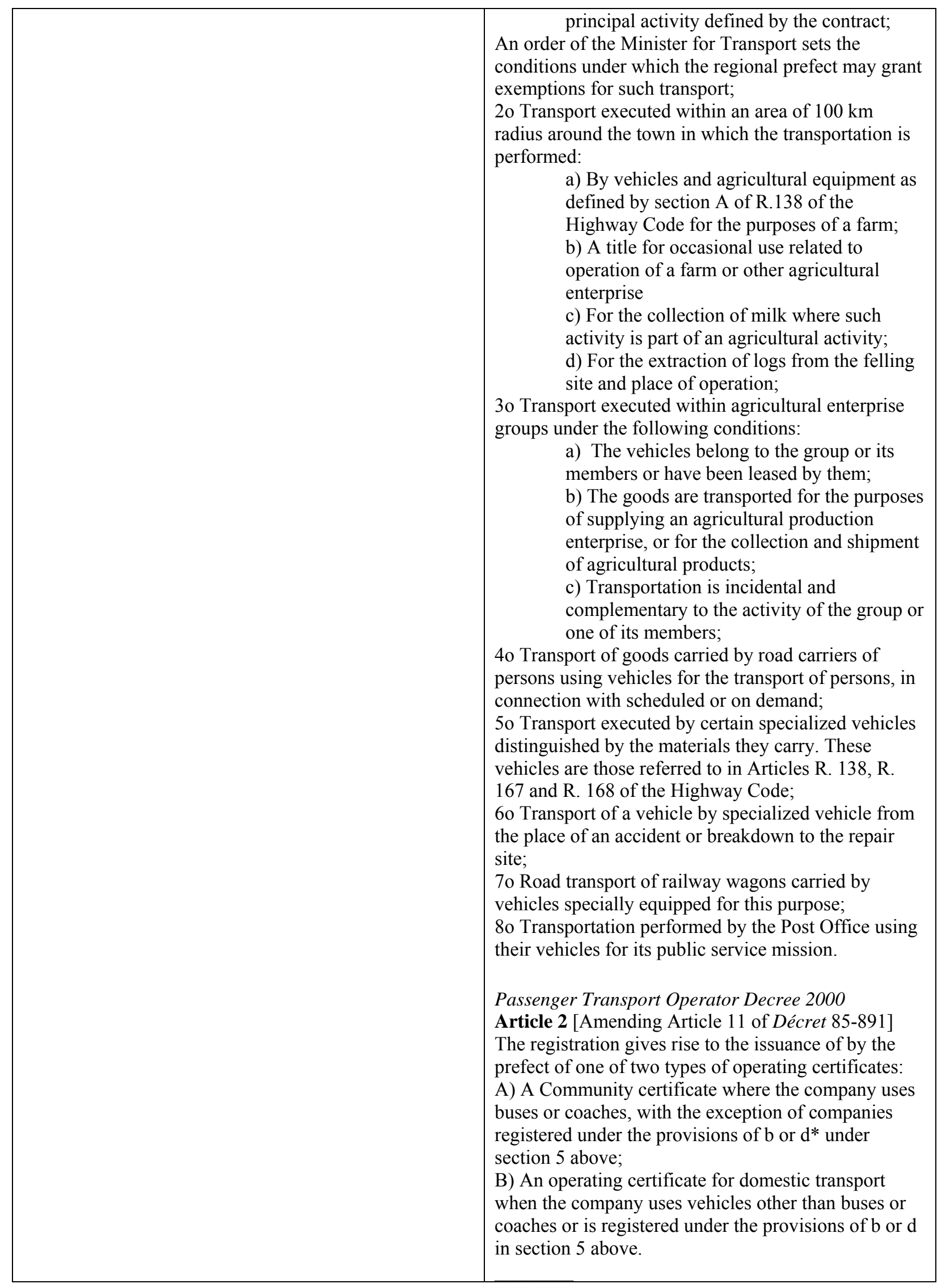




\begin{tabular}{|c|c|}
\hline & $\begin{array}{l}\text { * From Décret } 85-891 \text { : } \\
\text { b) A company that does the work of public road } \\
\text { transport of persons as accessory to a principal } \\
\text { business other than public road transport of people } \\
\text { and has only one vehicle used for this purpose; } \\
\text { d) An authority of local governments providing } \\
\text { transport for non-commercial purposes, with a } \\
\text { maximum of two vehicles. }\end{array}$ \\
\hline $\begin{array}{l}\text { Article 3(1): Undertakings wishing to engage in the } \\
\text { occupation of road transport operator shall: } \\
\text { (a) be of good repute; } \\
\text { (b) be of appropriate financial standing; } \\
\text { (c) satisfy the condition as to professional competence. }\end{array}$ & $\begin{array}{l}\text { Passenger Transport Operator Decree } 1992 \\
\text { Article } 1 \text { [Amending Article } 5 \text { of Décret } 85-891 \text { ] } \\
\text { Companies based in France who are engaged in public } \\
\text { passenger transport should be included in a register } \\
\text { kept by the departmental prefect. } \\
\text { Listing is subject to terms of professional reputation, } \\
\text { financial standing and professional competence } \\
\text { defined in Articles 6, 6-1 and } 7 \text { below. } \\
\text { Goods Transport Operator Decree } 1999 \\
\text { TITLE I. THE PRACTICE OF THE PROFESSION. } \\
\text { CARRIER OR LESSOR. } \\
\text { Section I: Conditions of exercise } \\
\text { Article 1 } \\
\text { Companies providing public transport of freight by } \\
\text { road, moving, or contracted freight transport (with } \\
\text { driver)...must be included the register of carriers and } \\
\text { lessors held by the prefect of the region where they } \\
\text { are located. The registration of carriers and lessors is } \\
\text { subject to terms of professional reputation, financial } \\
\text { standing and professional competence. }\end{array}$ \\
\hline $\begin{array}{l}\text { Article 3(2): Member States shall determine the } \\
\text { conditions which must be fulfilled by undertakings } \\
\text { established within their territory in order to satisfy the } \\
\text { good-repute requirement. They shall provide that this } \\
\text { requirement is not satisfied, or is no longer satisfied, if } \\
\text { the natural person or persons who are deemed to satisfy } \\
\text { this condition under paragraph 1: } \\
\text { (a) have been convicted of serious criminal offences, } \\
\text { including offences of a commercial nature, } \\
\text { (b) have been declared unfit to pursue the occupation of } \\
\text { road transport operator under any rules in force, } \\
\text { (c) have been convicted of serious offences } \\
\text { against the rules in force concerning: } \\
\text { - the pay and employment conditions in the } \\
\text { profession, or } \\
\text { - road haulage or road passenger transport, as } \\
\text { appropriate, in particular the rules relating to drivers' } \\
\text { driving and rest periods, the weights and dimensions of } \\
\text { commercial vehicles, road safety and vehicle safety, the } \\
\text { protection of the environment and the other rules } \\
\text { concerning professional liability. }\end{array}$ & $\begin{array}{l}\text { Goods Transport Operator Decree } 1999 \\
\text { TITLE I. THE PRACTICE OF THE PROFESSION. } \\
\text { CARRIER OR LESSOR. } \\
\text { Section I. Conditions of Exercise } \\
\text { Article } 2 \\
\text { II. - The requirement of professional integrity is not } \\
\text { satisfied when one of the people mentioned in (I)* } \\
\text { above: } \\
\text { Has a previous conviction in a French court entered in } \\
\text { Bulletin No. } 2 \text { of the criminal record, or a similar } \\
\text { conviction in a foreign jurisdiction...resulting in a } \\
\text { disqualification from a profession, trade, or business; } \\
\text { Has a previous conviction mentioned in Bulletin No. } 2 \\
\text { of the criminal record for any of the following } \\
\text { offenses: } \\
\text { a) Offences specified in Articles L. 1, L. 2, L. 4, L. 7, } \\
\text { L. 9, L. 9-1, L. } 12 \text { or L.19 of the Highway Code; } \\
\text { b) Offences specified in Articles L. 125-1, L. 125-3 } \\
\text { [unlawful hiring practices], L. 324-9, L. 324-10 } \\
\text { [hiring “concealed workers"] or L. 341-6 [hiring } \\
\text { illegal foreign workers] of the Labour Code; } \\
\text { [followed by references to various other lois, décrets, } \\
\text { and ordonnances related to business and transport, } \\
\text { dating from the 1940s to the 1990s] } \\
\text { *Refers to owners, shareholders, managing partners, } \\
\text { and board of directors }\end{array}$ \\
\hline
\end{tabular}




\begin{tabular}{|c|c|}
\hline $\begin{array}{l}\text { Article 3(4)(a): The condition relating to professional } \\
\text { competence shall consist in the possession of knowledge } \\
\text { corresponding to the level of training provided for in } \\
\text { Annex I* in the subjects listed therein. It shall be } \\
\text { established by means of a compulsory written } \\
\text { examination which may be supplemented by an oral } \\
\text { examination organised in the form set out in Annex I** } \\
\text { by the authority or body designated for that purpose by } \\
\text { the Member State. }\end{array}$ & $\begin{array}{l}\text { Goods Transport Operator Decree 1999 } \\
\text { TITLE I. THE PRACTICE OF THE PROFESSION. } \\
\text { CARRIER OR LESSOR. } \\
\text { Section I } \\
\text { Conditions of exercise } \\
\text { Article } 4 \\
\text { I. - The requirement of professional competence is } \\
\text { met if the natural person who provides permanent and } \\
\text { effective management of the transport activity or } \\
\text { rental company holds a certificate of professional } \\
\text { competence or, if the company uses exclusively } \\
\text { vehicles not exceeding } 3.5 \text { tonnes maximum weight } \\
\text { allowed, proof of professional competence. } \\
\text { II. - The certificate of professional competence is } \\
\text { issued by the regional prefect for people who have } \\
\text { passed the written examination of professional } \\
\text { competence. A jury chaired by the prefect of the } \\
\text { region is constituted for this purpose. The } \\
\text { examination will assess candidates' knowledge in civil } \\
\text { law, commercial law, employment law, tax law, } \\
\text { business and financial management, market access, } \\
\text { standards and operating techniques, and road safety. } \\
\text { Annexes to Goods Transport Professional } \\
\text { Competence Order 1999 } \\
\text { ANNEX I } \\
\text { List of topics referred to in Article 2: } \\
\text { A. - Elements of Civil Law } \\
\text { B. - Elements of Business Law } \\
\text { C. - Elements of Social Law } \\
\text { D. - Elements of Tax Law } \\
\text { E. - Business and Financial Management } \\
\text { F. - Market Access } \\
\text { G. - Technical Standards and Operations } \\
\text { H. - Road Safety } \\
\text { The candidate must: } \\
\text { 1. Know what qualifications are required for drivers } \\
\text { (driving licenses, medical certificates, certificates of } \\
\text { fitness, etc.). } \\
2 \text {. Be able to implement actions to ensure that } \\
\text { drivers comply with the rules, prohibitions and } \\
\text { restrictions of movement in force in different Member } \\
\text { States (speed limits, priorities, waiting and parking } \\
\text { restrictions, use of lights, road, etc.). } \\
\text { 3. Be able to develop guidelines for drivers on the } \\
\text { verification of safety standards on the one hand, the } \\
\text { condition of transport equipment and loading its } \\
\text { equipment and, secondly, on defensive driving. } \\
\text { 4. Be able to establish operating procedures for } \\
\text { accidents and implement appropriate procedures to } \\
\text { prevent recurrence of accidents or serious traffic } \\
\text { offenses. } \\
\end{array}$ \\
\hline
\end{tabular}




\begin{tabular}{|c|c|}
\hline & $\begin{array}{l}\text { The examination consists of: } \\
\text { - Multiple choice questions covering all subjects listed } \\
\text { in Annex I; } \\
\text { - A section on management and operation of the } \\
\text { enterprise covering all the topics in Annex I, } \\
\text { composed of questions and exercises. The total } \\
\text { duration of the tests is four hours. } \\
\text { Passenger Transport Competence Order } 2003 \\
\text { Article } 3 \\
1 \text {. The examination consists of: } \\
1^{\circ} \text { a questionnaire in the form of multiple choice } \\
\text { questions covering all subjects listed in Annex I; } \\
2^{\circ} \text { a trial on the management and operation of the } \\
\text { enterprise addressing all the knowledge contained in } \\
\text { Annex I, composed of questions and exercises } \\
\text { requiring an answer. } \\
\text { The total duration of the tests is four hours. } \\
\text { The total score is } 200 . \text { It breaks down as follows: } \\
1 \text { Multiple Choice: } 100 \text { points; } \\
2 \text { Responses to written test: } 100 \text { points. } \\
\text { Annex I } \\
\text { [Detailed list of topics under the following headings:] } \\
\text { Legal aspects of business life } \\
\text { Business and financial management of the company } \\
\text { Social Regulation } \\
\text { Professional Regulation } \\
\text { Technical standards and operations } \\
\text { Safety }\end{array}$ \\
\hline $\begin{array}{l}\text { Article 10(1): As from } 1 \text { January 1990, Member States } \\
\text { shall recognize as sufficient proof of professional } \\
\text { competence certificates as referred to in the fourth } \\
\text { subparagraph of Article } 3 \text { (4) which are issued by } \\
\text { another Member State. }\end{array}$ & $\begin{array}{l}\text { Goods Transport Operator Decree } 1999 \\
\text { TITLE I. THE PRACTICE OF THE PROFESSION. } \\
\text { CARRIER OR LESSOR. } \\
\text { Section I } \\
\text { Conditions of exercise } \\
\text { Article } 2 \\
\text { III. Individuals residing in France for less than five } \\
\text { years and whose states of previous residence belong } \\
\text { to the European Union must prove that they met the } \\
\text { requirement of professional integrity as defined by } \\
\text { these states for access to occupation of carrier or } \\
\text { lessor. } \\
\text { Passenger Transport Operator Decree 2007: } \\
\text { Article } 1 \text { [Amending Article } 7 \text { of Décret } 85-891] \\
\text { VII. The professional competence certificates issued } \\
\text { by the competent authorities of other Member States } \\
\text { of the European Union are accepted as sufficient } \\
\text { proof of professional competence. }\end{array}$ \\
\hline $\begin{array}{l}\text { Article 10a: Member States shall provide for systems of } \\
\text { penalties for infringements of the national provisions } \\
\text { adopted in accordance with this Directive and shall take } \\
\text { all the measures necessary to ensure that those penalties } \\
\text { are applied. The penalties thus provided for shall be } \\
\text { effective, proportionate and dissuasive. }\end{array}$ & $\begin{array}{l}\text { Goods Transport Operator Decree } 1999 \\
\text { TITLE V. ADMINISTRATIVE SANCTIONS AND } \\
\text { PENALTIES } \\
\text { Article } 18 \\
\text { Passenger Transport Operator Decree } 2000 \\
\text { Article } 3 \text { [Adding a new Article } 44-1 \text { to Décret 85- } \\
\text { 891] }\end{array}$ \\
\hline
\end{tabular}


[Identical texts in each of the two decrees]

When a violation of provisions relating to transport, working conditions or safety is found, a copy of a finding of infringement shall be addressed to the prefect of the region in which the company concerned is registered.

In view of this, and if the offense is a violation of at least the fifth class, or at least the third class in the event of repeated violations, the prefect may temporarily or permanently withdraw the administrative title held by the enterprise. The decision to permanently withdraw the administrative title can only occur if an initial decision to withdraw administrative titles has occurred during the previous five years.

The decision covers all administrative titles held by the company.

Throughout the duration of the temporary withdrawal of administrative titles of transport, no new administrative title of any kind can be issued to the company.

If the prefect finds that a violation of tort such as those mentioned in Title II Article 2 has been committed after at least a similar offense, he may order the detention of a vehicle or vehicles belonging to the enterprise for a period of three months, at the expense of the company.

The prefect's decision shall specify the place of detention, and the duration and terms of control by agents of the State.

France's transposition of the Operator CPC Directive was complicated by the existence of separate but similar processes for certifying operators of businesses engaged in goods transport and passenger transport. These processes were in place before the Operator CPC Directives 96/26/EC and 98/76/EC were enacted.

For transport of goods, France's initial transposition of the Operator CPC Directive was completed one month in advance of the EU deadline of September 30, 1999 through the Goods Transport Operator Decree. Some of the details required by the EU directive were part of the décret itself. Others were handled at ministry level through the Goods Transport Professional Competence Order and its annexes, issued in November of the same year.

Like the UK, France delegates issuance of Operator CPCs and maintenance of a registry of companies to officials at sub-state level, in this case the préfets [prefects] who are the executives at regional level. The scope of the French transposition is, however, not limited to the scope of the EU directive, and presents an interesting case of the required transposition of an EU directive being accompanied by a clarification of state-level rules in the same policy area but which fall outside the directive's scope. The approach was to incorporate professional competency and registration requirements for transport operators who use only lighter vehicles into the Goods Transport Operator Decree, which is chiefly a transposition of a directive applicable only to 
vehicles with a maximum permitted weight of 3.5 tonnes or more. Article 1 stipulates that any road transport operator must be listed on a register maintained at prefect level, and per the Operator CPC Directive, that any such entity must meet requirements related to professional competence, good repute, and financial standing (see transposition of EU Article 3(1) in Table 44). Article 10 of the Goods Transport Operator Decree distinguishes between a Communitylevel operating permit based on having met standards for operation of vehicles with maximum permitted weight of 3.5 tonnes or more, and a domestic operating permit for companies operating only vehicles below this weight limit (see transposition of EU article 1(2) in Table 4-4). ${ }^{55}$ Article 4 of the Goods Transport Operator Decree goes on to specify the testing necessary for operators who fall under the EU directive to obtain the CPC, but states also that other operators outside the directive's scope must nonetheless provide proof of professional competence. For the latter group required to hold the domestic operating permit, the decree goes on to state that the regional prefect will issue such a permit to persons who have "successfully met verification tests of knowledge, management, regulation of road transport, labor and safety, following a compulsory training organized by a licensed vocational training by the regional prefect" [Article 4(III)] (Ministère de l'équipement, des transports et du logement [Department of Infrastructure, Transport, and Housing], September 2, 1999).

France chose a written exam only to fulfill its CPC testing requirement for operators of both goods and passenger transport companies. A list of subject areas to be covered in the CPC exam, taken verbatim from the Operator CPC Directive, is found in Article 4 of the Goods Transport Operator Decree of 1999. Before the end of 1999, France then issued an arrêté and annexes providing more details about the length and format of the exam (consistent with the Operator CPC Directive). The detailed listing under each of the main topic areas to be covered is again a verbatim transposition of requirements given in Annex I of the EU directive. Transposition of these requirements was considerably slower for passenger transport, with the exam format and the complete list of topic areas not addressed until the Passenger Transport Decree of 2003.

Recognition of CPCs issued by other EU member states is addressed in the Goods Transport Operator Decree, although in somewhat more negative terms than in the Operator CPC

Directive. The French decree states that individuals operating a transport concern who have resided in France for fewer than five years and who formerly resided in another EU member state must provide proof of having obtained an operator CPC in that member state. For passenger transport, the French transposition is more explicit, but did not come until the Passenger Transport Operator Decree of 2007.

With respect to penalties for failure to comply with requirements to obtain an operating permit, the Goods Transport Operator Decree of 1999 and the Passenger Transport Operator Decree of 2000 appear to have correctly transposed the EU requirements. Using identical language, the two decrees state that violation of any of a number of provisions of the Labor and Highway codes, as well as many other statutes related to business and transport, disqualify an individual to hold an operating permit for road transport.

\footnotetext{
${ }^{55}$ In similar fashion, the corresponding regulations for passenger transport do not specify a vehicle weight below which the regulations do not apply. In fact, a 2010 regulation brought taxi services under the professional competence rules for passenger transport.
} 
In sum, France appears to have correctly transposed the Operator CPC Directive into its state law, although somewhat late for some provisions related to passenger transport, and in fact incorporated requirements of the Directive in the service of domestic policy needs.

\section{Road Transport Working Time Directive}

\section{Directive 2002/15/EC of the European Parliament and of the Council of 11 March 2002 on the organisation of the working time of persons performing mobile road transport activities}

Table 4-5. French transposition of Road Transport Working Time Directive (2002/15/EC)

\begin{tabular}{|c|c|}
\hline EU Directive & French Legislation and Regulation \\
\hline $\begin{array}{l}\text { Article 4: Maximum weekly working time } \\
\text { Member States shall take the measures necessary to } \\
\text { ensure that: } \\
\text { (a) the average weekly working time may not exceed } \\
48 \text { hours. The maximum weekly working time may be } \\
\text { extended to } 60 \text { hours only if, over four months, an } \\
\text { average of } 48 \text { hours a week is not exceeded. }\end{array}$ & $\begin{array}{l}\text { Road Freight Transport Working Time Decree } 2002 \\
\text { Article } 1 \\
\text { Item } 3 \text { of Article } 5 \text { of the Decree of } 26 \text { January } 1983 \\
\text { referred to above is replaced by the following provisions: } \\
3 \text { The length of time spent in the service of the employer, } \\
\text { or time of service, of road freight crews is set as follows: } \\
\text { The length of time of service for " long haul" or "long } \\
\text { distance" is fixed at } 43 \text { hours per week or } 186 \text { hours per } \\
\text { month as provided in paragraph } 3 \text { of Article } 4 \text { of this } \\
\text { Decree; } \\
\text { Road Passenger Transport Working Time Decree } 2003 \\
\text { Article } 5 \\
\text { The duration of the actual work may be, under the } \\
\text { provisions of Articles L. } 212-6 \text { and L. } 212-7 \text { of the } \\
\text { Labour Code, extended beyond the limits set by Article } \\
\text { L. } 212-1 \text { of the Code. Beyond a weekly forty-eight } \\
\text { hours, the extension is limited to: } \\
1 \text { Eight hours per week for security measures, backup, or } \\
\text { repair in case of accidents to plant or buildings; } \\
2 \text { Six hours per week for the repair of vehicles. }\end{array}$ \\
\hline $\begin{array}{l}\text { Article 5: Breaks } \\
\text { 1. Member States shall take the measures necessary to } \\
\text { ensure that, without prejudice to the level of } \\
\text { protection provided by Regulation (EEC) No } 3820 / 85 \\
\text { or, failing that, by the AETR Agreement, persons } \\
\text { performing mobile road transport activities, without } \\
\text { prejudice to Article 2(1), in no circumstances work for } \\
\text { more than six consecutive hours without a break. } \\
\text { Working time shall be interrupted by a break of at } \\
\text { least } 30 \text { minutes, if working hours total between six } \\
\text { and nine hours, and of at least } 45 \text { minutes, if working } \\
\text { hours total more than nine hours. }\end{array}$ & $\begin{array}{l}\text { Road Transport Working Time Ordinance } 2004 \\
\text { Article } 4 \text { [modifying Article L. 220-3 of the Labor Code] } \\
\text { On-road employees of trucking companies are entitled to } \\
\text { a break of at least thirty minutes when the total of their } \\
\text { daily work is more than six hours; the pause time is } \\
\text { increased to at least forty-five minutes when the total } \\
\text { time of their daily work more than nine hours. Breaks } \\
\text { may be subdivided into periods of at least fifteen minutes } \\
\text { duration each. The application of these provisions may be } \\
\text { reduced due to breaks because of driving under } \\
\text { Regulation (EEC) No } 3820 / 85 \text { of } 20 \text { December } 1985 \text { on } \\
\text { the harmonization of certain social legislation in transport } \\
\text { by road. } \\
\text { ARTT Passenger Transport Accord of April 18, } 2002 \\
\text { TITLE II : Working time, daily work, breaks, and weekly } \\
\text { rest } \\
\text { Article 9. Night work }\end{array}$ \\
\hline
\end{tabular}




\begin{tabular}{|c|c|}
\hline & $\begin{array}{l}\text { All work between } 9 \text { p.m. and } 6 \text { a.m. is considered night } \\
\text { work. The duration of continuous driving during these } \\
\text { hours cannot exceed } 4 \text { hours. } \\
\text { Urban Passenger Transport Working Time Decree 2006: } \\
\text { Article } 9 \text {. } \\
\text { Any employee whose daily working time exceeds six } \\
\text { hours receives a break of at least twenty minutes...The } \\
\text { break for lunch is at least forty-five minutes. }\end{array}$ \\
\hline $\begin{array}{l}\text { Article 7: Night work } \\
\text { 1. Member States shall take the measures necessary to } \\
\text { ensure that: } \\
\text { - if night work is performed, the daily working time } \\
\text { does not exceed ten hours in each } 24 \text { [hour] period, } \\
\text { - compensation for night work is given in accordance } \\
\text { with national legislative measures, collective } \\
\text { agreements, agreements between the two sides of } \\
\text { industry and/or national practice, on condition that } \\
\text { such compensation is not liable to endanger road } \\
\text { safety. }\end{array}$ & $\begin{array}{l}\text { Road Transport Working Time Ordinance } 2004 \\
\text { Article } 2 \text { [modifying Article L. } 213-11 \text { of the Labor } \\
\text { Code] } \\
\text { II. - The daily work performed by a night worker may not } \\
\text { exceed eight hours in an average period of twenty-four } \\
\text { hours over a reference period defined by agreement or } \\
\text { collective agreement extended or, failing that, by Order in } \\
\text { Council of State made after consultation with trade } \\
\text { unions nationally representative of employers and } \\
\text { employees in industries concerned. } \\
\text { Labor Code } 2008 \\
\text { Book II: Employment Regulations } \\
\quad \text { Title I: Conditions of Work } \\
\quad \text { Chapter III: NIGHT WORK } \\
\text { Article L. 213-3 } \\
\text { The duration of daily work performed by a night worker } \\
\text { may not exceed eight hours. }\end{array}$ \\
\hline $\begin{array}{l}\text { Article 11: Penalties } \\
\text { Member States shall lay down a system of penalties } \\
\text { for breaches of the national provisions adopted } \\
\text { pursuant to this Directive and shall take all the } \\
\text { measures necessary to ensure that these penalties are } \\
\text { applied. The penalties thus provided for shall be } \\
\text { effective, proportional and dissuasive. }\end{array}$ & $\begin{array}{l}\text { Road Transport Working Time Decree } 2007 \\
\text { Article } 11 \text { [Amending Article } 11 \text { of Décret } 83-40 \text { ] } \\
\text { Violations of the provisions of this Decree identified by } \\
\text { the territorial inspectors are subject to the following } \\
\text { penalties: } \\
\text { - Are punishable by a fine for contraventions of the fifth } \\
\text { class infringements of } 5 \text { and } 6 \text { of Article } 5 \text { of this Decree; } \\
\text { - Are punishable by a fine for contravention of the fourth } \\
\text { class breaches of other articles of this decree. } \\
\text { The violations will result in fines of as much as there are } \\
\text { employees improperly used. }\end{array}$ \\
\hline
\end{tabular}

The French Labor Code guarantees a high degree of social partner input into development and implementation of domestic legislation on working time, as well as possible waiver of such legislation via collective agreement. Article L. 212-2 of the Labor Code states:

The decrees set include the development and distribution of working hours, rest periods, conditions of use of penalties, the permanent or temporary exceptions that apply in certain cases and for certain jobs, how to recover lost working hours, and control measures for these various provisions. These decrees are made and revised after consultation with organizations of employers and employees concerned and considering, where appropriate, the results of negotiations between them... These measures may be waived by agreement or collective agreement... (République Française, March 2008). 
France's history of collective bargaining agreements with social partners in the transport industry dates to 1950, with dozens of amendments enacted to date. The agreements are broad in both application and scope. They apply to economic activities such as scheduled intercity passenger transport, sightseeing or charter excursions by bus, long-distance freight transport (domestic or international), ambulance service, transport of school students, local package delivery, and moving of household goods. Their scope includes topics referred to in subsequent EU formulations as "social" aspects of OSH legislation: working time, night work, overtime, health and safety committees, and employment contracts (République Française, 1950).

In 1983, a décret on working hours for workers transporting goods by road incorporated portions of the ever-evolving collective agreement with the social partners (Président de la République Française, January 27, 1983). Like the collective agreement itself, the 1983 décret has seen many amendments, some of which amend only the décret and others which also amend the Labor Code directly. This décret continues to be the foundation for France's working time regulations for the goods-transport industry, and is referred to in the preamble of almost all the recent regulations transposing the EU Road Transport Working Time Directive.

The economically damaging and divisive transport strikes of 1992 may be seen as an "external shock" that changed the terms of engagement between government and the social partners in the transport industry (P. Sabatier \& Weible, 2007). The strikes also spurred public outcry about working conditions for truck drivers; surprisingly, road transport companies also joined in the call for improved working conditions. The intensity of feeling surrounding the strikes that came from inside and outside the labor movement spurred a process of "re-regulation" of the French transport industry. Through re-regulation the process of completing liberalization of the goods transport industry, essentially an economic enterprise, was supplemented by a domestic process that focused on enhancing social regulation (Douillet \& Lehmkuhl, 2001, pp. 102, 114-116; P. Sabatier \& Weible, 2007, pp. 198-199; Stevens, 2004, pp. 212-213).

In 1993, the government responded to the labor unrest in the transport industry by forming a commission led by INRETS director Georges Dobias to study the issues and propose recommendations. In March 1994, the Dobias Commission published its Contrat de progrès pour le transport routier de marchandises [Contract for Progress for the Road Transport of Goods], a blueprint for action which included a recommendation that the social partners undertake a major overhaul of the 1950 collective agreement for road transport (Brodu, Caillat, \& Goutte, 2007; Douillet \& Lehmkuhl, 2001, p. 114). The new collective agreement, concluded on November 23, 1994, created a national tripartite commission to monitor its implementation. A ministerial circular of December 29, 1994 created a parallel organizational structure at regional level (Brodu, et al., 2007).

The 1994 collective agreement provided that in addition to being paid for driving time, drivers were to be paid for time spend loading, unloading, maintaining the vehicle, and completing paperwork, and a amendment several months later stipulated that waiting time was to be counted in calculating work time ${ }^{56}$ (République Française, 1994a, 1995). However, the agreement was

\footnotetext{
${ }^{56}$ The question of whether working time for drivers includes waiting time was apparently contentious EU-wide, and was finally confirmed in the ECJ in a ruling against a British motorcoach company (European Court of Justice, January 18,2001$)$.
} 
not signed by all organizations representative of the industry, leaving the door open for drivers who did not benefit from it to mount strikes in 1996 (Douillet \& Lehmkuhl, 2001, p. 102).

The 1994 collective agreement and its amendments were followed by a series of broad legislative initiatives on working time, which eventually reduced the standard work week for private-sector workers to 35 hours as a measure to reduce unemployment (Falkner, et al., 2005, p. 107). The first of these, the "Robien law," offered employers large cuts in their required social insurance contributions in return for 10 to 15 percent voluntary reductions in hours worked along with corresponding increases in job creation (Askenazy, 2008, p. 3). The Robien law was enacted during the presidency of Jacques Chirac and his conservative Prime Minister Alain Juppé. However, the more sweeping changes came under the Socialist Prime Minister Lionel Jospin, who served from 1997 until 2002. ${ }^{57}$ In 1998, the first "Aubry ${ }^{58}$ law" ("Aubry I") stipulated a 35-hour work week for large firms by 2000 and for smaller firms with fewer than 20 employees by 2002. In 2000, "Aubry II" made permanent the cuts in social insurance contributions enacted under Aubry I for employers that formalized a 35-hour work week through collective bargaining (Askenazy, 2008, pp. 4-6).

Aubry II also tackled employer efforts to manipulate certain categories of working time to artificially achieve a 35-hour work week by excluding "unproductive" periods such as rest breaks, holidays, and training periods from official calculations (Askenazy, 2008, p. 7). Aubry II addressed the issue by defining working time as "time during which the worker is at the employer's disposal and must conform to his orders without being able to take care of personal matters" (Président de la République Française, January 20, 2000). Despite this, it was still possible to circumvent the law's intent (as well as previous more advantageous collective agreements) through modified collective agreements. For example, a number of sectoral agreements, including road transport, allowed a system of "equivalent hours" which excluded time spent waiting for customers. Under the "equivalent hours" regime, work weeks well above 35 hours could be considered "equivalent" to the legal 35-hour week (Askenazy, 2008, p. 7).

The impact of "equivalent hours" on driver working hours in road transport would be considerable, as drivers' work days necessarily include time waiting to be dispatched and waiting for vehicles to be loaded or unloaded (or carrying out this work themselves). Not all drivers were covered by the 1994 collective agreement that counted waiting time as part of working time and required that drivers be paid for that time. Artificially deflating numbers of working hours through the "equivalent hours" system gave the appearance that transport workers were working within the 35-hour regime when in fact they were not. It is possible that with the significant decreases in unemployment of the late 1990 s and early 2000 s related to a general improvement in the economy, the policy imperative to decrease work hours throughout the labor market was lost, creating an environment that was again more accepting of longer hours for transport workers (Askenazy, 2008, pp. 7-9).

Activities surrounding transposition of relevant EU directives have thus been overlaid on longestablished mechanisms for government engagement with employers and labor unions, as well as

\footnotetext{
${ }^{57}$ By one account, these reforms were the culmination of a project envisioned as early as 1981, when the Socialist François Mitterand was elected President (Askenazy, 2008, pp. 2-3).

${ }^{58}$ Named after Martine Aubry, the labor minister in the Lionel Jospin government.
} 
broader partisan domestic debates on working time which affect the entire labor market. Given France's history of engagement with the social partners in transport, most of the topics covered by the Road Transport Working Time Directive had at least been covered in sectoral negotiations, even if the results were not completely congruent with EU requirements. A 1995 amendment to the 1994 collective agreement established separate "joint professional technical chapters" to monitor implementation of the agreement, one for public transport of passengers by road, and the other for transport of goods by road and auxiliary transport activities (République Française, 1994b). In some instances, France has issued separate transport regulations for the goods and passenger transport industries. The reason for the distinction may be the separation of these two branches within collective agreements. In any event, France's transpositions are generally correct for road transport, but incomplete for passenger transport for a number of provisions.

France's transposition of EU provisions for maximum working hours in road transport were accomplished through separate decrees for goods and passenger transport. Notwithstanding the possible avenues for non-compliance discussed above, France's rules for maximum weekly working time were essentially in compliance with the Road Transport Working Time Directive for goods and passenger transport by 2002 and 2003, respectively.

Provisions for rest breaks and night work for the goods transport industry were transposed through the Road Transport Working Time Ordinance of 2004, and in the case of maximum hours of night work were somewhat more protective than the EU directive. This was not the case for the passenger transport industry. Exhaustive searches of Legifrance and other sources yielded no corresponding provisions that were both comprehensive and covered all forms of passenger transport. A provision in a 2002 collective agreement covering passenger transport allows no more than four hours of consecutive driving between 9 p.m. and 6 a.m., but does not specify the length of breaks or the total numbers of permitted work hours at night. Another provision found in a 2006 décret specific to drivers engaged in transport of passengers in urban areas calls for a 20-minute break after six hours of work, and a 45-minute lunch break. In these cases where neither collective agreements nor regulations appear to guarantee that the duration of a night shift is consistent with the EU directive, the default presumably becomes the Labor Code, which limits nighttime work shifts to eight hours. ${ }^{59}$ As to breaks during the work shift, however, the Labor Code contains no blanket provisions that would cover all workers engaged in passenger transport.

Of the provisions of the Road Transport Working Time Directive considered here, only those addressing penalties for infractions of working time regulations do not appear to have been addressed in advance of the EU transposition deadline of March 23, 2005. By 2007, these provisions were transposed for goods transport, but not for passenger transport.

Overall, France's response to transposition of the Road Transport Working Time Directive reflects its history of engagement with the social partners in the transport sector. The resulting collective agreements are clearly considered to have at least a quasi-legal standing, as they are

\footnotetext{
${ }^{59}$ However, the preamble to the 2004 ordinance invokes the more comprehensive EU Working Time Directives 93/104/EC and 2003/88/EC, in addition to an older EU directive (3820/85/EEC) that covers working time for goods and passenger transport. It is possible, therefore, that a subsequent unpublished administrative decision has led to application of the Road Transport Working Time Ordinance of 2004 to transport of passengers as well as goods.
} 
made available through Legifrance along with laws and regulations emanating from government sources. Moreover, the government décrets and arrêtés frequently cite consultations with the social partners as inputs to the regulatory process.

From a purely administrative point of view, transposition was complicated by the practice of amending the government's umbrella agreement with the transport industry via separate agreements with various subsets of the industry. Such agreements were often negotiated separately for road and passenger transport; some were negotiated at levels as specialized as ambulance service or transport of students. It is possible that the incomplete transpositions for the passenger transport industry may be a casualty of this piecemeal approach.

\section{Working Time Directive}

\section{Directive 2003/88/EC of the European Parliament and of the Council of 4 November 2003 concerning certain aspects of the organisation of working time}

Table 4-6. French transposition of Working Time Directive (2003/88/EC)

\section{EU Directive \\ Article 1: Purpose and scope \\ 3. This Directive shall apply to all sectors of activity, both public and private, within the meaning of Article 2 of Directive 89/391/EEC, ${ }^{*}$ without prejudice to Articles 14, 17 , 18 and 19 of this Directive.}

*Article 2(1). This Directive shall apply to all sectors of activity, both public and private (industrial, agricultural, commercial, administrative, service, educational, cultural, leisure, etc.) (Commission of the European Communities, June 26, 1989).

Article 3: Daily rest

Member States shall take the measures necessary to ensure that every worker is entitled to a minimum daily rest period of 11 consecutive hours per 24-hour period.

\section{French Legislation and Regulations}

Aubry I Working Time Act 1998

Article 1 [Adding a new Article L. 212-1 to the Labor Code]

In establishments or occupations mentioned in Article L. $200-1^{*}$ as well as in agricultural, craft, and cooperative establishments and their dependencies, the legal duration of actual work of employees is fixed at thirtyfive hours per week from 1 January 2002. It is fixed at thirty-five hours per week from 1 January 2000 for companies with a workforce of over twenty employees and for economic and social units of more than twenty employees recognized by agreement or decided by the judge unless this number is reached between 1 January 2000 and December 31, 2001.

*Labor Code 2008

Article L. 200-1

Subject to the provisions of this Code are industrial and commercial establishments and their dependencies of any kind, whether public or private, secular or religious, for-profit or charitable, public or corporate offices, or civil societies, professional unions or associations of any nature whatsoever. Also subject to these provisions are establishments where employees are members of the family under the authority of either the father or mother or guardian, even when these establishments are operating on public roads.

Aubry I Working Time Act 1998

Article 6 [Inserting a new Article L. 220-1 as a Preliminary Chapter of Title II, Book II of the Labor Code]

Every employee has a daily rest period of at least eleven 


\begin{tabular}{|c|c|}
\hline & $\begin{array}{l}\text { consecutive hours. } \\
\text { This decree also provides for this provision to be waived } \\
\text { by collective agreement, or in the case of emergency } \\
\text { work due to accident, injury, or exceptional pressure of } \\
\text { work. } \\
\text { Aubry II Working Time Act } 2000 \\
\text { Article } 33 \text { [Amending Article } 997-2 \text { of the Rural Code] } \\
\text { XIII. Every employee has a daily rest period of at least } \\
\text { eleven consecutive hours. } \\
\text { Civil Service Working Time Decree } 2000 \\
\text { Article } 3 \text { - I. } \\
\text { Workers receive a minimum daily rest of eleven hours. }\end{array}$ \\
\hline $\begin{array}{l}\text { Article 4: Breaks } \\
\text { Member States shall take the measures necessary to ensure } \\
\text { that, where the working day is longer than six hours, every } \\
\text { worker is entitled to a rest break, the details of which, } \\
\text { including duration and the terms on which it is granted, shall } \\
\text { be laid down in collective agreements or agreements between } \\
\text { the two sides of industry or, failing that, by national } \\
\text { legislation. }\end{array}$ & $\begin{array}{l}\text { Aubry I Working Time Act } 1998 \\
\text { Article } 6 \text { [Inserting a new Article L. } 220-2 \text { as a } \\
\text { Preliminary Chapter of Title II, Book II of the Labor } \\
\text { Code] } \\
\text { No daily working time can be up to six hours without } \\
\text { the employee having a break for a minimum of twenty } \\
\text { minutes, unless a collective agreement provides for a } \\
\text { longer break. } \\
\text { Aubry II Working Time Act } 2000 \\
\text { Article } 33 \text { [Amending Article } 997-2 \text { of the Rural Code] } \\
\text { XIII. No daily working time can be up to six hours } \\
\text { without the employee having a break of a minimum of } \\
\text { twenty minutes, unless a longer break time is established } \\
\text { by collective agreement. } \\
\text { Civil Service Working Time Decree } 2000 \text { : } \\
\text { Article } 3 \text { - I. } \\
\text { No daily working time can be up to six hours without } \\
\text { the workers receiving a break of a minimum of twenty } \\
\text { minutes. }\end{array}$ \\
\hline $\begin{array}{l}\text { Article 5: Weekly rest period } \\
\text { Member States shall take the measures necessary to ensure } \\
\text { that, per each seven-day period, every worker is entitled to a } \\
\text { minimum uninterrupted rest period of } 24 \text { hours plus the } 11 \\
\text { hours' daily rest referred to in Article } 3 \text {. }\end{array}$ & $\begin{array}{l}\text { Civil Service Working Time Decree 2000: } \\
\text { Article } 3 \text { - I. } \\
\text { Weekly rest, including in principle Sunday, cannot be } \\
\text { less than thirty-five hours. } \\
\text { Public Hospital Working Time Decree 2002: } \\
\text { Article } 6 \\
\text { Workers receive a daily rest period of } 12 \text { consecutive } \\
\text { hours and a minimum weekly rest period of } 36 \\
\text { consecutive hours minimum. The number of rest days is } \\
4 \text { days for } 2 \text { weeks, two of them, at least, to run } \\
\text { consecutively, including one Sunday. }\end{array}$ \\
\hline $\begin{array}{l}\text { Article 6: Maximum weekly working time } \\
\text { Member States shall take the measures necessary to ensure } \\
\text { that, in keeping with the need to protect the safety and health } \\
\text { of workers: } \\
\text { (a) the period of weekly working time is limited by means of } \\
\text { laws, regulations and administrative provisions or by } \\
\text { collective agreements or agreements between the two sides } \\
\text { of industry; } \\
\text { (b) the average working time for each seven-day period, }\end{array}$ & $\begin{array}{l}\text { Aubry I Working Time Act } 1998 \\
\text { Article } 1 \text { [Adding a new Article L. 212-1 to the Labor } \\
\text { Code] } \\
\text { In establishments or occupations mentioned in Article L. } \\
200-1 * \text { as well as in agricultural, craft, and cooperative } \\
\text { establishments and their dependencies, the legal } \\
\text { duration of actual work of employees is fixed at thirty- } \\
\text { five hours per week from } 1 \text { January } 2002 . \text { It is fixed at } \\
\text { thirty-five hours per week from } 1 \text { January } 2000 \text { for }\end{array}$ \\
\hline
\end{tabular}




\begin{tabular}{|c|c|}
\hline including overtime, does not exceed 48 hours. & 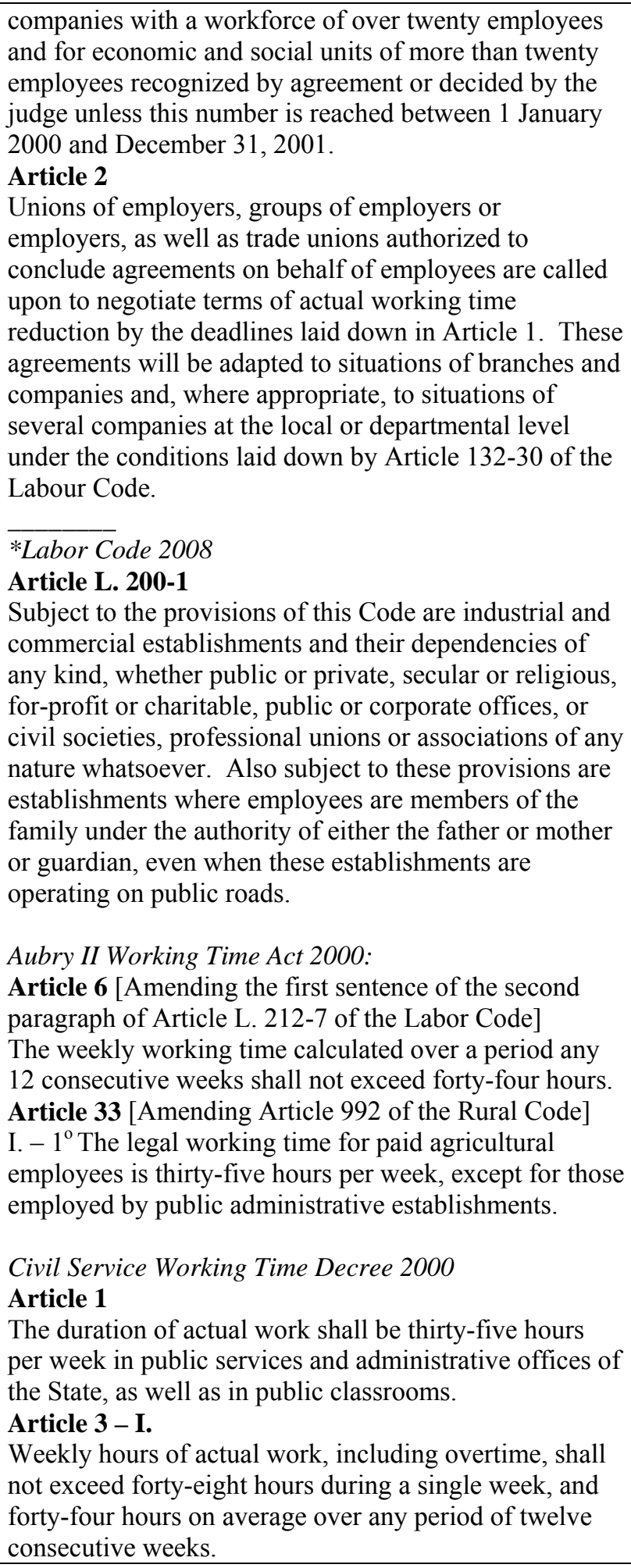 \\
\hline $\begin{array}{l}\text { Article 8: Length of night work } \\
\text { Member States shall take the measures necessary to ensure } \\
\text { that: } \\
\text { (a) normal hours of work for night workers do not exceed an } \\
\text { average of eight hours in any 24-hour period; } \\
\text { (b) night workers whose work involves special hazards or }\end{array}$ & $\begin{array}{l}\text { Labor Code } 2008 \\
\text { Article L. } 213-3 \\
\text { The duration of daily work performed by a night worker } \\
\text { may not exceed eight hours. }\end{array}$ \\
\hline
\end{tabular}




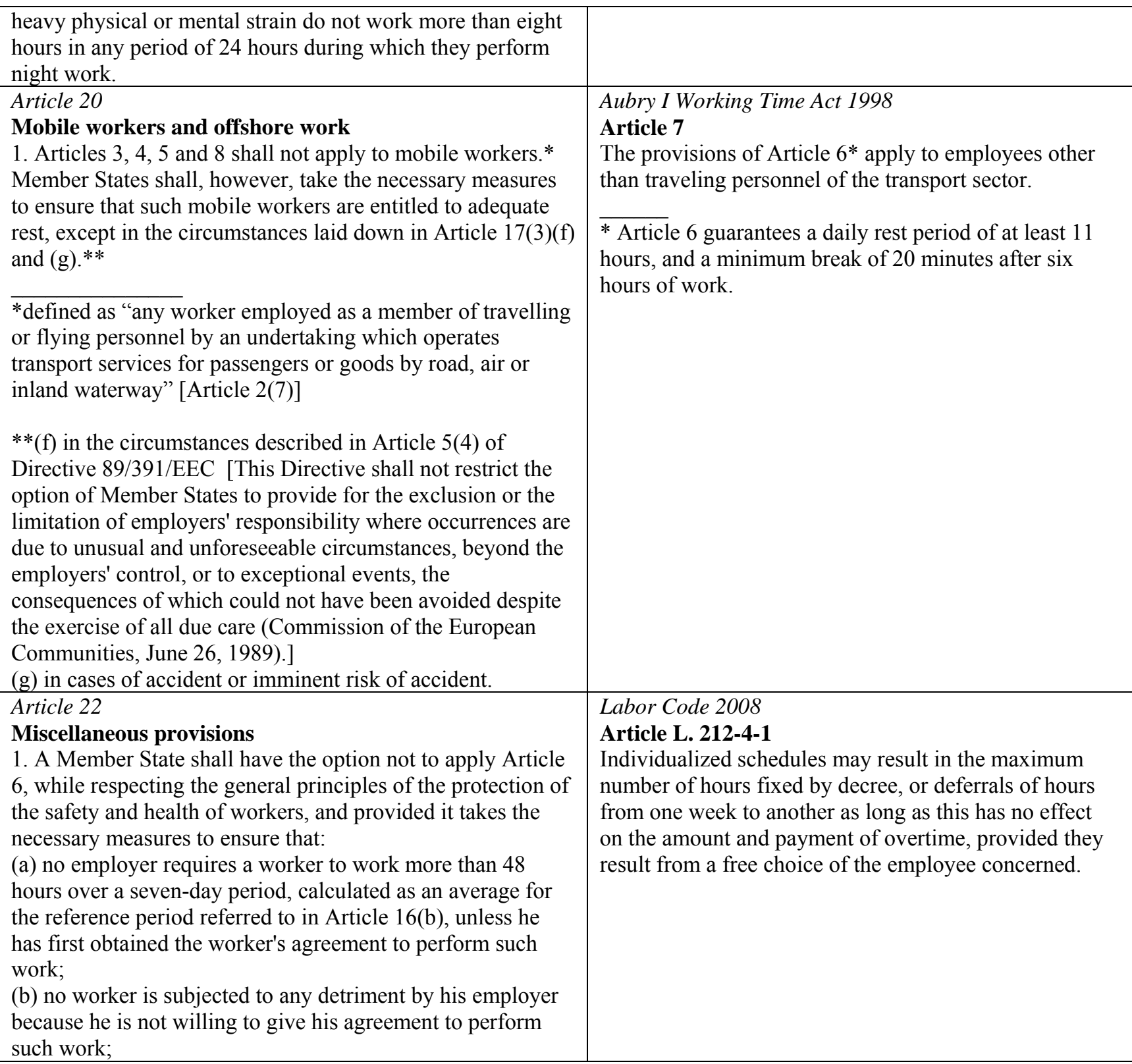

The Labor Code, supplemented by sector-specific collective agreements, provides the foundation for French working time laws. Before the Aubry I and II legislation of 1998 and 2000, France had no history of framework working time legislation to guide development of subsequent sector-specific regulations. The Aubry laws that implemented the 35-hour work week and the "equivalent hours" regime for the private sector were thus remarkable for their scope and effect. $^{60}$

${ }^{60}$ The Aubry laws also served the purpose of remedying deficiencies in France's transposition of the first EU working time directive (93/104/EC), which were the subject of a successful ECJ action against France for failure to transpose provisions related to night work, daily rest, and weekly rest. France did not dispute its failure to transpose, stating that it was in the process of approving legislation that would complete the transposition (i.e., Aubry II) (European Court of Justice, June 8, 2000). 
A number of governmental décrets enacted in the years after the Aubry laws implemented the Aubry provisions for various industry sectors, based on collective agreements with sectoral interest groups. Most of these décrets covered narrowly-defined sectors of the economy such as private residential health care facilities, private hospitals, public hospitals, customs agents, and technical workers in the entertainment industry. The only such measures with wide application covered civil servants (in 2000) and agricultural workers (in Aubry II itself and amending the Rural Code).

Overall, the provisions of the two Aubry laws covered the majority of the transposition requirements assessed for this research. Most of those considered here were done correctly, with varying levels of deviations for some of the transpositions that occurred via sector-based agreements. Of the provisions discussed here, only the transposition of Article 1 of the EU Working Time Directive, the requirement that all sectors of economic activity be covered, was completed through legislation that set the same standard across all industries. This was accomplished through a provision in the Aubry I law that made the 35-hour work week the default for all sectors. This was achieved by incorporating, by reference, the general statement of scope for the entire Labor Code.

In 1998, Aubry I set the statutory maximum work week at 35 hours for private-sector workers, but did not state the upper limits for any possible derogations that might be implemented via collective agreements. Two years later, Aubry II clarified Aubry I by stipulating that the maximum work week, calculated over 12 weeks, could not exceed 44 hours. Aubry II also extended the 35-hour rule to private-sector agricultural workers. Also in 2000, a décret extended the Aubry provisions to public employees, establishing 35 hours as the standard work week. Work hours for a single week were capped at 48, per EU requirements, and consistent with Aubry II, the work week could be extended to average 44 hours over a 12 -week period.

In the years after the Aubry laws were passed, a number of industry-specific collective agreements were concluded. All the agreements identified through this research established a maximum work week of 48 hours, as set by the Working Time Directive. However, some illustrate the application of the "equivalent hours" regime discussed earlier in connection with transposition of the Road Transport Working Time Directive. For example, for customs patrol officers on board ships, one hour of working time was equivalent to forty minutes for the purposes of official calculations of working time (Ministre du budget, October 12, 2007). Clearly, these workers would by definition not be driving motor vehicles during their work shift, but long work hours have also been linked to motor vehicle crashes while commuting to or from work (Barger, et al., 2005).

With respect to night work, France's transpositions are within the bounds of the EU directive. The general provisions in the Labor Code adopt the eight-hour maximum as specified in the EU directive, but offer the permitted derogations from the standard eight-hour shift in exceptional circumstances. In addition, a number of the industry-specific décrets offer similar derogations, some allowing night shifts as long as 12 to 14 hours as long as equivalent compensatory rest is provided (Ministre d'État, January 30, 2007; Ministre de l'emploi et de la solidarité, January 5, 2002; Ministre du travail, August 5, 2007, December 15, 2007). With night work, there are 
again examples of the application of the "equivalent hours" method of calculating official work time. For workers in private residential schools, each period of night work was counted as 45 percent of actual time worked; in other words, a ten-hour shift counted as only 4.5 hours. The worker was paid for the ten hours, but the employer had to count only 4.5 hours toward aggregate hours worked at the facility, and the worker could legally work far more hours than the basic 35 hours (Ministre du travail, August 5, 2007). On the other hand, collective agreements for some industries such as television and film production provided for wage premiums beyond a certain number of hours (République Française, 2006).

France's Labor Code provides for a form of the "individual opt-out" of working time laws allowed under Article 22 of the Working Time Directive. Legislation from1973 shows that individualized work schedules have been accepted for several decades, although it contains no reference to the possibility of an individualized schedule leading to violations of working time laws (Président de la République Française, December 30, 1973).

French working time law addresses Article 20 of the EU directive, which exempts mobile workers from a number of provisions but requires member states to ensure they receive adequate rest. Aubry I confirms that "traveling personnel in the transport sector" are exempt from guarantees of breaks and daily rest, but does not discuss applicability of any other working time provisions to this group of workers. This research found no evidence of regulatory measures implemented to ensure that mobile workers as defined by the European Commission receive adequate rest.

In conclusion, partisan-driven domestic legislation in the form of Aubry I and II, as well as the array of specialized collective agreements for working time, have arguably influenced the recent direction of French working time laws more so than EU directives. In fact, the regulations discussed here as transpositions of the EU Working Time Directive could be more accurately described as domestic implementations of the Aubry laws. The evidence from the body of legislation, regulations, and collective agreements examined here suggests that the French project of implementing the 35-hour work week and associated measures took precedence over any imperative to ensure that state-level law complied with the letter of the directive.

\title{
Seat Belt Directive
}

\author{
Directive 2003/20/EC of the European Parliament and of the Council of 8 April 2003 \\ amending Council Directive 91/671/EEC on the approximation of the laws of the \\ Member States relating to compulsory use of safety belts in vehicles of less than 3,5 \\ tonnes
}


Table 4-7. French transposition of Seat Belt Directive (2003/20/EC)

\begin{tabular}{|c|c|}
\hline EU Directive & French Regulation \\
\hline $\begin{array}{l}\text { Article 2(1)(a)(i): M1, N1, N2 and N3 vehicles: for M1, NI, } \\
\mathrm{N} 2 \text { and } \mathrm{N} 3^{61} \text { vehicles, Member States shall require that all } \\
\text { occupants of vehicles in use shall use the safety systems } \\
\text { provided. }\end{array}$ & $\begin{array}{l}\text { Light Vehicle Seat Belt Decree } 1991 \\
\text { Article } 1 \\
\text { The wearing of seatbelts is compulsory in traffic for } \\
\text { drivers and passengers of motor vehicles with a } \\
\text { permissible maximum laden weight not exceeding } 3.5 \\
\text { tonnes, equipped with safety belts. } \\
\text { Truck Seat Belt Decree } 2003 \\
\text { Article } 1 \\
\text { - Item I of Article R. } 412-1 \text { of the Highway Code is } \\
\text { replaced by the following provisions: } \\
\text { "I. - In traffic, a driver or passenger of a motor } \\
\text { vehicle, except buses and coaches whose gross vehicle } \\
\text { weight exceeds } 3.5 \text { tonnes, must wear an approved } \\
\text { safety belt as long as the seat he occupies is so fitted } \\
\text { under the provisions of Book III." * } \\
\text { *Book III is the section of the Highway Code that } \\
\text { contains vehicle equipment, design, and performance } \\
\text { standards. }\end{array}$ \\
\hline $\begin{array}{l}\text { Article 2(2)(a): M2 and M3 vehicles: Member States shall } \\
\text { require that all occupants aged three and over of M2 and M3 } \\
\text { vehicles in use shall use the safety systems provided while } \\
\text { they are seated. }\end{array}$ & $\begin{array}{l}\text { Bus Seat Belt Decree } 2003 \\
\text { Article } 1 \\
\text { In Article I of R. } 412-1 \text { of the Highway Code, the } \\
\text { words ", except for buses whose gross vehicle weight } \\
\text { exceeds } 3.5 \text { tonnes," are deleted. } \\
\text { Article } 2 \\
\text { In Article I of R. } 412-2 \text { of the Highway Code, the } \\
\text { words ", except for buses whose gross vehicle weight } \\
\text { exceeds } 3.5 \text { tonnes," are deleted, and after the words } \\
\text { "Book III," are inserted the words "and the number of } \\
\text { seats including the driver, does not exceed nine." }\end{array}$ \\
\hline $\begin{array}{l}\text { Article 2(2)(b): passengers in M2 and M3 vehicles [buses] } \\
\text { shall be informed of the requirement to wear safety belts } \\
\text { whenever they are seated and the vehicle is in motion. }\end{array}$ & $\begin{array}{l}\text { Bus Passenger Seat Belt Information Order 2003: } \\
\text { Article } 1 \\
\text { d) For vehicles which are equipped with seat belts in } \\
\text { accordance with the order of December } 5,1996 \\
\text { referred to above, }{ }^{*} \text { passengers are informed of the } \\
\text { requirement to wear the seat belt by at least one of the } \\
\text { following means: } \\
\text { - Symbol of the type shown in the Annex to Directive } \\
91 / 671 / \text { EEC referred to above, prominently displayed } \\
\text { at each seating position in question; } \\
\text { Tab sign in the form set out in Schedule } 8 \text { of this } \\
\text { Order, distributed in the vehicle and visible to all } \\
\text { passengers affected by sitting position. In all cases, a } \\
\text { sign must be placed close to the areas defined in } \\
\text { paragraphs a, b and c above [refers to positions for }\end{array}$ \\
\hline
\end{tabular}

${ }^{61}$ These categories refer to an old system of categorizing motor vehicles which was supplanted by the system now used for EU driving licenses. Essentially, $\mathrm{M}$ and $\mathrm{N}$ vehicles comprise vehicles of any size and weight which are intended to carry goods or passengers and are used primarily on public roadways (Commission of the European Communities, February 23, 1970). 


\begin{tabular}{|l|l|}
\hline & $\begin{array}{l}\text { other signage] and the access stairs. } \\
\text { Any of these information systems can be supplemented } \\
\text { as follows: } \\
\text { - By the driver, the attendant or the person designated } \\
\text { as leader; } \\
- \text { By audiovisual means. } \\
\text { *This order addressed belts and restraint systems, } \\
\text { anchorages for seat belts, the strength of seats and their } \\
\text { anchorages, and head restraints in motor vehicles. }\end{array}$ \\
\hline
\end{tabular}

France was an early adopter of seat belt regulations. The momentum generated by general concern about road safety and the appointment of the National Delegate for Road Safety in 1973 led to the first regulations that same year. The impetus for this policy initiative came from the Delegate, Christian Gerondeau, who became aware of the adoption of seat belt legislation in Australia and commissioned public opinion polls to gauge the likelihood that similar legislation would be accepted in France. He was surprised to discover that 80 percent of citizens who responded were convinced of the safety benefits of seat belts, and a similar percentage was supportive of the government instituting regulations to make belt use compulsory, at least outside urban areas (Gerondeau, 2006, p. 13). An arrêté of June 28, 1973 required belts to be used by all front-seat occupants of private passenger vehicles outside urban areas, and in 1975 this was extended to compulsory use in cities at night. In 1979, compulsory belt use for front-seat occupants of private passenger vehicles was expanded to all roads and all times of day, in 1989 to front-seat occupants of vehicles under 3.5 tonnes, and in 1990 to rear-seat occupants of vehicles under 3.5 tonnes (Observatoire national interministériel de la sécurité routière [National Interministerial Center for Road Safety], 2006, pp. 243-244).

France's Light Vehicle Seat Belt Decree of 1991, which required use of seat belts for all occupants of vehicles weighing less than 3.5 tonnes, had correctly transposed the previous Seat Belt Directive 91/671/EEC, and remained in compliance with the EU Seat Belt Directive 2003/20/EC with respect to provisions for lighter vehicles. The newer Seat Belt Directive was important for occupational driving because it added new requirements for trucks and buses. France lacked such provisions in its state-level law, but transposed the remaining provisions considered here by the end of 2003. The Truck Seat Belt Decree of May 14, 2003 imposed compulsory belt use for trucks, retaining an exception for buses. Less than two months later, the exception for buses was removed, and before the end of 2003, requirements for bus passengers to be informed of the requirement to use seat belts had been added by an arrêté. For France, the extension of seat belt laws to buses was significant because recently enacted state-level manufacturing standards now required buses to be equipped with seat belts. The transport ministry official responsible for road safety reminded regional prefects and police officials of the new requirements through an administrative circular:

The decree of July 9, 2003 ... now requires the wearing of seat belts for the driver and passengers of transit vehicles for people when the seat they occupy is equipped with a belt. In this regard it is noteworthy that all coaches with a maximum permissible gross laden weight (GVW) exceeding 3.5 tonnes, in circulation since 1st October 1999 must be equipped with seat belts (Direction de 
la sécurité et de la circulation routières [Directorate of Safety and Road Traffic], August 5, 2003).

\section{$\underline{\text { Summary and conclusions }}$}

\section{French transposition of EU directives}

Assessment of the French transposition of the six EU directives with relevance for occupational road safety suggests that although there is some evidence supporting Falkner and her colleagues' characterization as France as belonging to the "world of neglect," that is only part of the story. In many ways, France stands as much in the "world of domestic politics," not because there was substantial misfit between the content of EU directives and existing French law, but because French domestic processes and policy initiatives impeded or took precedence over automatic smooth transpositions.

France was notably late in transposing only one of the six directives assessed here. The French transposition of the Driving License Directive was over four years late, with a successful action against France in the ECJ and a few of the elements assessed in this research not necessarily transposed as of this writing. Transposition of the related Driver CPC Directive was about one year late. On the other hand, France's transposition of the Seat Belt Directive, which added new requirements for trucks and buses, was completed within a few months of the issuance of the directive.

Transpositions of the Operator CPC Directive and the Road Transport Working Time Directive were complicated by the fact that France had a history of enacting separate regulations for the goods and passenger transport sectors. For the former, initial transpositions for goods transport were undertaken fairly close to the EU deadlines, but transpositions for the passenger transport industry lagged behind (about four years for some elements).

For the most part, the Aubry laws of 1998 and 2000 took care of transposing the 2003 Working Time Directive in that they completed France's long-overdue transposition of the first Working Time Directive (93/104/EC), in addition to enacting the domestic policy priority of the 35-hour work week. In fact, Aubry II became law just two days before France would have been assessed a fine of $€ 142,000$ for failing to transpose night-work provisions of the first Working Time Directive (Falkner, et al., 2005, p. 108). Further transpositions were enacted through 2007 for a number of industries based on collective agreements, resulting in somewhat looser measures than found in the Aubry law for maximum work week and night work.

With some exceptions, the quality of the French transpositions was generally good, and transposition was reasonably timely except for the Driving License Directive. Rarely do the transpositions give the appearance that portions of EU directives were simply inserted into existing laws or used as the basis for new laws. The transpositions look like French laws with EU rules incorporated, not like EU directives translated into French. Another factor that allows the transpositions to retain their national character is the French practice of transposing directives by amending the codes of law. Many of the transposing décrets and arrêtés consisted of just a 
few lines which amended a single article in a code, and it was not unusual for the individual measures that constituted a transposition to be scattered across multiple codes of law.

\section{The primacy of domestic practices and politics}

Transposition of the Working Time Directive and the Driver CPC Directive show how France addressed EU directives but fit the result to the existing state-level approach. One example is the French practice of developing separate regulatory regimes for transport of goods and passengers, which affected the Operator CPC and Road Transport Working Time directives. The Driver CPC Directive offers another example of adapting an EU directive to a domestic system. The directive did not dictate the venues in which initial driver training was to be conducted, stating only that there needed to be a process for approving such centers. Historically, France had integrated initial training of drivers into its vocational training programs at secondary-school level under the aegis of the employment ministry, while "refresher" training and re-training of more experienced workers were within the purview of the transport ministry. Some of the latter training centers were public and others were private. For all three directives, a complicated system or process necessitated a correspondingly complicated response when it came time to transpose relevant directives. Transposing the Driver CPC Directive required changes in transport, employment, and education regulations, and transposing the Operator CPC and Road Transport Working Time directives took place separately for both the goods and passenger transport sectors in consultation with the peak associations linked to each sector. ${ }^{62}$

While the transposition of the Driver CPC Directive was driven by existing institutional arrangements, transposition of the Working Time Directive through the Aubry laws was a case of a state-level imperative (that is, the Socialist-driven reduction of the work week as a strategy to reduce unemployment) overshadowing an EU imperative. It is difficult to characterize the Aubry I law as anything but enactment of a domestic policy priority under the Socialist Jospin government. That it transposed several provisions of an EU directive seems almost incidental. (Aubry II, on the other hand, kept France from being assessed a substantial fine for nontransposition of the first Working Time Directive.)

\section{Corporatist governance of occupational road safety}

The literature states that French policy for the road transport industry follows the Continental model, reflecting a belief in the need for state intervention that stems from a desire to protect state-level economic interests, and a view of transport as a domestic public good (Kerwer \& Teutsch, 2001a, pp. 129-131; Stevens, 2004, p. 2). This generalization, while it may be true for competition policy, does not hold in the case of safety aspects of policy for the road transport industry, and it is not true at all for safety policy affecting operation of light vehicles in the work setting. Instead, France's overall approach to occupational road safety policy has been to set up corporatist-type governance where the state formalizes the structures and relationships but then engages with the social partners in developing and implementing policy. Three examples may be cited: the corporatist commission set up to monitor the revamped 1994 collective agreement for the road transport industry, the corporatism institutionalized in the structure and functioning of

\footnotetext{
${ }^{62}$ As described earlier, a collective agreement in 1994 was to be implemented separately for each of these two sectors (République Française, 1994b).
} 
CNAMTS/CRAMS interventions in occupational road safety, and the breadth of actors engaged through the Comité de pilotage. Only in exceptional cases such as the 35-hour work week, whose scope extended far beyond the road as a workplace, did a statist and interventionist approach dominate; even then, industries were invited to implement the law through collective agreements.

Evidence of the corporatist approach can be seen in French policy for the road transport industry and for OLVs. For the road transport industry, a history of collective agreements dating to 1950 institutionalized a consultative approach to developing state-level law; once the EU became involved in OSH and transport law, collective agreements also shaped France's responses to relevant EU directives. France also created a corporatist arrangement as part of the Contrat de progrès that followed the transport strikes of 1992 and the revised 1994 collective agreement. This provides further evidence to support an argument that the governance regime for the road transport industry is an exception to the general characterization of the French interest-group system as pluralist, with limited formal access to policymaking accorded the social partners (Douillet \& Lehmkuhl, 2001; Siaroff, 1999).

For lighter occupational vehicles, the placement of prevention services within the social insurance funds almost guaranteed a corporatist approach, given the formal involvement of the social partners in their governance. Employees and employers have a material stake in the funds; therefore, it is natural that they would be full partners in shaping injury prevention programs developed through these funds.

The ACF - Internal and external influences on policy

As the ACF suggests, occupational road safety policy for France is developed and implemented within a subsystem. There is certainly coordination at the policymaking stage, as virtually every piece of legislation or regulation examined for this research cites other relevant nongovernmental actors or government agencies other than the lead agency which were consulted as part of the legislative process.

As demonstrated by the creation of the position of National Road Safety Delegate in 1973, France was early to recognize that road safety spans multiple policy arenas. Similarly, the creation of the interagency Comite de pilotage shows an understanding that actors with both regulatory and non-regulatory roles ought to be engaged in setting policy for occupational road safety. In France, the policy subsystem for occupational road safety also extends to the social insurance agency CNAMTS and the regional CRAMs, thereby reinforcing and strengthening the framing of occupational road safety policy as a matter of concern for the social partners and not simply an area in which the state dictates policy.

The ACF may also be used to discuss the less predictable external impacts on the system which helped create conditions under which policy change in France became possible. The transport strikes of the early 1990s, which in some locations created roadblocks, had a direct effect on the lives of ordinary citizens and led to public concern about working conditions in the transport industry (Douillet \& Lehmkuhl, 2001, p. 114). In response, the government created the Dobias Commission to study the issues and propose solutions; based on the Commission's recommendations, there followed a substantial overhaul of the collective agreement between 
transport workers and industry. In 1997, a change from a conservative to a Socialist government created the conditions necessary for passage of major legislation that reduced the standard work week to 35 hours. Passage of the Aubry laws, long a priority for French Socialists, became possible politically only after conservatives relinquished power and the Socialist Jospin became Prime Minister (Askenazy, 2008, pp. 2-3). The 1998 and 2000 Aubry laws reflected the Socialists' preferred partisan strategy against unemployment: decreasing the number of hours worked so that employers would have to hire more workers. ${ }^{63}$

\section{MLG - More a matter of governance than delegation to sub-state units}

There is some evidence that the management of occupational road risk in France is organized along the lines Type I MLG would suggest. Although France has not created "purpose-built" jurisdictions to implement policy, there are a number of functions that operate at regional level, with general guidance from state level but allowing some discretion for local initiatives. The Labour Inspectorates are organized along regional lines, as are the CRAMs, the regional social insurance funds. The activities of the two organizational structures are complementary. The Labour Inspectorates are responsible for enforcing OSH regulations; the CRAMs work with the social partners to implement voluntary risk assessment and motor vehicle injury prevention programs, emphasizing risks associated with light vehicles not well-covered by OSH or transport safety regulations. At regional level, the work of the inspectorates and CRAMs are linked through coordinating committees (Institut national de recherche et de securité (INRS) [National Research and Safety Institute], 2010). The apparent level of coordination across agencies is noteworthy, considering the placement of the Labour Inspectorates within the labor ministry and the placement of CNAMTS and the CRAMs within the social insurance system. Another example of sub-state governance of occupational road safety is the delegation of authority for approval of operator CPCs to regional prefects. As with the regional coordination between the CRAMs and Labour Inspectorates, this activity is carried out within existing political jurisdictions. Finally, the national commission created to monitor implementation of the 1994 collective agreement for road transport was subsequently replicated at regional level. It is unclear how much sway the commissions hold at either state or regional level; however, it is possible they were organized at regional level to align with related governance structures already in place.

The cooperative arrangements between the French social partners and government just described also serve as examples of Type II MLG in which non-governmental actors work in concert with the government to manage and promote interactions in a policy area, but through policy instruments other than those which would be inherently governmental. Through the risk management activities developed by CNAMTS in cooperation with the CRAMs, the government becomes a promoter of voluntary risk management as a preferred policy instrument that complements regulation. This structure would be better described as "governance" more so than "government," and is consistent with a description of Type II MLG as including "dispersed selfrule on the part of diverse voluntary groups" (Marks \& Hooghe, 2004, p. 22). The involvement

\footnotetext{
${ }^{63}$ The Robien law of 1996 passed under conservative Prime Minister Alain Juppé instituted incentives for job creation through reductions in hours worked put in place by employers. However, this legislation was a neo-liberal policy instrument fundamentally different in tone than the Socialist Aubry laws that followed it.
} 
of the social partners in setting policy through collective agreements may also be cited as an example of non-governmental actors participating in governance.

\section{Limits of diffusion of French policy and practices}

The available evidence suggests that international actors other than the EU have had limited influence on French policy for occupational road safety, and the reverse. The language barrier has thus far been an impediment to the transfer of French policy and practice for occupational road safety beyond the Francophone world. Evidence of this is seen in the limited number of relevant documents provided by Legifrance in any language other than French. Legifrance contains official translations of some of the major codes of law dating to the Napoleonic era, but does not offer translations of more modern codes such as the Highway Code. In addition, French researchers in occupational road safety have rarely published in English-language journals, nor have research institutions such as INRETS regularly translated their reports for wider distribution. English is the language of discourse in the global road safety community, and information on the epidemiology of occupational MVCs in France and injury prevention strategies is largely unavailable to this community. One French interviewee apologized that her agency had not translated more resources into English, but then shrugged and asked, "Why would we?" (Institut national de recherche et de securite (INRS) [National Research and Safety Institute], April 28, 2010).

French subject-matter experts in occupational road safety are, however, beginning to become more engaged with their pan-European colleagues. Much of the progress may be attributed to transnational networks (Keck \& Sikkink, 1998). For example, a researcher at the U.S. National Institute for Occupational Safety and Health and a UK colleague became aware of the considerable unrecognized activity in France, and recommended that other colleagues in the UK and at ETSC try to involve key individuals from French government and NGOs. ${ }^{64}$ This has led to communication between the French and leaders in occupational road safety in the UK, successful efforts on the part of ETSC to bring French experts into its PRAISE program for work-related road safety, greater awareness of French policy and initiatives on the part of European Commission officials, and perhaps most important, more efforts by the French themselves to influence policy at EU level (Caisse nationale de l'assurance maladies des travailleurs salariés - Direction des Risques professionnels (CNAMTS-DRP), April 28, 2010; European Commission Directorate-General Mobility and Transport, May 6, 2010; European Transport Safety Council, May 7, 2010).

Further, there is greater potential for the diffusion of French policy for occupational road safety, as French researchers are just beginning to publish in English-language journals read widely in the occupational safety and road safety communities (Charbotel, Chiron, Martin, \& Bergeret, 2001; Charbotel, Martin, \& Chiron, 2010; Fort, et al., 2010). Barbara Charbotel was lead author or co-author on each of these studies, underscoring the importance of having an individual committed to changing an approach to dissemination of information (Keck \& Sikkink, 1998, pp. 18-22; P. Sabatier, 1998, p. 107).

\footnotetext{
${ }^{64}$ These initiatives were taken by the author of this document and Dr. Will Murray.
} 
Table 4-8. French legislation and regulations related to transposition of selected EU directives for occupational road safety

\begin{tabular}{|c|c|}
\hline French legislation or regulation & ource \\
\hline \multicolumn{2}{|l|}{ Driving License Directive (91/439/EEC) } \\
\hline $\begin{array}{l}\text { Driver's License Decree 1998: } \\
\text { Décret no } 98-1103 \text { du } 8 \text { décembre } 1998 \text { modifiant } \\
\text { certaines dispositions du code de la route relatives au } \\
\text { permis de conduire [Decree No. 98-1103 of } 8 \text { December } \\
\mathbf{1 9 9 8} \text { amending certain provisions of the Highway } \\
\text { Code relating to driving licenses]. }\end{array}$ & $\begin{array}{l}\text { Journal Officiel de la République Française (JORF), } \\
\text { December 9, 1998, n 285, p. 18525. } \\
\text { http://www.legifrance.gouv.fr/affichTexte.do;jsessioni } \\
\underline{\mathrm{d}=593 \mathrm{~F} 1502 \mathrm{CAFD122EDB93D82DFC5FFA4F.tpdjo}} \\
\underline{\text { 04v 1?cidTexte=JORFTEXT000000574105\&categor }} \\
\text { ieLien=id }\end{array}$ \\
\hline $\begin{array}{l}\text { Driver's License Order 1999: } \\
\text { Arrêté du } 8 \text { février } 1999 \text { relatif aux conditions } \\
\text { d'établissement, de délivrance et de validité du permis de } \\
\text { conduire [Order of } 8 \text { February } 1999 \text { concerning the } \\
\text { conditions of establishment, issue and validity of the } \\
\text { license (Version in effect as of December 10, 2010)]. }\end{array}$ & $\begin{array}{l}\text { Journal Officiel de la République Française (JORF), } \\
\text { February 20,1999, n 43, p. } 2675 . \\
\text { http://admi.net/jo/19990220/EQUS9900105A.html }\end{array}$ \\
\hline $\begin{array}{l}\mathrm{Sc} \\
\mathrm{Co} \\
\text { an }\end{array}$ & 4.htm \\
\hline $\begin{array}{l}\text { Medical Conditions Order 2005: } \\
\text { Arrêté du } 21 \text { décembre } 2005 \text { fixant la liste des affections } \\
\text { médicales incompatibles avec l'obtention ou le maintien } \\
\text { du permis de conduire ou pouvant donner lieu à la } \\
\text { délivrance de permis de conduire de durée de validité } \\
\text { limitée [Decree of } 21 \text { December } 2005 \text { establishing the } \\
\text { list of medical conditions incompatible with obtaining } \\
\text { or maintaining the driver's license or give rise to the } \\
\text { issuance of driving licenses of limited validity]. }\end{array}$ & $\begin{array}{l}\text { Journal Officiel de la République Française (JORF), } \\
\text { December 28, 2005, n 301, texte }{ }^{\circ} 113, \mathrm{p} .20098 . \\
\text { http://www.legifrance.gouv.fr/affichTexte.do;jessioni } \\
\text { d=2BF213E7125CDED51AEA3CB64AA95B34.tpdi } \\
\underline{\text { o14v 2?cidTexte=JORFTEXT000000265763\&catego }} \\
\underline{\text { rieLien=id }}\end{array}$ \\
\hline \multicolumn{2}{|l|}{ Driver CPC Directive (2003/59/EC) } \\
\hline $\begin{array}{l}\text { Training Center Approval Order 2008: } \\
\text { Arrêté du } 3 \text { janvier } 2008 \text { relatif à l' agrément des centres } \\
\text { of formation professionnelle habilités à dispenser la } \\
\text { formation professionnelle initiale et continue des } \\
\text { conducteurs du transportroutier of marchandises et de } \\
\text { voyageurs [Order of } 3 \text { January } 2008 \text { concerning the } \\
\text { accreditation of vocational training centers authorized } \\
\text { to provide vocational training and initial training of } \\
\text { drivers transporting goods and passengers by road]. }\end{array}$ & 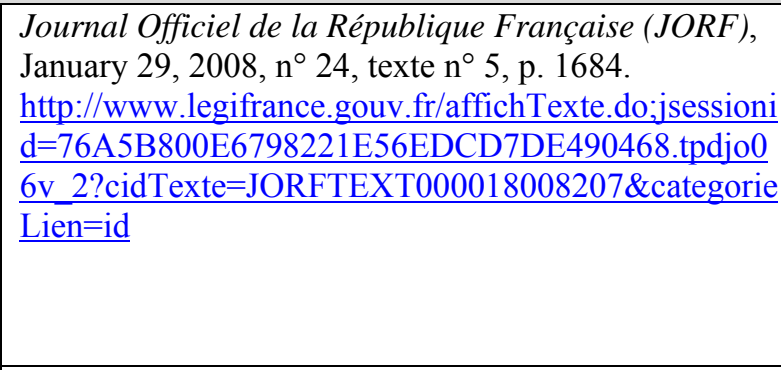 \\
\hline $\begin{array}{l}\text { Training Curriculum Order 2008: } \\
\text { Arrêté du } 3 \text { janvier } 2008 \text { relatif au programme et aux } \\
\text { modalités de mise en œuvre de la formation } \\
\text { professionnelle initiale et continue des conducteurs du } \\
\text { transport routier de marchandises et de voyageurs [Order } \\
\text { of } 3 \text { January } 2008 \text { concerning the program and } \\
\text { procedures for implementation of initial and } \\
\text { continuing vocational training of drivers of road } \\
\text { freight and passengers]. }\end{array}$ & $\begin{array}{l}\text { ciel de la République Française (JORF), } \\
\text { 2008, } \text { n }^{\circ} 24, \text { texte } \mathrm{n}^{\circ} 4 \text {, p. } 1675 . \\
\text { legifrance.gouv.fr/affichTexte.do;jsessioni } \\
\text { 0E6798221E56EDCD7DE490468.tpdjo0 } \\
\text { xte=JORFTEXT000018008166\&categorie }\end{array}$ \\
\hline $\begin{array}{l}\text { Training Recognition Order 2008: } \\
\text { Arrêté du } 26 \text { février } 2008 \text { fixant la liste des titres et } \\
\text { diplômes de niveau V admis en équivalence au titre de la } \\
\text { qualification initiale des conducteurs of certains véhicules } \\
\text { affectés aux transports routiers de marchandises ou de }\end{array}$ & $\begin{array}{l}\text { Journal Officiel de la République Française (JORF), } \\
\text { March 29, 2008, n 75, texte } \mathrm{n}^{\circ} \text { 1, p. 5351. } \\
\text { http://www.legifrance.gouv.fr/affichTexte.do;jsessioni } \\
\mathrm{d}=76 \mathrm{~A} 5 \mathrm{~B} 800 \mathrm{E} 6798221 \mathrm{E} \text { 6EDCD7DE490468.tpdjo0 } \\
\text { 6v 2?cidTexte=JORFTEXT000018501095\&categorie } \\
\text { Lien=id }\end{array}$ \\
\hline
\end{tabular}




\begin{tabular}{|c|c|}
\hline $\begin{array}{l}\text { the list of degrees and diplomas recognized as } \\
\text { equivalent to level } V \text { under the initial qualification for } \\
\text { drivers of certain vehicles for the carriage of road } \\
\text { freight or passengers]. }\end{array}$ & \\
\hline \multicolumn{2}{|l|}{ Operator CPC Directive (98/76/EC) } \\
\hline $\begin{array}{l}\text { Passenger Transport Operator Decree 1992: } \\
\text { Décret no 92-608 du } 3 \text { juillet } 1992 \text { modifiant le décret no } \\
\text { 85-891 du } 16 \text { août } 1985 \text { relatif aux transports urbains de } \\
\text { personnes et aux transports routiers non urbains de } \\
\text { personnes [Decree No. } 92-608 \text { of } 3 \text { July } 1992 \text { amending } \\
\text { Decree No. 85-891 of 16 August } 1985 \text { relating to urban } \\
\text { transport of people and non-urban road transport of } \\
\text { persons]. }\end{array}$ & $\begin{array}{l}\text { Journal Officiel de la République Française (JORF), } \\
\text { July 4, 1992, n }{ }^{\circ} 154, \text { p. 8908. } \\
\text { http://www.legifrance.gouv.fr/affichTexte.do;jsessioni } \\
\mathrm{d}=9 \mathrm{D} 824 \mathrm{AB} 7779334673 \mathrm{FF} 5807 \mathrm{~B} 650458 \mathrm{~B} 2 . \mathrm{tpdjo04} \\
\mathrm{v} \text { 1?cidTexte=JORFTEXT000000357311\&categorie } \\
\underline{\text { Lien=id }}\end{array}$ \\
\hline $\begin{array}{l}\text { Goods Transport Operator Decree 1999: } \\
\text { Décret n } 99-752 \text { du } 30 \text { août } 1999 \text { relatif aux transports } \\
\text { routiers de marchandises [Decree No. 99-752 of } 30 \\
\text { August } 1999 \text { relating to road freight transport]. }\end{array}$ & $\begin{array}{l}\text { Journal Officiel de la République Française (JORF), } \\
\text { September 2, 1999, n 203, p. 13140. } \\
\text { http://www.legifrance.gouv.fr/affichTexte.do;jsessioni } \\
\text { d=A41D4DC407627252A81E63FF61EDA450.tpdjo1 } \\
\text { 0v 2?cidTexte=JORFTEXT000000198352\&categorie } \\
\text { Lien=id }\end{array}$ \\
\hline $\begin{array}{l}\text { Goods Transport Professional Competence Order 1999: } \\
\text { Arrêté du } 17 \text { novembre } 1999 \text { relatif à la délivrance de } \\
\text { l'attestation de capacité professionnelle et du justificatif } \\
\text { de capacité professionnelle permettant l'exercice des } \\
\text { professions de transporteur public routier de } \\
\text { marchandises et de loueur de véhicules industriels avec } \\
\text { conducteur destinés au transport de marchandises } \\
\text { [Decree of } 17 \text { November } 1999 \text { on the issuing of the } \\
\text { certificate of professional competence and proof of } \\
\text { professional competence for the professions of public } \\
\text { road transport of goods and hire of industrial vehicles } \\
\text { with driver for the transport of goods]. }\end{array}$ & $\begin{array}{l}\text { Journal Officiel de la République Française (JORF), } \\
\text { November 30, 1999, n } 277, \text { p. } 17808 . \\
\text { http://admi.net/jo/19991130/EQUT9901444A.html }\end{array}$ \\
\hline $\begin{array}{l}\text { Annexes to Goods Transport Professional Competence } \\
\text { Order 1999: } \\
\text { Annexes à l'arrêté du } 17 \text { novembre } 1999 \text { relatif à la } \\
\text { délivrance de l'attestation de capacité professionnelle et } \\
\text { du justificatif de capacité professionnelle permettant } \\
\text { l'exercice des professions de transporteur public routier } \\
\text { de marchandises et de loueur de véhicules industriels } \\
\text { avec conducteur destinés au transport de marchandises } \\
\text { [Annexes to the Decree of } 17 \text { November } \mathbf{1 9 9 9} \text { on the } \\
\text { issuing of the certificate of professional competence } \\
\text { and proof of professional competence for the } \\
\text { professions of public road transport of goods and hire } \\
\text { of industrial vehicles with driver for the transport of } \\
\text { goods]. }\end{array}$ & $\begin{array}{l}\text { Bulletin Officiel 1999-242, Ministère de l'équipement, } \\
\text { des transports et du logement [Official Gazette of the } \\
\text { Department of Infrastructure, Transport, and } \\
\text { Housing]. } \\
\text { http://www.bulletin-officiel.developpement- } \\
\text { durable.gouv.fr/fiches/BO199924/A2420007.htm }\end{array}$ \\
\hline $\begin{array}{l}\text { Passenger Transport Operator Decree 2000: } \\
\text { Décret no } 2000-1127 \text { du } 24 \text { novembre } 2000 \text { relatif aux } \\
\text { transports routiers de personnes et modifiant le décret no } \\
85-891 \text { du } 16 \text { août } 1985 \text { [Decree No. 2000-1127 of } \mathbf{2 4} \\
\text { November } 2000 \text { on road transport of persons and } \\
\text { amending Decree No. 85-891 of } \mathbf{1 6} \text { August 1985]. }\end{array}$ & $\begin{array}{l}\text { Journal Officiel de la République Française (JORF), } \\
\text { November 25, 2000, } \mathrm{n}^{\circ} 273 \text {, texte } \mathrm{n}^{\circ} 32 \mathrm{p} .18787 . \\
\mathrm{http} / / \text { www.legifrance.gouv.fr/affichTexte.do;jsessioni } \\
\mathrm{d}=9 \mathrm{D} 824 \mathrm{AB} 7779334673 \mathrm{FF} 5807 \mathrm{~B} 650458 \mathrm{~B} 2 . \mathrm{tpdjo} 04 \\
\mathrm{v} \text { 1?cidTexte=JORFTEXT000000219657\&categorie } \\
\text { Lien=id }\end{array}$ \\
\hline $\begin{array}{l}\text { Passenger Transport Competence Order 2003: } \\
\text { Arrêté du } 13 \text { mai } 2003 \text { modifiant l'arrêté du } 20 \text { décembre } \\
1993 \text { relatif à la délivrance de l'attestation de capacité } \\
\text { professionnelle permettant l'exercice de la profession de }\end{array}$ & $\begin{array}{l}\text { Journal Officiel de la République Française (JORF), } \\
\text { June 11, 2003, n }{ }^{\circ} 133 \text {, texte } \mathrm{n}^{\circ} 4 \text {, p. } 13140 . \\
\text { http://www.legifrance.gouv.fr/affichTexte.do;jsessioni } \\
\text { d=B02FB5870F50F1112CBCB135574BA947.tpdjo0 }\end{array}$ \\
\hline
\end{tabular}




\begin{tabular}{|c|c|}
\hline $\begin{array}{l}\text { transporteur public routier de personnes [Order of } 13 \\
\text { May } 2003 \text { amending the Order of } 20 \text { December } 1993 \\
\text { on the issuing of the certificate of professional } \\
\text { competence for the practice of public road passenger } \\
\text { transport]. }\end{array}$ & $\begin{array}{l}\text { 3v 2?cidTexte=JORFTEXT000000419270\&dateText } \\
\text { e=\&oldAction=rechJO\&categorieLien }=\text { id }\end{array}$ \\
\hline $\begin{array}{l}\text { Passenger Transport Operator Decree 2007: } \\
\text { Décret } \mathrm{n}^{\circ} 2007-1743 \text { du } 11 \text { décembre } 2007 \text { modifiant } \\
\text { certaines dispositions relatives aux transports routiers de } \\
\text { personnes [Decree No. 2007-1743 of } 11 \text { December } 2007 \\
\text { amending certain provisions relating to road } \\
\text { passenger transport]. }\end{array}$ & $\begin{array}{l}\text { Journal Officiel de la République Française (JORF), } \\
\text { December 14, 2007, n }{ }^{\circ} 290, \text { texte } \mathrm{n}^{\circ} 1, \mathrm{p} .20186 . \\
\text { http://www.legifrance.gouv.fr/affichTexte.do?cidText } \\
\text { e=JORFTEXT000017644036\&dateTexte= }\end{array}$ \\
\hline \multicolumn{2}{|l|}{ Road Transport Working Time Directive (2002/15/EC) } \\
\hline $\begin{array}{l}\text { ARTT Passenger Transport Accord 2002: } \\
\text { ARTT accord du } 18 \text { avril } 2002 \text { [ARTT Accord of April } \\
\text { 18, 2002]. Annex to: Convention collective nationale des } \\
\text { transports routiers et activités auxiliaires du transport du } \\
21 \text { décembre } 1950 \text { [National collective agreement on } \\
\text { road transport and auxiliary transport activities of } \\
\text { December 21, 1950]. }\end{array}$ & $\begin{array}{l}\text { Paris: Legifrance. } \\
\text { http://www.legifrance.gouv.fr/affichIDCC.do?idArticl } \\
\text { e=KALIARTI000005850158\&idSectionTA=KALISC } \\
\text { TA000005723512\&cidTexte=KALITEXT000005679 } \\
\text { 055\&idConvention=KALICONT000005635624\&date } \\
\text { Texte=29990101 }\end{array}$ \\
\hline $\begin{array}{l}\text { Road Freight Transport Working Time Decree 2002: } \\
\text { Décret } n^{\circ} 2002-622 \text { du } 25 \text { avril } 2002 \text { relatif à la durée du } \\
\text { travail dans les entreprises de transport routier de } \\
\text { marchandises [Decree No. 2002-622 of } 25 \text { April } 2002 \text { on } \\
\text { working hours in companies with road freight]. }\end{array}$ & $\begin{array}{l}\text { Journal Officiel de la République Française (JORF), } \\
\text { April 28, 2002, }{ }^{\circ} \text { 100, texte } \mathrm{n}^{\circ} \text { 36, p. 7784. } \\
\text { http://www.legifrance.gouv.fr/affichTexte.do;jsessioni } \\
\mathrm{d}=\mathrm{C} 3948 E F 7 A 91 B 7 D B B 0 F B 5 A 38 C 45271407 . t p d j o 1 \\
\text { 4v 2?cidTexte=JORFTEXT000000407433\&dateText } \\
\text { e=\&oldAction=rechJO\&categorieLien=id }\end{array}$ \\
\hline $\begin{array}{l}\text { Road Passenger Transport Working Time Decree 2003: } \\
\text { Décret } \mathrm{n}^{\circ} 2003-1242 \text { du } 22 \text { decembre } 2003 \text { relatif à la } \\
\text { durée du travail dans les entreprises de transport routier } \\
\text { de personnes [Decree No. 2003-1242 of } 22 \text { December } \\
\text { 2003 on working time in road transport } \\
\text { undertakings]. }\end{array}$ & $\begin{array}{l}\text { Journal Officiel de la République Française (JORF), } \\
\text { December 24, 2003, n 297, texte } \mathrm{n}^{\circ} \text { 38, p. 22080. } \\
\text { http://www.legifrance.gouv.fr/affichTexte.do;jsessioni } \\
\mathrm{d}=\text { DC609006DB044860252EA29A86C7955F.tpdjo0 } \\
\text { 4v 3?cidTexte=JORFTEXT000000416669\&dateText } \\
\text { e=\&oldAction=rechJO\&categorieLien=id }\end{array}$ \\
\hline $\begin{array}{l}\text { Road Transport Working Time Ordinance 2004: } \\
\text { Ordonnance } \mathrm{n}^{\circ} 2004-1197 \text { du } 12 \text { novembre } 2004 \text { portant } \\
\text { transposition de directives communautaires et modifiant } \\
\text { le code de travail en matière d'aménagement du temps de } \\
\text { travail dans le secteur des transports [Ordinance No. } \\
\text { 2004-1197 of } 12 \text { November } 2004 \text { concerning the } \\
\text { transposition of EU directives and amending the } \\
\text { Labour Code on working time arrangements in the } \\
\text { transport sector]. }\end{array}$ & $\begin{array}{l}\text { Journal Officiel de la République Française (JORF), } \\
\text { November 14, 2004, n 265, texte }{ }^{\circ} \text { 26, p. } 19195 . \\
\text { http://www.legifrance.gouv.fr/affichTexte.do;jsessioni } \\
\mathrm{d}=\text { C3948EF7A91B7DBB0FB5A38C45271407.tpdjo1 } \\
\text { 4v 2?cidTexte=JORFTEXT000000445476\&dateText } \\
\text { e=\&oldAction=rechJO\&categorieLien=id }\end{array}$ \\
\hline $\begin{array}{l}\text { Urban Passenger Transport Working Time Decree 2006: } \\
\text { Décret } \mathrm{n}^{\circ} 2006-925 \text { du } 19 \text { juillet } 2006 \text { relatif à la durée du } \\
\text { travail dans les entreprises de transport public urbain de } \\
\text { voyageurs [Decree No. 2006-925 of } 19 \text { July } 2006 \\
\text { concerning working time in companies engaged in } \\
\text { public transport of passengers in urban areas]. }\end{array}$ & $\begin{array}{l}\text { Journal Officiel de la République Française (JORF), } \\
\text { July 28, 2006, n }{ }^{\circ} 173 \text {, texte }{ }^{\circ} \text { 32, p. } 11259 . \\
\text { http://www.legifrance.gouv.fr/affichTexte.do;jsessioni } \\
\text { d=D75D4A92589507A5961882273108F507.tpdjo05v } \\
\text { 1?cidTexte=JORFTEXT000000423284\&categorieLi } \\
\text { en=id }\end{array}$ \\
\hline $\begin{array}{l}\text { Road Transport Working Time Decree 2007: } \\
\text { Décret } n^{\circ} 2007-13 \text { du } 4 \text { janvier } 2007 \text { relatif à la durée du } \\
\text { travail dans les entreprises de transport routier de } \\
\text { marchandises [Decree No. 2007-13 of January } \mathbf{4 , 2 0 0 7} \\
\text { on working hours in companies with road freight]. }\end{array}$ & $\begin{array}{l}\text { Journal Officiel de la République Française (JORF), } \\
\text { January 5, 2007, }{ }^{\circ} 4 \text {, texte } \mathrm{n}^{\circ} \text { 14, p. } 179 . \\
\text { http://www.legifrance.gouv.fr/affichTexte.do;jsessioni } \\
\text { d=C3948EF7A91B7DBB0FB5A38C45271407.tpdjo1 } \\
\text { 4v 2?cidTexte=JORFTEXT000000820425\&dateText } \\
\text { e=\&oldAction=rechJO\&categorieLien=id }\end{array}$ \\
\hline \multicolumn{2}{|l|}{ Working Time Directive (2003/88/EC) } \\
\hline $\begin{array}{l}\text { Aubry } \\
\text { LOI } \mathrm{n}\end{array}$ & $\begin{array}{l}\text { Journal Officiel de la République Française ( } \\
\text { June } 14,1998, n^{\circ} 136 \text {, texte } n^{\circ} 100, \text { p. } 9029 .\end{array}$ \\
\hline
\end{tabular}




\begin{tabular}{|c|c|}
\hline $\begin{array}{l}\text { d'incitation relative à la réduction du temps de travail (1) } \\
\text { [LAW No. 98-461 of June 13, 1998: Guidance and } \\
\text { incentives on the reduction of working time (1)]. }\end{array}$ & $\begin{array}{l}\frac{\mathrm{http} / / \text { www.legifrance.gouv.fr/affichTexte.do;jsessioni }}{\mathrm{d}=76 \mathrm{~A} 5 \mathrm{~B} 800 \mathrm{E} 6798221 \mathrm{E} 56 \mathrm{EDCD} 7 \mathrm{DE} 490468 . \text { tpdjo00 }} \\
\text { 6v 2?cidTexte=JORFTEXT000000558109\&categorie } \\
\text { Lien=id }\end{array}$ \\
\hline $\begin{array}{l}\text { Aubry II Working Time Act 2000: } \\
\text { Loi n }{ }^{\circ} 2000-37 \text { du } 19 \text { janvier } 2000 \text { relative à la réduction } \\
\text { négociée du temps de travail (1) [Act No. 2000-37 of } \\
\text { January 19, } 2000 \text { on the negotiated reduction of } \\
\text { working time (1)]. }\end{array}$ & $\begin{array}{l}\text { Journal Officiel de la République Française (JORF), } \\
\text { January 20, 2000, }{ }^{\circ} 16, \text { texte } \mathrm{n}^{\circ} 2, \mathrm{p} .975 . \\
\text { http://legifrance.gouv.fr/affichTexte.do;jsessionid }=97 \\
\text { 7488ADED24F60C2324DC255B17DB9C.tpdjo07v } \\
\text { 3?cidTexte=JORFTEXT000000398162\&categorieLie } \\
\mathrm{n}=\mathrm{id}\end{array}$ \\
\hline $\begin{array}{l}\text { Civil Service Working Time Decree } 200 \\
\text { Décret } \mathrm{n}^{\circ} 2000-815 \mathrm{du} 25 \text { août } 2000 \mathrm{rel} \\
\text { l'aménagement et à la réduction du tem } \\
\text { la fonction publique de l'État [Decree } \\
\text { August } 2000 \text { relating to the developm } \\
\text { reduction of working time in the pub } \\
\text { State]. }\end{array}$ & 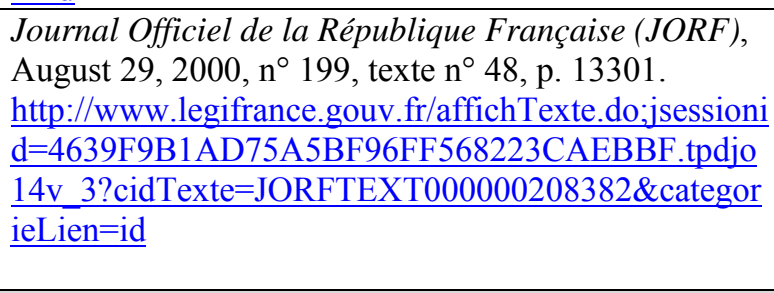 \\
\hline \multicolumn{2}{|l|}{ Seat Belt Directive (2003/20/EC) } \\
\hline $\begin{array}{l}\text { difiant } \\
\text { ecree No. 91- } \\
\text { in }\end{array}$ & $\begin{array}{l}\text { Journal Officiel de la République Française (JORF), } \\
\text { December 29, 1991, n 303, p. } 297 . \\
\text { http://www.legifrance.gouv.fr/affichTexte.do;jsessioni } \\
\text { d=7375BF2CFE993D860AAED7F43E6C9764.tpdjo0 } \\
\text { 7v_1?cidTexte=JORFTEXT000000355984\&categorie } \\
\text { Lien=id }\end{array}$ \\
\hline $\begin{array}{l}\text { Truck Seat Belt Decree 2003: } \\
\text { Décret } \mathrm{n}^{\circ} 2003-440 \mathrm{du} 14 \text { mai } 2003 \text { relatif à l'extension } \\
\text { de l'obligation du port de la ceinture de sécurité aux } \\
\text { occupants des poids lourds et modifiant le code de la } \\
\text { route [Decree No. 2003-440 of } 14 \text { May } 2003 \text { concerning } \\
\text { the extension of the compulsory wearing of seat belts } \\
\text { for occupants of trucks and amending the Highway } \\
\text { Code]. }\end{array}$ & $\begin{array}{l}\text { Journal Officiel de la République Française (JORF), } \\
\text { May 17, 2003, n }{ }^{\circ} 114 \text {, texte }{ }^{\circ} 17, \text { p. 8494. } \\
\text { http://www.legifrance.gouv.fr/affichTexte.do;jsessioni } \\
\text { d=A7EBAB3628D297E92A662B4AD3D1C998.tpdjo } \\
\text { 07v 1?cidTexte=JORFTEXT000000421201\&categor } \\
\text { ieLien=id }\end{array}$ \\
\hline $\begin{array}{l}\text { Bus Seat Belt Decree 2003: } \\
\text { Décret n }{ }^{\circ} 2003-637 \text { du } 9 \text { juillet } 2003 \text { relatif à l'extension } \\
\text { de l'obligation du port de la ceinture de sécurité aux } \\
\text { occupants des autobus et autocars et modifiant le code de } \\
\text { la route [Decree No. 2003-637 of } 9 \text { July } 2003 \\
\text { concerning the extension of the compulsory wearing of } \\
\text { seat belts for occupants of buses and to amend the } \\
\text { Highway Code]. }\end{array}$ & $\begin{array}{l}\text { Journal Officiel de la République Française (JORF), } \\
\text { July 10, 2003, n } 158, \text { texte n }{ }^{\circ} 25, \text { p. } 11716 \text {. } \\
\text { http://www.legifrance.gouv.fr/affichTexte.do;jsessioni } \\
\text { d=A7EBAB3628D297E92A662B4AD3D1C998.tpdjo } \\
\text { 07v 1?cidTexte=JORFTEXT000000604450\&categor } \\
\text { ieLien=id }\end{array}$ \\
\hline $\begin{array}{l}\text { Bus Passenger Seat Belt Information Order 2003: } \\
\text { Arrêté du } 16 \text { décembre } 2003 \text { modifiant l'arrêté du } 2 \text { juillet } \\
1982 \text { relatif aux transports en commun de personnes } \\
\text { [Order of } 16 \text { December } 2003 \text { amending the Decree of } 2 \\
\text { July } 1982 \text { on transit of persons]. }\end{array}$ & $\begin{array}{l}\text { Journal Officiel de la République Française (JORF), } \\
\text { January 3, 2004, }{ }^{\circ} 2 \text {, texte } \mathrm{n}^{\circ} \text { 23, p. } 297 . \\
\text { http://www.legifrance.gouv.fr/affichTexte.do;jsessioni } \\
\text { d=A7EBAB3628D297E92A662B4AD3D1C998.tpdjo } \\
\text { 07v 1?cidTexte=JORFTEXT000000431454\&categor } \\
\text { ieLien=id }\end{array}$ \\
\hline
\end{tabular}




\section{Chapter 5. Sweden: Occupational Road Safety as Part of a Larger Vision for Society}

The chapter begins with a review of the sources of Swedish law, major OSH and transport legislation, and agency roles and responsibilities that have influenced the development of occupational road safety policy in Sweden. This is followed by a discussion of a radical statelevel policy change implemented in the mid-1990s, Vision Zero, which shifted the focus of Swedish road safety policy from changing road user behavior to re-designing vehicles and the road system to tolerate human error, thereby eliminating deaths and serious injuries. Next, I review Swedish transposition of EU directives on driver licensing, certificates of professional competence for road transport operators and drivers, working time, and seat belts. In general, I find accurate transpositions consistent with the EU conception of worker protection as an end to be achieved by employers at all costs.

As suggested by the ACF, strong belief systems underpin Swedish policies associated with occupational road safety. Swedish transpositions reflect a holistic, integrative approach to policy making that emphasizes the individual's place as a member of society and addresses larger societal questions. In the case of the Working Time Directive, EU provisions were somewhat in conflict with Sweden's tradition of collective agreements.

The chapter concludes with a discussion of the evidence for and against the research hypotheses. There is limited support for the hypothesis that international actors will influence occupational road safety, and limited evidence of MLG of occupational road safety. Surprisingly, there is little evidence of ongoing interest-group interaction and influence on the responsible Swedish agencies after policies are enacted.

\section{$\underline{\text { Swedish legal instruments }}$}

Sweden's Instrument of Government (SFS 1974:152), one of the country's four Constitutional Acts, stipulates that basic rules about the rights and obligations of citizens must be determined by the Riksdag through legislation in the form of a lag [Act]. A long consultative process precedes introduction of a legislative bill, referred to as a proposition. First, a motion is made by a political party, a member of the Riksdag, the Government, an organization, or even a private individual. The motion is then referred through various expert groups inside and outside government as well as groups affected by the issue. Eventually, the Government sends the resulting proposition to the responsible Riksdag standing committee, which then considers it and issues a report summarizing its deliberations. ${ }^{65}$ In its report, the standing committee either accepts the proposition or makes amendments. The final version of the proposition then goes to the full Riksdag for a vote (Carlson, 2009, pp. 42-43; Hinnfors, 1997, p. 161).

\footnotetext{
${ }^{65}$ Riksdag committee reports have a high degree of legal authoritativeness in Swedish courts, often supplying details not found in the typically generic Acts of the Riksdag (Carlson, 2009, p. 42).
} 
Riksdag legislation may take the form of "framework" acts such as the Work Environment Act of 1977. This Act, like the various EU framework directives, is not necessarily intended to have direct practical application in the workplace. Rather, a framework act lays the foundation for more detailed regulations that will follow, leaving considerable scope for the responsible agency to issue regulations in line with current technical, social, and labor market developments (Arbetsmiljöverket, 2010b).

When enacting legislation, the Riksdag often delegates the authority under which future regulations are to be made. In some cases, this task is entrusted to a government ministry; in other cases, an administration or authority below ministry level is given the authority to develop regulations. For subject areas for which there are no detailed regulations developed, the relevant framework act is the default (Arbetsmiljöverket, 2010b).

After an Act of the Riksdag, the next highest level of Swedish legislation is a förordning [ordinance]. An ordinance is a ministry-level regulation issued by the Government using its power to issue regulations pertaining to enactment of legislation, or where the Riksdag has given it the express authority to issue regulations. The Government is limited to issuing regulations for which the most severe penalty is a fine; only the Riksdag is permitted to impose penalties involving criminal fines or imprisonment (Carlson, 2009, pp. 28-29; European Commission, European Judicial Network in Civil and Commercial Matters, 2010).

At highest levels, Swedish government ministries have relatively few personnel, and there are approximately 400 administrations and authorities under the ministries. This means that while general policy direction, budgetary issues, and long-term targets may be decided at ministry level, the administrations that fall below the ministries often take on roles that go beyond simple execution of ministerial decisions. It is not unusual for administrations such as Trafikverket [the Swedish Transport Administration] or its predecessor Vägverket [the Swedish Road Administration] to take on the "semi-political" tasks of determining broad policy directions and instruments, in addition to working out technical details of policy and implementation (Johansson, 2009, p. 826; Trafikverket, October 6, 2010). Accordingly, substantial regulatory activity is charged the administrations and authorities, who are given this authority by the Government. The resulting agency-level regulations are referred to as föreskrifter [regulations].

Legislative acts passed by the Riksdag are published in the Svensk författningssamling (SFS) [Swedish Code of Statutes], as are the Government ordinances developed at ministry level. The individual authorities and administrations with authority to develop their own regulations publish these in their own statute books.

$\underline{\text { Legislation and institutional structure for road safety }}$

Sweden has had a centralized road agency for over a century and a half. In 1841, oversight for road maintenance, a task that fell mainly to large landowners through whose property the roads ran, was consolidated at central-government level (Montelius, 2007). Sweden's first dedicated road safety agency, Trafiksäkerhetsverket [the Road Safety Authority] was created in 1968. Control of working time for professional drivers was placed within that agency, and the 
emphasis was on compliance with regulations rather than development of strategies to improve road safety (Trafikverket, October 6, 2010).

The 1970s saw substantial progress in reducing road traffic injuries in Sweden, a trend that continued into the 1980s. However, by the mid-to-late 1980s, progress slowed and there were calls for interventions to improve road safety performance in Sweden. At the same time, a movement to reduce government regulation took hold, influenced by the policies of the Reagan administration in the U.S. and the Thatcher government in the UK (Trafikverket, October 6, 2010).

Beginning in 1993, road safety policies were set or implemented by Vägverket, referred to as the Swedish Road Administration or the Swedish National Road Administration. As a result of stagnating road safety performance and uncertainty about the value of a regulatory approach, road safety, which had been relegated to Vägverket with little legislation surrounding it, became a political issue once again. For the technocrats in Vägverket, the early 1990s were spent "chasing after a new approach." A central policy theme was to develop strategies to change road user behaviors, an approach consistent with the prevailing thinking in most high-income countries at this time. This initial behavioral approach was reinforced by the fact that the first head of the road safety unit in Vägverket was trained as a psychologist (Trafikverket, October 6, 2010).

\section{Vision Zero: A radical change in course}

In 1995, Claes Tingvall was appointed as head of Vägverket's road safety unit, which proved to be a "shock" to Swedish transport policy (albeit not an "external shock," as the ACF would suggest). With support and engagement of the new government minister responsible for transport, Ines Uesmann, Dr. Tingvall advocated a radical shift in approach, abandoning the traditional emphasis on changing behaviors of individual road users and replacing it with a new "safe-systems" approach called Vision Zero (Johansson, 2009, p. 826; Trafikverket, October 6, 2010). According to a key informant who has spent two decades within the Swedish road safety bureaucracy, the impetus and conception for Vision Zero came almost exclusively from inside the Swedish government (Trafikverket, October 6, 2010). It is worth noting, however, that some of those involved in the development of Vision Zero came from the academic community, or later moved from public service to academia. Therefore, it is not accurate to say that Vision Zero originated entirely within a closed government policy subsystem, or that government personnel alone have been responsible for its diffusion beyond Sweden.

To a large extent, Vision Zero shifts responsibility for road safety away from the individual road user to designers of the road infrastructure and designers of vehicles. Although road users are expected to follow the rules of the road, designers are responsible for continuing modifications to the road system, as situations in which human error is continuing to lead to crash-related injuries are identified (Johansson, 2009, p. 827). Where traditional road safety approaches had the goal of preventing crashes, Vision Zero has the goal of eliminating death and serious injury. Vision Zero accepts the idea that road users will inevitably make errors; it aims to engineer the road environment and the vehicle such that they are so forgiving of human error that deaths and serious injuries will be eliminated. For example, Swedish car manufacturers were the first to 
install electronic stability control (ESC) technology, which senses instability and automatically takes corrective action. To prevent crashes on two-lane rural roads, Sweden has installed impact-absorbing crash barriers along center lines (Johansson, 2009, p. 829; Lie, 2010).

The adoption of Vision Zero was not purely the result of bureaucratic decision-making and subsequent implementation within Vägverket. On May 22, 1997, Vision Zero was formally introduced in the Riksdag by the Ministry of Enterprise, Energy, and Communications for ratification as a national policy (Sverige Riksdag, 1996/1997). Deliberations were held within the Riksdag's Transport Committee, which subsequently issued its report for consideration by the full Riksdag. Predictably, discussion within the Riksdag covered topics of special interest to individual legislators, for example, the safety of children, motorcycle safety, the need to encourage safer alternate forms of transport, and the negative environmental impacts of transport. In approving the government's proposal on October 9, 1997, the Riksdag made no statutory changes, nor does it appear to have appropriated additional funds for road safety. However, it did endorse the concept of Vision Zero and the pursuit of a systems-based approach for the elimination of deaths and serious injuries on Sweden's roads (Trafikutskottets, 1997/1998).

Shortly after Vision Zero received support in the Riksdag, there followed the first umbrella legislation defining expectations for road users' behavior: the Road Traffic Ordinance 1998 (SFS 1998:1276). Basic provisions stipulate that road users "show care towards children, the elderly, school patrols and the people who it appears have a disability or illness..." [Chapter 2 § 1] (Kommunikationsdepartementet [Ministry of Communications (Sweden)], October 13, 1998). The Ordinance also covers standard rules of the road such as obeying traffic signs and signals, obeying traffic police, yielding to emergency vehicles, exercising caution at intersections, staying at the scene of an accident, maintaining safe distances between vehicles, maintaining safe speeds, yielding to pedestrians, and mandatory use of seat belts. Many of these provisions were not new; this was simply the first time they were brought together in a single piece of legislation. For example, the Ordinance incorporated requirements for seat belt use that have been part of Swedish law since the 1970s. The Road Traffic Ordinance has been amended many times, in some instances to accommodate new requirements specified by EU directives.

Vision Zero was further refined and reinforced by the Tylösand Declaration, which came out of a stakeholder meeting held in 2007. The five articles of the Declaration affirm the right of individuals to use roads without threat to life or health, the right to sustainable mobility, the right to use the road without placing others at risk, the right to information about any potential safety problem within the road transport system, and the right to expect continuous improvement within the road system through corrective actions taken by any entities responsible for safety hazards (Lie \& Tingvall, June 15-18, 2009). The Tylösand Declaration has implications for work-related road safety in that workers are included within the general population of road users who are guaranteed these rights. Further, the third and fifth articles would seem to apply to transport companies that operate large vehicles that have the potential to disproportionately affect the well-being of other road users. These provisions are consistent with Vision Zero's recognition that for companies, road safety is important for protection of the brand name and reputation (Lie, 2010). This philosophy may be a natural consequence of the institutional placement of the 
transport agencies with the Ministry of Enterprise, Energy, and Communications, as well as the linkage of freight and passenger transport to economic well-being.

In a step that had direct impact on worker safety, the Swedish government in 2009 mandated new environmental and traffic safety rules for all vehicles procured for public vehicle fleets. One element of this policy is that by 2012, 75 percent of government-owned vehicles will be equipped with alcohol interlocks ("alcolocks") that prevent a vehicle from starting if the driver is impaired (European Transport Safety Council, 2009). This requirement has been fully implemented at central-government level, and is also applicable to governments at county and municipal level, where implementation is underway (Lie, 2010).

Purchasing standards for vehicles used on official business are continuously updated with an eye to energy efficiency, emissions, and safety. ${ }^{66}$ One provision requires that purchasing decisions be made with consideration to the potential harm to pedestrians associated with different vehicle models, a nod to Sweden's concerns for protecting the larger society (Lie, 2010). In addition, road safety and environmental policy in Sweden are increasingly linked, with environmentally conscious driving covered in all licensing curricula, and environmental degradation linked to excessive speeds (Trafikverket, October 6, 2010).

Although Vision Zero was formulated as a framework for managing the entire transport system, it has implications for the management of road safety within companies and organizations. ${ }^{67}$ Under a traditional approach to road safety, which emphasized efforts to control behavior of individual drivers, the assumption would be that employee drivers are responsible for their own behavior and that the company would not necessarily become involved or suffer repercussions if a serious incident occurred. In this model, the legal sanctions for violations of road traffic rules would affect the driver, and he or she, not the company, would incur fines or other penalties such as loss of license. The contribution of Vision Zero to occupational road safety is its support of a shift of responsibility away from the individual driver to the company or organization that employs the driver. In the same way that Vision Zero sees the road environment as a system that should be forgiving of human error, it also calls for a management system at organizational level that is responsible for modifying the conditions of work such that the potential for road traffic injury is reduced if not eliminated. Having groups of employee drivers operating under common rules and policies in the larger road system would seem to be more efficient than trying to influence behavior of thousands of drivers interacting with the road system as individuals.

In addition to the "safe-system" principle, another theme of Vision Zero is that ethical responsibility is paramount; it should be possible to achieve safety goals without regulation, although regulation can be used to "back things up" (Trafikverket, October 6, 2010). The link to

\footnotetext{
${ }^{66}$ Even rental vehicles for use by government agencies are subject to strict safety standards: a 5-star crash rating through the European New Car Assessment Programme, ESC, and a seat belt reminder for the driver's position (European Transport Safety Council, 2009).

${ }^{67}$ The implications are perhaps more radical for workers who drive light vehicles, who are covered by few occupational safety regulations, than for heavy-vehicle drivers. However, the Vision Zero philosophy can inform policies for both sets of drivers because regulations for heavy-vehicle drivers are not exhaustive in their coverage of safety and operations.
} 
the importance of ethical behavior by organizations in managing road risk for workers, even in the absence of supporting regulation, is obvious.

Today, transport policy for Sweden falls under the Ministry of Enterprise, Energy, and Communications, which is also responsible for economic development, competition policy, management of state-owned enterprises, information technology, energy security, and regional policy. At EU level, this ministry is represented in the Council of Ministers on the Council for Transport, Telecommunications and Energy and the Competitiveness Council (Government Offices of Sweden, 2010).

In April 2010, most of Vägverket's operations were absorbed by a new intermodal transport agency, Trafikverket [the Swedish Transport Administration]. Reflecting Sweden's view of the interconnectedness and systemic nature of all aspects of transport, Trafikverket is responsible for long-term planning for road, rail, maritime and air traffic. It is also responsible for building, operating, and maintaining public roads and railways (Trafikverket, 2010). Consistent with its placement within the Ministry of Enterprise, Trafikverket's mission links transport policy to achieving goals for economic efficiency, international competitiveness, and sustainability (Ministry of Enterprise, 2010).

Other Vägverket responsibilities were assigned to Transportstyrelsen [the Swedish Transport Agency], another new agency which began operations in January 2009. Like Trafikverket, this agency's scope is intermodal. Transportstyrelsen is responsible for commercial transport on Swedish roads, and is thus charged with developing and implementing regulations for professional drivers related to professional competence, driving time, and rest periods. In addition, it is responsible for regulating professional competence of road transport operators. It also handles administrative and fiscal tasks such as registering changes of ownership for transport companies, and collecting vehicle taxes and congestion fees. Not surprisingly, Transportstyrelsen's mission is congruent with that of Trafikverket, emphasizing goals of accessibility, efficiency, safety, environmental responsibility, and achieving fair competition within the transport industry (Ministry of Enterprise, 2010).

Legislation and institutional structure for occupational safety

The Swedish government agency responsible for OSH is Arbetsmiljöverket (the Swedish Work Environment Authority), formed in 2001 when ten regional labor inspectorates were merged with the National Board of Occupational Safety and Health. The framework legislation for the work of Arbetsmiljöverket is the Work Environment Act of 1977, which pre-dates EU activity in this policy area. Arbetsmiljöverket is responsible for enforcing and updating the Act and its supplementary regulations, as well as dealing with transposition of EU directives related to OSH.

The Work Environment Act (WEA) covers all Swedish workplaces, regardless of whether work is performed on industrial premises or outside, or in the public or private sector. Although most of its provisions are more germane to the employer-employee relationship, it also covers selfemployed workers and those working in family businesses. The stated purpose of the WEA is to "prevent ill health and accidents at work and to otherwise achieve a healthy work environment" [Chapter 1, 1 §, as amended by Law (1994:579)] (Arbetsmarknadsdepartementet [Ministry of 
Labour (Sweden)], December 19, 1977). Commentary from Arbetsmiljöverket stresses that the WEA is concerned "not only with prevention of accidents and ill-health at work but also with job content, the aim being for the working environment to yield a positive return in the form of job diversity, job satisfaction, social participation and personal development" (Arbetsmiljöverket, 2010b).

General provisions of the WEA are broad enough to be applied to all work settings, including the roadway. The WEA stipulates that working conditions must be adapted to accommodate individual differences in physical and mental abilities, and that individuals are to be given a voice in shaping their own work situations. It also requires that technology, work organization, and content of the job "shall be designed so that the employee is not subjected to physical and psychological pressures that can cause illness or accidents" [Chapter 2, $1 \S]$ (Arbetsmarknadsdepartementet [Ministry of Labour (Sweden)], December 19, 1977). The WEA also emphasizes that workplaces of all kinds are to be arranged and equipped such that they are acceptable from an environmental standpoint [Chapter 2, 3 §] (Arbetsmarknadsdepartementet [Ministry of Labour (Sweden)], December 19, 1977).

Other provisions of the WEA mention equipment or vehicles specifically. One states that "machinery, equipment, and other technical devices shall be designed, positioned and used in such a way to ensure adequate safeguards against ill health and accidents" [Chapter $2,5 \S]$ (Arbetsmarknadsdepartementet [Ministry of Labour (Sweden)], December 19, 1977). Another stipulates that "vehicles used to transport personnel must be suitable for this purpose;" this could be construed to mean not just transport of workers from one part of a facility to another, but also that safe means of transport is to be available regardless of the work setting [Chapter $2,8 \S$ ] (Arbetsmarknadsdepartementet [Ministry of Labour (Sweden)], December 19, 1977).

The language of the WEA regarding responsibility for workplace safety and health, like the EU directives that followed it, places the burden squarely on the employer and makes few allowances for employer measures to fail. The text reads as follows:

The employer shall take all the precautions necessary to prevent the employee from being exposed to health hazards or accident risks. One basic principle in this connection shall be for everything capable of leading to ill-health or accidents to be altered or replaced in such a way that the risk of ill-health or accidents is eliminated [Chapter 3, 2 §] (Arbetsmarknadsdepartementet [Ministry of Labour (Sweden)], December 19, 1977). ${ }^{68}$

The WEA also prefigures the EU Framework Directive for OSH (89/391/EEC) by calling for ongoing assessment of occupational risks, specifying that the employer "shall investigate work injuries, continuously investigate the hazards of the activity and take the measures thus prompted" [Chapter 3, 2a §] (Arbetsmarknadsdepartementet [Ministry of Labour (Sweden)], December 19, 1977).

\footnotetext{
${ }^{68}$ A commentary on the WEA by the Arbetsmiljöverket appears to leave this text somewhat open to interpretation, saying that the Act "implies that, if the risk cannot be fully eliminated, the employer must instead take steps to reduce it" (Arbetsmiljöverket, 2010b).
} 
At the same time, workers are expected to work with employers to support a safe workplace by complying with OSH regulations, using safety devices, and informing the employer of potentially unsafe conditions [Chapter 3, 4 §] (Arbetsmarknadsdepartementet [Ministry of Labour (Sweden)], December 19, 1977). In addition, in workplaces with more than five employees, the trade union or responsible worker organization appoints a safety delegate to represent employees on matters related to workplace safety and working conditions. The employer must consult with the safety delegate when planning changes in work processes that may affect safety and health. The safety delegate has the authority to shut down operations if in his or her judgment the work environment poses imminent dangers to safety or health [Chapter 6] (Arbetsmarknadsdepartementet [Ministry of Labour (Sweden)], December 19, 1977). Although Arbetsmiljöverket enforces OSH law and issues penalties for infractions, Sweden's safety delegate system gives worker representatives an unusually high level of responsibility for ensuring compliance with OSH law (Carlson, 2009, p. 388).

Arbetsmiljöverket issued provisions related to occupational risk assessment in a 2001 regulation (AFS 2001:1) identified as a transposition of the EU Framework Directive on OSH (89/391/EEC). The regulation stipulates that "the employer shall regularly investigate working conditions and assess the risks of any person being affected by ill-health or accidents at work" [8 $\S$ ] and that "in the event of an employee meeting with ill-health or an accident at work and of a serious incident at work, the employer shall investigate the causes, so that risks of ill-health and accidents can be prevented in the future" [9 §] (Arbetsmiljöverket, 2001). The non-statutory "guidance" portion of the regulation clarifies that systematic management of the work environment "encompasses the whole of the activity, regardless of whether it is carried on in the same place all the time, is dispersed or is moveable," implying that the regulation extends to the road as a workplace (Arbetsmiljöverket, 2001, p. 15).

In 2003 and 2004, Arbetsmiljöverket and Vägverket developed a guidance document that confirmed that the provisions of the EU Framework Directive 89/391/EEC were to extend to assessment of road risk for all Swedish workers who drive for work purposes, not only those employed as professional drivers (Arbetsmiljöverket, 2003/2004). The document was developed jointly by Matts-Åke Belin of Vägverket and Carl-Axel Sundström of Arbetsmiljöverket. Because it was an interpretation of existing law (the WEA and AFS 2001:1), no formal approval at either parliamentary or ministerial level was needed. Symbolically, the document was important because it showed coordination between two agencies with a stake in occupational road safety. Operationally, it resulted in instructions to labor inspectors to cover road safety in their evaluations of employer compliance with risk assessment requirements. ${ }^{69}$ However, by some accounts partisan politics have since intervened. After the change in 2006 to a center-right government, enforcement activities at Arbetsmiljöverket were cut back. Reportedly, the requirement for employers to conduct risk assessments for road safety now goes largely unenforced, except for some discretion exercised at regional level (Trafikverket, October 6, 2010). However, an Arbetsmiljöverket official stated that although implementation efforts were strongest in 2005 and 2006, the 2003/2004 guidance remains in effect (Arbetsmiljöverket, November 11, 2010).

\footnotetext{
${ }^{69}$ This is in marked contrast to the 2003 guidance document issued by the HSE in the UK, which advised employers that their risk assessment procedures ought to include road risk, but which was not accompanied by resources to allow inspectors to check on compliance.
} 


\section{$\underline{\text { Swedish transposition of EU directives }}$}

A number of Swedish government sources on the Internet provide access to acts, ordinances, regulations, and legislative histories. Many major statutes such as the WEA and Working Time Act are available in English translation. The Riksdag Web site, www.riksdagen.se, is especially useful for retrieving the motions, propositions, and committee reports that preceded formal legislation. In addition, some government agencies provide commentary along with key legislation relevant to their missions. Notisum AB (www.notisum.se), a private company, provides free access to statutes and case law from as early as the 1970s. Some legislation and regulations no longer in force were difficult to locate on Swedish government sites. The ILO NATLEX database was useful in providing information on Swedish legislation from the 1970s and 1980s that has since been repealed.

Table 5-1 below is a summary of the Swedish government bodies responsible for the legislation and regulations discussed in the following sections. It also provides the names of the sources of law for the Riksdag and relevant government agencies. Table 5-8 at the end of this chapter provides full citations for all the transposing laws and regulations for Sweden identified through this research.

Table 5-1. Swedish government bodies and sources of law related to occupational road safety

\begin{tabular}{|c|c|c|c|c|}
\hline Swedish Name & English Name & Ministry & Sources of Law & Notes \\
\hline \multicolumn{5}{|l|}{ Legislative Body } \\
\hline Riksdag & Parliament & $\mathrm{n} / \mathrm{a}$ & $\begin{array}{l}\text { Svensk } \\
\text { författningssamling } \\
\text { (SFS) [Swedish } \\
\text { Code of Statutes] }\end{array}$ & \\
\hline Trafikutskottets & $\begin{array}{l}\text { Transport } \\
\text { Committee -- } \\
\text { Parliament }\end{array}$ & $\mathrm{n} / \mathrm{a}$ & & $\begin{array}{l}\text { Reports to the } \\
\text { Riksdag on road } \\
\text { safety } \\
\text { propositions }\end{array}$ \\
\hline \multicolumn{5}{|l|}{ Ministries } \\
\hline Näringsdepartementet & $\begin{array}{l}\text { Ministry of } \\
\text { Enterprise }\end{array}$ & $\begin{array}{l}\text { Enterprise, } \\
\text { Energy, and } \\
\text { Communications }\end{array}$ & $\begin{array}{l}\text { Svensk } \\
\text { författningssamling } \\
\text { (SFS) [Swedish } \\
\text { Code of Statutes] }\end{array}$ & $\begin{array}{l}\text { May issue } \\
\text { regulations on } \\
\text { authority } \\
\text { delegated from } \\
\text { Riksdag }\end{array}$ \\
\hline Kommunikationsdepartementet & $\begin{array}{l}\text { Ministry of } \\
\text { Communications }\end{array}$ & $\begin{array}{l}\text { Enterprise, } \\
\text { Energy, and } \\
\text { Communications }\end{array}$ & $\begin{array}{l}\text { Svensk } \\
\text { författningssamling } \\
\text { (SFS) [Swedish } \\
\text { Code of Statutes] }\end{array}$ & $\begin{array}{l}\text { May issue } \\
\text { regulations on } \\
\text { authority } \\
\text { delegated from } \\
\text { Riksdag }\end{array}$ \\
\hline Arbetsmarknadsdepartementet & $\begin{array}{l}\text { Ministry of } \\
\text { Labour }\end{array}$ & & $\begin{array}{l}\text { Svensk } \\
\text { författningssamling } \\
\text { (SFS) [Swedish } \\
\text { Code of Statutes] }\end{array}$ & $\begin{array}{l}\text { May issue } \\
\text { regulations on } \\
\text { authority } \\
\text { delegated from } \\
\text { Riksdag }\end{array}$ \\
\hline \multicolumn{5}{|l|}{ Transport Agencies } \\
\hline Vägverket (1993-2010) & $\begin{array}{l}\text { Swedish Road } \\
\text { Administration }\end{array}$ & $\begin{array}{l}\text { Enterprise, } \\
\text { Energy, and }\end{array}$ & $\begin{array}{l}\text { Vägverkets } \\
\text { författningssamling }\end{array}$ & $\begin{array}{l}\text { Activities } \\
\text { incorporated }\end{array}$ \\
\hline
\end{tabular}




\begin{tabular}{|c|c|c|c|c|}
\hline & & Communications & $\begin{array}{l}\text { (VVFS) [Swedish } \\
\text { National Road } \\
\text { Administration } \\
\text { Statute Book] }\end{array}$ & $\begin{array}{l}\text { into } \\
\text { Trafikverket in } \\
2010\end{array}$ \\
\hline Trafikverket (2010- ) & $\begin{array}{l}\text { Swedish } \\
\text { Transport } \\
\text { Administration }\end{array}$ & $\begin{array}{l}\text { Enterprise, } \\
\text { Energy, and } \\
\text { Communications }\end{array}$ & $\begin{array}{l}\text { None at this time- } \\
\text { regulatory } \\
\text { responsibilities } \\
\text { assigned to } \\
\text { Transportstyrelsen }\end{array}$ & $\begin{array}{l}\text { Intermodal, } \\
\text { long-term } \\
\text { planning of } \\
\text { transport } \\
\text { infrastructure } \\
\end{array}$ \\
\hline Transportstyrelsen (2009- ) & $\begin{array}{l}\text { Swedish } \\
\text { Transport Agency }\end{array}$ & $\begin{array}{l}\text { Enterprise, } \\
\text { Energy, and } \\
\text { Communications }\end{array}$ & $\begin{array}{l}\text { Transportstyrelsens } \\
\text { författningssamling } \\
\text { (TSFS) [Swedish } \\
\text { Transport Agency } \\
\text { Regulations] }\end{array}$ & $\begin{array}{l}\text { Develops and } \\
\text { enforces } \\
\text { transport } \\
\text { regulations }\end{array}$ \\
\hline \multicolumn{5}{|l|}{ OSH Agency } \\
\hline Arbetsmiljöverket (2001- ) & $\begin{array}{l}\text { Swedish Work } \\
\text { Environment } \\
\text { Authority }\end{array}$ & Employment & $\begin{array}{l}\text { Arbetsmiljöverkets } \\
\text { författningssamling } \\
\text { (AFS) [Statute Book } \\
\text { of the Swedish } \\
\text { Work Environment } \\
\text { Authority] }\end{array}$ & $\begin{array}{l}\text { Consolidated } \\
\text { ten Labour } \\
\text { Inspectorate } \\
\text { districts and the } \\
\text { National Board } \\
\text { of Occupational } \\
\text { Safety and } \\
\text { Health }\end{array}$ \\
\hline
\end{tabular}

\section{Driving License Directive}

\section{Council Directive 91/439/EEC of 29 July 1991 on driving licences [consolidated version of January 1, 2007]}

Responsibility for driver licensing in Sweden is split between Transportstyrelsen and Trafikverket. Transportstyrelsen is responsible for the content of driving tests for both regular and commercial driving licenses, and for determining traffic rules and regulations and the penalties associated with infractions. Trafikverket, however, continues to manage the operational aspects of regular and commercial licensing: conducting tests, collecting fees, and issuing licenses. These administrative functions are separate from regulatory aspects of licensing in part because some politicians would like to privatize them, and it may be easier to do so in the future if these functions are kept outside Transportstyrelsen, the regulatory agency (Trafikverket, October 6, 2010). Until 2010, administration of driving licenses was the responsibility of the county administrative boards; now this is done at central-government level by Trafikverket, with the justification that centralization will allow more automation and lead to faster and more consistent service (Trafikverket, 2009).

Table 5-2. Swedish transposition of Driving License Directive (91/439/EEC)

\begin{tabular}{|l|l|}
\hline EU Directive & Swedish Legislation and Regulations \\
\hline $\begin{array}{l}\text { Article 1(2): Driving licences issued by Member States shall } \\
\text { be mutually recognized. }\end{array}$ & $\begin{array}{l}\text { Driving Licences Act 1998 } \\
\text { Chapter 6. Foreign License } \\
\text { Validation of Sweden } \\
\text { A foreign driver's license issued in an EEA Member }\end{array}$ \\
\hline
\end{tabular}




\begin{tabular}{|c|c|}
\hline & $\begin{array}{l}\text { State is valid in Sweden, according to its content. If the } \\
\text { holder of such a license is a permanent resident of } \\
\text { Sweden, also applies the provisions of Chapter } 3 \text {. Such } \\
\text { license equated with a Swedish license for the purposes } \\
\text { of Chapter } 4.4 \text { or } 6-8 \S \S \text {. } \\
\text { Other foreign license is valid in Sweden according to } \\
\text { their content. } \\
2 \S \text { A foreign driver's license does not apply in Sweden } \\
1 \text { st if it is invalid in the state where it was issued, } \\
2 \text { nd if it has been replaced by a Swedish driver's } \\
\text { license, } \\
3 \text { rd if the holder also has a Swedish driver's license and } \\
\text { this is suspended or revoked, or } \\
4 \text { th the license holder in the case referred to in Chapter } \\
3 . \S 13 \text { first paragraph } 5 \text { explains that he wants to keep } \\
\text { the Swedish license. } \\
\text { If the driving license is issued in a non-EEA country, it } \\
\text { does not apply in Sweden if the holder is registered in } \\
\text { Sweden for more than a year. }\end{array}$ \\
\hline $\begin{array}{l}\text { Article 3(1): The driving licence provided for in Article1 } \\
\text { shall authorize the driving of vehicles in the following } \\
\text { categories: [See Figure } 2 \text { above for a graphic showing } \\
\text { standard vehicle classes.] }\end{array}$ & 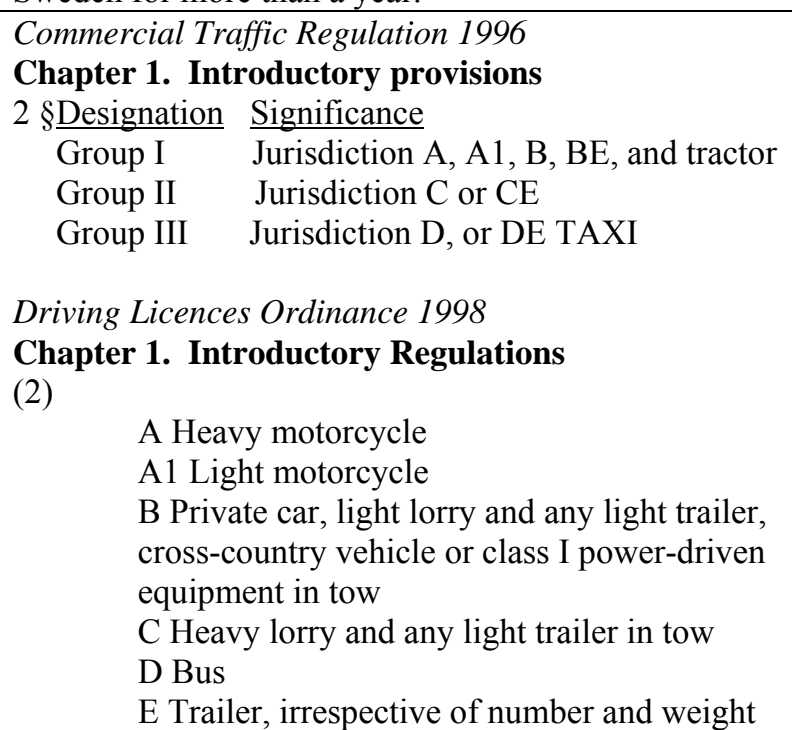 \\
\hline $\begin{array}{l}\text { Article 4(1): Driving licences shall state the conditions on } \\
\text { which the driver is authorized to drive. [Annex I (added by } \\
2000 / 56 / \mathrm{EC} \text { ) provides a list of harmonized Community codes } \\
\text { to be used on member-state licenses. These address } \\
\text { restrictions based on need for corrective lenses, vehicle } \\
\text { adaptations such as modified control layouts or assistive } \\
\text { devices, and a Certificate of Professional Competence (CPC) } \\
\text { to operate a commercial motor vehicle (this last provision } \\
\text { added by } 2003 / 59 / \mathrm{EC}) .]\end{array}$ & $\begin{array}{l}\text { Licence Format Regulation } 2003 \\
\text { Terms } \\
10 \text { §Use the following codes: } \\
\text {--Code } 01-99 \text { : Community code } \\
\text {--Code } 100 \text { and above: National codes that apply to } \\
\text { Swedish territory } \\
\text { Annex } 2 \text { to the Regulations VVFS (2003:68) on } \\
\text { driving licence design and content } \\
\text { Lists codes called for in Article 4(1). } \\
\text { Revised Licence Format Regulation } 2006 \\
\text { Appendix } 2 \text { on driving licence design and content } \\
\text { Repeats codes called for in Article } 4(1) \text { and adds CPC } \\
\text { code per 2003/59/EC: } \\
\quad 95 \text {. Driver holding a CPC complying with the } \\
\text { obligation of professional competence referred } \\
\text { to in Article } 3 \text { until ... (e.g. } 95.01 .01 .2012)\end{array}$ \\
\hline Article 6(1): The minimum age conditions for the issue of & Driving Licences Act 1998 \\
\hline
\end{tabular}




\begin{tabular}{|c|c|}
\hline $\begin{array}{l}\text { driving licences shall be as follows: } \\
\text { (a) } 16 \text { years: } \\
\text { - for subcategory A1; } \\
\text { - for subcategory B1; } \\
\text { (b) } 18 \text { years: } \\
\text { - for category A... } \\
\text { - for categories B, B }+ \text { E; } \\
\text { - for categories C, C + E and subcategories C1, C1 + E... } \\
\text { (c) } 21 \text { years: } \\
\text { - for the categories D and D + E and subcategories D1, D1 } \\
+ \text { E... } \\
\text { [various derogations and exceptions permitted] }\end{array}$ & $\begin{array}{l}\text { Chapter } 3 \text {. Issue and validity of licenses, tractor } \\
\text { license and license } \\
1 \S \text { Prerequisites for issuing a licence: } \\
\text { a) } 15 \text { years for the privilege AM,* } \\
\text { b) } 16 \text { years for permission A1 } \\
\text { c) } 18 \text { years for ratings A, B, C and E, } \\
21 \text { years for the power D... }\end{array}$ \\
\hline $\begin{array}{l}\text { Article 7(1): Driving licences shall, moreover, be issued only } \\
\text { to those applicants: (a) who have passed a test of skills and } \\
\text { behaviour and a theoretical test and who meet medical } \\
\text { standards, in accordance with the provisions } \\
\text { of Annexes II and III; }\end{array}$ & $\begin{array}{l}\text { Driving Curriculum for Class B vehicles } 1996 \\
\text { The training for a licence shall contain the following } \\
\text { main elements, creating such attitudes, knowledge, and } \\
\text { skills necessary for traffic behaviour. } \\
\text { Theory of Education } \\
1^{\text {st }} \text { Vehicle knowledge } \\
3^{\text {rd }} \text { Traffic rules } \\
5^{\text {th }} \text { Traffic treacherous situations } \\
7^{\text {th }} \text { Man's limited ability } \\
9^{\text {th }} \text { Completion and application of certain } \\
\text { provisions } \\
\text { Driving Courses } \\
2^{\text {thd }} \text { Vehicle knowledge } \\
4^{\text {th }} \text { Operation [Covers mirrors, reversing, } \\
\text { shifting, braking, turning, parking] } \\
6^{\text {th }} \text { Driving in traffic [Covers following } \\
\text { distance, speed, overtaking, roundabouts, } \\
\text { intersections, vulnerable road users, risk } \\
\text { awareness] } \\
8^{\text {th } \text { Driving under special conditions }} \\
\text { Professional Driver Qualification and Training } \\
\text { Regulation 2008 } \\
\text { Chapter 1. Introductory Provisions } \\
\S 2 \text { The applicant shall be both theoretically and } \\
\text { practically able to use his knowledge. }\end{array}$ \\
\hline $\begin{array}{l}\text { ANNEX II } \\
\text { I. MINIMUM REQUIREMENTS FOR DRIVING TESTS } \\
\text { 2. Content of the theory test concerning all vehicle } \\
\text { categories } \\
\text { 2.1. Questions must be asked on each of the points listed } \\
\text { below, the content and form of the questions being left to the } \\
\text { discretion of each Member state: } \\
\text { [Followed by list of topics under these headings: Road traffic } \\
\text { regulations, The driver, The road, Other road users, General } \\
\text { rules and regulations and other matters, Precautions } \\
\text { necessary when alighting from the vehicle, Mechanical } \\
\text { aspects with a bearing on road safety, Vehicle safety } \\
\text { equipment, and Rules regarding vehicle use in relation to the } \\
\text { environment ] }\end{array}$ & $\begin{array}{l}\text { Driving Curriculum for Class B vehicles } 1996 \\
\text { Theory of Education } \\
1^{\text {st }} \text { Automotive Knowledge } \\
\quad 1.1 \text { The Vehicle } \\
\quad 1.4 \text { Environment } \\
3^{\text {rd }} \text { Traffic [Covers speed limits, signage and marking, } \\
\text { overtaking, and vulnerable road users] } \\
7^{\text {th }} \text { Man's limited ability [Covers human factors: } \\
\text { attitudes, social context of driving, impairment, and } \\
\text { fatigue] } \\
9^{\text {th } \text { Completion and implementation of certain }} \\
\text { provisions [Covers driving on different types of roads, } \\
\text { in inclement weather, and at night] } \\
\quad 9.7 .1 \text { Seat belts and protective equipment }\end{array}$ \\
\hline $\begin{array}{l}\text { Annex II } \\
\text { II. KNOWLEDGE, SKILL AND BEHAVIOUR FOR } \\
\text { DRIVING A POWER-DRIVEN VEHICLE }\end{array}$ & $\begin{array}{l}\text { The Driving Licences Act 1998, the Driving Licences } \\
\text { Regulation 1998, and the Driving Licences Ordinance } \\
1998 \text { do not cover specific provisions for these classes }\end{array}$ \\
\hline
\end{tabular}




\begin{tabular}{|c|c|}
\hline $\begin{array}{l}\text { Specific provisions concerning categories } C, C+E, C 1 \text {, } \\
C 1+E, D, D+E, D 1 \text { and } D 1+E^{70}\end{array}$ & $\begin{array}{l}\text { of vehicles. This was accomplished in transposing the } \\
\text { Driver CPC Directive (2003/59/EC). } \\
\text { Professional Driving Skills Ordinance } 2007 \\
\text { Annex } \\
\text { Learning objectives cover the vehicle's technical } \\
\text { features and functions, loading and stability, passenger } \\
\text { safety, rules for freight transport, safety equipment, } \\
\text { physical fitness, company image, crash risk factors, } \\
\text { and what to do in the event of a crash. } \\
\text { Professional Driver Qualification and Training } \\
\text { Regulation } 2008 \\
\text { Chapter } 2 \text {. Advanced training on rational driving in } \\
\text { safety } \\
\text { Learning objectives cover the topics in the Professional } \\
\text { Driving Skills Regulation } 2007 \text { in more detail. } \\
\text { [Separate objectives for knowledge ("The applicant } \\
\text { must be familiar with...") and skills ("The applicant } \\
\text { must be able to...")] }\end{array}$ \\
\hline $\begin{array}{l}\text { ANNEX III } \\
\text { MINIMUM STANDARDS OF PHYSICAL AND MENTAL } \\
\text { FITNESS FOR DRIVING A POWER-DRIVEN VEHICLE } \\
\text { [includes sight, hearing, CVD, diabetes, alcohol, mental } \\
\text { illness, drugs and medications] }\end{array}$ & $\begin{array}{l}\text { Commercial Traffic Regulation } 1996 \\
\text { Chapters } 2 \text { through 12, 14: Standards for vision, } \\
\text { hearing and balance, musculoskeletal functions, } \\
\text { cardiovascular disease, diabetes, neurological diseases, } \\
\text { epilepsy and other disorders of consciousness, kidney } \\
\text { disease, dementia and other cognitive disorders, } \\
\text { alertness disturbance [such as sleep apnea], use of } \\
\text { drugs affecting the ability to drive motor vehicles, } \\
\text { mental disorders } \\
\text { Chapter 15. Medical examination: Standards by } \\
\text { which physician is to judge fitness to drive } \\
\text { Chapter 16. Sight-testing: Specific standards for } \\
\text { vision tests, and requirements for referrals for } \\
\text { additional testing }\end{array}$ \\
\hline
\end{tabular}

The original deadline for transposition of the Driving License Directive was June 30, 1994, approximately three years after it was enacted. Sweden did not accede to the EU until January 1, 1995 and therefore transposed this directive along with numerous others as part of the requirements of accession to the EU. For Sweden, along with Finland, the deadline for transposition was extended to December 31, 1997 (Commission of the European Communities, March 28, 2002, p. 2). Despite this, Sweden did not complete its initial transposition of the Driving License Directive by the end of 1997. Licensing legislation (the Driving Licences Act 1998) was enacted in June 1998, followed by publication of a Regulation and Ordinance by Vägverket in July and December of the same year. The Driving Licences Act and Ordinance were comprehensive, whereas the Regulation focused on medical fitness to drive.

Although the formal transposition of the Driving License Directive was not completed by the deadline set by the EU, in reality many of its provisions were found in other Swedish law which

\footnotetext{
${ }^{70}$ These vehicle classes are typically used for carrying freight and passengers. Because of their function, weight, and configuration, they are singled out for special consideration by regulations. See Figure 2 for a graphic displaying all the standard vehicle classes used in the EU.
} 
became effective well before Sweden's transposition deadline. The Commercial Traffic Regulation 1996 contains standards for medical fitness of prospective license holders that are nearly identical to requirements found in 91/439/EEC. ${ }^{71}$ Sweden's transposition accords special importance to the medical fitness of persons who operate commercial vehicles, with "greater tolerance allowed for the holding in group I than in group II and III" (group I being passenger vehicles and groups II and III being heavy trucks and buses) [Chapter 1. 4 §] (Vägverket, July 10, 1996a). In other words, operators of large trucks and buses are to be held to a higher standard of medical fitness.

The Commercial Traffic Regulation 1996 also correctly transposes the vehicle groupings specified in Annex III of 91/439/EEC. Here, drivers of smaller passenger vehicles make up Group 1, while drivers of heavy-goods and passenger transport vehicles are combined to form Group 2.

The Driving Curriculum for Class B Vehicles 1996, the regulation that covers operation of passenger vehicles, goes far beyond what is required by the EU Driving License Directive. As required by the EU, the licensing process requires the applicant to pass both a theory test and a practical on-road driving test. However, rather than simply listing the topics to be covered, the Swedish regulation contains learning objectives and in some cases prescribes maneuvers that the examiner is to ensure the driver can complete.

The attention given by the Class B Driving Curriculum to the social components of driving is particularly noteworthy. One provision states that successful applicants for a license must be able to "explain how expectations, needs, motives, and past experience affect the driver's perception, interpretation, and decisions in different traffic situations" [Theory of Education, 7.2.2]. Further, the regulation requires that the driver understand how an individual's identity, ideals, perception of reality, self-knowledge, and sense of responsibility shape his or her driving behavior [Theory of Education, Personal Maturity, 7.3.1] (Vägverket, July 10, 1996b). These two passages reflect the Swedish goal for an individual to be cognizant of his impact on a system or a community, echoing a model of driver education being developed in Finland around the same time by Esko Keskinen. Under the Keskinen model, the development of driving skills is hierarchical, beginning with skills in maneuvering a vehicle and progressing to an understanding of traffic situations. At higher levels of awareness, the learner begins to understand the broader "goals and context for driving," and will ultimately make driving decisions based on "goals for life and skills for living” (Berg, 2006, pp. i15-i16; Hatakka, Keskinen, Gregersen, Glad, \& Hernetkoski, 2002, pp. 202-204).

In its initial 1998 transpositions of the Driving License Directive, Sweden does not appear to have addressed requirements that tests for licensing to drive large trucks and buses cover topics specific to those types of vehicles (as specified in Annex II of 91/439/EEC). This was not completed until 2007 and after, as part of Sweden's (largely correct) transpositions of the Driver CPC Directive 2003/59/EC, discussed below. That said, although Sweden may not have reproduced these training points into its initial responses to the Driving License Directive, it seems clear that Sweden's system of training professional drivers has been recognized as a

\footnotetext{
${ }^{71}$ The title of this regulation is somewhat misleading. It addresses licensing standards and requirements for all Swedish drivers, not just those licensed to operate commercial motor vehicles.
} 
model for other countries to follow. A U.S. study tour examining European training practices praised the Swedish approach, stating that it reflected a belief that broad, holistic training will result in safer driving. In addition, the report noted that Swedish trainees are required to demonstrate safety consciousness and an understanding of the role the driver plays in society, in addition to technical skills (Federal Highway Administration, 2000, pp. 5-7).

When Sweden did transpose the Directive's requirements for "Specific provisions concerning categories C, C+E, C1, C1+E, D, D+E, D1 and D1+E," it handled the licensing of professional drivers of large trucks and buses in much the same way as licensing of Class B passenger vehicles, making a distinction between knowledge to be assessed by the theoretical test, and skills to be demonstrated through the on-road driving test. In its transpositions of the Driver CPC Directive, the first of which was published in 2007, Sweden also covered the topics initially required by the Driving License Directive.

In the Licence Format Regulation 2003, Sweden correctly transposed the "harmonized Community codes" added by Directive 2000/56/EC, which modified 91/439/EEC. In a 2006 revision, Sweden added code 95, which was added by the Driver CPC Directive 2003/59/EC and covers drivers who hold a Certificate of Professional Competence (CPC) to transport freight or passengers.

Finally, the principle of mutual recognition, which was sufficiently problematic for member states as to comprise nearly one-third of the Commission's transposition review for the entire Directive (Commission of the European Communities, March 28, 2002), was in fact incorporated correctly into Swedish law. Sweden's Driving License Act 1998 gave holders of licenses issued by other states in the European Economic Area (EEA) the option of exchanging their license for a Swedish license, but guaranteed recognition of the original licenses should the holders elect not to exchange them. ${ }^{72}$ (Recognition of non-Community foreign licenses was, however, limited to one year, after which time the holder would be obliged to exchange the foreign license for a Swedish license. This stipulation has since been eliminated in SFS 2003:522.)

\section{Driver CPC Directive}

\section{Directive 2003/59/EC of the European Parliament and of the Council of 15 July 2003 on the initial qualification and periodic training of drivers of certain road vehicles for the carriage of goods or passengers, amending Council Regulation (EEC) No 3820/85 and Council Directive 91/439/EEC and repealing Council Directive 76/914/EEC}

The "Driver CPC Directive" covers requirements for qualification and training of drivers of C, $\mathrm{D}$, and $\mathrm{E}$ category vehicles. Licensing requirements for these drivers are handled separately within the Driving License Directive; qualification and training requirements are handled by

\footnotetext{
${ }^{72}$ The Commission's bone of contention with many member states was that they required individuals taking up residence there for any length of time to turn in foreign licenses and obtain licenses issued by that member state. In other words, "recognition" was limited to the process of exchanging a foreign license (Commission of the European Communities, July 16, 2001, p. 40).
} 
Directive 2003/59/EC. Within a given member state, the requirements apply to nationals of that state, as well as third-country nationals employed by a business based in another member state [Article 1]. This directive requires member states to implement systems for initial qualification that will lead to a Certificate of Professional Competence (CPC) for individual drivers. Member states may elect to qualify drivers through tests only (written and on-the-road), or through class attendance combined with tests [Article 3] (Commission of the European Communities, September 10, 2003).

Table 5-3. Swedish transposition of Driver CPC Directive (2003/59/EC)

\section{EU Directive \\ Article 6: CPC certifying the initial qualification \\ 1.CPC certifying an initial qualification \\ (a) CPC awarded on the basis of course attendance and a test: In accordance with Article 3(1)(a)(i), Member States shall require trainee drivers to attend courses in a training centre approved by the competent authorities in accordance with section 5 of Annex I,* hereinafter referred to as 'approved training centre'. These courses shall cover all the subjects referred to in section 1 of Annex I.**}

(b) CPC awarded on the basis of tests: In accordance with Article 3(1)(a)(ii), Member States shall require trainee drivers to pass the theoretical and practical tests referred to in section 2(2.2) of Annex I.***

*Annex I, Minimum Qualification and Training Requirements: Section 5, Approval of the initial qualification and periodic training

**Annex I, Minimum Qualification and Training

Requirements: Section 1, List of Subjects

***Annex I, Minimum Qualification and Training

Requirements: Section 2, Compulsory initial qualification provided for in Article 3(1)(a); Subsection 2.2, Option involving a test

\section{Swedish Legislation and Regulations}

Professional Driver Qualification and Training

Regulation 2008

Chapter 4. CPC

$1 \S$ Transport Agency shall issue a certificate of professional competence on basic skills to a driver who:

--has completed the training

--has successfully passed the test, and

--holds a license for which the training is given.

Chapter 5. Permission to conduct training, etc.

$2 \S$ Approval to conduct training activities should include the following:

$1^{\text {st }}$ a training plan that specifies topics

$2^{\text {nd }}$ information about teachers' qualifications and fields of activity

$3^{\text {rd }}$ data on educational facilities and teaching materials $4^{\text {th }}$ available about available resources for the practical work and the vehicles used, and

$5^{\text {th }}$ information on the conditions of participation in education, including the number of places

Chapter 2. Advanced training on rational driving in safety

Learning objectives cover the topics in section 1 of Annex I of the Directive.

Professional Driving Skills Ordinance 2007

Annex

Learning objectives cover the topics in section 1 of Annex I of the Directive.

Professional Driver Competence Act 2007

Chapter 6. CPC, etc.

$1 \S$ A qualification card is valid for five years from the date it was issued.

2 § A driver qualification card issued in another EEA Member State is valid in Sweden, according to its content.

\section{Chapter 7. Training Venue}

$1 \S$ A driver who is a Swedish citizen or national of another EEA Member State shall obtain the basic skills in Sweden if he or she is permanently resident in Sweden. 


\begin{tabular}{|c|c|}
\hline & $\begin{array}{l}2 \S \text { A driver who is not a national of an EEA Member } \\
\text { State may obtain the basic skills in Sweden, if he or she } \\
\text { is employed or engaged by a company established in } \\
\text { Sweden. The same applies for permanent residence or } \\
\text { work permits that have been issued to the driver in this } \\
\text { country. } \\
\text { Professional Driving Test Regulation } 2010 \\
\text { Chapter } 2 \text {. The test at the Transport } \\
\text { Administration } \\
2 \text { § The test is different ... for drivers carrying goods } \\
\text {..with vehicles that require driver's competence C or } \\
\text { CE than ... for drivers who transport passengers with } \\
\text { vehicles requiring driver's competence D or ED. } \\
3 \text { § The test will consist of written questions. } \\
6 \text { § The test will consist of } 60 \text { questions... To pass at } \\
\text { least } 48 \text { correct answers. } \\
7 \S \text { The time to take the test should not exceed } 50 \\
\text { minutes. } \\
\text { Common Rules for Driving Tests } 2009 \\
\text { Chapter } 3 \text {. Examinations at the SRA } \\
2 \text { § The duration of the test shall be not more than } 50 \\
\text { minutes to jurisdiction A, A1 and B and a maximum of } \\
40 \text { minutes for permission BE, C, CE, D, ED. }\end{array}$ \\
\hline $\begin{array}{l}\text { Article 7: Periodic training } \\
\text { Periodic training shall consist of training to enable holders of } \\
\text { a CPC as referred to in Article } 6 \text { and the drivers referred to in } \\
\text { Article } 4 * \text { to update the knowledge which is essential for their } \\
\text { work, with specific emphasis on road safety and the } \\
\text { rationalization of fuel consumption. This training shall be } \\
\text { organised by an approved training centre, in keeping with } \\
\text { section } 5 \text { of Annex I.** } \\
\text { *Refers to those with "acquired rights" (those who already } \\
\text { hold a recently-issued category C, D, or E license) } \\
\text { **Annex I, Minimum Qualification and Training } \\
\text { Requirements: Section 5, Approval of the initial qualification } \\
\text { and periodic training }\end{array}$ & $\begin{array}{l}\text { Professional Driver Competence Act } 2007 \\
\text { Chapter } 5 \text {. Training } \\
\mathbf{4} \S \text { A driver who has completed his first training as } 2 \\
\text { or } 3 \S \text { will then undergo periodic training every five } \\
\text { years, before the expiry of the validity of the CPC. } \\
\text { Chapter } 7 \text {. Training Venue } \\
3 \text { \& A driver referred to in } 1 \text { or } 2 \S \text { will receive } \\
\text { refresher training in Sweden if he is permanently } \\
\text { resident in Sweden or working in this country. }\end{array}$ \\
\hline
\end{tabular}

Like the UK, Sweden did not meet the September 9, 2006 deadline for transposition of the Driver CPC Directive. The initial Swedish legislation, the Professional Driver Competence Act, was enacted in November 2007 and became effective at the beginning of 2008. The Act was followed closely by the Professional Driving Skills Ordinance in December 2007 and the Professional Driver Qualification and Training Regulation in February 2008. Swedish law emphasizes that its scope is limited to drivers whose primary job is to carry goods and passengers; exemptions include drivers of vehicles "used for transporting materials and equipment for the driver to use in their work, provided that driving the vehicle is not the driver 's principal activity" [Chapter 2, $4 \S, 8^{\text {th }}$ ] (Näringsdepartementet [Ministry of Enterprise (Sweden)], November 29, 2007). 
Sweden's transpositions of the Driver CPC Directive faithfully transpose the list of subjects to be covered by the training courses leading to initial qualification of drivers, as well as standards for accreditation of training centers. For initial qualification of drivers, Sweden has evidently chosen the first option offered in Article 6 of Directive 2003/59/EC: course attendance followed by a written test. The initial Swedish legislation and regulations enacted in 2007 and 2008 do not discuss the format or content of these tests. Additional regulations put in place in 2009 and 2010 specify that written tests for Class C and D vehicles should be different than those for passenger vehicles. They also specify number of questions, time limits, and number of correct answers needed to pass (see Table 5-3 above). Although the Swedish regulation is not particularly prescriptive with regard to content of the written test, neither is the Driver CPC Directive all that specific on this point. ${ }^{73}$

The initial transposing Swedish legislation, the Professional Driver Competence Act, guarantees Swedish recognition of driver qualification cards issued in any other state in the EEA [Chapter 6, $2 \S]$. However, Sweden does take steps to ensure that trainees and CPC holders will receive training in Sweden to the extent possible. Swedish citizens or permanent residents with citizenship in another EEA country who wish to obtain initial CPC qualification are required to take the basic training in Sweden. Similarly, for Swedish citizens or EEA nationals with permanent residency, periodic refresher training must be taken in Sweden [Chapter 7, $3 \S$ ] (Näringsdepartementet [Ministry of Enterprise (Sweden)], November 29, 2007).

\section{Operator CPC Directive}

\section{Council Directive 98/76/EC of 1 October 1998 amending Directive 96/26/EC on admission to the occupation of road haulage operator and road passenger transport operator and mutual recognition of diplomas, certificates and other evidence of formal qualifications intended to facilitate for these operators the right to freedom of establishment in national and international transport operations}

Table 5-4. Swedish transposition of Operator CPC Directive (98/76/EC)

\begin{tabular}{|l|l|}
\hline EU Directive & Swedish Legislation and Regulations \\
\hline Article 1(2) & Commercial Traffic Act 1998 \\
1. This Directive shall not apply to undertakings & Chapter 1. Scope of the Act \\
engaged in the occupation of road haulage operator by & 1 § This law applies to commercial traffic, meaning the \\
means of motor vehicles or combinations of vehicles the & services which: \\
maximum authorised weight of which does not exceed & 1st out of cars, trucks, buses, off-road vehicles or \\
3,5 tonnes. Member States may, however, lower this & tractors with attached trailer (traktortåg) and \\
limit for all or some categories of transport operations. & $2^{\text {nd }}$ means that vehicles and drivers in return for \\
2a. Member States may, after consulting the & payment made available to the public for transportation \\
Commission, exempt from the application of all or some & of passengers or goods. \\
of the provisions of this Directive road haulage & 3 § Commercial traffic can be managed as: \\
undertakings engaged exclusively in national transport & 1st Regular services for hire or reward for passengers \\
\hline
\end{tabular}

\footnotetext{
73 The Driver CPC Directive states only: “At the end of that training, Member States' competent authorities or the entity designated by them shall give the driver a written or oral test. The test must include at least one question on each of the objectives in the list of subjects under section 1" [Annex II, 2.1] (Commission of the European Communities, September 10, 2003).
} 


\begin{tabular}{|c|c|}
\hline $\begin{array}{l}\text { operations having only a minor impact on the transport } \\
\text { market because of: } \\
\text { - the nature of the goods carried, or } \\
\text { - the short distance involved. }\end{array}$ & 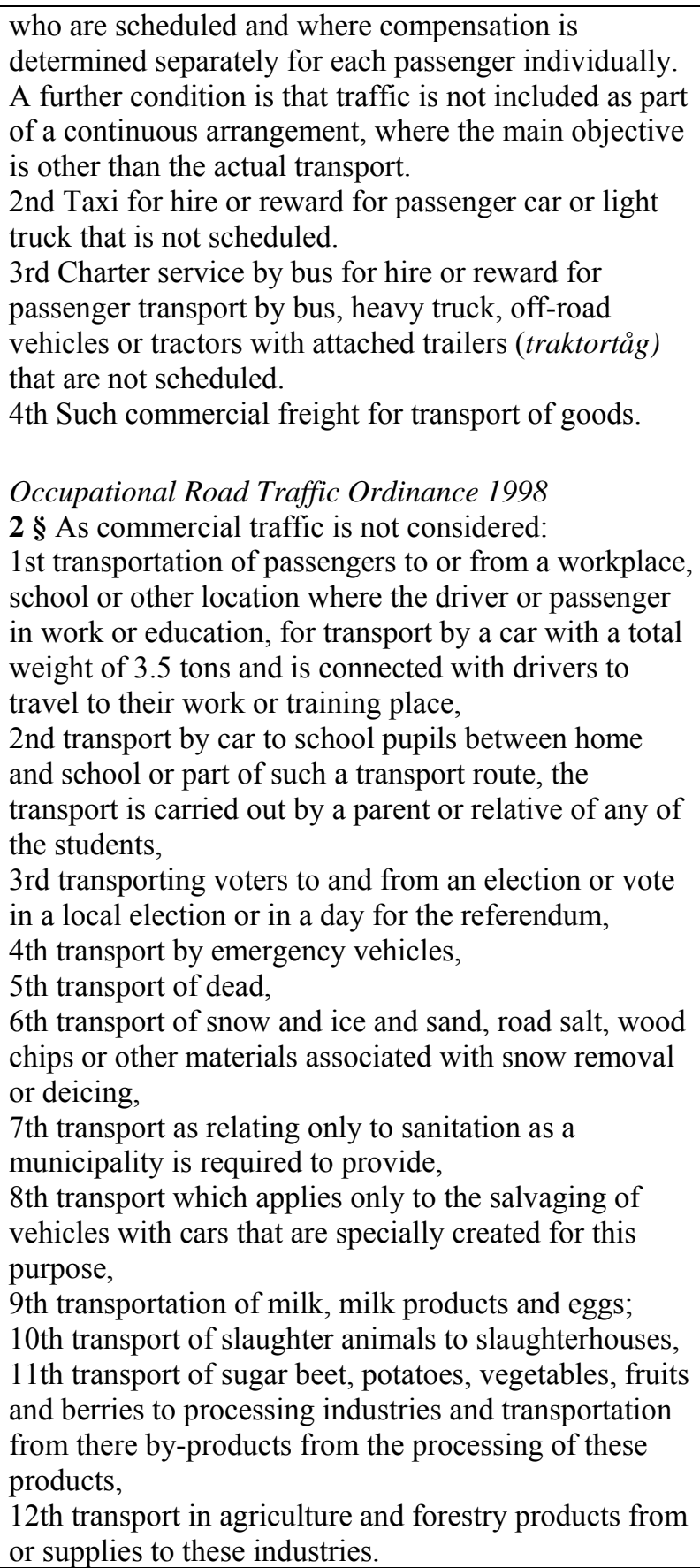 \\
\hline $\begin{array}{l}\text { Article 3(1): Undertakings wishing to engage in the } \\
\text { occupation of road transport operator shall: } \\
\text { (a) be of good repute; } \\
\text { (b) be of appropriate financial standing; } \\
\text { (c) satisfy the condition as to professional competence. }\end{array}$ & $\begin{array}{l}\text { Commercial Traffic Act } 1998 \\
\text { Chapter } 2 \text {. Operating } \\
5 \S \text { Operating licenses may only be given to the person } \\
\text { according to their skills, economic conditions and a } \\
\text { good reputation is deemed appropriate to run the } \\
\text { business. } \\
\mathbf{9} \S \text { Applicants for operating licenses should have the } \\
\text { financial resources to in a proper way start and run the } \\
\text { company. } \\
\S 8 \text { The requirement of professional competence shall } \\
\text { be deemed satisfied by the person who has passed the } \\
\text { written examinations conducted by the Transport }\end{array}$ \\
\hline
\end{tabular}




\begin{tabular}{|c|c|}
\hline & Administration. \\
\hline $\begin{array}{l}\text { Article 3(2): Member States shall determine the } \\
\text { conditions which must be fulfilled by undertakings } \\
\text { established within their territory in order to satisfy the } \\
\text { good-repute requirement. They shall provide that this } \\
\text { requirement is not satisfied, or is no longer satisfied, if } \\
\text { the natural person or persons who are deemed to satisfy } \\
\text { this condition under paragraph 1: } \\
\text { (a) have been convicted of serious criminal offences, } \\
\text { including offences of a commercial nature, } \\
\text { (b) have been declared unfit to pursue the occupation of } \\
\text { road transport operator under any rules in force, } \\
\text { (c) have been convicted of serious offences } \\
\text { against the rules in force concerning: } \\
\text { - the pay and employment conditions in the } \\
\text { profession, or } \\
\text { - road haulage or road passenger transport, as } \\
\text { appropriate, in particular the rules relating to drivers' } \\
\text { driving and rest periods, the weights and dimensions of } \\
\text { commercial vehicles, road safety and vehicle safety, the } \\
\text { protection of the environment and the other rules } \\
\text { concerning professional liability. }\end{array}$ & $\begin{array}{l}\text { Commercial Traffic Act } 1998 \\
\text { Chapter 2. Operating } \\
\mathbf{1 1} \S \text { In the examination of the applicant in respect of } \\
\text { the requirement of good repute is to be considered the } \\
\text { applicant's willingness and ability to satisfy its } \\
\text { obligations to the community, obedience to the law in } \\
\text { general and other relevant factors. } \\
\text { The requirement of good repute is not satisfied by the } \\
\text { person who is convicted of: } \\
\text { 1st serious criminal offenses, including, } \\
\text { 2nd serious or repeated violations of: } \\
\text { a) this Act or regulations issued pursuant to this Act; } \\
\text { b) the regulations or rules of road and road transport, in } \\
\text { particular rules applicable to driving and rest times, } \\
\text { vehicle weight and size, vehicle equipment and } \\
\text { condition or provision of essential importance for } \\
\text { traffic, road safety or environmental protection, or } \\
\text { c) provisions on pay and employment conditions in the } \\
\text { industry. }\end{array}$ \\
\hline $\begin{array}{l}\text { Article 3(4) }(a) \text { : The condition relating to professional } \\
\text { competence shall consist in the possession of knowledge } \\
\text { corresponding to the level of training provided for in } \\
\text { Annex I* in the subjects listed therein. It shall be } \\
\text { established by means of a compulsory written } \\
\text { examination which may be supplemented by an oral } \\
\text { examination organised in the form set out in Annex I** } \\
\text { by the authority or body designated for that purpose by } \\
\text { the Member State. }\end{array}$ & $\begin{array}{l}\text { Commercial Traffic Act } 1998 \\
\text { Chapter 2. Operating } \\
\mathbf{8} \S \text { The test will cover the skills that an operator should } \\
\text { have in terms of mainly: } \\
\text { 1st law, } \\
\text { 2nd management and financial management of a } \\
\text { company, } \\
\text { 3rd technical standards and operating conditions, and } \\
\text { 4th road safety. }\end{array}$ \\
\hline 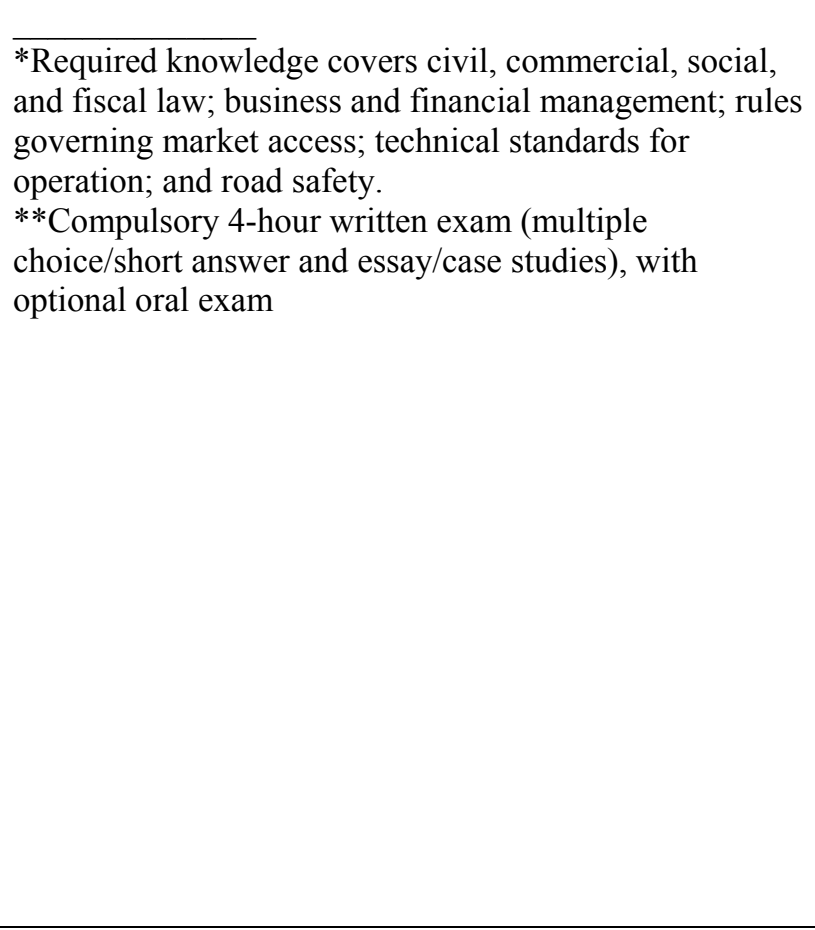 & $\begin{array}{l}\text { Professional Competency Regulation } 2001 \\
\text { [Contains detailed listing of topics which are consistent } \\
\text { with but not a verbatim transposition of the EU } \\
\text { directive, covering the following areas as prescribed by } \\
\text { the directive]: } \\
\text { Chapter } 2 \text {. Law } \\
\text { Chapter } 3 \text {. Business and financial management of a } \\
\text { company } \\
\text { Chapter } 4 \text {. Technical standards and operating } \\
\text { conditions } \\
\text { Chapter } 5 \text {. Road safety } \\
\text { Test of Professionalism Regulations } 2010 \\
\text { Chapter } 2 \text {. The test of professionalism } \\
\S 2 \text { A competency test of freight transport, passenger } \\
\text { transport by bus or person-by taxi is composed of two } \\
\text { blocks as follows. } \\
\text { 1st Written questions within the knowledge areas listed } \\
\text { in Transport Agency Regulations (VVFS 2001:51) on } \\
\text { proficiency for professional traffic. } \\
\text { 2nd Written information (case studies) which consists } \\
\text { of an application test with data in the knowledge } \\
\text { domains in Annex 1. }\end{array}$ \\
\hline
\end{tabular}


Article 10(1): As from 1 January 1990, Member States shall recognize as sufficient proof of professional competence certificates as referred to in the fourth subparagraph of Article 3 (4) which are issued by another Member State.
Chapter 3. Breakdown of the sample and test time 1 \& The test may be completed in full (Blocks 1 and 2) or in any order. The primary topics are as follows: 1st Law.

2nd Business and financial management of a company. 3rd Technical standards and operating conditions and traffic safety.

4th Case studies.

$2 \S$ The test period for the full test is 4 hours and 15 minutes.

\section{Commercial Traffic Act 1998}

\section{Chapter 2. Operating}

$8 \S$ The requirement of proficiency may also be fulfilled by the person who can show a certificate of professional qualification issued by a State of the European Economic Area (EEA) in accordance with Council Directive 96/26/EC of 29 April 1996 on admission to the occupation of persons and goods by road and the mutual recognition of diplomas, certificates and other evidence to promote the effective use of these operators in the field of national and international transport.

Article 10a: Member States shall provide for systems of penalties for infringements of the national provisions adopted in accordance with this Directive and shall take all the measures necessary to ensure that those penalties are applied. The penalties thus provided for shall be effective, proportionate and dissuasive.

\section{Commercial Traffic Act 1998}

\section{Chapter 6. Penalties, etc.}

1 \& Anyone who intentionally operates commercial traffic under this Act without a permit is convicted of illegal commercial traffic to a fine or imprisonment not exceeding one year. A licensee who willfully or negligently violates the conditions that have been issued in the state is sentenced to a fine.

Sweden's transposition of the Operator CPC Directive was largely accomplished through the Commercial Traffic Act 1998 and the Occupational Road Traffic Ordinance 1998, some months in advance of the January 1999 deadline. The Ordinance, published just two weeks after the Act, provided more details to guide implementation.

Although much of the Operator CPC Directive is quite prescriptive, the scope statements allow member states a good deal of discretion in determining the kinds of businesses that will be required to hold a CPC. Member states are not required to apply the directive to vehicles under 3.5 tonnes, but they may choose to do so. On the other hand, they are permitted to exempt certain categories of operations as long as these are carried out entirely within the domestic market, are a small part of the transport market, and can be justifiably excluded on the basis of the goods carried or short distances involved.

In the basic transposing legislation for Sweden, the Commercial Traffic Act 1998, commercial traffic is defined as encompassing freight and passenger transport for hire, including taxi service. Thus, although Sweden did not choose to cover all vehicles under 3.5 tonnes under the Operator CPC Directive, it did extend the CPC requirement to taxi service, which generally involves lighter vehicles. However, Sweden, in the Occupational Road Traffic Ordinance 1998, at the same time took advantage of the discretion given by the Operator CPC Directive to exempt a range of vehicle operations. 
The Commercial Traffic Act 1998 accurately cited the three primary requirements for certification as a road transport operator: professional competence, viable financial standing, and good repute. The same Act correctly stated the conditions under which a transport operator would no longer satisfy the requirements for good repute. However, a report on transpositions of the Operator CPC Directive across the EU-15 member states faults Sweden's transposition of this particular item [that is, Article 3(2)] for its lack of specificity and lack of rigor compared to other member states (NEA Transport Research and Training, Transport Innovation and Systems (TIS), \& T.M.C. Asser Instituut, 2005, pp. 13-14). At issue was a passage in the Commercial Traffic Act 1998 that accompanies the listing of disqualifying offenses:

Chapter 2, 11 §: In the examination of the applicant in respect of the requirement of good repute to be considered the applicant's willingness and ability to satisfy its obligations to the community, obedience to the law in general and other relevant factors. (Näringsdepartementet [Ministry of Enterprise (Sweden)], June 11, 1998)

The report argues that the Swedish legislation allows the authorities too much discretion in their review of a CPC application, noting that "willingness and ability to satisfy...obligations" are not sufficiently objective criteria. Also of concern to the authors of the report is Sweden's delegation of authority for review of CPC applications to the twenty-one County Administrative Boards. Decentralized review is seen as a barrier to the uniform application of the state-level legislation, creating potential for "firm tourism" wherein prospective operators go from region to region seeking officials who may be receptive to their applications (NEA Transport Research and Training, et al., 2005, p. 36). However, it must be noted that Sweden's delegation of authority related to Operator CPCs does not appear to be substantially different than the arrangement in the UK, where regional Traffic Commissioners are responsible.

Sweden's transposition of provisions of the EU directive related to the content of the CPC exam [Article 3(4)(a)] did not meet the 1999 deadline for overall transposition. The regulations on exam content were developed by Vägverket under authority delegated by the Government, and were largely completed in 2001. The resulting regulation, the Professional Competency Regulation 2001 (VVFS 2001:51), includes a list of topics that is consistent with the Operator CPC Directive. However, the Swedish regulation does a good deal more than reproduce the Directive; it cites a number of overarching training goals and learning objectives. For example, the applicants must be able to "use knowledge both theoretically and practically," "use their own conclusions [to] evaluate the result," "perform a work task from beginning to end," and "explore, compare, and assess the result" [Chapter 1, 2 §] (Vägverket, May 11, 2001). This language suggests that the Vägverket staff members who developed the regulation ascribed enough importance to training effectiveness to explicitly address the means by which this would be achieved.

As was the case with a similar provision in the Driving License Directive, Sweden correctly transposed the provision of the Operator CPC Directive that required recognition of CPCs issued 
in another member state. Sweden's recognition extended to the EEA states that did not belong to the EU.

Sweden transposed most of the Operator CPC Directive correctly and within the required time frame through legislation in the Riksdag and a Government ordinance that followed soon thereafter. It lagged behind in transposing certain more detailed requirements, a task that fell to Vägverket. Vägverket's 2001 transposition, however, was not a mere parroting back of the Directive, and added considerable value through its careful articulation of desired training outcomes.

\section{Road Transport Working Time Directive}

\section{Directive 2002/15/EC of the European Parliament and of the Council of 11 March 2002 on the organisation of the working time of persons performing mobile road transport activities}

Unlike the UK, where working hours for road transport workers are managed within the DfT body of regulations, and working hours for other industries are the responsibility of the HSE, Sweden placed all working-hours rules within its OSH agency, the Arbetsmiljöverket. This is stated in the Road Transport Working Time Act 2005 (Sweden's transposition of the EU directive) [22 §] (Näringsdepartementet [Ministry of Enterprise (Sweden)], June 13, 2005). It is also reflected in the WEA's incorporation by reference of the working time regulations for road transport and other occupations [Chapter 2, 10§] (Arbetsmiljöverket, 2010b). However, this arrangement changed as of 2011, when responsibility for enforcing the Road Transport Working Time Act shifted to Transportstyrelsen. Enforcement of working time legislation for other work settings has remained in the Arbetsmiljöverket (Arbetsmiljöverket, December 1, 2010, November 11, 2010).

Table 5-5. Swedish transposition of Road Transport Working Time Directive (2002/15/EC)

\begin{tabular}{|c|c|}
\hline EU Directive & Swedish Legislation \\
\hline $\begin{array}{l}\text { Article 4: Maximum weekly working time } \\
\text { Member States shall take the measures necessary to } \\
\text { ensure that: } \\
\text { (a) the average weekly working time may not exceed } \\
48 \text { hours. The maximum weekly working time may be } \\
\text { extended to } 60 \text { hours only if, over four months, an } \\
\text { average of } 48 \text { hours a week is not exceeded. }\end{array}$ & $\begin{array}{l}\text { Road Transport Working Time Act } 2005 \\
\text { Regular working hours } \\
5 \text { § The standard working week shall not exceed } 40 \text { hours } \\
\text { per week. As required by the nature of work or working } \\
\text { conditions in general, the working time is } 40 \text { hours per } \\
\text { week on average over the last four weeks. }\end{array}$ \\
\hline $\begin{array}{l}\text { Article } 5 \text { : Breaks } \\
1 . \text { Member States shall take the measures necessary to } \\
\text { ensure that, without prejudice to the level of } \\
\text { protection provided by Regulation (EEC) No } 3820 / 85 \\
\text { or, failing that, by the AETR Agreement, persons } \\
\text { performing mobile road transport activities, without } \\
\text { prejudice to Article 2(1), in no circumstances work for } \\
\text { more than six consecutive hours without a break. } \\
\text { Working time shall be interrupted by a break of at } \\
\text { least } 30 \text { minutes, if working hours total between six }\end{array}$ & $\begin{array}{l}\text { Road Transport Working Time Act } 2005 \\
\text { Breaks and pauses } \\
\mathbf{1 8} \S \text { Work should never be longer than six consecutive } \\
\text { hours without a break. Break must be at least } 30 \text { minutes, } \\
\text { if working between six and nine hours. If working time } \\
\text { exceeds nine hours, the break shall be at least } 45 \text { minutes. } \\
\text { The break may be divided into periods of at least } 15 \\
\text { minutes each. }\end{array}$ \\
\hline
\end{tabular}




\begin{tabular}{|c|c|}
\hline $\begin{array}{l}\text { and nine hours, and of at least } 45 \text { minutes, if working } \\
\text { hours total more than nine hours. }\end{array}$ & \\
\hline $\begin{array}{l}\text { Article 7: Night work } \\
\text { 1. Member States shall take the measures necessary to } \\
\text { ensure that: } \\
\text { - if night work is performed, the daily working time } \\
\text { does not exceed ten hours in each } 24 \text { [hour] period, } \\
\text { - compensation for night work is given in accordance } \\
\text { with national legislative measures, collective } \\
\text { agreements, agreements between the two sides of } \\
\text { industry and/or national practice, on condition that } \\
\text { such compensation is not liable to endanger road } \\
\text { safety. }\end{array}$ & $\begin{array}{l}\text { Road Transport Working Time Act } 2005 \\
\text { Night work } \\
14 \S \text { Night work means work in any part of the period } \\
\text { which begins at } 1: 00 \text { and ends at } 5.00 \text {. } \\
\text { 15 } \S \text { If night work is included in a } 24 \text { - hour period } \\
\text { beginning after completion of such a rest period referred } \\
\text { to in Article } 8 \text { or } 9 \text { of the European Parliament and } \\
\text { Council Regulation ( EC ) No 561/2006, Article } 8 \text { of the } \\
\text { AETR or } 13 \text { or } 14 \S \text { Working Time (1982:673), working } \\
\text { time during that period must not exceed ten hours. } \\
\text { Derogations by collective agreements } \\
2 \S \text { The collective agreements concluded or approved by } \\
\text { a central employee bargaining unit, exceptions to the } \\
\text { provisions of } 5 \text {-9 } \S \S, \S 12 \text { second paragraph, and } 15 \text { and } \\
16 \S \S \text {. Through such a collective bargaining agreement: } \\
1 \text { st time period for calculating the maximum working } \\
\text { hours under } \S 12 \text { first paragraph may be extended to up to } \\
\text { six months; } \\
2 \text { nd another period of the night than those specified in } \S \\
14 \text { be determined, but would be at or after } 0: 00 \text { pm. } 7: 00 \text {. } \\
\text { Such a collective agreement referred to in the first } \\
\text { paragraph may also determine the extent to which periods } \\
\text { of waiting to be counted as working time. Periods of } \\
\text { waiting means that the worker cannot dispose freely of } \\
\text { his time, but must be at his workplace prepared to } \\
\text { perform work, under the provisions of } \S 12 \text { third } \\
\text { paragraph, second paragraph of } \S 15 \text { and } \S 18 \text { third } \\
\text { paragraph. } \\
\text { Exceptions to } \S 8 \text { second and third paragraphs may also } \\
\text { be made under the collective agreements concluded by a } \\
\text { local employee bargaining unit. Such exceptions, } \\
\text { however, may extend no longer than one month from the } \\
\text { date of conclusion. } \\
3 \S \text { An employer bound by collective agreements referred } \\
\text { to in } \S 2 \text { may apply the agreement to workers who are not } \\
\text { members of the contracting employees but who are } \\
\text { engaged in such work covered by the agreement. } \\
4 \S \text { A collective agreement is void to the extent that it } \\
\text { entails less favorable rules apply to employees than those } \\
\text { prescribed by this Act. }\end{array}$ \\
\hline $\begin{array}{l}\text { Article 11: Penalties } \\
\text { Member States shall lay down a system of penalties } \\
\text { for breaches of the national provisions adopted } \\
\text { pursuant to this Directive and shall take all the } \\
\text { measures necessary to ensure that these penalties are } \\
\text { applied. The penalties thus provided for shall be } \\
\text { effective, proportional and dissuasive. }\end{array}$ & $\begin{array}{l}\text { Road Transport Working Time Act } 2005 \\
\text { Penalties etc. } \\
25 \S \text { A fine or imprisonment not exceeding one year shall } \\
\text { be imposed on employers who intentionally or } \\
\text { negligently violates an injunction or prohibition issued } \\
\text { pursuant to } \S 24 \text {. This does not apply if the injunction or } \\
\text { prohibition has been combined with a penalty. } \\
26 \S \text { A fine is imposed on an employer who willfully or } \\
\text { negligently } \\
\text { 1st schedules work so that } \\
\text { a) the employee's working hours have exceeded what is } \\
\text { permitted under the provisions of this Act; }\end{array}$ \\
\hline
\end{tabular}




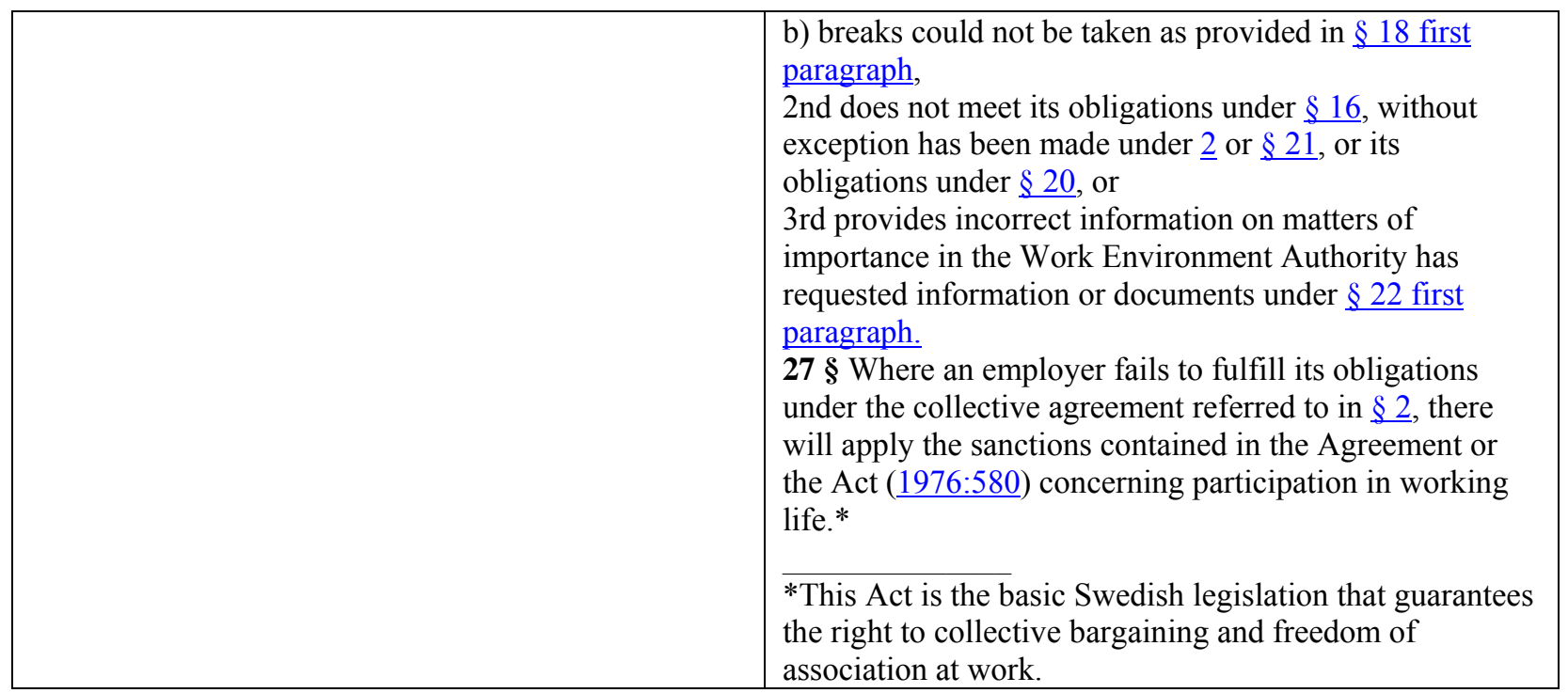

There has been longstanding pan-European concern about working time for drivers who transport freight and passengers in large trucks and buses. Efforts to manage the issue came first through international agreements such as the AETR and then through EU directives. ${ }^{74}$ Long before it joined the EU, Sweden like most other high-income countries had its own legislation on working hours in road transport. As early as 1972, Sweden set requirements for maximum working hours during a 24-hour period, required rest breaks, and logbooks for recording working hours (Kommunikationsdepartementet [Ministry of Communications (Sweden)], January 12, 1972).

On its accession to the EU, Sweden was required to incorporate the existing body of EU directives into its state-level law. At that time, the EU working time rules were in the form of a regulation $(85 / 3820 / \mathrm{EEC})$ that had direct application and therefore required no state-level transposition. The 1972 Swedish law and its subsequent amendments were repealed late in 1994 in anticipation of the EU regulation taking effect upon Sweden's 1995 accession to the EU.

After Regulation 85/3820/EEC, the next EU legislation on working time in transport operations was the Road Transport Working Time Directive (2002/15/EC). Having repealed its 1972 law, Sweden drafted entirely new legislation in response to the EU directive. Sweden's Road Transport Working Time Act 2005 was enacted in June of that year, slightly less than three months after the EU transposition deadline.

Sweden's transposition of the Road Transport Working Time Directive closely parallels its transposition of the Working Time Directive in its adherence to a 40-hour work week despite the option to adopt the 48-hour work week allowed by the EU. Other than this particular point, the Swedish transposition does not deviate substantially from the EU directive, correctly transposing provisions related to rest breaks, night work, and penalties. Of note, the Swedish legislation goes into considerable detail about the conditions under which derogation may be obtained through

\footnotetext{
${ }^{74}$ Whereas the AETR (developed under the aegis of the UN Economic Commission for Europe) applies strictly to international road transport, the EU directives cover domestic journeys as well.
} 
collective agreements between labor and management, reflecting the Swedish tradition of social dialogue in the workplace. This emphasis on problem-solving without government necessarily being involved is a cornerstone of the Swedish model of labor and employment law, which is founded on beliefs that the state ought to be neutral with respect to interactions between the social partners, and that legislation is an unwelcome interference in the labor market (Carlson, 2009 , p. 363). In general, Swedish labor legislation has offered labor and management considerable opportunity to opt out of statutory requirements, based on a "policy core belief" that problems are best solved by the parties most directly involved (Carlson, 2009, p. 37; P. Sabatier \& Weible, 2007, pp. 194-196).

Sweden is unusual in that it has developed state-level regulations for working time and rest periods for workers who drive lighter vehicles, which complement the EU Road Transport Working Time Directive. For drivers of light as well as heavy vehicles, the stated aims of Swedish regulations are to ensure fair competition, promote better road safety, and improve the social situation of drivers. The importance of managing working hours for operators of heavy and light occupational vehicles seem to be viewed on a par with one another, with the primary distinction being that heavy-vehicle regulations are guided by EU policy and light-vehicle regulations by state-level policy decisions (Yrkestrafiken.se, 2010).

The Swedish rules applicable to drivers of lighter vehicles date from 1994, when an ordinance (SFS 1994:1297) was enacted to address work time and rest periods for certain workplace drivers of vehicles under 3.5 tonnes (the EU cutpoint that distinguishes between "light" and "heavy" vehicles). This is an area in which the EU has to date issued no directives. The Swedish working time ordinance for light vehicles is enforced by Transportstyrelsen along with the police (Arbetsmiljöverket, December 1, 2010). The ordinance applies to drivers of vehicles in this class used for mail transport, commercial taxi service, transport of school students, and transport of milk from farms to market [2 §] (Näringsdepartementet [Ministry of Enterprise (Sweden)], August 9, 1994). Similar to the Road Transport Working Time Act 2005, it requires at least an eleven-hour rest period in the twenty-four-hour period before the transport activity starts [3 3$]$ (Näringsdepartementet [Ministry of Enterprise (Sweden)], August 9, 1994).

The Swedish working time rules for light vehicles also require all drivers, employed or selfemployed, to maintain a personal logbook for recording rest periods, and to have the logbook available for inspection by law enforcement officers during each journey [5 $\S-10 \S]$ (Näringsdepartementet [Ministry of Enterprise (Sweden)], August 9, 1994). A subsequent regulation by Vägverket sets out more detailed procedures for maintaining the logbook, and also offers the option of tracking driving hours using a tachograph (an electronic on-board data recorder required by a $1985 \mathrm{EU}$ directive $(85 / 3820 / \mathrm{EEC})$ applicable to large vehicles transporting passengers and freight) (Vägverket, December 9, 1994). It is noteworthy that drivers of light vehicles might be expected to record their driving hours via on-board equipment. This indicates a general acceptance in Sweden that such monitoring is not punitive, but a safety measure for the worker's protection. It also suggests that Sweden's framing of occupational road safety is holistic, taking in workers other than the truck and bus drivers traditionally managed through road safety and OSH regulations. 


\title{
Working Time Directive
}

\section{Directive 2003/88/EC of the European Parliament and of the Council of 4 November 2003 concerning certain aspects of the organisation of working time}

\author{
Table 5-6. Swedish transposition of Working Time Directive (2003/88/EC)
}

\begin{tabular}{|c|c|}
\hline EU Directive & Swedish Legislation \\
\hline $\begin{array}{l}\text { Article 1: Purpose and scope } \\
\text { 3. This Directive shall apply to all sectors of activity, both } \\
\text { public and private, within the meaning of Article } 2 \text { of } \\
\text { Directive } 89 / 391 / \text { EEC, } * \text { without prejudice to Articles } 14,17 \text {, } \\
18 \text { and } 19 \text { of this Directive. }\end{array}$ & $\begin{array}{l}\text { Working Hours Act } 1982 \\
\text { Scope } \\
\mathbf{1} \text { § This Act shall apply to all activities in which an } \\
\text { employee performs work on behalf of an employer, } \\
\text { subject to the restrictions referred to in Section } 2 \text {. }\end{array}$ \\
\hline $\begin{array}{l}\text { *Article 2(1). This Directive shall apply to all sectors of } \\
\text { activity, both public and private (industrial, agricultural, } \\
\text { commercial, administrative, service, educational, cultural, } \\
\text { leisure, etc.) (Commission of the European Communities, } \\
\text { June 26, 1989). }\end{array}$ & \\
\hline $\begin{array}{l}\text { Article 3: Daily rest } \\
\text { Member States shall take the measures necessary to ensure } \\
\text { that every worker is entitled to a minimum daily rest period } \\
\text { of } 11 \text { consecutive hours per 24-hour period. }\end{array}$ & $\begin{array}{l}\text { Working Hours Act Amendment \#1 } 2005 \\
\text { Disposition of working hours, etc. } \\
\mathbf{1 3} \S \text { All employees shall have at least eleven hours } \\
\text { consecutive hours of free time for every period of } \\
\text { twenty-four hours (daily rest period). Deviations may be } \\
\text { made temporarily provided this is caused by some } \\
\text { special circumstance that it was not possible to } \\
\text { anticipate by the employer, subject to the precondition } \\
\text { that the employee is given corresponding compensatory } \\
\text { leave. }\end{array}$ \\
\hline $\begin{array}{l}\text { Article 4: Breaks } \\
\text { Member States shall take the measures necessary to ensure } \\
\text { that, where the working day is longer than six hours, every } \\
\text { worker is entitled to a rest break, the details of which, } \\
\text { including duration and the terms on which it is granted, shall } \\
\text { be laid down in collective agreements or agreements between } \\
\text { the two sides of industry or, failing that, by national } \\
\text { legislation. }\end{array}$ & $\begin{array}{l}\text { Working Hours Act } 1982 \\
\text { Disposition of working hours, etc. } \\
\mathbf{1 5} \S \text { Rest intervals are defined as interruptions in daily } \\
\text { working hours during which employees are not obliged } \\
\text { to remain at the workplace. } \\
\text { The employer shall state the duration and disposition of } \\
\text { rest intervals in advance and as exactly as circumstances } \\
\text { permit. } \\
\text { Rest intervals are to be arranged in such a way that the } \\
\text { employees do not carry out work for more than five } \\
\text { consecutive hours. The number, duration and disposition } \\
\text { of rest intervals must be satisfactory with regard to } \\
\text { working conditions. } \\
\text { Exemptions by the National Board of Occupational } \\
\text { Safety and Health } \\
\mathbf{1 9} \text { \& Where a collective bargaining agreement as } \\
\text { referred to in Section } 3 \text { cannot be concluded, the } \\
\text { Swedish Work Environment Authority may allow the } \\
\text { following where there is special cause: } \\
\text { 5. deviations from Section } 10 \text { a, Sections } 13 \text { - } 14 \text { and } \\
\text { Section } 15 \text {, second and third paragraphs. }\end{array}$ \\
\hline $\begin{array}{l}\text { Article 5: Weekly rest period } \\
\text { Member States shall take the measures necessary to ensure } \\
\text { that, per each seven-day period, every worker is entitled to a }\end{array}$ & $\begin{array}{l}\text { Working Hours Act } 1982 \\
\text { Disposition of working hours, etc. } \\
\mathbf{1 4} \text { §Employees are entitled to not less than thirty-six }\end{array}$ \\
\hline
\end{tabular}




\begin{tabular}{|c|c|}
\hline $\begin{array}{l}\text { minimum uninterrupted rest period of } 24 \text { hours plus the } 11 \\
\text { hours' daily rest referred to in Article } 3 \text {. }\end{array}$ & $\begin{array}{l}\text { consecutive hours of free time (weekly rest) within } \\
\text { every period of seven days. This weekly rest shall not } \\
\text { include stand-by hours when an employee is permitted } \\
\text { to stay away from the workplace but must remain at the } \\
\text { employer's disposal in order to carry out work should } \\
\text { the need arise. }\end{array}$ \\
\hline $\begin{array}{l}\text { Article 6: Maximum weekly working time } \\
\text { Member States shall take the measures necessary to ensure } \\
\text { that, in keeping with the need to protect the safety and health } \\
\text { of workers: } \\
\text { (a) the period of weekly working time is limited by means of } \\
\text { laws, regulations and administrative provisions or by } \\
\text { collective agreements or agreements between the two sides } \\
\text { of industry; } \\
\text { (b) the average working time for each seven-day period, } \\
\text { including overtime, does not exceed } 48 \text { hours. }\end{array}$ & 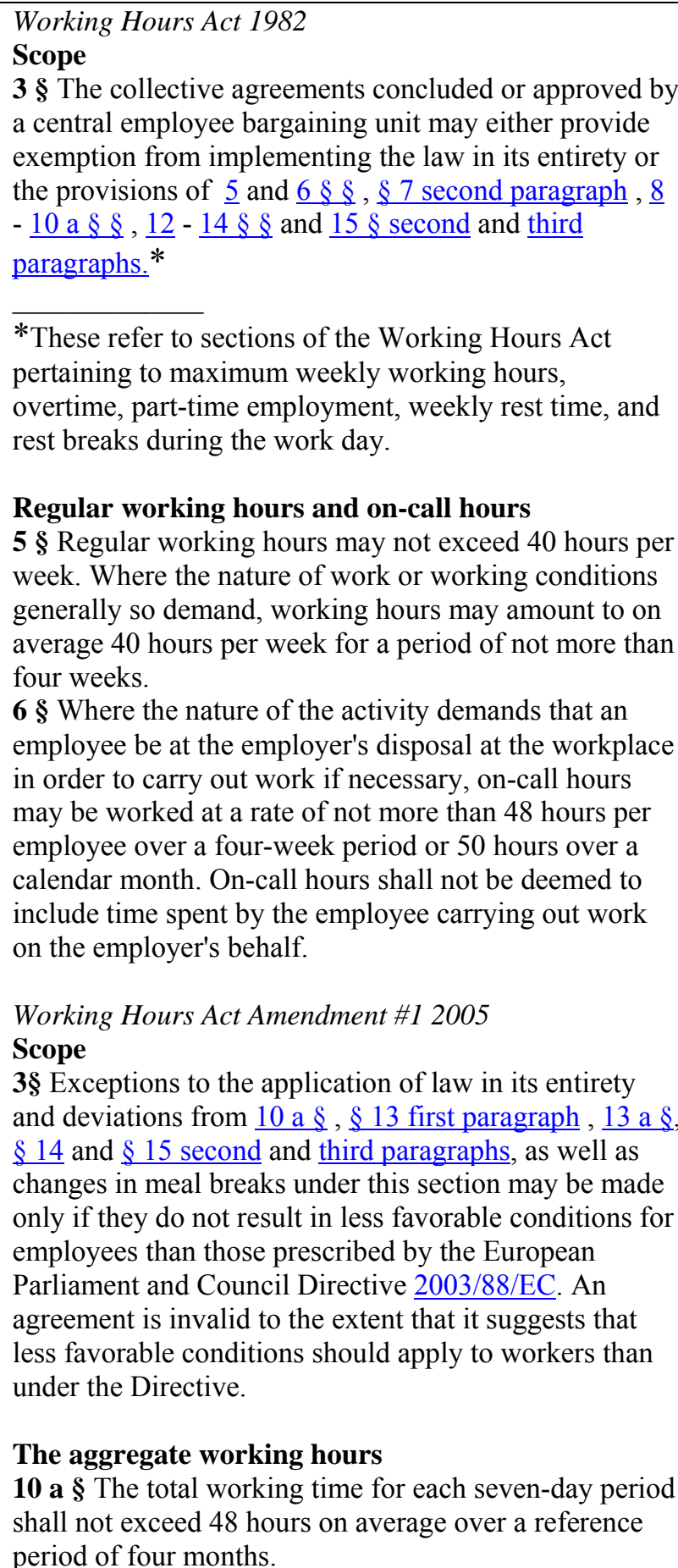 \\
\hline $\begin{array}{l}\text { Article 8: Length of night work } \\
\text { Member States shall take the measures necessary to ensure } \\
\text { that: }\end{array}$ & $\begin{array}{l}\text { Working Hours Act Amendment } \# 12005 \\
\text { Working time, etc. } \\
13 \text { a } \S \text { The working hours for night work may, for any }\end{array}$ \\
\hline
\end{tabular}


(a) normal hours of work for night workers do not exceed an average of eight hours in any 24-hour period;

(b) night workers whose work involves special hazards or heavy physical or mental strain do not work more than eight hours in any period of 24 hours during which they perform night work. period of twenty-four hours, not exceed eight hours on average over a reference period of four months. The average calculation shall be counted from the reference period twenty-four hours for every period of seven days. Vacation and sick leave during the time when the employee would otherwise have worked is to be treated as time worked.

Night workers whose work involves special hazards or heavy physical or mental strain shall not work more than eight hours in any period of twenty-four hours that they perform work during the night. Deviations may be made temporarily, if it is caused by some special circumstance that could not be foreseen by the employer, provided that the employee is given equivalent compensatory rest.

The night worker means a person who normally works at least three hours of his shift during the night and will probably perform at least one third of their annual working time during night. The night means the period between 22 o'clock and 6 o'clock.

\section{Article 20}

\section{Mobile workers and offshore work}

1. Articles 3, 4, 5 and 8 shall not apply to mobile workers.* Member States shall, however, take the necessary measures to ensure that such mobile workers are entitled to adequate rest, except in the circumstances laid down in Article 17(3)(f) and $(\mathrm{g})$.** $^{* *}$

*defined as "any worker employed as a member of travelling or flying personnel by an undertaking which operates transport services for passengers or goods by road, air or inland waterway" [Article 2(7)]

**(f) in the circumstances described in Article 5(4) of Directive 89/391/EEC [This Directive shall not restrict the option of Member States to provide for the exclusion or the limitation of employers' responsibility where occurrences are due to unusual and unforeseeable circumstances, beyond the employers' control, or to exceptional events, the consequences of which could not have been avoided despite the exercise of all due care (Commission of the European Communities, June 26, 1989).]

$(\mathrm{g})$ in cases of accident or imminent risk of accident.

$2 \S$ This Act does not apply to the following:
Working Time Act Amendment \#1 2005

\section{Scope}

$2 \S$ This Act does not apply to the following:

4. work on board a ship;

The Government, or the authority appointed by the Government, may prescribe that this Act shall apply to work on board a ship that is exempted from the provisions concerning resting time contained in the Resting Time for Seamen Act (1998:958).

\section{Working Time Act Amendment \#2 2005}

\section{Scope}

5. work within the scope of the Working Hours for Certain Road Transport Work Act (2005:395).

\section{Working Time Act Amendment \#3 2005}

\section{Scope}

$2 \S$ The provisions contained in Section 10 a, Section 13, first paragraph, Section 13 a and Section 14, third paragraph, second sentence do not apply when the Working Hours, etc. of Mobile Workers in Civil Aviation Act (2005:426) applies or within government operations such as for example the Armed Forces, the Police and protection and emergency services for work that is special for such operations and which is of such a kind that a conflict cannot be avoided with the Directive 2003/88/EC of the European Parliament and of the Council of 4 November 2003 concerning certain aspects of the organisation of working time.

The Working Hours, etc. of Mobile Workers in Civil Aviation Act contains provisions on annual working time and days free of all duty at the place of posting for 


\begin{tabular}{|c|c|}
\hline & $\begin{array}{l}\text { such mobile workers. } \\
\text { Working Time Act Amendment } 2008 \\
\text { Scope } \\
2 \S \text { The provisions of } \S 13 \text { first paragraph }, \S 14 \text { and } \S \\
\frac{15 \text { third paragraph does not apply where the law }}{(\underline{2008: 475)} \text { on driving and rest in international rail }} \\
\text { applies. }\end{array}$ \\
\hline $\begin{array}{l}\text { Article } 22 \\
\text { Miscellaneous provisions } \\
\text { 1. A Member State shall have the option not to apply Article } \\
6 \text {, while respecting the general principles of the protection of } \\
\text { the safety and health of workers, and provided it takes the } \\
\text { necessary measures to ensure that: } \\
\text { (a) no employer requires a worker to work more than } 48 \\
\text { hours over a seven-day period, calculated as an average for } \\
\text { the reference period referred to in Article } 16(\text { b), unless he } \\
\text { has first obtained the worker's agreement to perform such } \\
\text { work; } \\
\text { (b) no worker is subjected to any detriment by his employer } \\
\text { because he is not willing to give his agreement to perform } \\
\text { such work; }\end{array}$ & $\begin{array}{l}\text { Working Hours Act } 1982 \\
\text { Scope } \\
3 \S \text { The collective agreements concluded or approved by } \\
\text { a central employee bargaining unit may either provide } \\
\text { exemption from implementing the law in its entirety or } \\
\text { the provisions of } \underline{5} \text { and } 6 \S \S, \S 7 \text { second paragraph }, \underline{8} \\
-10 \text { a } \S \S, 12-14 \S \S \text { and } 15 \S \text { second and third } \\
\text { paragraphs. } \\
\text { Regular working hours and on-call hours } \\
5 \S \text { Regular working hours may not exceed } 40 \text { hours per } \\
\text { week. Where the nature of work or working conditions } \\
\text { generally so demand, working hours may amount to on } \\
\text { average } 40 \text { hours per week for a period of not more than } \\
\text { four weeks. } \\
6 \text { } \S \text { Where the nature of the activity demands that an } \\
\text { employee be at the employer's disposal at the workplace } \\
\text { in order to carry out work if necessary, on-call hours } \\
\text { may be worked at a rate of not more than } 48 \text { hours per } \\
\text { employee over a four-week period or } 50 \text { hours over a } \\
\text { calendar month. On-call hours shall not be deemed to } \\
\text { include time spent by the employee carrying out work } \\
\text { on the employer's behalf. }\end{array}$ \\
\hline
\end{tabular}

Sweden was an early adopter of working time legislation, passing its framework Working Hours Act in 1982, which was at the time in compliance with many provisions of the EU directive that followed two decades later. ${ }^{75}$ For example, the EU directive requires that workers not be permitted to work more than six hours before a break; in Sweden, the limit has been five hours since 1982. Similarly, Swedish rules for mandatory daily and weekly rest periods were already compliant with the EU Working Time Directive; the Working Hours Act of 1982 was at least as protective or slightly more protective on these points.

Sweden's overall transposition of 2003/88/EC did not, however, meet the EU deadline of August 2004. Moreover, the process was greatly complicated by a case that was successfully brought against Sweden in the ECJ for incomplete transposition of 93/104/EC, the original EU Working Time Directive (European Court of Justice, July 23, 2005, September 11, 2004). The case against Sweden was argued on three main points:

- That Swedish legislation did not guarantee a minimum daily rest period of eleven consecutive hours in each twenty-four-hour period [Article 3];

\footnotetext{
75 The 1977 WEA also mentions that working hours are to be taken into consideration in decisions about workplace technologies, work organization, and the content of jobs. However, the WEA, as framework legislation, did not contain specific requirements, leaving that task to the relevant ministry (at the time, the Ministry of Labour).
} 
- That Swedish legislation extended the reference period used to compute deviations from average weekly working hours beyond the four months provided for in the Directive [Article 6]; and

- That the Directive's special provisions for night work were not incorporated into Swedish legislation [Article 8].

With respect to Article 3, Sweden argued that because the majority of workers were covered by collective agreements, non-transposition of EU provisions on minimum daily rest was not critical. The Commission contended, however, that this was not a valid reason for failure to transpose, and that state law must ensure that this protection was available to all workers (European Court of Justice, September 11, 2004).

In response to the ECJ judgment, several changes were made to the Working Hours Act in April through June of 2005 to bring Sweden into compliance with the EU Working Time Directive. Most of these were accomplished through the Working Hours Act Amendment \#1 (SFS 2005:165), which modified Sections 3 and 8 of the Act to remedy previous omissions related to minimum daily rest periods and night work, respectively.

A number of other changes were made to the Working Hours Act in 2005. One of these was a more complete transposition of Article 20 of the EU directive, which said that although some of the provisions did not apply to mobile workers, member states were still expected to set standards to allow these workers to obtain adequate rest. Sweden's solution was to incorporate by reference its regulations for working time and rest periods for certain groups of transport workers. Rules for truck drivers, air crews, and seafarers were added by reference in 2005, and rules for railway workers were added in 2008.

Another 2005 change was potentially quite far-reaching. In 1982, the original Working Hours Act set the maximum work week in Sweden at 40 hours, compared to the EU maximum of 48 hours set by the Working Hours Directive. However, Sweden's Working Hours Act allowed derogations from the maximum weekly working hours through collective agreements, as well as similar derogations for numerous other aspects of working time legislation, including overtime, weekly rest time, and rest breaks (see Swedish transposition of Article 6 in Table 5-6 above). Thus, although the maximum Swedish work week of 40 hours suggests that Swedish working time legislation afforded more protection than the EU legislation, such a conclusion is questionable given the range of possible derogations from this and many other provisions. However, a 2005 amendment to the Working Hours Act stipulated that any exceptions could be made by collective agreement "only if they do not result in less favorable conditions for employees than those prescribed by the European Parliament and Council Directive 2003/88/EC" (Näringsdepartementet [Ministry of Enterprise (Sweden)], April 5, 2005). This limited the effect of all types of derogations, and in effect set an upper limit on derogations from the maximum weekly work hour provisions, capping them at the EU 48-hour maximum.

Swedish transposition of the "individual opt-out" provision of the EU directive [Article 22(1)(a)] is somewhat ambiguous. The Swedish transposition falls back on Sections 3 and 5 of the 1982 Working Time Act, which cover maximum weekly working hours and overall options for derogations from numerous working time provisions via collective agreements. The Swedish 
legislation does not explicitly address the issue of derogations for individual workers. However, an Arbetsmiljöverket attorney with expertise in working time regulations confirms that Section 3 of the current Working Time Act may be interpreted to mean that all permissible types of derogations may be authorized through collective agreements, including arrangements with individual workers as provided for in the EU Working Time Directive (Arbetsmiljöverket, December 1, 2010).

\section{Seat Belt Directive}

\section{Directive 2003/20/EC of the European Parliament and of the Council of 8 April 2003 amending Council Directive 91/671/EEC on the approximation of the laws of the Member States relating to compulsory use of safety belts in vehicles of less than 3,5 tonnes}

Table 5-7. Swedish transposition of Seat Belt Directive (2003/20/EC)

\begin{tabular}{|c|c|}
\hline EU Directive & Swedish Regulations \\
\hline $\begin{array}{l}\text { Article 2(1)(a)(i): M1, N1, N2 and N3 vehicles: for M1, NI, } \\
\mathrm{N} 2 \text { and } \mathrm{N} 3^{76} \text { vehicles, Member States shall require that all } \\
\text { occupants of vehicles in use shall use the safety systems } \\
\text { provided. }\end{array}$ & $\begin{array}{l}\text { Amendment to Traffic Legislation } 1974 \\
\text { The Traffic Committee proposes Parliament to adopt } \\
\text {.. the draft law amending the Law (1916: 312) } \\
\text { concerning liability for damage in consequence of } \\
\text { automobile traffic [requiring mandatory use of seat } \\
\text { belts]. } \\
\text { Road Traffic Ordinance } 1998 \\
\text { Chapter 4. Provisions for the Operation of Motor } \\
\text { Vehicles } \\
\mathbf{1 0} \S \text { When traveling by road in a car, a truck, a three-or } \\
\text { four-wheeled motorcycle with a body or a three-or } \\
\text { four-wheeled scooter with a body, the following } \\
\text { applies to the use of seat belts and other safety devices: } \\
\text { 1st All occupants of a vehicle equipped with safety } \\
\text { belts must use a seat that is equipped with seat belts, if } \\
\text { such a place is available, and use the belt. }\end{array}$ \\
\hline $\begin{array}{l}\text { Article 2(2)(a): M2 and M3 vehicles: Member States shall } \\
\text { require that all occupants aged three and over of M2 and M3 } \\
\text { vehicles in use shall use the safety systems provided while } \\
\text { they are seated. }\end{array}$ & $\begin{array}{l}\text { Road Traffic Ordinance Amended } 2006 \\
\text { Chapter 4. Provisions for the Operation of Motor } \\
\text { Vehicles } \\
\mathbf{1 0} \text { a } \S \text { Anyone who is older than three years and } \\
\text { traveling in a bus which is equipped with safety belts } \\
\text { must use a seat that is equipped with seat belts, if such } \\
\text { a place is available, and use the belt. For local transport } \\
\text { in urban areas, however, passengers may use a location } \\
\text { other than a place that is equipped with seat belts. }\end{array}$ \\
\hline $\begin{array}{l}\text { Article 2(2)(b): passengers in M2 and M3 vehicles [buses] } \\
\text { shall be informed of the requirement to wear safety belts } \\
\text { whenever they are seated and the vehicle is in motion. }\end{array}$ & $\begin{array}{l}\text { Road Traffic Ordinance Amended } 2006 \\
\text { Chapter 4. Provisions for the Operation of Motor } \\
\text { Vehicles }\end{array}$ \\
\hline
\end{tabular}

\footnotetext{
${ }^{76}$ These categories refer to an old system of categorizing motor vehicles which was supplanted by the system now used for EU driving licenses. Essentially, $\mathrm{M}$ and $\mathrm{N}$ vehicles comprise vehicles of any size and weight which are intended to carry goods or passengers and are used primarily on public roadways (Commission of the European Communities, February 23, 1970).
} 
10 a § Passengers of a bus shall be informed of the requirement to wear a seat belt in the manner that the Transportation Board prescribes.

A Swedish law for mandatory use of safety belts went into effect in 1975, but the topic was discussed in the Riksdag as early as 1971, when the King of Sweden requested the Riksdag to look into the matter in response to a letter from citizens Mr. and Mrs. Hjorth Thunvall. The King's request, in the form of Bill 1971:204, asked the Riksdag to consider requiring that cars be equipped with safety belts (Trafikutskottets, 1971). The issue was considered by the Trafikutskottets [Traffic Committee] of the Riksdag, which consulted the Trafiksäkerhetsverket in developing its recommendations. In its report back to the full Riksdag, the Trafikutskottets rejected the proposal, more on the basis of further research and development needs and ongoing activity than on the actual merits of the proposal:

The low frequency of use has led to an examination of the possibilities of obtaining some form of automatically-acting protection. Efforts should therefore focus on producing belts that are easy to use. In this context, the Committee also recalled the campaign for safety belts in the interaction between Trafiksäkerhetsverket, the National Police and the insurance company Folksam going on for some time. (Trafikutskottets, 1971)

Proposals to require mandatory use of safety belts, as opposed to simply equipping vehicles with them as in the 1971 initiative, were successfully introduced in 1974 and became effective in January of 1975. Unlike the 1971 effort, the 1974 proposal for mandatory belt use was formally introduced in the Riksdag as an amendment to existing legislation, a law from 1916 addressing liability for damage occurring as a consequence of automobile traffic. ${ }^{77} 78$

Based on background information in the proposal, there was evidently substantial consultative activity surrounding safety belts between 1971 and 1974. In 1972, Sweden, along with Denmark, Norway, and Finland, began to participate in a commission of the Nordic countries that was formed to develop common recommendations for safety belts. Within Sweden, consultation was broad-based, with the participation of Trafiksäkerhetsverket, the insurance company Folksam, the OSH agency, county governments, the automobile club, a trade union, and many others. The commission's conclusions, cited in the proposal, considered Swedish crash data, the status of safety belt legislation in other countries, arguments for and against mandatory belt use, and estimated lives saved if belt use were to be increased beyond the current estimate of 10 to 30 percent (Sverige Riksdag, 1974).

Government and worker groups expressed divergent opinions on the proposed safety belt law. The OSH agency stated that it viewed safety belts as a form of worker protection in the spirit of its commitment to occupational safety, even if the obligation to wear safety belts was not currently part of the law. On the other hand, the Swedish Transport Workers' Federation

\footnotetext{
${ }^{77}$ In practice, the requirement to wear a seat belt would mean that front seat occupants would be required to do so, as many vehicles on the road at the time would not have had rear seat belts.

${ }^{78}$ Sweden did not pass "umbrella" legislation on rules of the road until 1998. Presumably, the 1916 legislation was the most appropriate existing legislation to which the seat belt provisions could be attached.
} 
cautioned that serious practical problems might arise if the requirement were to be extended to all commercial traffic, and advised that public information campaigns ought to be tried first (Sverige Riksdag, 1974).

Like the 1971 initiative, the 1974 proposal went through the Trafikutskottets, which in its report to the Riksdag reiterated many of the findings presented in the proposal and reviewed a number of objections raised during the consultations that were part of its fact-finding process. Ultimately, the proposal was approved based on clear evidence that seat belts save lives and a conviction that legislation was the best avenue for increasing belt use in Sweden. In this initial legislation, certain exceptions were allowed, for example, for those presenting a doctor's certificate, for those engaged in local mail distribution, and for taxi drivers, who had strongly opposed the law (Trafikutskottets, 1974).

In 1998, Sweden passed the Road Traffic Ordinance, which combined various provisions governing road user behavior in a single piece of legislation. This legislation was already in compliance with nearly all provisions of the 2003 EU Seat Belt Directive. One exception was the requirement that bus passengers be informed of the requirement to wear a seat belt while the vehicle was in motion; this was remedied in 2006 with an amendment to the Road Traffic Ordinance, which missed the transposition deadline by nearly seven months.

\section{$\underline{\text { Summary and conclusions }}$}

\section{Swedish transposition of EU directives}

In their assessment of EU member states' transposition of selected labor and employment directives, Falkner et al. (2005), categorize Sweden as belonging to the "world of law observance" (Falkner, et al., 2005, pp. 332-333). With some qualifications, the research described here supports the hypothesis that Sweden belongs to the "world of law observance" for directives related to occupational road safety.

Although accuracy and quality of the transpositions were generally good, Sweden met with some difficulty in meeting EU transposition deadlines for the six directives considered in this research. Transposition delays were six months for the Driving License Directive, fourteen months for the Driver CPC Directive, three months for the Road Transport Working Time Directive, seven months for the Seat Belt Directive, and eight to ten months for the Working Time Directive (amended several times). Only the Operator CPC Directive was transposed in advance of the EU deadline. Transposition of the Driving License Directive missed the deadline by six months, although many of the provisions in the umbrella Driving Licences Act of 1998 were present in various agency-level regulations previously promulgated by Vägverket. Of note, Sweden correctly transposed the requirement for mutual recognition of driving licenses from other EU member states, a challenge for many other member states (Commission of the European Communities, March 28, 2002).

Sweden's transposition of the Driver CPC Directive, although late, showed no serious deficiencies in the quality of the transpositions of the key articles examined through this research. Although the Operator CPC Directive was transposed in advance of the EU deadline, 
the 1998 Swedish transposition, an Act of the Riksdag, was marked by some minor omissions that were not remedied until 2001 by an agency-level Vägverket regulation.

It is interesting to note that for two of the late transpositions, the Working Time Directive and the Seat Belt Directive, Sweden had decades-old state-level law that was already largely in compliance with the new EU directives. Moreover, in the case of the Working Time Directive, a case was successfully brought against Sweden for failure to transpose, suggesting that at least for the six directives examined here, Sweden does not fit wholly into the "world of law observance" suggested by Falkner and her colleagues.

The ACF - A strong role for "deep core" beliefs

There is strong support for the hypothesis, based on the ACF, that belief systems will play a strong role in framing of policy related to occupational road safety. For Sweden, evidence of those beliefs comes from the literature, legislation, and regulations. One of the most pervasive beliefs, undoubtedly a "deep core belief" as articulated by the ACF, is the view of the individual as a cog within the larger society and system. This is reflected in Vision Zero, Sweden's systembased road safety framework, which places comparatively little emphasis on changing individuals' behaviors, instead concentrating on creating a system such that individual differences and deficiencies are of little consequence to the proper functioning of the system. Individuals will inevitably make errors, but the system will accommodate these errors. Another example is Swedish driver licensing law, which draws on Nordic theories of driver education that link acquisition of driving experience to a progression toward self-actualization and personal maturity; positive driving behaviors and positive life goals go hand in hand (Berg, 2006; Hatakka, et al., 2002; Vägverket, July 10, 1996b).

The literature notes that Swedish policy debates and decisions have been underpinned by larger questions of what kind of society Swedish citizens want to have, driven by "non-materialistic values" (J. Richardson, Gustafsson, \& Jordan, 1982, pp. 7-8; Ruin, 1982, p. 151). One example from Swedish transport policy of the 1960s and 1970s is the debate about the relative merits of road and rail transport, which was not based on economic efficiency so much as concerns about the negative environmental and societal impacts of freight transport by truck (J. J. Richardson, 1979, p. 345). Another example is the more recent Vision Zero, which is much more than a policy frame for road safety. Vision Zero is imbued with ethical elements, leaving no question that the government must bring to bear whatever resources are necessary to achieve road safety goals. Achieving those goals is seen as one step in realizing a much larger vision of a risk-free society (Fahlquist, 2006; Johansson, 2009). The related Tylösand Declaration reinforces the premises of Vision Zero, articulating rights to use the road safely as basic rights of citizenship (Lie \& Tingvall, June 15-18, 2009).

Sweden's policy for occupational road safety has elements of the Continental form of transport policy described earlier, which sees transport as a public good where the state has some responsibility to intervene in pursuit of economic and social welfare goals (Stevens, 2004, p. 2). Sweden's policy is a hybrid because it has pursued social welfare goals for workplace safety and transport safety using state-driven approaches, but has chosen a liberal path economically. In 1963, the Swedish government decided to pursue a market-driven approach to road transport policy, relaxing provisions for entry and licensing in the road transport industry (J. J. Richardson, 
1979, pp. 344-345). Implementation was slow, but the decision nonetheless shows Sweden as positioned between the Anglo-Saxon approach to transport as exemplified by the UK, and the Continental approach as exemplified by France.

One key informant interviewed for this research distinguished between a reactionary AngloSaxon policy regime and an anticipatory Swedish policy regime for road safety, stating that the Anglo-Saxon regime is built on the premise that "you can do whatever you want, but if something goes wrong, we'll nail you," as opposed to the Swedish regime, where "the focus is on prevention" (Trafikverket, October 6, 2010). In other words, Sweden tries to anticipate problems and "engineer" them out of the road environment instead of adopting a punitive approach that sanctions individuals.

\section{Sweden's institutions and policymaking modes do matter}

Swedish institutional arrangements and its particular mode of policymaking have each influenced the development of its policy for occupational road safety. Here, we can draw on the $\mathrm{ACF}$, thinking of these attributes as stable parameters of the policy environment that affect how policy is enacted (P. Sabatier, 1998, pp. 102-103; P. Sabatier \& Weible, 2007, p. 199). We can also look to the "policy styles" literature and other literature, where Swedish policymaking is described extensively as corporatist, consensus-seeking, anticipatory, and deliberative (Gallagher, et al., 2006, pp. 443-445; Premfors, 1981, pp. 244-245; J. J. Richardson, 1979, pp. 342-344; Ruin, 1982; Siaroff, 1999; Sverdrup, 2003, p. 2). Ruin (1982) summarizes the Swedish system as follows:

In practice, [Swedish policymaking ideas have] meant that policy-makers, in their day-to-day political decision-making, should seek agreement among participants and avoid conflict; should try to build large majorities for policies rather than force their standpoint on minorities; and compromise rather than cling rigidly to their own policy preferences. Furthermore, this has meant an emphasis on trying to direct events rather than letting events dictate policy, on being active and innovative rather than reactive (Ruin, 1982, p. 141).

Indeed, the policy subsystem for occupational road safety in Sweden seems to function in this manner, certainly at the legislative stage. All the Riksdag committee reports consulted for this research demonstrate the consensus-building and consultative nature of the legislative process (Sverige Riksdag, 1974; Trafikutskottets, 1971, 1974, 1997/1998). These reports cite questions and comments from numerous interest groups and even private citizens, responding to each in documenting committee deliberations and recommendations.

Vision Zero is an example of an anticipatory policy initiative that originated within the Vägverket bureaucracy, but which was later introduced in the Riksdag for the purpose of obtaining parliamentary endorsement (Trafikutskottets, 1997/1998). Taken at face value, this process may appear out-of-sequence; we might instead expect to see the parliament direct an executive agency to move policy in a particular direction, not to have that direction determined within the agency and submitted to the parliament for approval after the fact. 
Certain features of the Swedish institutional structure may have made this sequence of events possible, and more broadly, created the conditions which made possible the radical shift in policy that Vision Zero represented. First, when Sweden's constitution was rewritten in 1975, the Riksdag became a unicameral legislature, with the entire body elected at one time. Ruin argues that such a system creates conditions conducive to radical policy change (Ruin, 1982, p. 148). In addition, the Swedish executive branch is characterized by large independent agencies such as Trafikverket and Transportstyrelsen, and comparatively small ministries; the independent agencies have wide discretion for developing policy, which may or may not be based on legislative guidance (Elvander, 1974, pp. 37-38; Ruin, 1982, p. 141; Trafikverket, October 6, 2010). Further, the independent Swedish executive agencies have substantial resources at their disposal and are thus able to move ahead with programs of research and policy development without having to depend on dedicated appropriations from the Riksdag (Trafikverket, October 6, 2010). Finally, the civil service in Sweden is highly sectoralized, that is, both high-level bureaucrats and technical experts tend to specialize in one topic area throughout their government careers (Bale, 2008, p. 82; Freeman, 1985, p. 474; Ruin, 1982, pp. 152-153). The long-term presence of subject-matter specialists, as opposed to generalists, may have resulted in a stable cadre of experts within the bureaucracy who were well-equipped to do the critical and visionary thinking necessary for development of Vision Zero.

\section{Integration of road safety and occupational safety policy}

Sweden exhibits substantial integration of occupational road safety into both its overall road safety policy and its occupational safety policy, again a reflection of both culture and institutions. There are several possible reasons for this success: a tradition of integration, institutional arrangements that facilitate that integration, and cross-agency cooperation.

First, there is evidence that suggests that occupational safety interests were included in early discussions about the general direction Swedish road safety policy ought to take. In 1971, the Trafikutskottets [Transport Committee] of the Riksdag reported that an interagency commission had been formed under Trafiksäkerhetsverket to develop recommendations. The commission's members represented government agencies with responsibilities for road design and maintenance, urban planning, schools, medical care, driver training, and environment. Also included were occupational safety authorities, which suggests that workers were at this time already recognized as an important category of road user (Trafikutskottets, 1971).

Second, Swedish transport agencies have been placed under the ministry responsible for industry policy and competition, currently called the Ministry of Enterprise, Energy, and Communications. The implication for occupational road safety is that the economic and safety aspects of road transport are managed within the same ministry. At highest levels of that ministry, the potential for linkages between competition policy and road safety policy are greater than if these policy areas were housed within separate ministries. However, this arrangement may mean that one distinct policy area is omitted: the general OSH requirements as applied to road safety, which fall under Arbetsmiljöverket in the Ministry of Employment.

Third, despite the division of responsibility for occupational road safety between the transport and OSH agencies, cross-agency cooperation resulted in development of a policy to clarify that the risk assessment requirements of the EU Framework Directive for OSH (89/391/EEC) 
extended to the roadway as a workplace. Road safety expertise from Vägverket and occupational safety expertise from Arbetsmiljöverket combined to develop this policy, which resulted in a change in inspection protocols for Arbetsmiljöverket labor inspectors. However, the initiative was not sustained due to budgetary re-allocations following the shift to a center-right government. Here, in the absence of regulatory change to institutionalize the new policy, entrepreneurial actions at bureaucratic levels were susceptible to partisan politics and thus insufficient to result in permanent policy change.

\section{Deviations from the "spirit" of EU law?}

The Swedish transpositions assessed in this research, taken at face value, show no philosophical misfit with the EU approach to worker safety, which articulates employer responsibilities for worker protection in absolute terms. The EU approach is consistent with Sweden's framework OSH legislation, the WEA of 1977, which states that "the employer shall take all the precautions necessary to prevent the employee from being exposed to health hazards or accident risks" [Chapter 3, 2a §] (Arbetsmarknadsdepartementet [Ministry of Labour (Sweden)], December 19, 1977). However, this absolute employer responsibility is qualified by other portions of the WEA and other elements of the Swedish legal and policy traditions. For example, the WEA itself provides that workers work with employers to support a safe workplace by complying with OSH regulations, using safety devices, and informing the employer of potentially unsafe conditions. This is accomplished through a system of safety delegates and committees [Chapter 3, $4 \S$ ] (Arbetsmarknadsdepartementet [Ministry of Labour (Sweden)], December 19, 1977). This arrangement suggests that although employers are ultimately responsible, workers are not seen as merely receivers of employer actions.

In addition, a tradition of derogation from labor law based on collective bargaining agreements means that regulatory provisions which accurately transpose EU directives may not be as broadly effective as they might appear. These concerns are particularly applicable to transposition of the Working Time Directive, where joining the EU created a potential misfit with Sweden's long tradition of social partner arrangements. The Swedish allowances for derogation are not contrary to the EU directive, but the potential for them to be applied is far greater in a country such as Sweden, where trade union membership was estimated to be between 80 and 89 percent in 2007 (European Foundation for the Improvement of Living and Working Conditions, 2009, p. 23). As these high levels of union density would suggest, membership in Sweden is not limited to predominantly "blue-collar" occupational groups. Together, the Swedish Confederation for Professional Employees (TCO) and the Swedish Confederation of Professional Associations (SACO) represented 53 percent of the unionized workforce in 2007. The "blue-collar" trade union, the Swedish Trade Union Confederation (LO), represented 44 percent (European Foundation for the Improvement of Living and Working Conditions, 2009, pp. 12-13). If unions negotiate derogations from Sweden's state-level working time requirement of an average 40 hours per week, such derogations have the potential for wide effect across the workforce.

\section{Bureaucratic discretion - a mixed record of success}

The experience of Sweden shows that bureaucratic discretion in the absence of reinforcing legislation or regulation can be a weak policy instrument. The coordination between Vägverket and Arbetsmiljöverket that resulted in the 2003/2004 decision to explicitly link occupational road 
safety with OSH enforcement came about through contact between key staff in both agencies. There was no question as to the legitimacy of this policy decision; both agencies were empowered to make these sorts of determinations. However, because the decision had neither the force of law or regulation, it was not carried through when the government changed and resources became scarcer. In this case, bureaucratic discretion did not lead to permanent policy change. Rather, the discretionary nature of the policy left it vulnerable to being marginalized once partisan policy preferences changed. ${ }^{79}$

Vision Zero, on the other hand, was conceptualized within Vägverket, at agency level, but subsequently received a stamp of approval from the Riksdag that allowed it to become institutionalized. After the 1997 decision in the Riksdag, however, Vision Zero has continued to progress primarily through bureaucratic decision-making, not through additional legislation or rulemaking. In fact, Sweden has little legislation or regulation on road and infrastructure design, a curious situation for a country generally seen as a world leader in road safety. The reason for this is that, historically, the Riksdag has entrusted road building and road safety to the transport agency (Vägverket and now Trafikverket) (Trafikverket, October 6, 2010).

Vägverket and Trafikverket representatives have given numerous presentations and papers on Vision Zero around the world, and Swedish universities welcome international students who want to take ideas from Vision Zero back to their home countries. The spread of Vision Zero has, however, indirectly led to an EU directive that is not popular within Trafikverket. This is Directive 2008/96/EC on road infrastructure safety management, which will require substantial Swedish transposition because of the manner in which Sweden has handled its highly successful road safety initiatives - through the transport agencies, with little interference from either the Riksdag or the ministry under which the transport agencies sit. The new directive is expected to result in a newly politicized environment for road safety and road construction in which policy deliberations normally handled within the Trafikverket bureaucracy will be elevated to the partisan political environment. This is likely to be an unwelcome drain on Trafikverket's time and resources, given its accustomed autonomy (Trafikverket, October 6, 2010). In this instance, success in the international arena, in the form of an EU directive that embraces the Swedish approach, has led to complications in the domestic arena for the agency that developed that approach.

\section{MLG - Greater applicability for Type II}

Evidence of the role of Type I MLG in decision-making for occupational road safety in Sweden is weak. This is not surprising; although Sweden has a large public sector at all levels of government, is it nonetheless a unitary state with policy set at central-government level (albeit often implemented at lower levels). With respect to occupational road safety, sub-national authorities, generally County Administrative Boards, have some latitude in applying the law to individual cases, but do not set overarching policy. For example, while County Administrative Boards assess applicant qualifications for an Operator CPC case by case, they do not have the discretion to change criteria or procedures. The Commercial Traffic Regulation of 1996 allows

\footnotetext{
${ }^{79}$ The Swedish situation with respect to application of the Framework Directive to the roadway may be contrasted to the UK. In the UK, similar "guidance" was less effective than it could have been because no resources were allocated toward its implementation. Partisan politics have had little bearing on the outcome thus far.
} 
Country Administrative Boards somewhat more latitude with regard to investigation of drunken driving offenses; here, Boards decide whether individual cases merit special investigation [SFS 1996:200, 13§] (Vägverket, July 10, 1996a). Further, county and local authorities perform a wide range of functions across nearly all policy areas, including transportation; there are no special jurisdictions linked to transportation akin to the Traffic Areas found in the UK. The sole exception related to occupational road safety is that the Arbetsmiljöverket activities at sub-state level are coordinated through ten regional labor inspectorates that are not aggregations of counties or municipalities (Arbetsmiljöverket, November 11, 2010).

In the case of driver licensing, administrative activities are being consolidated rather than delegated to lower levels of government. Recent institutional reforms have resulted in centralization of administrative functions formerly performed at county level, with the rationale that centralization and increased automation will improve efficiency and responsiveness (Trafikverket, 2009).

This research found some evidence that Type II MLG plays a role in Sweden's governance of occupational road safety. There is documentation of broad interest-group input into road safety legislation in Sweden. All the Riksdag propositions and committee reports examined through this research, some dating to the early 1970s, demonstrate careful accounting for the positions of constituencies that provided input into the proposed legislation and responded at various stages of consultation processes. Further, historical accounts of policy decisions describe the involvement of stakeholders such as road transport companies in broad-based government commissions (J. Richardson, et al., 1982; J. J. Richardson, 1979). In addition, current information from Arbetsmiljöverket describes formal consultations with labor and industry as integral to development of any OSH regulation (Arbetsmiljöverket, 2010a). Surprisingly, however, interviews with key informants revealed little influence on either the development or implementation of recent occupational road safety policy on the part of outside interest groups from labor or industry. Informants from both Trafikverket and Arbetsmiljöverket indicated that neither Vision Zero nor the decision to emphasize road safety under the Arbetsmiljöverket risk assessment regime was influenced by industry, labor, the media, or the public. Nor did they report that ongoing consultation with interest groups is part of their agencies' day-to-day implementation of policy related to occupational driving (Arbetsmiljöverket, November 11, 2010; Trafikverket, October 6, 2010).

\section{Sweden as an exporter of policy}

There is little evidence from the literature, interviews, or Swedish government documents to support the hypothesis that international actors have influenced domestic policy for occupational road safety. Instead, Sweden has allied itself with neighboring states to develop regional recommendations for transport policy, which in turn may become inputs to state-level policy. This occurs through several venues. One is the Nordiskt vägforum [Nordic Road Association], of which Sweden was a founding member in 1935, today made up of Norway, Sweden, Finland, Iceland, Denmark, and the Faeroe Islands. This organization works primarily through a number of thematic technical committees, and is focused more on engineering, planning, and design solutions to transport problems rather than initiatives to directly change road users' behaviors (Nordiskt vägforum [Nordic Road Association], 2011). A Riksdag committee report from 1971 
cites recommendations from a Nordic Road Committee ${ }^{80}$ as an influence on the direction of Swedish policy for seat belts (Trafikutskottets, 1971). Finally, the overarching policy alliance of Nordic countries, the Nordic Council, provides a formal mechanism for engagement between governments on a variety of policy issues. Although the Nordic Council publicizes events related to road safety, it appears that transport is not one of the key policy areas on which the Nordic Council is directly engaged; it is in fact the Nordic Road Association that serves this function (Nordic Council, 2011). Sweden is thus engaged in formal Nordic policy networks as a participant, with exchanges of information and policy ideas possible in both directions.

That Sweden has not been substantially influenced by international actors is not surprising because Sweden has in fact been an exporter of its road safety policies, and in many cases has developed policies well in advance of its EU neighbors and other high-income countries. In addition, even the EU has had limited influence on Sweden because EU directives were generally congruent with existing Swedish conceptions about occupational safety and road safety. One of the few exceptions identified through this research was the Working Time Directive, which to some extent presented a conflict with the Swedish tradition of substituting collective agreements for government regulation.

Table 5-8. Swedish legislation and regulations related to transposition of selected EU directives for occupational road safety

\begin{tabular}{|c|c|}
\hline Swedish legislation or regulation & Source \\
\hline \multicolumn{2}{|l|}{ Driving License Directive (91/439/EEC) } \\
\hline $\begin{array}{l}\text { Commercial Traffic Regulation 1996: } \\
\text { Vägverkets föreskrifter (1996:200) om medicinska krav } \\
\text { för innehav av körkort, traktorkort och } \\
\text { taxiförarlegitimation mm. [SNRA regulations } \\
\text { (1996:200) on medical requirements for driving } \\
\text { license, tractor license and taxi driver's ID, etc.] }\end{array}$ & $\begin{array}{l}\text { Vägverket. (1996). Vägverkets författningssamling } \\
\text { (VVFS) [Swedish National Road Administration } \\
\text { Statute Book] VVFS 1996:200, July 10,1996. } \\
\text { http://translate.google.com/translate?hl=en\&sl=sv\&tl= } \\
\text { en\&u=http\%3A\%2F\%2Fwww20.vv.se\%2Fvvfs\%2Fla } \\
\text { grum dokument historik.asp\%3Fdokumentbeteckning } \\
\text { \%3D1996\%3A200 }\end{array}$ \\
\hline $\begin{array}{l}\text { Driving curriculum for Class B vehicles 1996: } \\
\text { Vägverkets föreskrifter om kursplaner, behörighet B. } \\
\text { [Regulations concerning curriculum, class B]. }\end{array}$ & $\begin{array}{l}\text { Vägverket. (1996). Vägverkets författningssamling } \\
\text { (VVFS) [Swedish National Road Administration } \\
\text { Statute Book] VVFS 1996:168, July 10, 1996. } \\
\text { http://translate.google.com/translate?hl=en\&sl=sv\&tl= } \\
\text { en\&u=http\%3A\%2F\%2Fwww20.vv.se\%2Fvvfs\%2Fla } \\
\text { grum dokument historik.asp\%3Fdokumentbeteckning } \\
\text { \%3D1996\%3A168 }\end{array}$ \\
\hline $\begin{array}{l}\text { Driving Licences Act 1998: } \\
\text { Körkortslag. [Driving Licences Act.] }\end{array}$ & $\begin{array}{l}\text { Näringsdepartementet }{ }^{81} \text { [Ministry of Enterprise } \\
\text { (Sweden)]. (1998). Svensk författningssamling (SFS) } \\
\text { [Swedish Code of Statutes] SFS 1998:488, June 11, } \\
\text { 1998. } \\
\text { http://www.notisum.se/rnp/sls/lag/19980488.htm }\end{array}$ \\
\hline Driving Licences Ordinance 1998: & Näringsdepartementet [Ministry of Enterprise \\
\hline
\end{tabular}

\footnotetext{
${ }^{80}$ Although the Riksdag reference is not clear on this point, it is possible that the committee referred to is one of the technical committees of the Nordic Road Association.

${ }^{81}$ In this reference and all following references to Acts, the responsible government ministry is cited. This approach is consistent with the attributions found in Swedish government sources. However, any Act is by definition legislation approved in the Riksdag. Other instruments of law such as ordinances and regulations are promulgated at Government level and at administration and authority levels, respectively.
} 


\begin{tabular}{|c|c|}
\hline Körkortsförordning. [Driving Licences Ordinance]. & $\begin{array}{l}\text { (Sweden)]. (1998). Svensk författningssamling (SFS) } \\
\text { [Swedish Code of Statutes] SFS 1998:980, July 2, } \\
\text { 1998. } \\
\text { http://translate.google.com/translate?hl=en\&sl=sv\&u= } \\
\text { http://www.notisum.se/rnp/sls/lag/19980980.HTM\&ei } \\
\text { =d4idTP6MG8SAlAeG9 i6Cg\&sa=X\&oi=translate\&c } \\
\text { t=result\&resnum=1\&ved=0CBkQ7gEwAA\&prev=/sea } \\
\text { rch\%3Fq\%3D1998:980\%26hl\%3Den\%26rls\%3Dcom. } \\
\text { microsoft:en-us:IE- } \\
\text { SearchBox\%26rlz\%3D1I7SMSN en\%26prmd\%3Div }\end{array}$ \\
\hline $\begin{array}{l}\text { Driving Licences Regulation 1998: } \\
\text { Vägverkets föreskrifter om ändring i föreskrifterna } \\
\text { (VVFS 1996:200) om medicinska krav för innehav av } \\
\text { körkort mm. [Swedish National Road Administration } \\
\text { provisions regarding a revision of the provisions } \\
\text { (VVFS 1996:200) on the medical requirements for } \\
\text { possession of a driving licence, etc.] }\end{array}$ & $\begin{array}{l}\text { Vägverket. (1998). Vägverkets författningssamling } \\
\text { (VVFS) [Swedish National Road Administration } \\
\text { Statute Book] VVFS 1998:89, December 18, 1998. } \\
\text { http://www.vV.se/PageFiles/12660/9889eng000015\%5 } \\
\text { B1\%5D.pdf?epslanguage=sv }\end{array}$ \\
\hline $\begin{array}{l}\text { Licence Format Regulation 2003: } \\
\text { Vägverkets föreskrifter om körkortets utformning och } \\
\text { innehåll. [SRA regulations for the licence form and } \\
\text { content]. }\end{array}$ & $\begin{array}{l}\text { Vägverket. (2003). Vägverkets författningssamling } \\
\text { (VVFS) [Swedish National Road Administration } \\
\text { Statute Book] VVFS 2003:68, September 17, 2003. } \\
\text { http://translate.google.com/translate?hl=en\&sl=sv\&u= } \\
\text { http://www20.vv.se/vvfs/lagrum dokument historik.as } \\
\text { p\%3Fdokumentbeteckning\%3D2003:68\&ei=9YWdT } \\
\text { MvFN8X7lwe4senuAg\&sa=X\&oi=translate\&ct=result } \\
\text { \&resnum=1\&ved=0CBYQ7gEwAA\&prev=/search\%3 } \\
\text { Fq\%3DVVFS\%2B2003:68\%26hl\%3Den\%26rls\%3Dc } \\
\text { om.microsoft:en-us:IE- } \\
\text { SearchBox\%26rlz\%3D1I7SMSN en\%26prmd\%3Div }\end{array}$ \\
\hline $\begin{array}{l}\text { Revised License Format Regulation 2006: } \\
\text { Vägverkets föreskrift (VVFS 2006:22) om ändring in } \\
\text { föreskrifterna (VVFS 2003:68) om körkortets } \\
\text { utformning och innehåll. [SRA regulations amending } \\
\text { the rules (VVFS 2003:68) on driving license design } \\
\text { and content]. }\end{array}$ & $\begin{array}{l}\text { Vägverket. (2006). Vägverkets författningssamling } \\
\text { (VVFS) [Swedish National Road Administration } \\
\text { Statute Book] VVFS 2006:22, February 24, } 2006 . \\
\text { http://www20.vv.se/vvfs/pdf/2006nr022.pdf }\end{array}$ \\
\hline $\begin{array}{l}\text { Professional Driving Skills Ordinance 2007: } \\
\text { Förordning (2007:1470) om yrkesförarkompetens. } \\
\text { [Ordinance on professional driving skills]. }\end{array}$ & $\begin{array}{l}\text { Näringsdepartementet [Ministry of Enterprise } \\
\text { (Sweden)]. (2007). Svensk författningssamling (SFS) } \\
\text { [Swedish Code of Statutes] SFS 2007: 1470, } \\
\text { December 19, 2007. } \\
\text { http://www.notisum.se/rnp/sls/lag/20071470.htm }\end{array}$ \\
\hline $\begin{array}{l}\text { Professional Driver Qualification and Training } \\
\text { Regulation 2008: } \\
\text { Vägverkets föreskrifter (VVFS 2008:159) om } \\
\text { grundläggande kompetens och fortbildning for förare } \\
\text { som utför gods - eller persontransporter [SRA } \\
\text { regulations on the qualification and training of } \\
\text { drivers who carry freight or passengers]. }\end{array}$ & $\begin{array}{l}\text { Vägverket. (2008). Vägverkets författningssamling } \\
\text { (VVFS) [Swedish National Road Administration } \\
\text { Statute Book] VVFS 2008:159, March 7, 2008. } \\
\text { http://www.yrkestrafiken.se/Global/Publikationer/VV } \\
\underline{\text { 2008.159.pdf }}\end{array}$ \\
\hline \multicolumn{2}{|l|}{ Driver CPC Directive (2003/59/EC) } \\
\hline $\begin{array}{l}\text { Professional Driver Competence Act 2007: } \\
\text { Lag (2007:1157) om yrkesförarkompetens. } \\
\text { [Professional Driver Competence Act]. }\end{array}$ & $\begin{array}{l}\text { Näringsdepartementet [Ministry of Enterprise } \\
\text { (Sweden)]. (2007). Svensk författningssamling (SFS) } \\
\text { [Swedish Code of Statutes] SFS 2007:1157, } \\
\text { November 29, 2007. } \\
\text { http://www.notisum.se/rnp/sls/lag/20071157.htm }\end{array}$ \\
\hline $\begin{array}{l}\text { Professional Driving Skills Ordinance 2007: } \\
\text { Förordning (2007:1470) om yrkesförarkompetens. } \\
\text { [Ordinance on Professional Driving Skills]. }\end{array}$ & $\begin{array}{l}\text { Näringsdepartementet [Ministry of Enterprise } \\
\text { (Sweden)]. (2007). Svensk författningssamling (SFS) } \\
\text { [Swedish Code of Statutes] SFS 2007:1470, }\end{array}$ \\
\hline
\end{tabular}




\begin{tabular}{|c|c|}
\hline & $\begin{array}{l}\text { December 19, } 2007 . \\
\text { http://www.notisum.se/rnp/sls/lag/20071470.htm }\end{array}$ \\
\hline $\begin{array}{l}\text { Professional Driver Qualification and Training } \\
\text { Regulation 2008: } \\
\text { Vägverkets föreskrifter (VVFS 2008:159) om } \\
\text { grundläggande kompetens och fortbildning for förare } \\
\text { som utför gods - eller persontransporter [SRA } \\
\text { regulations on the qualification and training of } \\
\text { drivers who carry freight or passengers]. }\end{array}$ & $\begin{array}{l}\text { Vägverket. (2008). Vägverkets författningssamling } \\
\text { (VVFS) [Swedish National Road Administration } \\
\text { Statute Book] VVFS 2008:159, March 7, 2008. } \\
\text { http://www.yrkestrafiken.se/Global/Publikationer/VV } \\
\text { 2008.159.pdf }\end{array}$ \\
\hline $\begin{array}{l}\text { Common Rules for Driving Tests 2009: } \\
\text { Transportstyrelsens föreskrifter och allmänna råd om } \\
\text { förarprov, gemensamma bestämmelser. [Transport } \\
\text { Agency regulations and guidelines on driving tests, } \\
\text { common rules]. }\end{array}$ & $\begin{array}{l}\text { Transportstyrelsen. (2009). Transportstyrelsens } \\
\text { författningssamling (TSFS) [Swedish Transport } \\
\text { Agency Statute Book] TSFS 2009:68, July 2, 2009. } \\
\text { http://translate.googleusercontent.com/translate c?hl=e } \\
\text { n\&sl=sv\&u=http://www.transportstyrelsen.se/Global/R } \\
\text { egler/TSFS/TSFS_2009- } \\
\text { 68.pdf\%3Fepslanguage\%3Dsv\&prev=/search\%3Fq\%3 } \\
\text { DTSFS\%2B2010:36\%26hl\%3Den\%26rls\%3Dcom.mic } \\
\text { rosoft:en-us:IE- } \\
\text { SearchBox\%26rlz\%3D1I7SMSN_en\%26prmd\%3Div } \\
\text { \&rurl=translate.google.com\&twu=1\&usg=ALkJrhgBO } \\
\text { W-DtmPBxBISe9qUpC j86JTkA }\end{array}$ \\
\hline $\begin{array}{l}\text { Professional Driving Test Regulation 2010: } \\
\text { Transportstyrelsens föreskrifter och allmänna råd om } \\
\text { prov för yrkesförarkompetens. [Transport Agency } \\
\text { regulations and guidelines: The test for professional } \\
\text { driving skills]. }\end{array}$ & $\begin{array}{l}\text { Transportstyrelsen. (2010). Transportstyrelsens } \\
\text { författningssamling (TSFS) [Swedish Transport } \\
\text { Agency Statute Book] TSFS 2010:36, March 18, } \\
2010 . \\
\text { http://www.transportstyrelsen.se/Global/Regler/TSFS } \\
\text { svenska/TSFS\%202010-36.pdf?epslanguage=sv } \\
\end{array}$ \\
\hline \multicolumn{2}{|l|}{ Operator CPC Directive (98/76/EC) } \\
\hline $\begin{array}{l}\text { Commercial Traffic Act 1998: } \\
\text { Yrkestrafiklag. [Commercial Traffic Act]. }\end{array}$ & $\begin{array}{l}\text { Näringsdepartementet [Ministry of Enterprise } \\
\text { (Sweden)]. (1998). Svensk författningssamling (SFS) } \\
\text { [Swedish Code of Statutes], SFS 1998:490, June 11, } \\
\text { 1998. } \\
\text { http://www.notisum.se/rnp/sls/lag/19980490.htm }\end{array}$ \\
\hline $\begin{array}{l}\text { Occupational Road Traffic Ordinance 1998: } \\
\text { Yrkestrafikförordning. [Occupational Road Traffic } \\
\text { Ordinance]. }\end{array}$ & $\begin{array}{l}\text { Näringsdepartementet [Ministry of Enterprise } \\
\text { (Sweden)]. (1998). Svensk författningssamling (SFS) } \\
\text { [Swedish Code of Statutes] SFS 1998:779, June 25, } \\
\text { 1998. } \\
\text { http://www.notisum.se/rnp/sls/lag/19980779.htm }\end{array}$ \\
\hline $\begin{array}{l}\text { Professional Competency Regulation 2001: } \\
\text { Vägverkets föreskrifter om yrkeskunnande för } \\
\text { yrkesmässig trafik. [SRA Regulations on Proficiency } \\
\text { for Professional Use]. }\end{array}$ & $\begin{array}{l}\text { Vägverket. (2001). Vägverkets författningssamling } \\
\text { (VVFS) [Swedish National Road Administration } \\
\text { Statute Book] WVFS 2001:51, May 11, 2001. } \\
\text { http://translate.google.com/translate?hl=en\&sl=sv\&u= } \\
\text { http://www20.vv.se/vvfs/lagrum dokument historik.as } \\
\text { p\%3Fdokumentbeteckning\%3D2001:51\&ei=nwSgTJC } \\
\text { NFMP6lweXufjECQ\&sa=X\&oi=translate\&ct=result\&r } \\
\text { esnum=1\&ved=0CBYQ7gEwAA\&prev=/search\%3Fq } \\
\text { \%3DVVFS\%2B2001:51\%26hl\%3Den\%26rls\%3Dcom } \\
\underline{\text { microsoft:en-us:IE- }} \\
\text { SearchBox\%26rlz\%3D1I7SMSN en\%26prmd\%3Divb }\end{array}$ \\
\hline $\begin{array}{l}\text { Test of Professionalism Regulations 2010: } \\
\text { Transportstyrelsens föreskrifter och allmänna råd om } \\
\text { prov i yrkeskunnande för yrkesmässig trafik. } \\
\text { [Transport Agency regulations and guidelines on the } \\
\text { test of professionalism for commercial purposes]. }\end{array}$ & $\begin{array}{l}\text { Transportstyrelsen. (2010). Transportstyrelsens } \\
\text { författningssamling (TSFS) [Swedish Transport } \\
\text { Agency Statute Book] TSFS 2010:37, March 3, 2010. } \\
\text { http://translate.googleusercontent.com/translate c?hl=e } \\
\text { n\&sl=sv\&tl=en\&u=http://www.transportstyrelsen.se/G } \\
\text { lobal/Regler/TSFS svenska/TSFS\%25202010- }\end{array}$ \\
\hline
\end{tabular}




\begin{tabular}{|c|c|}
\hline & $\begin{array}{l}\text { 37.pdf\%3Fepslanguage\%3Dsv\&rurl=translate.google.c } \\
\text { om\&twu=1\&anno=2\&usg=ALkJrhgOYS4Kg5bq- } \\
\text { mJuxhYSrIFyX8xGzg }\end{array}$ \\
\hline \multicolumn{2}{|c|}{ Road Transport Working Time Directive $(2002 / 15 / \mathrm{EC})$} \\
\hline $\begin{array}{l}\text { Road Transport Working Time Proclamation 1972: } \\
\text { Kungörelse (1972:602) om arbetstid vid vägtransport, } \\
\text { mm. [Proclamation (1972:602) on working at the } \\
\text { road, etc.]. }\end{array}$ & $\begin{array}{l}\text { Kommunikationsdepartementet [Ministry of } \\
\text { Communications (Sweden)]. (1972). Svensk } \\
\text { författningssamling (SFS) [Swedish Code of Statutes] } \\
\text { SFS 1972:602, January 12, 1972. } \\
\text { http://translate.google.com/translate?hl=en\&sl=sv\&tl= } \\
\text { en\&u=http\%3A\%2F\%2Fwww.notisum.se\%2Frnp\%2F } \\
\text { sls\%2Flag\%2F19720602.htm }\end{array}$ \\
\hline $\begin{array}{l}\text { Road Transport Working Time Act 2005: } \\
\text { Lag om arbetstid vid visst vägtransportarbete (Lag } \\
\text { 2005/395). [The Working Hours for Certain Road } \\
\text { Transport Work Act (2005: 395), with Amendments } \\
\text { up to and including SFS 2007:92]. }\end{array}$ & $\begin{array}{l}\text { Näringsdepartementet. [Ministry of Enterprise } \\
\text { (Sweden)]. (2005). Svensk författningssamling (SFS) } \\
\text { [Swedish Code of Statutes] SFS 2005:395, June 13, } \\
2005 . \\
\text { http://www.notisum.se/rnp/sls/lag/20050395.htm } \\
\text { http://www.sweden.gov.se/content/1/c6/10/49/80/c5b0 } \\
\text { cf3c.pdf } \\
\text { NOTE: The version of this legislation currently } \\
\text { available has been updated to refer to a 2006 EU } \\
\text { regulation that followed the } 2002 \text { Road Transport } \\
\text { Working Time Directive. }\end{array}$ \\
\hline \multicolumn{2}{|l|}{ Working Time Directive (2003/88/EC) } \\
\hline $\begin{array}{l}\text { Working Hours Act 1982: } \\
\text { Arbetstidslagen. [Working Hours Act (1982:673), with } \\
\text { amendments up to and including Svensk } \\
\text { författningssamling (SFS) 2005:428]. }\end{array}$ & $\begin{array}{l}\text { Arbetsmarknadsdepartementet. [Ministry of Labour } \\
\text { (Sweden).] (2005). } \\
\text { http://www.sweden.gov.se/content/1/c6/10/49/79/7b82 } \\
\underline{743 d . p d f} \\
\text { http://translate.google.com/translate?hl=en\&sl=sv\&tl= } \\
\text { en\&u=http\%3A\%2F\%2Fwww.notisum.se\%2Fpub\%2F } \\
\text { Wide.aspx\%3Fpageid\%3D229\%26type\%3DSFSG\%26 } \\
\text { span\%3D\%255B2005\%255D\%26parent\%3D289 } \\
\text { http://www.notisum.se/rnp/sls/fakta/a9820673.htm }\end{array}$ \\
\hline $\begin{array}{l}\text { Working Hours Act Amendment \#1 2005: } \\
\text { Lag (2005:165) om ändring i arbetstidslagen (1982:673). } \\
\text { [Law amending the Working Hours Act (1982:673)]. }\end{array}$ & $\begin{array}{l}\text { Näringsdepartementet. [Ministry of Enterprise } \\
\text { (Sweden).] (2005.) Svensk författningssamling (SFS) } \\
\text { [Swedish Code of Statutes] SFS 2005:165, April 5, } \\
2005 . \\
\text { http://translate.google.com/translate?hl=en\&sl=sv\&u= } \\
\text { http://www.notisum.se/rnp/sls/sfs/20050165.PDF\&ei= } \\
\text { mIPHTIPYDoLGlQe999DGAg\&sa=X\&oi=translate\& } \\
\text { ct=result\&resnum=1\&ved=0CBcQ7gEwAA\&prev=/se } \\
\text { arch\%3Fq\%3DSFS\%2B2005:165\%26hl\%3Den\%26rls } \\
\text { \%3Dcom.microsoft:en-us:IE- } \\
\text { SearchBox\%26rlz\%3D1I7SMSN_en }\end{array}$ \\
\hline $\begin{array}{l}\text { Working Hours Act Amendment \#2 2005: } \\
\text { Lag (2005:397) om ändring i arbetstidslagen (1982:673). } \\
\text { [Law amending the Working Hours Act (1982:673)]. }\end{array}$ & $\begin{array}{l}\text { Näringsdepartementet. [Ministry of Enterprise } \\
\text { (Sweden).] (2005.) Svensk författningssamling (SFS) } \\
\text { [Swedish Code of Statutes] SFS 2005:397, June 13, } \\
\text { 2005. } \\
\text { http://translate.google.com/translate?hl=en\&sl=sv\&u= } \\
\text { http://www.notisum.se/rnp/sls/sfs/20050397.pdf\&ei=fz } \\
\text { nQTJiCPMP lgf05qiHBg\&sa=X\&oi=translate\&ct=res } \\
\text { ult\&resnum=3\&ved=0CCUQ7gEwAg\&prev=/search\% } \\
\text { 3Fq\%3DSFS\%2B2005:397\%26hl\%3Den\%26rls\%3Dc } \\
\text { om.microsoft:en-us\%26prmd\%3Div }\end{array}$ \\
\hline $\begin{array}{l}\text { Working Hours Act Amendment \#3 2005: } \\
\text { Lag (2005:428) om ändring i arbetstidslagen (1982:673). }\end{array}$ & $\begin{array}{l}\text { Näringsdepartementet. [Ministry of Enterprise } \\
\text { (Sweden).] (2005.) Svensk författningssamling (SFS) }\end{array}$ \\
\hline
\end{tabular}




\begin{tabular}{|c|c|}
\hline [Law amending the Working Hours Act (1982:673)]. & $\begin{array}{l}\text { [Swedish Code of Statutes] SFS 2005:428, June 14, } \\
2005 . \\
\text { http://translate.googleusercontent.com/translate c?hl=e } \\
\text { n\&sl=sv\&u=http://www.notisum.se/rnp/sls/sfs/200504 } \\
\text { 28.pdf\&prev=/search\%3Fq\%3DSFS\%2B2005:428\%26 } \\
\text { hl\%3Den\%26rls\%3Dcom.microsoft:en- } \\
\text { us\%26prmd\%3Div\&rurl=translate.google.com\&usg=A } \\
\text { LkJrhjC4HJE2jv8Ce BMAHWe2PMRIUGQw }\end{array}$ \\
\hline $\begin{array}{l}\text { Working Hours Act Amendment 2008: } \\
\text { Lag (2008:476) om ändring i arbetstidslagen (1982:673). } \\
\text { [Law amending the Working Hours Act (1982:673)]. }\end{array}$ & $\begin{array}{l}\text { Näringsdepartementet. [Ministry of Enterprise } \\
\text { (Sweden).] (2008). Svensk författningssamling (SFS) } \\
\text { [Swedish Code of Statutes] SFS 2008:476, June 16, } \\
\text { 2008. } \\
\text { http://translate.googleusercontent.com/translate c?hl=e } \\
\text { n\&sl=sv\&u=http://www.notisum.se/rnp/sls/sfs/200804 } \\
\text { 76.pdf\&prev=/search\%3Fq\%3DSFS\%2B2005:428\%26 } \\
\text { hl\%3Den\%26rls\%3Dcom.microsoft:en- } \\
\text { us\%26prmd\%3Div\&rurl=translate.google.com\&usg=A } \\
\text { LkJrhieUlB7Lhbn-SOysVvPLLu0wTZsJw }\end{array}$ \\
\hline $\begin{array}{l}\text { Working Time Ordinance for Light Vehicles 1994: } \\
\text { Förordning (1994:1297) om vilotider vid vissa } \\
\text { vägtransporter inom landet. [Ordinance (1994:1297) } \\
\text { on rest periods at certain road traffic within the } \\
\text { country.] }\end{array}$ & $\begin{array}{l}\text { Näringsdepartementet. [Ministry of Enterprise } \\
\text { (Sweden)]. (1994). Svensk författningssamling (SFS) } \\
\text { [Swedish Code of Statutes] SFS 1994:1297, August 9, } \\
\text { 1994. } \\
\text { http://translate.google.com/translate?hl=en\&sl=sv\&tl= } \\
\text { en\&u=http\%3A\%2F\%2Fwww.notisum.se\%2Frnp\%2F } \\
\text { sls\%2Flag\%2F19941297.htm }\end{array}$ \\
\hline $\begin{array}{l}\text { Working Time Recordkeeping Regulation for Light } \\
\text { Vehicles 1994: } \\
\text { Vägverkets föreskrifter om personlig tidbok mm. [SRA } \\
\text { regulations on personal logbook]. }\end{array}$ & $\begin{array}{l}\text { Vägverket. (1994). Vägverkets författningssamling } \\
\text { (VVFS) [Swedish National Road Administration } \\
\text { Statute Book] VVFS 1994:40, December 9, 1994. } \\
\text { http://translate.google.com/translate?hl=en\&sl=sv\&u= } \\
\text { http://www.akeri.se/files/bilder/sa/filer/VVFS 19944 } \\
\text { O Foreskrift om personlig tidbok.pdf\&ei=CT QTOn } \\
\text { xFIGClAeF2dSDBg\&sa=X\&oi=translate\&ct=result\&r } \\
\text { esnum=3\&ved=0CCQQ7gEwAg\&prev=/search\%3Fq } \\
\text { \%3DVVFS\%2B1994:40\%26hl\%3Den\%26rls\%3Dcom } \\
\text {.microsoft:en-us\%26prmd\%3Div }\end{array}$ \\
\hline \multicolumn{2}{|l|}{ Seat Belt Directive (2003/20/EC) } \\
\hline $\begin{array}{l}\text { Amendment to Traffic Legislation 1974: } \\
\text { Betänkande 1974:TU15 Trafikutskottets betänkande i } \\
\text { anledning av propositionen 1974:86 angående skyldighet } \\
\text { att använda bilbälte jämte motioner. [Report 1974: } \\
\text { TU15 Transport Committee's report into the bill } \\
\text { 1974:86 on duty to wear safety belts along with } \\
\text { motions.] }\end{array}$ & $\begin{array}{l}\text { Trafikutskottets, Sverige Riksdag. [Traffic } \\
\text { Committee, Riksdag]. (1974). } \\
\text { http://www.riksdagen.se/webbnav/?nid=3322\&doktyp } \\
\text { =bet\&dok_id=FX01TU15\&rm=1974\&bet=TU15 }\end{array}$ \\
\hline $\begin{array}{l}\text { Road Traffic Ordinance 1998: } \\
\text { Trafikförordning. [Road Traffic Ordinance]. }\end{array}$ & $\begin{array}{l}\text { Kommunikationsdepartementet. [Ministry of } \\
\text { Communications (Sweden)]. (1998). Svensk } \\
\text { författningssamling (SFS) [Swedish Code of Statutes] } \\
\text { SFS 1998:1276, October 13, 1998. } \\
\text { http://translate.google.com/translate?hl=en\&sl=sv\&tl= } \\
\text { en\&u=http\%3A\%2F\%2Fwww.notisum.se\%2Frnp\%2F } \\
\text { sls\%2Flag\%2F19981276.htm }\end{array}$ \\
\hline $\begin{array}{l}\text { Road Traffic Ordinance Amended 2006: } \\
\text { Förordning om ändring i trafikförordningen } \\
\text { (1998:1276). (2006). [Regulation amending the Road } \\
\text { Traffic Ordinance (1998:1276).] }\end{array}$ & $\begin{array}{l}\text { Näringsdepartementet. [Ministry of Enterprise } \\
\text { (Sweden)]. (2006). Svensk författningssamling (SFS) } \\
\text { [Swedish Code of Statutes] SFS 2006:1208, } \\
\text { December 1, 2006. } \\
\text { http://translate.google.com/translate?hl=en\&sl=sv\&u= }\end{array}$ \\
\hline
\end{tabular}




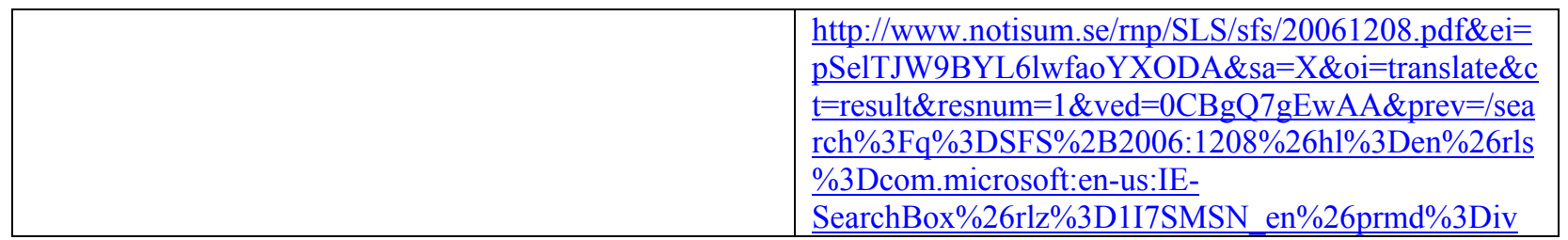




\section{Chapter 6. Conclusions}

This concluding chapter begins with a review and synthesis of the transpositions of six EU directives relevant to occupational road safety: Driving License Directive 91/439/EEC, Driver CPC Directive 2003/59/EC, Operator CPC Directives 96/26/EC and 98/76/EC, working time directives 2002/15/EC and 2003/88/EC, and Seat Belt Directive 2003/20/EC. For Sweden and the UK, transpositions generally followed the patterns suggested by Falkner et al. (2005), with Sweden generally responsive to EU requirements, and the UK guided by domestic politics. For this group of directives, however, France did not conform to the pattern of "neglect" observed by Falkner et al., and would more accurately be placed with the UK in the "world of domestic politics" for this particular policy area. Although Sweden generally observed EU directives, its transpositions were also influenced by domestic practices and beliefs.

Following this is a summary of the applicability of the ACF to occupational road safety policy in the three countries. As the ACF proposes, belief systems, the dynamics of policy subsystems, institutional arrangements, and internal and external "shocks" are all shown to have some bearing on the development of occupational road safety policy in the three member states. Also consistent with the ACF, interest groups and epistemic communities have played a role in policy development and intervention in all three member states, with the social partners formally integrated into policymaking in both Sweden and France but active in the UK through broadbased epistemic communities that lack a formalized role and must compete for access. Next, I review the role of international actors. There is limited evidence that international actors (other than the EU, of course) have influenced policy within member states, although in some cases international organizations provide a forum for exchange of ideas between member states and between the European Commission and member states.

The research finds limited evidence of Type I MLG. Although there are a few instances of substate flexibility at program level, most policy is set at state level through legislation and regulation, and instructions for policy execution come from bureaucrats in the central government. Type II MLG is, however, shown to be relevant to occupational road safety policy, particularly in the sense that the management of occupational road safety tends to be a combination of "government" and "governance," with non-governmental actors participating formally in governance through consultation and collective agreements in France and Sweden, and less formally in the UK through self-regulation with government acquiescence.

\section{Transposition of EU directives}

The transposition assessments for the six EU directives related to occupational road safety did not refute the claims of Falkner et al. (2005) that the UK's transpositions belong to the "world of domestic politics" and Sweden's belong to the "world of law observance." However, it may be argued that France does not deserve to be relegated to the "world of neglect" for this particular policy area. A case can be made that all three member states in fact belong to a "world of domestic politics," with their policy responses influenced to varying degrees by domestic beliefs and processes. The EU directives considered here may have been intended to harmonize conditions across member states, but the resulting state-level laws are by no means identical and 
retain essential features of the state-level laws and policy instruments that preceded them. Table 6-1 below summarizes the main features of the transpositions of the six EU directives by the three member states.

The UK transpositions were colored by a "policy core belief" originating in the 1974 HSW Act that required employers to ensure worker safety "so far as is reasonably practicable" [Section 2(1)] (HMSO, 1974). This belief is reflected in British transpositions to the present day, despite the fact that EU directives frame employer responsibilities as more absolute. Although the British concept originated in the OSH policy subsystem, it is found in British transport-related law and regulations that are developed and enforced outside the OSH community. The UK encountered its greatest challenge in transposing the Working Time Directive; across all six directives and all three member states, this is the only instance in which the member state had no existing legislation as a starting point for transposition. The omission in British law may be attributed to a deep-seated belief rooted in economic liberalism that working time was a matter to be agreed on by the employer and employee and that its regulation would be harmful to business. Domestic opposition to the first Working Time Directive (93/104/EC) was sufficiently strong that the UK brought a case against the European Commission in the ECJ on the grounds that working time did not fall under the EU's competence for OSH regulation and was therefore not subject to legislation by QMV. The UK lost the case in the ECJ but continued to resist transposition, complying only after the more leftist Labour government came to power in 1997.

In the UK, there is a clear divide between OSH-type directives implemented by the HSE (for this research, the Working Time Directive) and transport-type EU directives implemented through DfT and the police (the remaining five directives examined here). In France, the distinction is somewhat blurred, as a state-level tradition of collective bargaining has influenced the transposition of both transport-type and OSH-type directives.

France's transpositions accommodated existing modes of policymaking and institutional arrangements, although in some instances the status quo may have made transposition more complicated. For example, transposition of the Driver CPC Directive required modification of regulations in several policy realms to accommodate the domestic practice of initially qualifying drivers of commercial vehicles through vocational education under the aegis of the employment ministry, and providing re-training and refresher training for experienced drivers through the transport ministry. In addition, France chose to transpose the Road Transport Working Time Directive separately for goods and passenger transport because collective bargaining was segmented along these sectoral lines. Finally, the dominance of the domestic debate on the 35hour work week offers strong evidence that state-level policy discourse can be far more potent than initiatives originating at EU level. Again, as in the UK, the pressure for change came from the left. However, unlike the UK, whose Working Time Regulations were enacted solely to transpose the first EU Working Time Directive, France's Aubry laws were enacted to serve a partisan domestic policy priority, the 35-hour work week championed by the Socialists.

Moreover, the very process of transposing regulations is considerably different in France than in the UK, where the government by virtue of its simultaneous control over the executive and legislative branches can generally push through the policies it chooses. In France, consultation with the "social partners" is integral to issuance of governmental decrees and orders. This 
process may introduce delays in transposition. Another source of delay is the body of domestic collective agreements that may pre-date EU directives. An example from this research is the EU working time directives, where the transposition process would necessarily include examination of existing agreements one by one to assess their conformance with the new directives. Finally, any transposition would require lawmakers to determine whether any proposed measures would conflict with or require amendments to one of the many French codes of law.

I argue that the only directive of the six in which France may be shown to have truly "neglected" transposition was the Driving License Directive. The successful ECJ proceeding against France centered on a fairly minor provision related to the duration of the on-road driving assessment, but as administrative documents reveal, France was grappling with more fundamental issues surrounding licensing which were not resolved for more than a decade after the directive was first issued. For the other five directives, France's delays were not appreciably longer than those of Sweden or the UK, and the quality of its transpositions was not appreciably lower. Rather than characterizing French policymaking as a matter of neglect, it would be more accurate to say that some French transpositions fell victim to societal and administrative distractions at domestic level. The sources of these distractions were domestic priorities such as the 35-hour work week and processes such as established practices of social-partner engagement and collective agreements.

As Falkner et al. would predict, Swedish transpositions generally reflect compliance with EU directives, although some were completed a few months past EU deadlines. Transpositions of the directives related to licensing and training reflect Sweden's leadership in conceptualizing training models, as well as Sweden's "policy core belief" that sees the driver as an individual who interacts with the road system as a member of a larger society. Transpositions of the Seat Belt Directive and the two working time directives were based on existing regulations that were already largely in compliance at the time EU directives were issued.

The only Swedish provisions identified here that raise serious concerns about the safety of occupational drivers are those that allow the work week to be increased from the standard 40 hours to 48 hours by collective agreement. However, this concern is balanced somewhat by the fact that Sweden, unlike the other two member states, has working-time regulations that cover drivers of OLVs. The positive impact of these light-vehicle regulations may be greater than the negative impact of collective agreements that allow the work week to average 48 hours over a reference period of four months. ${ }^{82}$

Table 6-1. Summary table: State-level transpositions of EU directives

\begin{tabular}{|l|l|l|l|}
\hline Directive & \multicolumn{3}{|c|}{ Member State } \\
\hline & United Kingdom & France & Sweden \\
\hline Driving License & $\begin{array}{l}\text {--Late transposition } \\
\text {--Incomplete transposition of }\end{array}$ & $\begin{array}{l}\text {--Very late transposition } \\
\text {--ECJ action for non- }\end{array}$ & $\begin{array}{l}\text {--Slightly late transposition } \\
\text {--Many provisions already }\end{array}$ \\
\hline
\end{tabular}

\footnotetext{
${ }^{82}$ Consider the U.S., where truck drivers are exempt from working-hours protections of the Fair Labor Standards Act, and are currently permitted to drive up to 11 hours in a work shift and may be "on duty" up to 60 hours over any 7-day period (Federal Motor Carrier Safety Administration, 2010). Moreover, the U.S. has no OSH regulations whatsoever for OLV drivers.
} 


\begin{tabular}{|c|c|c|c|}
\hline & some elements & transposition & $\begin{array}{l}\text { in state law } \\
\text {--Emphasizes social aspects } \\
\text { of driving }\end{array}$ \\
\hline Driver CPC & $\begin{array}{l}\text {--Transposed several months } \\
\text { late } \\
\text {--“Test-only" option } \\
\text {--Some elements incorporated } \\
\text { by reference }\end{array}$ & $\begin{array}{l}\text {--Transposed to conform with } \\
\text { domestic processes for } \\
\text { vocational training } \\
\text {--"Training + test" option }\end{array}$ & $\begin{array}{l}\text {--Transposed more than one } \\
\text { year late } \\
\text {--"Training + test" option }\end{array}$ \\
\hline Operator CPC & $\begin{array}{l}\text {--Idea of "professional } \\
\text { competence" dates from } 1968 \\
\text { RTA } \\
\text {--Existing regulations largely } \\
\text { in compliance } \\
\text {--Some ambiguity on } \\
\text { recognition of non-UK CPCs }\end{array}$ & $\begin{array}{l}\text {--Vague on recognition of } \\
\text { CPCs from other states } \\
\text {--Followed state-level } \\
\text { precedent of separate } \\
\text { regulations for goods and } \\
\text { passenger transport } \\
\text {--Operators outside directive's } \\
\text { scope also required to provide } \\
\text { proof of professional } \\
\text { competence }\end{array}$ & $\begin{array}{l}\text {--Late transposition for } \\
\text { content of CPC exam, but } \\
\text { high-quality transposition of } \\
\text { training objectives }\end{array}$ \\
\hline $\begin{array}{l}\text { Road Transport } \\
\text { Working Time }\end{array}$ & $\begin{array}{l}\text {--Timely and correct } \\
\text { transposition } \\
\text {--Incorporates domestic policy } \\
\text { belief of ensuring worker } \\
\text { safety "so far as is reasonably } \\
\text { practicable" }\end{array}$ & $\begin{array}{l}\text {--Transposed against backdrop } \\
\text { of laws adopting 35-hour work } \\
\text { week } \\
\text {--Followed state-level } \\
\text { precedent of separate } \\
\text { regulations for goods and } \\
\text { passenger transport } \\
\text {--Collective bargaining a key } \\
\text { input }\end{array}$ & $\begin{array}{l}\text {--Existing legislation largely } \\
\text { in compliance } \\
\text {--40-hour work week, but } \\
\text { derogation opportunities } \\
\text {--Complementary state law } \\
\text { for lighter vehicles }\end{array}$ \\
\hline Working Time & $\begin{array}{l}\text {--Substantial misfit with } \\
\text { domestic beliefs } \\
\text {--Very late transposition } \\
\text {--“Individual opt-out" } \\
\text {--Unsuccessful action against } \\
\text { European Commission } \\
\text { ("treaty-base game") }\end{array}$ & $\begin{array}{l}\text {--Transposed against backdrop } \\
\text { of laws adopting 35-hour work } \\
\text { week } \\
\text {--Variations via sectoral } \\
\text { collective agreements } \\
\text {--Lack of provisions to ensure } \\
\text { adequate rest for "mobile } \\
\text { workers" }\end{array}$ & $\begin{array}{l}\text {--Existing legislation largely } \\
\text { in compliance } \\
\text {--ECJ action for non- } \\
\text { transposition } \\
\text {--40-hour work week. but } \\
\text { widespread derogations } \\
\text { possible via collective } \\
\text { agreements }\end{array}$ \\
\hline Seat Belt & $\begin{array}{l}\text {--Limited occupation-based } \\
\text { exemptions } \\
\text {--Incorporates domestic policy } \\
\text { belief of taking all reasonable } \\
\text { steps to inform bus passengers }\end{array}$ & $\begin{array}{l}\text {--Early adopter of passenger- } \\
\text { vehicle laws } \\
\text {--Required new laws for } \\
\text { trucks and buses }\end{array}$ & $\begin{array}{l}\text {--State-level law largely in } \\
\text { compliance long before } \\
\text { Directive } \\
\text {--Required new law that bus } \\
\text { passengers be informed }\end{array}$ \\
\hline
\end{tabular}

It is important to consider not just the fact of transposition, but the degree to which a transposition took advantage of options to weaken safety provisions. The Swedish transposition of the two working time directives is a case in point. Swedish working-time law sets the standard work week at 40 hours, but the option for derogations from this through collective agreements means that the actual work week may be pushed closer toward the EU limit of 48 hours that it might appear. Similar derogations are possible in France, but the likely impact is far greater in Sweden because of its high levels of union membership. 


\section{Applicability of the Advocacy Coalition Framework (ACF)}

For the three member states individually and also for the EU-member state relationship, the ACF provides a valid model for policy development and change in occupational road safety. Virtually every component of the ACF can be applied to varying effect to a discussion of this policy area:

- Policymaking as taking place within a subsystem

- Stable features of a polity that mediate the types of policies that are enacted and how they are enacted

- Policy beliefs which are amenable to change to varying degrees

- Varying opportunity structures that make policy change more or less likely

- "External shocks" that lead to more sweeping change than might otherwise have been possible

- "Policy learning" as transferring ideas in a more incremental way within and across polities

\section{The ACF - Policy subsystems and belief systems}

One of the foundations of the ACF is the primacy of subsystems - actors inside and outside government with a material, ideological, or intellectual interest in outcomes for a particular policy area (P. Sabatier, 1998, p. 99; P. Sabatier \& Weible, 2007, pp. 192-193). Another key element of the ACF is belief systems. These may be "deep core beliefs," fundamental beliefs about human nature and core societal values which are generally the product of childhood socialization and transcend the subsystem, so are thus difficult to change; "policy core beliefs" about the most appropriate policy instruments and strategies, which are specific to the subsystem and also difficult to change; and policy core preferences and secondary beliefs, which may be more amenable to change (P. Sabatier \& Weible, 2007, pp. 194-195).

In the UK, the regulation of occupational road safety is firmly in the realm of the transport policy subsystem. The DfT is responsible for enforcing the regulations covering the operation of large trucks and buses which reflect British transpositions of EU relevant directives. The DfT has also been the primary governmental supporter of research on occupational road safety, and provided seed funding for the employer-led DfBB program.

This does not mean, however, that policy ideas originating in the OSH subsystem have been without influence. Although key players in the OSH agency HSE are fully aware that MVCs are the leading cause of occupational fatalities in the UK, their ability to act is limited because the roadway is out of their designated jurisdiction for enforcement. Nonetheless, the joint HSE/DfT 2003 Driving at Work guidance uses the EU Framework Directive for OSH as the basis for informing employers that their responsibility for risk assessment extends to employees who drive for work. Further, Driving at Work reminds employers that "The Health and Safety at Work Act 1974 requires you to ensure, so far as is reasonably practicable, the health and safety of all employees while at work" (Health and Safety Executive, 2003, p. 3). This "policy core belief" that employer responsibility is not absolute pre-dates EU competence for OSH and has remained a part of British occupational safety policy despite EU directives that frame employer responsibility as requiring that they take all possible measures to ensure a safe work environment. 
In France, the framing of occupational road safety as a multi-sectoral policy issue has been reinforced within the last decade by the formation of the Comite de pilotage, which brings together representatives from the transport and labor ministries and the social insurance funds (the primary fund CNAMTS along with specialized funds for government and agricultural workers). Reflecting the fact that direct consultation to employers is provided through the regional social insurance funds (the CRAMs), the current roster of the Comité de pilotage includes representatives from four different CRAMs in addition to the state-level CNAMTS (Ministère de l'écologie, de l'énergie, de développement durable et de la mer, Sécurité routière [Ministry of Ecology, Energy, Sustainable Development, and the Sea, Road Safety Unit], 2010).

The literature tells us that in the case of transport policy, France has followed the interventionist Continental model (Kerwer \& Teutsch, 2001a, pp. 129-131; Stevens, 2004, p. 2). For the safetyrelated components of transport policy, however, this does not hold. While French competition policy does follow the Continental model, driven by the idea that national industries ought to be protected, occupational road safety policy is, even for the road transport industry, driven by a social policy ethos. The domestic "re-regulation" movement of the 1990s was fueled by concerns about the working conditions of truck drivers, and was therefore a project of social regulation, not economic regulation. Re-regulation was therefore linked to the OSH policy subsystem, where the social insurance funds were key players. Because the social insurance funds were involved, the social partners were automatically brought into the subsystem. This development created the environment that made it possible for the Comite de pilotage to be constituted as it was - incorporating CNAMTS and the CRAMs, which view occupational road safety as encompassing the operation of OLVs in addition to the large commercial vehicles covered by EU legislation (Caisse nationale de l'assurance maladies des travailleurs salariés Direction des Risques professionnels (CNAMTS-DRP), April 28, 2010; Caisse regionale de l'assurance maladie (CRAM), April 28, 2010).

In Sweden, government recognition of occupational aspects of road safety as a component of general road safety discussions can be documented from the early 1970s (Trafikutskottets, 1971). Policy development has taken place primarily within a government-dominated subsystem, with input into proposed legislation coming from interest groups and civil society as a matter of course. The subsystem is not as closed as it might appear, however, as some individuals have moved between government service and academia.

There is substantial congruence between Swedish models and policy instruments for road safety and occupational safety. Deeply-held societal and policy beliefs have shaped legislation and policy in both arenas. One of the most pervasive beliefs, a "deep core belief" as suggested by the $\mathrm{ACF}$, is the view of the individual as a cog within the larger society and system. The 1977 WEA and the Vision Zero road safety initiative conceptualize work and driving, respectively, as taking place within systems that can be modified to reduce or eliminate harm without placing a great deal of emphasis on changing individual behavior.

Swedish policy is influenced by larger questions of what kind of society Swedish citizens want to have, driven by "non-materialistic values" (J. Richardson, et al., 1982, pp. 7-8). Even a comprehensive policy framework such as Vision Zero is but one element within a larger vision of a risk-free society (Fahlquist, 2006; Johansson, 2009). Over the years, Sweden's holistic and 
integrative approach has meant that occupational road safety has been quite well-integrated into its overall road safety policy, and crucially, it has not been explicitly placed outside the reach of OSH policy. A history of engagement and cooperation between agencies and technical experts has helped to maintain that integration. Moreover, Sweden is a small, homogeneous country, which may confer certain advantages for reaching consensus on policy content and instruments.

Sweden's policy for occupational road safety has elements of the Continental form of transport policy described earlier, which sees transport as a public good where the state has some responsibility to intervene in pursuit of economic and social welfare goals (Stevens, 2004, p. 2). However, Sweden's policy is a hybrid because it has pursued social welfare goals for workplace safety and transport safety using state-driven approaches, but has chosen a liberal path economically. Therefore, Sweden looks more like France in its emphasis on social aspects of workplace safety and road safety, but more like the UK in its economic policies related to transport as an industry.

\section{The ACF - Epistemic communities and interest groups}

The ACF emphasizes the role of information and "policy learning" in policy change; therefore, technical experts play an important role in informing policymakers and the public (P. Sabatier \& Weible, 2007, p. 192). Within the three member states, interest groups have influenced policy to varying degrees. In the UK, epistemic communities, NGOs, and business-based interests have created a robust complementary subsystem for occupational road safety, which interacts with UK governments at various levels. The research community in the UK has produced what is arguably the strongest body of research on the topic found anywhere in the world. Its members also participate in transnational policy networks through forums such as the UN Road Safety Collaboration, the ETSC's PRAISE initiative, and the Transportation Research Board, an influential U.S.-based body that has strong international representation.

Despite the international legitimacy of the UK epistemic community and its engagement with its state-level government on the topic of occupational road safety, it does not appear to have been particularly successful in changing domestic legislation or regulations. This policy community has nonetheless succeeded in using a number of multiple-fatality crashes to keep occupational road safety in the public eye. In addition, it has clearly influenced occupational road safety practice by promoting voluntary initiatives that at present appear to be more acceptable to both business and government than is the prospect of new regulations.

Non-governmental actors in the UK succeeded in framing occupational road safety as a public safety issue that transcends occupational safety. They have not, however, altered the prevailing domestic policy ideas, which are aligned with liberal, market-driven precepts. The essence of these ideas is as follows: Organizations that effectively manage road risk will also be more competitive in the marketplace because their operating costs and liability-related expenses will be lower; therefore, managing risk is inherently an organizational function, not a government function. The actors within the extra-governmental subsystem seem to accept this as a political reality and, based on the interviews conducted for this research, are resigned to taking whatever support they can from the government while forging their own path. This is a case of nongovernmental actors stepping in where the government has not elected to use all the policy levers that might be available. 
In France, interest groups from labor and industry are more formally engaged with government than in the UK through corporatist arrangements that involve the social partners in collective bargaining for the road transport industry and voluntary prevention efforts delivered through the regional social insurance funds. In addition, governmental decrees and orders on occupational road safety frequently cite related collective agreements. Finally, working conditions for some occupational drivers, notably truck drivers, have been the impetus for work stoppages that have taken the issue out of the labor policy community into a much wider public consciousness.

In Sweden, there is less evidence of strong interest-group activism for occupational road safety policy. The principles underlying Vision Zero were developed within the government; they guide occupational road safety policy because they permeate all facets of road safety policy. Thus, the messages of road safety interest groups identified through this research, notably NTF and the Quality III Organisation, echo Vision Zero precepts, but these groups do not necessarily work formally with the government. The key government informants interviewed for this research did not cite regular consultation with labor or industry as a part of policy implementation of government policies.

Interest-group formation and activity levels in the three member states have followed both "supply-side" and "demand-side" dynamics as described by Mahoney (Mahoney, 2004). "Supply-side" activity is more common, as evidenced by media and NGO advocacy in the UK, labor actions and employer inputs to policy in France, and position statements from the NTF road safety NGO in Sweden. In the UK, government research funds and seed funding for DfBB may be seen as examples of "demand-side" responses wherein the government uses its resources to steer the policy debate in a particular direction based on the nature and constraints of the policy environment. The body of research produced in the UK emphasizes management and assessment of individual drivers, along with the imperative that organizations should implement management systems for road safety within existing OSH systems. Although policy guidance from the UK reminds organizations of what government requires them to do, it is quite clear that prudent risk management requires far more than following government-set minimums to reach desired goals (Global Road Safety Partnership, May 4, 2010). Furthermore, governmentsupported research from the UK generally steers clear of recommending new government policy or regulation, which is not all that surprising in the context of the UK's liberal transport market and a political climate that does not support new regulation (Department for Transport (United Kingdom), April 30, 2010).

It is also possible that in France, government support for work on occupational road safety within institutions such as Eurogip and CNAMTS with strong corporatist elements demonstrates a similar "demand-side" dynamic. In Sweden, inputs from the social partners are also institutionalized within the legislative process. However, there is little evidence that the government has provided material or other support to non-governmental actors with the goal of changing the way occupational road risk is managed by businesses or organizations, nor does the government routinely consult with non-governmental actors on questions of implementation (Arbetsmiljöverket, November 11, 2010). 


\section{The ACF - Stable system parameters}

The ACF allows for stable parameters of the policy environment that affect how policy is enacted (P. Sabatier, 1998, pp. 102-103; P. Sabatier \& Weible, 2007, p. 199). The policy environment for occupational road safety in the UK reflects system-wide beliefs about the relationship between business and government: a fundamental neo-liberal belief that the business community should to the extent possible function without government intervention. The policy subsystem for occupational road safety also operates under the premise that further regulation is unlikely in the foreseeable future (Department for Transport (United Kingdom), April 30, 2010). Therefore, the HSE and DfT have encouraged self-regulation to promote road safety at work by businesses, through initiatives such as the Driving at Work policy guidance and DfBB. The government's pro-business and pro-market stance is balanced somewhat by the "cause or permit" provisions in the RTA, and the corporate manslaughter legislation. It must be noted, though, that these measures are more concerned with holding companies accountable for their employees' actions on the road than on protecting workers themselves.

The other notable stable feature of the UK system is its pluralist structure that gives interest groups no formal or privileged role in policymaking (Gallagher, et al., 2006, pp. 452-453; Siaroff, 1999). The policy subsystem for occupational road safety is varied and fluid. In a situation where the government might be expected to take action - for example, if the government were contemplating a change to its RIDDOR data collection - business, researchers, NGOs, and advocates would all compete for access and influence with government policymakers. On the other hand, in venues such as DfBB, government officials are on a par with the many other actors contributing to the discussion. Although the positions of the agencies they represent are well-understood by the other parties, these individuals appear to have no special standing in the decidedly non-government-centered subsystem.

In France, the formulation of policy for occupational road safety policy draws from a wellestablished corporatist orientation toward labor relations that formally involves the "social partners" from labor and industry in wage-bargaining and policy consultations with the government (Douillet \& Lehmkuhl, 2001). It should be noted, however, that while collective bargaining is a strong feature of labor relations within the road transport industry, fewer groups of workers who drive OLVs are covered by such agreements.

Another stable parameter of the French policy environment is the use of corporatist structures to create temporary or permanent institutions related to occupational road safety, again more for road transport workers than for those who are employed in other industries and drive OLVs. One example is the Dobias Commission, which recommended a major revision of the 1950 collective agreement for the road transport industry as an antidote to the strikes of the early 1990s; a tripartite commission was subsequently formed to monitor the new agreement (Brodu, et al., 2007; Douillet \& Lehmkuhl, 2001, p. 114). Other examples of corporatist institutions within the occupational road safety subsystem in France are Eurogip, the Comite de pilotage, and the social insurance funds that play a central role in occupational injury prevention. Compared to the majority of collective bargaining agreements and consultative mechanisms such as the Conseil supérieur des transports, these institutions and arrangements are less formalized and cover a broader range of employee drivers. Employer and employee interest groups participate 
in the governance of each of these institutions (Caisse nationale de l'assurance maladies des travailleurs salariés - Direction des Risques professionnels (CNAMTS-DRP), April 28, 2010; Eurogip, April 28, 2010).

The ACF also provides for consideration of the policy brokers and resources with the subsystem (P. Sabatier, 1998, pp. 102-104). The governmental actors in the French policy subsystem for occupational road safety have generally adhered to existing policy frames and instruments in response to pressure to transpose EU directives. This may be in part attributable to France's generally low capacity for instituting the kinds of administrative reforms that a more direct transposition of some of the EU directives considered here would have required. Although the corps of senior civil servants may move between ministries, lower-level bureaucrats tend to remain strongly attached to a topical or functional sector throughout their careers and may be averse to major changes in processes (Knill, 1998, p. 21). In the case of non-regulatory policy responses such as the CNAMTS injury prevention initiatives and the Comité de pilotage, however, French bureaucrats have shown the ability to work effectively across ministries and with the social partners.

For Sweden, there are a number of relatively enduring features of the political system that have influenced the course of policy for occupational road safety. Some of these are specific to the policy subsystem for occupational road safety; others are more general. Overall, the Swedish system is marked by a strong corporatist orientation (Ruin, 1982; Siaroff, 1999). For occupational road safety, there is evidence of formal consultation of the social partners in legislative processes. However, corporatism is less evident in Swedish implementation of policy (Arbetsmiljöverket, November 11, 2010), in contrast to France, where engagement with the social partners was observed at both the legislative and implementation stages and for both regulatory and non-regulatory initiatives.

Institutional features and arrangements are also relevant to the Swedish case. The placement of Swedish transport agencies under the same ministry responsible for industry policy and competition means that the economic and safety aspects of road transport are managed in the same ministry. This may increase the likelihood of linkages between competition policy and road safety policy. In addition, although the general OSH requirements as applied to road safety fall under Arbetsmiljöverket in the Ministry of Employment, there is evidence of cross-agency collaboration between Arbetsmiljöverket and Vägverket to develop joint guidance that extended the risk assessment requirements of the EU Framework Directive for OSH (89/391/EEC) to the roadway as a workplace (Arbetsmiljöverket, 2003/2004).

Stable characteristics of the Swedish executive agencies and civil service may also have affected the development of policies relevant to occupational road safety, in particular Vision Zero. Among these is the independence of executive agencies such as Trafikverket and the level of resources allocated to them (Elvander, 1974; Ruin, 1982, p. 141; Trafikverket, October 6, 2010). In addition, the Swedish civil service is highly sectoralized; individuals tend to become subjectmatter specialists and remain in the same sector throughout their careers (Bale, 2008, p. 82; Ruin, 1982, pp. 152-153). This arrangement reflects Sweden's normative orientation toward long-range planning and policy as a way of shaping society (Freeman, 1985, p. 474; Ruin, 1982, 
p. 151), and creates a stability and continuity within the workforce conducive to the development of policy innovations such as Vision Zero.

\section{The ACF - External systemic influences on policy}

The ACF also considers the less predictable external impacts on the system, that is, those coming from outside the policy subsystem, which help to create conditions under which major policy change becomes possible. For occupational road safety in the UK, the most influential of these have been changes in government, and events in the society at large that cause non-governmental actors to call for change (P. Sabatier, 1998, pp. 102-103; P. Sabatier \& Weible, 2007, pp. 201205). One example of the former is the UK's transposition of the first EU Working Time Directive, for which domestic partisan politics played a key role in the delay and opposition to its transposition. The Directive was strongly opposed by the Conservative government and became politically tenable only after the more leftist Blair Labour government came to power. The latter mechanism is exemplified by campaigns in the 1990s through regional and national media outlets, as well as NGOs such as RoSPA and Brake. These campaigns provided policy inputs that were more affective than technical, using the "external shocks" of multiple-fatality occupational crashes to energize public opinion and press the government to intervene.

The same two external forces - changes in the governing coalition and changes in public opinions - affected occupational road safety policy in France, as they did in the UK (P. Sabatier, 1998, pp. 102-103). Early in the 1990s, transport strikes disrupted the lives of ordinary citizens and led to public concern about working conditions in the transport industry (Douillet \& Lehmkuhl, 2001, p. 114). In response, the government created the Dobias Commission to study the issues and propose solutions; based on Dobias Commission recommendations, there followed a substantial overhaul of the collective agreement between transport workers and industry. In 1997, a change from a conservative to a Socialist government created the conditions necessary for passage of major legislation that reduced the standard work week to 35 hours. Passage of the Aubry laws, long a priority for French Socialists, became possible politically only after conservatives relinquished power and the Socialist Jospin became Prime Minister (Askenazy, 2008, pp. 2-3).

Based on the literature and interviews of key informants, Sweden does not appear to have suffered the external shocks that have had some influence on policy in the other two EU member states. Vision Zero, the most profound policy shift seen in Sweden, does not appear to have originated with political entrepreneurship or broad societal pressures, but was a product of the anticipatory, deliberative process inside government the literature suggests is typical of Swedish policymaking (Gallagher, et al., 2006, pp. 443-445; Premfors, 1981, pp. 244-245; J. J. Richardson, 1979, pp. 342-344; Sverdrup, 2003, p. 2). The bureaucracy in which Vision Zero developed reacted not to public outcry, alarming statistics, or partisan pressures, but to a plateau in progress toward internal road safety goals set by Vägverket (Trafikverket, October 6, 2010).

\section{$\underline{\text { Mobilizations of bias }}$}

Outside the ACF, the concept of "mobilization of bias" as described by Baumgartner and Jones (1993) informs the discussion of policy change. A mobilization may be positive, implying a 
wave of enthusiasm for tackling a problem in the public arena, or negative, implying a backlash from policymakers or the public against a policy instrument currently in place to address a problem (Baumgartner \& Jones, 1993, pp. 88-89). The idea of mobilization of bias is not explicit in the ACF, but it complements the discussion above. It is worth noting, as there is some element of this present for all three member states discussed here.

The idea of a "negative mobilization of bias" may also be used to characterize how the media and NGOs in the UK capitalized on negative public perceptions of careless or overworked employee drivers to push for government action (Baumgartner \& Jones, 1993, pp. 86-89). Interest-group advocacy brought about some government response, including formation of the commission that produced the Dykes Report and the decision to develop the DfT/HSE Driving at Work document. However, no sweeping changes in the form of new regulations or new institutional structures have thus far come about as a result of advocacy from technical experts or civil society.

The development of French policy for occupational road safety has elements of both positive and negative mobilizations of bias (Baumgartner \& Jones, 1993, pp. 86-89). The labor unrest that led to the transport strikes of the 1990 s was a negative mobilization that spilled over into civil society, creating inconvenience for the public and bringing concerns about working conditions for an entire industry into the public eye. On the other hand, formation of the Comité de pilotage was a positive mobilization based on a desire to develop a coordinated response to the problem of work-related MVCs.

In contrast, there is no evidence that Sweden experienced the negative mobilizations of bias that appear to have had some influence on policy in the other two EU member states. As described above, the impetus for Vision Zero originated inside the Vägverket bureaucracy, based on a determination that progress toward the agency's road safety goals had reached a plateau (Trafikverket, October 6, 2010). The move toward Vision Zero can therefore be seen as a positive mobilization based on what was perceived internally as a less-than-positive development.

\section{$\underline{\text { Influence of international actors }}$}

This research revealed limited evidence that international bodies such as the UN Road Safety Collaboration or resolutions by the UN have had any influence on occupational road safety policy in the three member states. The UN Road Safety Collaboration is a useful forum for exchange of information, but it is not the only opportunity for interaction among the key road safety officials in the three member states, nor does the Collaboration have any power to ask delegates to commit their state to take specific actions. UN resolutions on road safety are far more meaningful for low- and middle-income countries with limited capacity for road safety management than for the three states that are central to this research. The UK, France, and Sweden might look to UN resolutions to support technical assistance agreements with developing countries, but would find nothing in them that would cause them to change their domestic road safety programs. 
There are, however, organizations in Europe that are well-positioned to act as policy brokers for occupational road safety in the EU. ETSC, a quasi-governmental interest group with ties to the European Commission, has played a key role in identifying occupational road safety as a distinct policy issue for Europe, recognizing possible policy levers, and finding linkages between EU transport policy areas and occupational road safety that were heretofore not appreciated. Examples include a proposed EU directive on cross-border enforcement, championed by the Belgian presidency, which would create more uniform penalties for traffic violations across the EU. For individuals driving for work, the potential for stricter and uniformly-applied penalties may be a deterrent to future violations (European Transport Safety Council, 2011, May 7, 2010). ETSC, through its PRAISE initiative, has also used its role as a pan-EU interest group as a platform to issue a number of thematic reports on occupational road safety covering topics such as assessment of high-risk drivers, distracted driving, and in-vehicle technologies. Its location in Brussels, its broad-based membership, and the legitimacy conferred by its connection to the European Commission facilitates relationships with policy networks across the EU at various geographic levels. Moreover, these attributes give ETSC formal and informal access to officials in the EU bureaucracy. ETSC also provides non-adversarial forums where participants learn from subject matter experts about occupational road risks and discuss policy alternatives with policymakers from member states and the European Commission.

At member-state level, Paris-based Eurogip functions as a "think tank" concerned with France's interactions with the rest of Europe in the realm of OSH policy. Because it routinely compiles and synthesizes information on OSH topics, drawing on data from throughout the EU, its subject-matter expertise gives it the potential to play a pan-European role. For example, Eurogip has prepared several documents addressing occupational road safety that compare the French prevention regime with the systems that exist in other EU member states (Eurogip, 2003, 2007, 2009). Eurogip has also developed statistical reviews of occupational injuries specific to other EU member states, including Belgium, Germany, the Czech Republic, Italy, Austria, and Spain. In addition to providing data on the incidence and causes of occupational injuries, including onroad injuries, these reviews also discuss each member state's social insurance and prevention system for occupational injuries (Eurogip, 2011). However, the reach and influence of Eurogip are hampered by the fact that many of its products have not been translated from French into other major EU languages. Most of the statistical reviews have been translated into English, but only one of the major documents on occupational road safety (Eurogip 2003) has been translated from French.

At regional level, alliances of Nordic countries function as formal policy networks for their member states. The Nordic Road Association concentrates on cooperation on transport policy, and the Nordic Council is engaged in a much broader range of issues, some of which are also linked to transport (for example, environment and employment). This research did not uncover any concrete evidence that the Nordic networks have directly influenced either EU-level policies or state-level policies outside their membership. However, the fact that the majority of documents from the various Nordic policy networks are available in English, the international language of discourse for road safety, increases the likelihood that Nordic policy will influence policies outside the region. 
This research found limited evidence that Sweden's Vision Zero framework has directly led to new EU directives. However, Vision Zero has certainly had an indirect effect on policy and practice in the EU and beyond. That states should aspire to eliminate all deaths and serious injuries on roads, and that this can be achieved using a systems-based approach, were radical ideas in the 1990s. Gradually, though, other EU member states came to adopt components of the Swedish philosophy, and today Vision Zero no longer appears as singular and radical as it once did. A comprehensive policy document produced by the OECD ${ }^{83}$ concludes: "A Safe System approach is the only way to achieve the vision of zero road fatalities and serious injuries and requires that the road system be designed to expect and accommodate human error" (Joint Transport Research Centre of the OECD \& International Transport Forum, 2008, p. 15). Sweden's Vision Zero, along with the Netherlands initiative Sustainable Safety, are cited as exemplifying a "safe system" approach to road safety (Joint Transport Research Centre of the OECD \& International Transport Forum, 2008, p. 14). Norway has adopted its own version of Vision Zero (Elvebakk \& Steiro, 2009). Today, even the U.S., which has a poorer road safety record than most EU member states (other than the recent accession countries) and has not been particularly receptive to Vision Zero to this point, has begun to discuss how to move "Toward Zero Deaths" (American Association of State Highway Transportation Officials (AASHTO), 2010).

In the realm of occupational road safety, the development of the ISO 39001 standard for road safety management demonstrates a transfer of Vision Zero precepts to organizations, based on the premise that managing employees' interactions with the road system is a responsibility shared by organizations with government and other stakeholders (International Organization for Standardization (ISO), 2009). ISO 39001 is a transfer of policy at two levels. First, it seeks to promote voluntary application of the Swedish safe-system approach to organizations and businesses in other geographic areas. In addition, the intended recipients and users of the policy are no longer just governments, but organizations that operate motor vehicles. This situation falls somewhat outside the literature, which generally focuses on government-to-government transfer; non-governmental actors are cited as coercive or consultative agents of policy change, but they are not seen as potential adopters of policy ideas originating in governments (Bennett, 1991; Bulmer \& Padgett, 2005; Dolowitz \& Marsh, 2000; Wolman, 1992). One source, however, also admits the possibility of "convergence around broad policy objectives and principles but scope for divergence with regard to the instruments adopted, type of legislation or institutional modes of policy control/delivery" [my italics] (D. Stone, 2004, p. 548). Moreover, ideas and discourses are subject to transfer and adoption independent of governmental structures (D. Stone, 2004, p. 556). Stone's interpretation would seem to be broad enough to accommodate the transfer of Vision Zero policy ideas from one type of institution to another, in this case from government to businesses or other types of organizations through the ISO standard-setting process.

At the level of individual policies, policymakers in other EU states continue to look to Swedish initiatives as leading indicators of what might eventually be politically acceptable in their own states. For example, Sweden's procurement specifications requiring government fleet vehicles to be equipped with alcolocks provided support for a recent Belgian initiative (European Transport Safety Council, 2010b, January 14, 2011).

\footnotetext{
${ }^{83}$ This example of the OECD as an agent of policy learning and transfer is not unique (D. Stone, 2004, p. 553).
} 
Through initiatives such as PRAISE and DfBB, and independently through discussions among themselves, MNCs are an important conduit through which cross-border policy learning takes place (RoadSafe, May 6, 2010). MNCs typically own, lease, or hire large trucks for transport of raw materials, parts, and finished goods across member-state borders. They also provide OLVs for use by sales or customer service representatives and by executives. As such, they are acutely aware of the distinctions between the coverage of heavy and light occupational vehicles by EU and member-state law, and adjustments in company policies that need to be made on a state-bystate basis. One opinion leader in global road safety interviewed for this research noted that for forward-thinking fleet safety executives, the state-level or EU regulatory environment cannot be the end point for development of company policy. This individual characterized the application of much road safety policy at the state and sub-state level as a failing because it forces businesses to separately assess each country in which they operate to determine what steps are necessary to fill the gap between the level of protection offered by state-level law and the level of protection needed to achieve company-wide road safety goals (Global Road Safety Partnership, May 4, 2010).

\section{Applicability of multi-level governance (MLG)}

There is some evidence of Type I MLG at work within each of the three EU member states examined here, but not enough to make a compelling case that policy decisions regarding occupational road safety policy have been delegated to sub-state levels of government. In all three countries, the institutional structure for labor inspectorates is organized into sub-state units, but this is for purposes of implementation and reflects only limited discretion to develop local initiatives that might emphasize unregulated aspects of occupational driving such as OLVs. One exception common to all three countries is the evaluation and approval of applications for Operator CPCs, which has been delegated to regional officials: regional prefects in France, Traffic Commissioners in the UK, and County Administrative Boards in Sweden. However, only in the case of the UK has this function been delegated to a jurisdiction that has been "purpose-built" to deal with road safety matters. In the other two states, existing governmental units are responsible.

Evidence of Type II MLG within the member states is somewhat stronger, although it has played out differently in the UK than in France and Sweden. France and Sweden are similar in that MLG gives the social partners a role in policy through collective agreements, taking advantage of flexibility offered by EU directives to arrive at policy solutions acceptable to particular industry sectors. Both countries also allow the social partners formal input to legislation. France has additional public-private partnerships for injury prevention programs delivered through the social insurance funds, whereas Sweden has no similar mechanism. Type II MLG in the UK takes the form of a much more informal interaction between the pluralist interest-group structure and the government, with the government ceding a role to non-governmental actors by encouraging voluntary action by interest groups but not providing those interest groups formal entrée to the legislative arena.

If we look at policy with the relationship between the EU and member states in mind, we can also see Type II MLG at work. The EU has assumed responsibility for governing the aspects of 
occupational road safety related to road transport of goods and passengers and has transmitted those policies to the member states. (The imperative for regulation of goods transport is not at all surprising, given the link with the single European market.) However, operation of OLVs has until recently been viewed at EU level as outside its remit, so its governance has been taken up by member states. The history of inaction by the EU is not necessarily because the EU lacks clear competence in this area or has neglected to exercise its competence. It is simply that the European Commission directorates with a stake in the issue are just beginning to recognize opportunities for coordination and opportunities to attach occupational road safety to existing regulations such as the 2009 Working Equipment Directive (Commission of the European Communities, March 10, 2009; European Commission Directorate-General for Employment, May 5, 2010; European Commission Directorate-General Mobility and Transport, May 6, 2010; European Transport Safety Council, May 7, 2010). Policy ideas are coming from member states; for example, France has proposed that OLVs be classified as working equipment as member states complete their transpositions of the 2009 Working Equipment Directive (Caisse nationale de l'assurance maladies des travailleurs salariés - Direction des Risques professionnels (CNAMTS-DRP), April 28, 2010). There is also evidence of a convergence of ideas coming from member states and from European Commission level, as an official from DG MOVE raised the same idea independently while being interviewed for this research (European Commission Directorate-General Mobility and Transport, May 6, 2010).

\section{$\underline{\text { Summing up }}$}

For both large-truck safety and OLV safety, policy for occupational road safety remains essentially a domestic matter for the UK, France, and Sweden. Although it is true that the EU has regulated occupational safety for truck transport under the umbrella of creating a single European market for transport services, the application of those regulations remains a state-level concern. This is in part due to the desire to ensure that uniform safety standards are in place to protect domestic markets from encroachment by foreign transport companies that might create unfair competition by undercutting safety standards. In addition, to minimize pressures from advocacy groups and the public, member-state governments have an interest in operating the safest possible road system.

No EU regulations exist in certain policy niches related to occupational road safety; for example, the EU has issued no regulations or directives that directly address working time for operators of OLVs less than 3.5 tonnes. The way in which the three member states have addressed this particular regulatory gap reflects the overall approach of each state: Sweden through a societal road safety model supported by regulation, France through a combination of voluntary prevention initiatives led by the social insurance funds in concert with the social partners, and the UK through self-regulation by businesses and employer-led networks with some government support.

This research has shown that occupational road safety is a policy area that combines traditional "government" with "governance" through domestic policy subsystems, with some role for international policy networks. How it is managed in each of the three member states discussed here depends in part whether it is couched as a transport safety issue tied to business or industrial policy, as in the UK, or as a social welfare issue tied more closely to OSH policy, as in France 
and Sweden. For this policy area, it is statist France, not corporatist Sweden, that turns out to be the more corporatist of the two, and this may be attributed to the placement of occupational injury prevention functions within the social security agencies, where a corporatist approach is a well-entrenched approach. Another factor may be formal tripartite consultative mechanisms and collective bargaining for the road transport industry, which appear to be sector-specific exceptions to the conventional characterization of France as lacking corporatist institutions. The UK benefits from active epistemic communities, but its governance of occupational road safety lives up to expectations that risk management by employers will be framed as a business matter, not a social welfare issue.

The theoretical implications of this research are twofold. First, for this particular policy area and for the three member states, the ACF provides a more complete account than does MLG. The ACF sees policymaking as taking place within a subsystem. Participants in that subsystem represent varied interests, but tend to espouse shared beliefs at societal level and policy level. The ACF allows us to consider the stable features of the policymaking environment that are preconditions for any assessment of policy change, as well as the external forces that may "shock" the environment and create conditions under which a major policy change may occur (P. Sabatier, 1998; P. Sabatier \& Weible, 2007; P. A. Sabatier \& Jenkins-Smith, 1999).

Type I MLG, which focuses on delegation of governmental functions to sub-state units, is not especially salient for occupational road safety policy. There are a few relevant functions that have been passed to sub-state level in the three member states discussed here, notably review and approval of applications for the CPC required for operating a road transport entity. However, these are not representative of policy as a whole, and their delegation to sub-state bodies speaks more to a quest for administrative expediency than to true transfer of governance. Type II MLG does offer some insight into this policy area through its emphasis on interest groups and its distinction between "government" and "governance" (Bache \& Flinders, 2004; Marks \& Hooghe, 2004, p. 22) Certainly, the voluntary, self-regulatory element of policy for occupational road safety provides an example of the development of non-governmental or quasi-governmental solutions when additional controls are politically infeasible or unacceptable. However, the ACF, through its emphasis on policy subsystems made up of governmental and non-governmental actors, does not limit the discussion to government-centered policy initiatives.

Finally, this research offers some insight into the question of whether politics drives policies, or whether the reverse may in fact be true. The conventional "policy styles" approach holds that at state level, policymakers develop stable approaches to dealing with policy issues, which lead to consistent policy outcomes (J. Richardson, 1982). Freeman (1985) argues that we should also consider the possibility that the nature of a policy area may lead to similar policies across states, to some extent overriding state-level styles (Freeman, 1985). I argue that for occupational road safety policy in the UK, France, and Sweden, there remain significant differences in policy instruments, institutional arrangements, and underlying societal beliefs. Despite the imposition of EU directives intended to create some level of consistency, all three member states have responded in ways that reflect state-level beliefs and approaches. 


\section{Bibliography}

American Association of State Highway Transportation Officials (AASHTO). (2010).

Toward Zero Deaths: A national strategy on highway safety. Retrieved January 12, 2011, from http://safety.transportation.org/activities.aspx

Arbetsmarknadsdepartementet [Ministry of Labour (Sweden)]. (December 19, 1977). Arbetsmiljölag [Work Environment Act]. Svensk författningssamling (SFS) [Swedish Code of Statutes], SFS 1977:1160.

Arbetsmiljöverket. (2001). Systematiskt arbetsmiljöarbete: Arbetsmiljöverkets föreskrifter om systematiskt arbetsmiljöarbete och allmänna råd om tillämpningen av föreskrifterna. [Systematic work environment management: Provisions of the Swedish Work Environment Authority on systematic work environment management, together with general recommendations on the implementation of the provisions]. Arbetsmiljöverkets Författningssamling (AFS) [Swedish Work Environment Authority Statute Book], AFS 2001:1.

Arbetsmiljöverket. (2003/2004). Road safety -- A work environment issue. Solna, Sweden: Arbetsmiljöverket [Swedish Work Environment Authority].

Arbetsmiljöverket. (2010a). Framing of provisions by the Work Environment Authority. Retrieved December 5, 2010, from http://www.av.se/inenglish/lawandjustice/framing/

Arbetsmiljöverket. (2010b). The Work Environment Act - with commentary as worded on 15th February 2010 [SFS 1977:1160]. Retrieved October 30, 2010, from http://www.av.se/inenglish/lawandjustice/workact/index.aspx

Arbetsmiljöverket. (December 1, 2010). Personal communication with Jurist.

Arbetsmiljöverket. (November 11, 2010). Telephone interview with Safety Specialist.

Asare, B., Cairney, P., \& Studlar, D. T. (2009). Federalism and multilevel governance in tobacco policy: The European Union, the United Kingdom, and devolved UK institutions. Journal of Public Policy, 29(1), 79-102.

Askenazy, P. (2008). A primer on the 35-hour in France, 1997-2007 (IZA Discussion Paper, No. 3402). Bonn: Forschungsinstitut zur Zukunft der Arbeit.

Association of Chief Police Officers. (2001). Road death investigation manual. Basingstoke, England: ACPO, National Operations Faculty.

Bache, I., \& Flinders, M. (2004). Themes and issues in multi-level governance. In I. Bache \& M. Flinders (Eds.), Multi-level governance (pp. 1-11). Oxford: Oxford University Press.

Baldwin, R. (1996). Regulatory legitimacy in the European context: The British Health and Safety Executive. In G. Majone (Ed.), Regulating Europe (pp. 83-105). London and New York: Routledge.

Bale, T. (2008). European politics: A comparative introduction (2nd edition). Basingstoke: Palgrave Macmillan.

Banks, T., Davey, J. D., Biggs, H. C., \& King, M. J. (2010). A review of the effectiveness of occupational road safety initiatives. In L. Dorn, G. Matthews \& I. Glendon (Eds.), Driver behaviour and training (Vol. 4). Aldershot, England: Ashgate (In press).

Barger, L. K., Cade, B. E., Ayas, N. T., Cronin, J. W., Rosner, B., Speizer, F. E., et al. (2005). Extended work shifts and the risk of motor vehicle crashes among interns. New England Journal of Medicine, 352(2), 125-134. 
Barrett, B. (2009). The Health and Safety (Offences) Act 2008: The cost of behaving dangerously at the workplace. Industrial Law Journal, 38(73).

Battle, D. L. (October 18, 2002). Reform of the practical examination of driver's license category B, (Memorandum to driver training officials). Paris: Ministère de l'Equipement, des Transports, du Logement, du Tourisme et de la Mer, Direction de la Sécurité et de la Circulation routières, Sous direction de la formation du conducteur [Department of Infrastructure, Transport, Housing, Tourism and the Sea, Directorate of Safety and Traffic, Sub-directorate for Driver Training]

Baumgartner, F. R., Green-Pedersen, C., \& Jones, B. D. (2006). Comparative studies of policy agendas. Journal of European Public Policy, 13, 959-974.

Baumgartner, F. R., \& Jones, B. D. (1993). Agendas and instability in American politics. Chicago and London: University of Chicago Press.

BBC News. (2010). BBC On This Day (October 8): 1987: Zeebrugge disaster was no accident. Retrieved August 21, 2010, from http://news.bbc.co.uk/onthisday/hi/dates/stories/october/8/newsid 2626000/2626265. stm

Bekefi, T. (2006). The Global Road Safety Partnership and lessons in multisectoral collaboration. Cambridge, MA: Harvard University, John F. Kennedy School of Government,Corporate Social Responsibility Initiative.

Belzer, M. H. (2000). Sweatshops on wheels: winners and losers in trucking deregulation. New York: Oxford University Press.

Bennett, C. J. (1991). What is policy convergence and what causes it? British Journal of Political Science, 21(2), 215-233.

Bennetto, J. (October 10, 1993). Lorries carry a deadly cargo: Cost-cutting haulage companies breach safety laws. Independent (UK). Retrieved from http://www.independent.co.uk/news/uk/lorries-carry-a-deadly-cargo-costcuttinghaulage-companies-breach-safety-laws-1509861.html

Berg, H.-Y. (2006). Reducing crashes and injuries of young drivers: what kind of prevention should we be focusing on? Injury Prevention, 12(June), i15-i18.

Beyers, J., Eising, R., \& Maloney, W. (2008). Much we study, little we know? The study of interest group politics in Europe and elsewhere. West European Politics, 31(6), 1103 1128.

Bibbings, R. (1997). Occupational road risk: towards a management approach. Journal of the Institution of Occupational Safety and Health, 1(1), 61-75.

Boggan, S. (November 19, 1993). The M40 Crash: Day trip to disaster for 11 young musicians: Steve Boggan outlines the events leading to the accident which killed 11 pupils and a teacher after an outing to London. Independent (UK). Retrieved from http://www.independent.co.uk/news/uk/the-m40-crash-day-trip-to-disaster-for-11young-musicians-steve-boggan-outlines-the-events-leading-to-the-accident-whichkilled-11-pupils-and-a-teacher-after-an-outing-to-london-1505175.html

Börzel, T., \& Risse, T. (2005). Public-private partnerships: Effective and legitimate tools of international governance? In E. Grande \& L. W. Pauly (Eds.), Complex sovereignty. Reconstituting political authority in the twenty-first century (pp. 195-216). Toronto: University of Toronto Press.

Börzel, T. A. (2002). Pace-setting, foot-dragging, and fence-sitting: Member state responses to Europeanization. Journal of Common Market Studies, 40(2), 193-214. 
Bovens, M., 't Hart, P., \& Peters, B. G. (2001). Analysing governance success and failure in six European states. In M. Bovens, P. t. Hart \& B. G. Peters (Eds.), Success and failure in public governance: A comparative analysis (pp. 12-29). Cheltenham: Edward Elgar.

Brake. (2010). Brake's fleet safety campaign. Retrieved February 26, 2010, from http://www.brake.org.uk/campaigns/fleet-safety.

Brodu, T., Caillat, A., \& Goutte, M. (2007). Rapport interacadémique Île-de-France relatif aux domaines des transports et de la logistique - 2001 [Interacademic Report for Îlede-France Relating to Transport and Logistics - 2001]. Paris: Académie de Versailles.

Broughton, J., Baughan, C. J., Pearce, L., Smith, L., \& Buckle, G. (2003). Work-related road accidents (No. 582). Berkshire, England: Transport Research Laboratory.

Bulmer, S., \& Padgett, S. (2005). Policy transfer in the European Union: An institutionalist perspective. British Journal of Political Science, 35(1), 103-126.

Caisse nationale de l'assurance maladies des travailleurs salariés - Direction des Risques professionnels (CNAMTS-DRP). (April 28, 2010). Personal interview with Consulting Engineer. Paris, France.

Caisse regionale de l'assurance maladie (CRAM), Île-de-France [Regional Health Insurance Fund, Île-de-France]. (April 28, 2010). Personal interview with Consulting Engineer. Paris, France.

Carlson, L. (2009). The fundamentals of Swedish law: A guide for foreign lawyers and students. Lund, Sweden: Studentlitteratur AB.

Centre des Liaisons Européennes et Internationales de Sécurite Sociale (CLEISS) [Center for European and International Social Security]. (2010). The French Social Security: II: Insurance for occupational accidents and occupational diseases. Retrieved December 19, 2010, from http://www.cleiss.fr/docs/regimes/regime france2.html

Charbotel, B., Chiron, M., Martin, J.-L., \& Bergeret, A. (2001). Work-related road accidents in France. European Journal of Epidemiology, 17, 773-778.

Charbotel, B., Martin, J. L., \& Chiron, M. (2010). Work-related versus non-work-related road accidents, developments in the last decade in France. Accident Analysis \& Prevention, 42(2), 604-611.

Clarke, D. D., Ward, P., Bartle, C., \& Truman, W. (2009). Work-related road traffic collisions in the UK. Accident Analysis and Prevention, 41(2), 345-351.

Comité de pilotage pour la prevention du risque routier professionnel [Steering Committee for the Prevention of Occupational Road Risk]. (2007). Livre blanc: 12 propositions pour un vehicule utilitaire plus sûr [White paper: 12 proposals for a safer utility vehicle]. Paris: Comité de pilotage.

Commission Internationale des Examens de Conduite Automobile (CIECA). (2010). Survey on the implementation of the directive 2003/59/EC laying down the initial qualification and periodic training of drivers of certain road vehicles for the carriage of goods or passengers. Brussels: CIECA.

Commission of the European Communities. (1983). Progress towards a Common Transport Policy - Inland transport. Communication from the Commission to the Council. COM (83) 58 final, 9 February 1983, COM (83) 58 final/2, 15 February 1983. Brussels. 
Commission of the European Communities. (1985). Completing the internal market. White Paper from the Commission to the European Council (Milan, 28-29 June 1985). COM (85) 310 final, 14 June 1985. Brussels.

Commission of the European Communities. (April 9, 1992). COUNCIL REGULATION (EEC) No 881/92 of 26 March 1992 on access to the market in the carriage of goods by road within the Community to or from the territory of a Member State or passing across the territory of one or more Member States. Official Journal of the European Communities, L 95, 1-13.

Commission of the European Communities. (December 1, 2000). REPORT FROM THE COMMISSION: State of implementation of Council Directive 93/104/EC of 23 November 1993 concerning certain aspects of the organisation of working time ('Working Time Directive') [COM (2000) 787 Final]. Brussels: Commission of the European Communities.

Commission of the European Communities. (February 2, 2000). COMMUNICATION FROM THE COMMISSION on the precautionary principle [COM (2000) 1]. Brussels: Commission of the European Communities.

Commission of the European Communities. (February 23, 1970). Council Directive 70/156/EEC of 6 February 1970 on the approximation of the laws of the Member States relating to the type-approval of motor vehicles and their trailers. Official Journal of the European Communities, L 042, 1-15.

Commission of the European Communities. (January 1, 2007). Council Directive 91/439/EEC of 29 July 1991 on driving licences [Consolidated version of January 1, 2007]. Official Journal of the European Communities. Retrieved August 13, 2010, from http://eurlex.europa.eu/LexUriServ/LexUriServ.do?uri=CELEX:31991L0439:EN:NOT

Commission of the European Communities. (July 16, 2001). Eighteenth annual report on monitoring the application of Community law (2000). Volume I: Introduction: Situation sector by sector (COM 2001309 final). Brussels.

Commission of the European Communities. (June 26, 1989). Council Directive 89/391/EEC of 12 June 1989 on the introduction of measures to encourage improvements in the safety and health of workers at work. Official Journal of the European Communities, L 183, 1.

Commission of the European Communities. (June 26, 2002). COMMUNICATION FROM THE COMMISSION: The European social dialogue, a force for innovation and change. Proposal for a COUNCIL DECISION establishing a Tripartite Social Summit for Growth and Employment [COM (2002) 341]. Brussels: Commission of the European Communities.

Commission of the European Communities. (March 10, 2009). Directive 2009/104/EC of the European Parliament and of the Council of 16 September 2009 concerning the minimum safety and health requirements for the use of working equipment by workers at work (second individual directive within the meaning of Article 16(1) of Directive 89/391/EEC. Official Journal of the European Communities, L260, 5-19.

Commission of the European Communities. (March 23, 2002). DIRECTIVE 2002/15/EC OF THE EUROPEAN PARLIAMENT AND OF THE COUNCIL of 11 March 2002 on the organisation of the working time of persons performing mobile road transport activities. Official Journal of the European Union, L 80, 35-39. 
Commission of the European Communities. (March 28, 2002). Commission interpretative communication on Community driver licensing. Official Journal of the European Communities, C 077, 5-24.

Commission of the European Communities. (May 9, 2003). Directive 2003/20/EC of the European Parliament and of the Council of 8 April 2003 amending Council Directive 91/671/EEC on the approximation of the laws of the Member States relating to compulsory use of safety belts in vehicles of less than 3,5 tonnes. Official Journal of the European Communities, L 115, 63-67.

Commission of the European Communities. (November 18, 2003). DIRECTIVE 2003/88/EC OF THE EUROPEAN PARLIAMENT AND OF THE COUNCIL of 4 November 2003 concerning certain aspects of the organisation of working time. Official Journal of the European Union, L 299, 9-19.

Commission of the European Communities. (November 30, 1989). Council Directive 89/654/EEC of 30 November 1989 concerning the minimum safety and health requirements for the workplace (first individual directive within the meaning of Article 16(1) of Directive 89/391/EEC). Official Journal of the European Communities, L 393, 170.

Commission of the European Communities. (September 10, 2003). Directive 2003/59/EC of the European Parliament and of the Council of 15 July 2003 on the initial qualification and periodic training of drivers of certain road vehicles for the carriage of goods or passengers, amending Council Regulation (EEC) No 3820/85 and Council Directive 91/439/EEC and repealing Council Directive 76/914/EEC. Official Journal of the European Union, L 226, 4-17.

Council of the European Union. (December 2-3, 2010). Council conclusions on road safety: 3052th TRANSPORT, TELECOMMUNICATIONS and ENERGY Council meeting. Brussels: European Community.

Darby, P., Murray, W., \& Raeside, R. (2009). Applying online fleet driver assessment to help identify, target and reduce occupational road safety risks. Safety Science, 47(3), 436442.

Department for Transport (United Kingdom). (2004). Safety culture and work-related road accidents (Research Report No. 51). London: Department for Transport and BOMEL Limited.

Department for Transport (United Kingdom). (2008). Report on the review of the UK's implementation of the EU road transport working time Directive. Retrieved August 15,2010 , from http://www.dft.gov.uk/pgr/freight/road/workingtime/rptworkingtimedirective

Department for Transport (United Kingdom). (April 30, 2010). Personal interview with Senior Policy Adviser, Road User Safety Division. London, England.

Dimmer, A., \& Parker, D. (1999). The accidents, attitudes, and behaviour of company car drivers. In G. B. Grayson (Ed.), Behavioural research in road safety IX (pp. 78-85). Wokingham, England: Transport Research Laboratory.

Directgov (United Kingdom). (2010). Information codes on your driving licence. Retrieved August 16, 2010, from http://www.direct.gov.uk/en/Motoring/DriverLicensing/WhatCanYouDriveAndYour Obligations/DG_10022623 
Direction de la sécurité et de la circulation routières [Directorate of Safety and Road Traffic]. (August 5, 2003). Circulaire no 2003-58 du 5 août 2003 relative au décret no 2003637 du 9 juillet 2003 étendant l'obligation du port de la ceinture de sécurité aux occupants des autobus et des autocars (publié au JO du 10 juillet 2003, page 11716) [Circular ${ }^{\circ}{ }^{2003-58}$ of August 5, 2003 relating to Decree No. 2003-637 of 9 July 2003 extending the compulsory wearing of seat belts for occupants of buses and coaches (published in the Official Journal of 10 July 2003, page 11716)], Bulletin Officiel de la Ministère de l'équipement, des transports et du logement [Official Gazette of the Ministry of Infrastructure, Transport, and Housing].

Dolowitz, D. P., \& Marsh, D. (2000). Learning from abroad: the role of policy transfer in contemporary policy making. Government 13, 5-24.

Douillet, A.-C., \& Lehmkuhl, D. (2001). Strengthening the opposition and pushing change: The paradoxical impact of Europe on the reform of French transport. In A. Héritier, D. Kerwer, C. Knill, D. Lehmkuhl, M. Teutsch \& A.-C. Douillet (Eds.), Differential Europe: The European Union impact on national policymaking (pp. 99-131). Lanham, MD: Rowman \& Littlefield.

Downs, A. (1972). Up and down with ecology: The issue-attention cycle. Public Interest, 28, $38-50$.

Downs, C., Keigan, M., Maycock, G., \& Grayson, G. (1999). The safety of fleet car drivers: a review (No. 390). Wokingham, England: Transport Research Laboratory.

Dudley, G., \& Richardson, J. (1996). Why does policy change over time? Adversarial policy communities, alternative policy arenas, and British trunk roads policy, 1945-1995. Journal of European Public Policy, 3, 63-83.

Eberlein, B., \& Grande, E. (2005). Reconstituting political authority in Europe: Transnational regulatory networks and the informalization of governance in the European Union. In E. Grande \& L. W. Pauly (Eds.), Complex sovereignty. Reconstituting political authority in the twenty-first century (pp. 146-167). Toronto: University of Toronto Press.

Elvander, N. (1974). Interest groups in Sweden. Annals of the American Academy of Political and Social Science, 413, 27-43.

Elvebakk, B., \& Steiro, T. (2009). First principles, second hand: Perceptions and interpretations of vision zero in Norway. Safety Science, 47(7), 958-966.

Eurogip. (2003). The work-related road risk in Europe: Which extent? Which prevention? Paris: Eurogip.

Eurogip. (2007). The obligation to assess occupational risks: The Framework Directive and its transposition in the countries of the EU-15. Paris: Eurogip.

Eurogip. (2009). Le risque routier encouru par les salariés en Europe [Road risk incurred by employees in Europe] (Eurogip-40/F). Paris: Eurogip.

Eurogip. (2010). Statistical review of occupational injuries France: Data 2008 (Eurogip48/E). Paris: Eurogip.

Eurogip. (2011). Liste des publications: statistiques [List of publications: statistics]. Retrieved February 14, 2011, from http://www.eurogip.fr/fr/listepublications.php?id theme $=27 \&$ id theme $=27 \&$ page $=2$

Eurogip. (April 28, 2010). Personal interview with Project Manager. Paris, France. 
European Agency for Safety and Health at Work. (May 5, 2010). Personal interview with two Project Managers in the Working Environment Information Unit. Brussels, Belgium.

European Commission. (2009a). Causes and circumstances of accidents at work in the EU. Brussels: European Commission Directorate-General for Employment, Social Affairs and Equal Opportunities, F4 Unit.

European Commission. (2009b). The social situation in the European Union 2008: New insights into social inclusion. Brussels: European Commission, Directorate-General for Employment, Social Affairs and Equal Opportunities - Unit E.1; Eurostat - Unit F.4.

European Commission, European Judicial Network in Civil and Commercial Matters. (2005). Legal order -- France. Retrieved August 26, 2010, from http://ec.europa.eu/civiljustice/legal_order/legal_order_fra en.htm

European Commission, European Judicial Network in Civil and Commercial Matters. (2010). Swedish legal order. Retrieved November 6, 2010, from http://ec.europa.eu/civiljustice/legal order/legal order swe en.htm

European Commission Directorate-General for Employment, Social Affairs, and Equal Opportunities. (May 5, 2010). Personal interview with Policy Officer. Brussels, Belgium.

European Commission Directorate-General Mobility and Transport. (2010a). EU road safety policy. Retrieved February 17, 2010, from http://ec.europa.eu/transport/road_safety/specialist/policy/index_en.htm\#10

European Commission Directorate-General Mobility and Transport. (2010b). Professional drivers. Retrieved February 17, 2010, from http://ec.europa.eu/transport/road_safety/users/professional-drivers/index en.htm

European Commission Directorate-General Mobility and Transport. (2010c). Work-related road safety. Retrieved February 17, 2010, from http://ec.europa.eu/transport/road safety/specialist/knowledge/work/index.htm

European Commission Directorate-General Mobility and Transport. (May 6, 2010). Personal interview with Policy Officer, Road Safety. Brussels, Belgium.

European Community. (July 29, 1992). Treaty on European Union [Maastricht Treaty]. Official Journal of the European Communities, C 191, 1-115.

European Court of Justice. (2003). JUDGMENT OF THE COURT (Second Chamber)13 February 2003 in Case C-85/02: Commission of the European Communities v French Republic(1) (Failure by a Member State to fulfil its obligations -- Failure to implement Directive 91/439/EC). European Court Reports, I, 1696-1701.

European Court of Justice. (January 18, 2001). Judgment of the Court (Fifth Chamber) in Case C-297/99, Reference to the Court under Article 234 EC by Nottingham Magistrates' Court (United Kingdom), for a preliminary ruling in the criminal proceedings pending before that court against Skills Motor Coaches, Ltd, B.J. Farmer, C.J. Burley, and B. Denman, on the interpretation of Article 15 of Council Regulation (EEC) No 3821/85 of 20 December 1985 on recording equipment in road transport (OJ 1985 L 370, p. 8). .

European Court of Justice. (July 23, 2005). JUDGMENT OF THE COURT (Sixth Chamber) of 26 May 2005 in Case C-287/04: Commission of the European Communities v Kingdom of Sweden (Failure of a Member State to fulfil its obligations - Directive 
93/104/EC - Organisation of working time - Failure to transpose within the prescribed period). Official Journal of the European Communities, C 182, 17. European Court of Justice. (June 8, 2000). JUDGMENT OF THE COURT (Second Chamber), 8 June 2000 (1) (Failure by a Member State to fulfil its obligations Directive 93/104/EC - Organisation of working time - Failure to transpose). European Court Reports, Case C-46/99.

European Court of Justice. (November 12, 1996). Judgment of the Court of 12 November 1996. United Kingdom of Great Britain and Northern Ireland v Council of the European Union. Council Directive 93/104/EC concerning certain aspects of the organization of working time - Action for annulment. Case C-84/94. European Court Reports, I-05755.

European Court of Justice. (September 11, 2004). Action brought on 5 July 2004 by the Commission of the European Communities against the Kingdom of Sweden (Case C287/04). Official Journal of the European Communities, C 228, 26.

European Economic Community. (1957). Treaty establishing the European Economic Community [Treaty of Rome]. Brussels: European Economic Community.

European Economic Community. (June 29, 1987). Single European Act. Official Journal of the European Communities, L 169, 1-29.

European Foundation for the Improvement of Living and Working Conditions. (2009). Trade union membership 2003-2008. Dublin: European Foundation for the Improvement of Living and Working Conditions.

European Foundation for the Improvement of Living and Working Conditions. (2010). Framework agreements (Industrial Relations Dictionary). Retrieved April 14, 2010, from http://www.eurofound.europa.eu/areas/industrialrelations/dictionary/definitions/single europeanact.htm

European Transport Safety Council. (2009). How can in-vehicle safety equipment improve road safety at work? Brussels: European Transport Safety Council.

European Transport Safety Council. (2010a). ETSC memorandum to the Spanish Presidency on the European road safety policy: Road safety under the Spanish chairmanship of the Presidency of the EU. Brussels: European Transport Safety Council.

European Transport Safety Council. (2010b). Minister Schouppe announces the implementation of alcolocks in Belgium [Press release, December 9, 2010]. Brussels: European Transport Safety Council.

European Transport Safety Council. (2010c). PRAISE: Preventing Road Accidents and Injuries for the Safety of Employees. Retrieved February 2, 2010, from http://www.etsc.eu/PRAISE.php

European Transport Safety Council. (2011). Proposal for Directive "facilitating crossborder enforcement in the field of road safety" (Position statement of the European Transport Safety Council). Brussels: European Transport Safety Council.

European Transport Safety Council. (January 14, 2011). Personal communication with Policy Director.

European Transport Safety Council. (June 24, 2010). Transport ministers discuss road safety at work (press release). Brussels: European Transport Safety Council.

European Transport Safety Council. (May 7, 2010). Personal interview with Policy Director and Project Officer. Brussels, Belgium. 
Fahlquist, J. N. (2006). Responsibility ascriptions and Vision Zero. Accident Analysis \& Prevention, 38(6), 1113-1118.

Falkner, G., Treib, O., Hartlapp, M., \& Leiber, S. (2005). Complying with Europe: EU harmonization and soft law in the member states. Cambridge: Cambridge University Press.

Fassenot, T. (2010). Work-related road safety in France. Paper presented at the PRAISE International Seminar on Work-related Road Safety, Barcelona, Spain, June 14, 2010.

Federal Highway Administration. (2000). Commercial vehicle safety: Technology and practice in Europe. Washington, DC: Federal Highway Administration, Office of International Programs.

Federal Motor Carrier Safety Administration. (2010). Hours-of-service regulations. Retrieved January 10, 2011, from http://www.fmcsa.dot.gov/rulesregulations/topics/hos/index.htm

Fort, E., Pourcel, L., Davezies, P., Renaux, C., Chiron, M., \& Charbotel, B. (2010). Road accidents, an occupational risk. Safety Science, 48(10), 1412-1420.

Freeman, G. P. (1985). National styles and policy sectors: Explaining structured variation. Journal of Public Policy, 5(4), 467-496.

Freund, D. M. (2007). Foundations of commercial vehicle safety: laws, regulations, and standards (2007 L. Ray Buckendale Lecture). Warrendale, PA: Society of Automotive Engineers.

Furbisher, J. (October 15, 1994). Faulty lorries backs calls for tighter HGV curbs. Yorkshire Post, pp. 1, 6-7.

Gallagher, M., Laver, M., \& Mair, P. (2006). Representative government in modern Europe: Institutions, parties, and governments (fourth edition). New York: McGraw- Hill.

George, S. (2004). Multi-level governance and the European Union. In I. Bache \& M. Flinders (Eds.), Multi-level governance (pp. 107-126). Oxford: Oxford University Press.

Gerondeau, C. (2006). Road safety in France: Reflections on three decades of road safety policy. London: FIA Foundation.

Global Road Safety Partnership. (May 4, 2010). Personal interview with Chief Executive. Geneva, Switzerland.

Government Offices of Sweden. (2010). Ministry of Enterprise, Energy, and Communications. Retrieved October 4, 2010, from http://www.sweden.gov.se/sb/d/2067

Grayson, G. (1999). Company cars and road safety. In G. Grayson (Ed.), Behavioural research in road safety $I X$ (pp. 65-70). Wokingham, England: Transport Research Laboratory.

Greenaway, J., \& Grantham, A. (2000). Transport policy paradigms at the local level: The Norwich Inner Ring Road. Public Administration, 78(4), 815-833.

Gregersen, N. P., Brehmer, B., \& Moren, B. (1996). Road safety improvements in large companies. An experimental comparison of different measures. Accident Analysis and Prevention, 28(3), 297-306.

Hatakka, H., Keskinen, E., Gregersen, N. P., Glad, A., \& Hernetkoski, K. (2002). From control of the vehicle to personal self-control; broadening the perspectives to driver education. Transportation Research Part F, 5, 201-215. 
Hayward, J. (1982). Mobilising private interests in the service of public ambitions: the salient element in the dual French policy style? In J. Richardson (Ed.), Policy styles in western Europe (pp. 111-140). London: George Allen \& Unwin.

Health and Safety Executive. (2003). Driving at work: Managing work-related road safety (INDG 382). London: Health and Safety Executive.

Health and Safety Executive. (2010). The Health and Safety Executive statistics 2009/10. London: Health and Safety Executive.

Health and Safety Executive. (April 30, 2010). Personal interview with Senior Policy Adviser. London, England.

Héritier, A. (2001). Differential Europe: The European Union impact on national policymaking. In A. Héritier, D. Kerwer, C. Knill, D. Lehmkuhl, M. Teutsch \& A.-C. Douillet (Eds.), Differential Europe: The European Union impact on national policymaking (pp. 1-21). Lanham, MD: Rowman \& Littlefield.

Héritier, A., Kerwer, D., Knill, C., Lehmkuhl, D., Teutsch, M., \& Douillet, A.-C. (Eds.). (2001). Differential Europe: The European Union impact on national policymaking. Lanham, MD: Rowman \& Littlefield.

Héritier, A., \& Knill, C. (2001). Differential responses to European politics: A comparison. In A. Héritier, D. Kerwer, C. Knill, D. Lehmkuhl, M. Teutsch \& A.-C. Douillet (Eds.), Differential Europe: The European Union impact on national policymaking (pp. 257-294). Lanham, MD: Rowman \& Littlefield.

Hilal, N. (2008). Unintended effects of deregulation in the European Union: The case of road freight transport. Sociologie du Travail, 50(Supp 1), e19-e29.

Hinnfors, J. (1997). Still the politics of compromise? Agenda setting strategy in Sweden. Scandinavian Political Studies, 20(2), 159-177.

Hix, S. (2005). The political system of the European Union (2nd ed.). Basingstoke: Palgrave Macmillan.

HMSO. (1968). Transport Act 1968 (1968 Chapter 73). Retrieved November 26, 2010, from http://www.legislation.gov.uk/ukpga/1968/73/enacted

HMSO. (1974). Health and Safety at Work etc. Act 1974 (Chapter 37). Retrieved January 11, 2011, from http://www.legislation.gov.uk/ukpga/1974/37/contents/enacted

HMSO. (1988). Road Traffic Act 1988 (1988 Chapter 52). Retrieved August 15, 2010, from http://www.opsi.gov.uk/acts/acts1988/ukpga_19880052 en_1

HMSO. (1991). The Motor Vehicles (Wearing of Seat Belts in Rear Seats by Adults) Regulations 1991 (S.I. $n^{\circ} 1255$ of 1991). Retrieved August 19, 2010, from http://www.statutelaw.gov.uk/content.aspx?LegType=All+Legislation\&title=wearing + of + seat + belts\&searchEnacted $=0$ \&extentMatchOnly $=0$ \& confersPower $=0$ \&blanketA $\underline{\text { mendment }=0 \& \text { sortAlpha }=0 \& \text { TYPE }=Q S \& \text { PageNumber }=1 \& \text { NavFrom }=0 \& \text { parentActiv }}$ eTextDocId=3268979\&ActiveTextDocId=3268979\&filesize $=22124$

HMSO. (1995). Goods Vehicle Operators (Licensing of Operators) Act 1995 (Chapter 23). Retrieved August 17, 2010, from http://www.opsi.gov.uk/si/si1999/uksi 19992430 en.pdf

HMSO. (1999). Goods Vehicle Operators (Qualifications) Regulations 1999 (S.I. n 2430 of 1999). Retrieved August 18, 2010, from http://www.opsi.gov.uk/si/si1999/uksi_19992430_en.pdf

HMSO. (2005). The road transport (working time) regulations 2005 (S.I. n 639 of 2005). Retrieved August 13, 2010, from http://www.opsi.gov.uk/si/si2005/20050639.htm 
HMSO. (2007). Corporate Manslaughter and Corporate Homicide Act 2007 (2007 Chapter

19). Retrieved November 28,2010 , from

http://www.legislation.gov.uk/ukpga/2007/19

HMSO. (2008). Road traffic and vehicles: The Motor Vehicles (Wearing of Seat Belts)

(Amendment) Regulations (Northern Ireland) 2008 (Statutory Rules of Northern Ireland 2008, No. 29). Retrieved August 19, 2010, from

http://www.opsi.gov.uk/sr/sr2008/nisr 20080029 en 1

Hooghe, L., \& Marks, G. (2001). Multi-level governance and European integration. Lanham, MD: Rowman \& Littlefield Publishers.

Hooghe, L., \& Marks, G. (2003). Unraveling the central state, but how? Types of multi-level governance. American Political Science Review, 97(2), 233-243.

Howard, E. (2009). Zero deaths, zero injuries. ISO Focus(October), 15-18.

Institut national de recherche et de securité (INRS) [National Research and Safety Institute]. (2010). Occupational risk prevention in France. Retrieved December 20, 2010, from http://en.inrs.fr/inrs-pub/inrs01.nsf/IntranetObjectaccesParIntranetID/OM:Rubrique:D1B6D891DB5BF813C1256E5300388D8D/\$FIL E/Visu.html

Institut national de recherche et de securité (INRS) [National Research and Safety Institute]. (April 28, 2010). Personal interview with Coordinator, International Relations. Paris, France.

International Organization for Standardization (ISO). (2009). TC 241 project committee: Road-traffic safety management system. Retrieved February 3, 2010, from http://www.iso.org/iso/iso technical committee.html?commid=558313

International Traffic Safety Data and Analysis Group. (2011). IRTAD road safety 2010 annual report. Paris: International Transport Forum and Organization for Economic Co-operation and Development.

Jacobs, G., Aeron-Thomas, A., \& Astrop, A. (2000). Estimating global road fatalities (TRL Report 445). Crowthorne, England: Transport Research Laboratory.

Johansson, R. (2009). Vision Zero - Implementing a policy for traffic safety. Safety Science, 47(6), 826-831.

Joint Transport Research Centre of the OECD, \& International Transport Forum. (2008). Towards zero: Ambitious road safety targets and the safe systems approach: Summary document. Paris: Organization for Economic Cooperation and Development.

Keck, M., \& Sikkink, K. (1998). Activists beyond borders: Advocacy networks in international politics. Ithaca: Cornell University Press.

Keller, B. (2003). Social dialogues at sectoral level: The neglected ingredient of European industrial relations. In B. Keller \& H.-W. Platzer (Eds.), Industrial relations and European integration: Trans- and supranational developments and prospects (pp. 3057). Aldershot, England: Ashgate.

Kerwer, D., \& Teutsch, M. (2001a). Elusive Europeanization: Liberalizing road haulage in the European Union. Journal of European Public Policy, 8(1), 124-143.

Kerwer, D., \& Teutsch, M. (2001b). Transport policy in the European Union. In A. Héritier, D. Kerwer, C. Knill, D. Lehmkuhl, M. Teutsch \& A.-C. Douillet (Eds.), Differential Europe: The European Union impact on national policymaking (pp. 23-56). Lanham, MD: Rowman \& Littlefield. 
Knill, C. (1998). European policies: The impact of national administrative traditions. Journal of Public Policy, 18(1), 1-28.

Knill, C. (2001). Reforming transport policy in Britain: Concurrence with Europe but separate development. In A. Héritier, D. Kerwer, C. Knill, D. Lehmkuhl, M. Teutsch \& A.-C. Douillet (Eds.), Differential Europe: The European Union impact on national policymaking (pp. 57-97). Lanham, MD: Rowman \& Littlefield.

Kommunikationsdepartementet [Ministry of Communications (Sweden)]. (January 12, 1972). Kungörelse (1972:602) om arbetstid vid vägtransport, mm [Proclamation (1972:602) on working at the road, etc.]. Svensk författningssamling (SFS) [Swedish Code of Statutes], SFS 1972:602.

Kommunikationsdepartementet [Ministry of Communications (Sweden)]. (October 13, 1998). Trafikförordning. [Road Traffic Ordinance]. Svensk författningssamling (SFS) [Swedish Code of Statutes], SFS 1998:1276.

Lancaster, R., \& Ward, R. (2002). The contribution of individual factors to driving behaviour: Implications for managing work-related road safety (No. 020). London, England: Health \& Safety Executive

Lawton-Smith, H. (1995). Deregulation and privatization in the UK freight, and bus and coach industries. In S. A. Morrison, G. Yarrow, H. Lawton-Smith, H. Yamauchi \& H. Murakami (Eds.), International comparison of privatization and deregulation among the USA, the UK and Japan (Vol. III.B, pp. 137-174). Tokyo: Economic and Social Research Institute.

Legifrance. (2010). Apropos de droit [About Law]. Retrieved December 17, 2010, from http://www.legifrance.gouv.fr/html/aproposdroit/aproposdroit_uk.htm\#e

Leibfried, S. (2005). Social policy: Left to the judges and the markets? In H. Wallace, W. Wallace \& M. A. Pollack (Eds.), Policy-making in the European Union (fifth edition) (pp. 243-278). Oxford: Oxford University Press.

Lepermis.com [License.com]. (2010). ANNEXE N ${ }^{\circ} 4$ introduite par l'arrêté du 8 février 1999: MODALITES PRATIQUES DE L'EXAMEN DU PERMIS DE CONDUIRE DES CATEGORIES C - E (C) - D - E (D) [Schedule No. 4 of the Order of February 8, 1999: Practical elements of the driving license exam for categories $\mathrm{C}, \mathrm{C}(\mathrm{E}), \mathrm{D}$, and D(E)]. Retrieved December 17, 2010, from http://www.lepermis.com/annexe4.htm

Lie, A. (2010). Vehicle safety policy - Swedish Transport Administration. Paper presented at the PRAISE Annual Brunch Event, Brussels, Belgium, May 6, 2010.

Lie, A., \& Tingvall, C. (June 15-18, 2009). Government status report from Sweden. Paper presented at the 21st International Technical Conference on the Enhanced Safety of Vehicles.

Lijphart, A. (1999). Patterns of democracy: Government forms and performance in thirty-six countries. New Haven, CT: Yale University Press.

Lowe, D. (2007). A study manual of professional competence in road haulage (12th edition). London: Kogan Page Limited.

Lynn, P., \& Lockwood, C. (1999). The accident liability of company car drivers (No. 317). Wokingham, England: Transport Research Laboratory.

Mahoney, C. (2004). The power of institutions: State and interest-group activity in the European Union. European Union Politics, 5(4), 441-466.

Mahoney, C., \& Baumgartner, F. (2008). Converging perspectives on interest group research in Europe and America. West European Politics, 31(6), 1253-1273. 
Majone, G. (1993). The European Community between social policy and social regulation. Journal of Common Market Studies, 31(2), 153-170.

Majone, G. (1994). The rise of the regulatory state in Europe. West European Politics, 17(3), 77-101.

Marks, G. (1993). Structural policy and multilevel governance in the EC. In A. Cafruny \& G. Rosenthal (Eds.), The Maastricht debates and beyond (Vol. 2, The state of the European Community, pp. 391-411). Boulder, CO: Lynne Rienner.

Marks, G., \& Hooghe, L. (2004). Contrasting visions of multi-level governance. In I. Bache \& M. Flinders (Eds.), Multi-level governance (pp. 15-30). Oxford: Oxford University Press.

McCorry, B., \& Murray, W. (1993). Reducing commercial vehicle road accident costs. International Journal of Physical Distribution and Logistics Management, 23(4), 35 41.

McCubbins, M. D. (1985). The legislative design of regulatory structure. American Journal of Political Science, 29(4), 721-748.

McCubbins, M. D., Noll, R. G., \& Weingast, B. R. (1987). Administrative procedures as instruments of political control. Journal of Law, Economics, and Organization, 3(2), 243-277.

Ministère de l'écologie, du développement et de l'aménagement durables [Ministry of Ecology, Development, and Sustainable Planning]. (January 29, 2008). Arrêté du 3 janvier 2008 relatif au programme et aux modalités de mise en œuvre de la formation professionnelle initiale et continue des conducteurs du transport routier de marchandises et de voyageurs [Order of 3 January 2008 concerning the program and procedures for implementation of initial and continuing vocational training of drivers of road freight and passengers]. Journal Officiel de la République Française (JORF), $N^{\circ} 24$, texte $n^{\circ} 4,1675$.

Ministère de l'écologie, du développement et de l'aménagement durables [Ministry of Ecology, Development, and Sustainable Planning]. (March 29, 2008). Arrêté du 26 février 2008 fixant la liste des titres et diplômes de niveau $\mathrm{V}$ admis en équivalence au titre de la qualification initiale des conducteurs of certains véhicules affectés aux transports routiers de marchandises ou de voyageurs [Decree of 26 February 2008 establishing the list of degrees and diplomas recognized as equivalent to level $\mathrm{V}$ under the initial qualification for drivers of certain vehicles for the carriage of road freight or passengers]. Journal Officiel de la République Française (JORF), $N^{\circ} 75$, texte $n^{\circ} 1,5351$.

Ministère de l'éducation nationale, de la jeunesse et de la vie associative [Ministry of National Education, Youth, and Community Living]. (2010). Lycée des métiers [Trades high school]. Retrieved December 17, 2010, from http://eduscol.education.fr/cid47596/le-label-lycee-des-metiers.html

Ministère de l'équipement, des transports et du logement. (October 6, 2003). Communication from the Minister of Infrastructure, Transport, and Housing to departmental prefects (Administrative Circular). Paris: Ministère de l'équipement, des transports et du logement, Sécurité routière, Direction de la sécurité et de la circulation routière, Sousdirection de la formation du conducteur.

Ministère de l'équipement, des transports et du logement [Department of Infrastructure, Transport, and Housing]. (September 2, 1999). Décret n 99-752 du 30 août 1999 
relatif aux transports routiers de marchandises [Decree No. 99-752 of 30 August 1999 relating to road freight transport]. Journal Officiel de la République Française (JORF), $N^{\circ}$ 203, 13140.

Ministère de l'équipement, des transports, du logement, du tourisme et de la mer [Ministry of Infrastructure, Transport, Housing, Tourism, and the Sea]. (June 5, 2003). Arrêté du 19 mai 2003 relatif à la réforme de l'épreuve pratique de l'examen du permis de conduire de la catégorie B Decree of 19 May 2003 on the reform of the practical test of driving license test in category B]. Journal Officiel de la République Française (JORF), $N^{\circ} 43$, texte $n^{\circ} 19,9567$.

Ministère de l'écologie, de l'énergie, de développement durable et de la mer [Ministry of Ecology, Energy, Sustainable Development, and the Sea]. (2004). The new license, a tool for safety. Retrieved December 11, 2010, from

http://www2.securiteroutiere.gouv.fr/data/revue/permis/passer_le_permis/passer_quat re.html

Ministère de l'écologie, de l'énergie, de développement durable et de la mer, Sécurité routière [Ministry of Ecology, Energy, Sustainable Development, and the Sea, Road Safety Unit]. (2010). Le comité de pilotage. Retrieved June 21, 2010, from http://www.risque-routier-professionnel.fr/-Les-institutions-s-engagent-.html

Ministère de travaux publics, des transports et du tourism et logement, et Ministère du travail [Ministry of Public Works, Transport, and Tourism, and Ministry of Labor]. (December 25, 1958). Ordonnance $n^{\circ}$ 58-1310 du 23 décembre 1958 concernant les conditions du travail dans les transports routiers publics et privés en vue d'assurer la sécurité de la circulation routière [Ordinance No. 58-1310 of 23 December 1958 concerning the conditions of work in public and private road transport to ensure the safety of road traffic]. Journal Officiel de la République Française (JORF), 11810.

Ministre d'État, Ministre de l'intérieur et de l'aménagement du territoire; Ministre de l'emploi, de la cohésion sociale et du logement; Garde des sceaux; Ministre de la justice; Ministre de la santé et des solidarités; Ministre délégué à l'emploi, au travail et à l'insertion professionnelle des jeunes; et Ministre délégué à la sécurité sociale, aux personnes âgées, aux personnes handicapées et à la famille [Minister of State; Minister of the Interior and Territorial Development; Minister of Employment, Social Cohesion, and Housing; Keeper of the Seals; Minister of Justice; Minister of Health and Solidarity; Minister of Employment, Labor, and Youth Employment; and Minister of Social Security, Aging, Disabled Persons, and the Family]. (January 30, 2007). Décret $n^{\circ} 2007-106$ du 29 janvier 2007 relatif à la durée d'équivalence de la durée légale du travail dans les établissements sociaux et médico-sociaux gérés par des personnes privées à but non lucratif et complétant le code de l'action sociale et des familles (partie réglementaire) [Decree No. 2007-106 of 29 January 2007 on the period equivalent to the legal duration of work in social and medico-social establishments run by private non-profit and amending the Code of Social Action and Families (regulatory part)]. Journal Officiel de la République Française (JORF), $N^{\circ}$ 25 , texte $n^{\circ} 10,1833$.

Ministre de l'emploi et de la solidarité, Ministre de l'économie, des finances et de l'industrie; Ministre de la fonction publique et de la réforme de l'Etat; Ministre délégué à la santé; et Secrétaire d'Etat au budget [Minister for Employment and Solidarity; Minister for Economy, Finance, and Industry; Minister for Public Service and State Reform; 
Minister of Health; and Secretary of State for Budget]. (January 5, 2002). Décret no 2002-9 du 4 janvier 2002 relatif au temps de travail et à l'organisation du travail dans les établissements mentionnés à l'article 2 de la loi no 86-33 du 9 janvier 1986 portant dispositions statutaires relatives à la fonction publique hospitalière [Decree No. 20029 dated January 4, 2002 relating to working time and work organization in the establishments mentioned in Article 2 of Law No. 86-33 of 9 January 1986 on statutory provisions relating to public hospitals]. Journal Officiel de la République Française (JORF), $N^{\circ} 4$, texte $n^{\circ} 12,316$.

Ministre de l'équipement, des transports et du logement et Ministre de l'emploi et de la solidarité [Minister of Infrastructure, Transport, and Housing, and Minister of Employment and Solidarity]. (April 27, 2001). Arrêté du 29 mars 2001 relatif à la création d'un Comité de pilotage national pour la prévention du risque routier encouru par les salariés [Order of 29 March 2001 on the establishment of a national steering committee for the prevention of road risks incurred by employees]. Journal Officiel de la République Française (JORF), $N^{\circ}$ 99, texte $n^{\circ} 206648$.

Ministre des transports, de l'équipement, du tourisme et de la mer; Ministre de l'intérieur et de l'aménagement du territoire; Ministre de l'emploi, de la cohésion sociale et du logement; Ministre de l'économie, des finances et de l'industrie; Ministre de la santé et des solidarités; et Ministre de l'agriculture et de la pêche [Minister of Transport, Infrastructure, Tourism, and the Sea; Minister of the Interior and Territorial Development; Minister of Employment, Social Cohesion, and Housin; Minister of Economy, Finance, and Industry; Minister of Health and Solidarity; and Minister of Agriculture and Fisheries]. (June 10. 2006). Arrêté du 27 mars 2006 relatif à la création du comité de pilotage pour la prévention du risque routier professionnel [Order of 27 March 2006 on the establishment of the steering committee for the prevention of occupational road risk]. Journal Officiel de la République Française (JORF), $N^{\circ} 133$, texte $n^{\circ} 17,8821$.

Ministre du budget, des comptes publics et de la fonction publique [Minister of Budget, Public Accounts, and Public Service]. (October 12, 2007). Décret $n^{\circ}$ 2007-1456 du 10 octobre 2007 relatif aux horaires d'équivalence applicables aux emplois de certains agents en fonction dans les services relevant de la direction générale des douanes et droits indirects [Decree No. 2007-1456 of 10 October 2007 on schedule equivalence apply to employment of certain agents according to the services within the Directorate General of Customs and Excise]. Journal Officiel de la République Française (JORF), $N^{\circ} 237$, texte $n^{\circ} 23,0$.

Ministre du travail, des relations sociales et de la solidarité [Minister of Labor, Social Relations, and Solidarity]. (August 5, 2007). Décret n 2007-1180 du 3 août 2007 relatif aux équivalences de nuit dans l'enseignement privé sous contrat [Decree No. 2007-1180 of August 3, 2007 on night equivalences in private schools under contract]. Journal Officiel de la République Française (JORF), $N^{\circ} 180$, texte $n^{\circ} 13$, 13147.

Ministre du travail, des relations sociales et de la solidarité [Minister of Labor, Social Relations, and Solidarity]. (December 15, 2007). Décret n 2007-1753 du 13 décembre 2007 fixant un régime d'équivalence quotidien dans la branche de la production audiovisuelle [Decree No. 2007-1753 of 13 December 2007 establishing a 
system of equivalence in the audiovisual production industry]. Journal Officiel de la République Française (JORF), $N^{\circ} 291$, texte $n^{\circ} 21,20243$.

Ministry of Enterprise, Energy, and Communications (Sweden). (2010). Government agencies. Retrieved October 4, 2010, from http://www.sweden.gov.se/sb/d/3486

Ministry of Justice (United Kingdom). (2007). A guide to the Corporate Manslaughter and Corporate Homicide Act 2007. London: Ministry of Justice.

Montelius, J.-O. (2007). Svensk vägadministration: En historisk översikt [The Swedish Road Administration: An historical overview]. Borlänge, Sweden: Vägverkets Museum.

Murray, W. (2000). Crash counting: a review of fleet crash reporting in the UK. Paper presented at the Road Safety Research, Policing, and Education Conference, Brisbane, Australia.

Murray, W., Ison, S., Gallemore, P., \& Nijjar, H. (2009). Effective occupational road safety programs: A case study of Wolseley. Transportation Research Record: Journal of the Transportation Research Board, 2096, 55-64.

Murray, W., Pratt, S., Hingston, J., \& Dubens, E. (2009). Promoting global initiatives for occupational road safety: Review of occupational road safety worldwide.

Nottingham, England/Washington, DC: Interactive Driving Systems, Inc., National Institute for Occupational Safety and Health.

Murray, W., Pratt, S., \& Watson, B. (2008). Sources of data on occupational road safety: An international review. Paper presented at the Australasian Research, Policing, and Education Conference, Adelaide, Australia, November 10-12, 2008.

Murray, W., \& Watson, B. (2010). Work-related road safety as a conduit for community road safety. Journal of the Australasian College of Road Safety, 21(5), 65-71.

Murray, W., \& Whiteing, T. (1995). Reducing commercial vehicle accidents through accident databases. Logistics Information Management, 8(3), 22-29.

Näringsdepartementet [Ministry of Enterprise (Sweden)]. (April 5, 2005). Lag (2005:165) om ändring i arbetstidslagen (1982:673). [Law amending the Working Hours Act (1982:673)]. Svensk författningssamling (SFS) [Swedish Code of Statutes], SFS 2005:165.

Näringsdepartementet [Ministry of Enterprise (Sweden)]. (August 9, 1994). Förordning (1994:1297) om vilotider vid vissa vägtransporter inom landet. [Ordinance (1994:1297) on rest periods at certain road traffic within the country.]. Svensk författningssamling (SFS) [Swedish Code of Statutes], SFS 1994:1297.

Näringsdepartementet [Ministry of Enterprise (Sweden)]. (June 11, 1998). Yrkestrafiklag. [Commercial Traffic Act]. Svensk författningssamling (SFS) [Swedish Code of Statutes], SFS 1998:490.

Näringsdepartementet [Ministry of Enterprise (Sweden)]. (June 13, 2005). Lag om arbetstid vid visst vägtransportarbete (Lag 2005/395). [The Working Hours for Certain Road Transport Work Act (2005: 395), with Amendments up to and including SFS 2007:92]. Svensk författningssamling (SFS) [Swedish Code of Statutes], SFS 2005:395.

Näringsdepartementet [Ministry of Enterprise (Sweden)]. (November 29, 2007). Lag (2007:1157) om yrkesförarkompetens. [Professional Driver Competence Act]. Svensk författningssamling (SFS) [Swedish Code of Statutes], SFS 2007:1157.

Nationalforeningen for Trafiksakerhetens Framjande (NTF) [National Society for Road Safety]. (2006). What does NTF Think? NTF's policy 2006-2007. Stockholm. 
NEA Transport Research and Training, Transport Innovation and Systems (TIS), \& T.M.C. Asser Instituut. (2005). Study on admission to the occupation of road transport operator: Review of current arrangements in member states and acceding countries: Report to the European Commission (Contract ETU/B27040B/E1/S07.27846/2003). Rijswijk, The Netherlands.

Nordic Council. (2011). About Nordic co-operation. Retrieved February 20, 2011, from http://www.norden.org/en/about-nordic-co-operation

Nordiskt vägforum [Nordic Road Association]. (2011). Nordiskt vägforum NVF. Retrieved February 20, 2011, from http://www.nvfnorden.org/

Nordsieck, W. (2010a). Parties and elections in Europe - France. Retrieved July 21, 2010, from http://www.parties-and-elections.de/france.html.

Nordsieck, W. (2010b). Parties and elections in Europe - Sweden. Retrieved July 21, 2010, from http://www.parties-and-elections.de/sweden.html.

Observatoire national interministériel de la sécurité routière [National Interministerial Center for Road Safety]. (2006). La sécurité routière en France: Bilan de l'année 2005

[Road safety in France: The year 2005]. Paris: La documentation Française.

Occupational Road Safety Alliance. (2010). Managing occupational road safety: an opportunity for business. Retrieved February 26, 2010, from http://www.orsa.org.uk/.

Palmer, A. (September 7, 1993). Six die as lorry rams shop. Yorkshire Post, p. 1.

Patton, M. Q. (2005). Qualitative research \& evaluation methods (3rd edition). Thousand Oaks, CA: Sage Publications.

Peden, M., Scurfield, R., Sleet, D., Mohan, D., Hyder, A. A., Jarawan, E., et al. (Eds.). (2004). World report on road traffic injury prevention. Geneva: World Health Organization.

Pollard, D. (1998). Sourcebook on French law (second edition). London: Cavendish Publishing Limited.

Premfors, R. (1981). National policy styles and higher education in France, Sweden and the United Kingdom. European Journal of Education, 16(2), 253-262.

Président de la République Française. (December 30, 1973). Loi n 73-1195 du 27 décembre 1973 relatif à l'amelioration des conditions de travail [Law No. 73-1195 of December 27, 1973 relating to the improvement of working conditions]. Journal Officiel de la République Française (JORF), $N^{0}$ 105, texte $n^{\circ} 304,14146$.

Président de la République Française. (January 7, 1992). LOI no 91-1414 du 31 décembre 1991 modifiant le code du travail et le code de la santé publique en vue de favoriser la prévention des risques professionnels et portant transposition de directives européennes relatives à la santé et à la sécurité du travail (1) [ACT No. 91-1414 of 31 December 1991 amending the Labour Code and the Code of Public Health to promote the prevention of occupational hazards and transposing EU directives on health and safety (1)]. Journal Officiel de la République Française (JORF), $N^{\circ}$ 5, 319.

Président de la République Française. (January 20, 2000). LOI n ${ }^{0} 2000-37$ du 19 janvier 2000 relative à la réduction négociée du temps de travail (1) [ACT No. 2000-37 of 19 January 2000 on the negotiated reduction of working time (1)]. Journal Officiel de la République Française (JORF), $N^{\circ} 16$, texte $n^{\circ} 2,975$.

Président de la République Française. (January 27, 1983). Décret n 83-40 du 26 janvier 1983 relatif aux modalities d'application des dispositions du Code du travail 
concernant la durée du travail dans les enterprises de transport routier de marchandises [Decree No. 83-40 of January 26, 1983 Relating to Implementation of the Provisions of the Labor Code for Working Time in the Business of Road Transport of Goods]. Journal Officiel de la République Française (JORF), 475.

Président de la République Française. (July 8, 1972). Décret n 72-608 du 5 juillet 1972 instaurant un comité interministériel de la sécurité routière [Decree No. 72-608 of 5 July 1972 establishing an interministerial committee for road safety ]. Journal Officiel de la République Française (JORF), 7114.

Princen, S. (2009). Agenda-setting in the European Union. Basingstoke: Palgrave Macmillan.

Princen, S., \& Kerremans, B. (2008). Opportunity structures in the EU multilevel system. West European Politics, 31(6), 1129-1146.

Quality Three Organisation. (2005). Quality III System Manual. Solna, Sweden: Quality Three Organisation/QIII.

République Française. (1950). Convention collective nationale des transports routiers et activités auxiliaires du transport du 21 décembre 1950 [National collective agreement on road transport and auxiliary transport activities of December 21, 1950]. Paris: Legifrance.

République Française. (1994a). Accord du 23 novembre 1994 sur le temps de service, les repos récupérateurs et la rémunération des personnels de conduite marchandise "grands routiers" ou "longue distance" [Agreement of 23 November 1994 on the time of service, rest recovery and compensation for "major road" or "long distance" transport of goods]. Paris: Legifrance.

République Française. (1994b). OPCA transports, Avenant nº 1 du 28 décembre 1994, Constitution de sections professionnelles paritaires techniques [OPCA Transport, Amendment No. 1 of December 28, 1994, Formation of joint professional technical chapters]. Paris: Legifrance.

République Française. (1995). Avenant $n^{\circ} 1$ du 6 juillet 1995 relatif aux conditions spécifiques d'application de l'accord du 23 novembre 1994 sur le temps de service, les repos récupérateurs et la rémunération des personnels de conduite "grands routier" ou "longue distance" [Amendment No. 1 of 6 July 1995 concerning the specific conditions of application of the Agreement of 23 November 1994 at the time of service, rest recovery and compensation for "major road" or "long distance" transport of goods]. Paris: Legifrance.

République Française. (2006). Convention collective nationale de la production audiovisuelle du 13 décembre 2006 [National collective agreement for audiovisual production December 13, 2006]. Paris: Legifrance.

République Française. (March 2008). Code du travail [Labor Code]. Retrieved December 17-21, 2010, from http://www.legifrance.gouv.fr/affichCode.do?cidTexte=LEGITEXT000006072050\& dateTexte $=20080319$

Rhodes, M. (1995). A regulatory conundrum: Industrial relations and the social dimension. In S. Leibfried \& P. Pierson (Eds.), European social policy: Between fragmentation and integration (pp. 78-122). Washington, DC: Brookings Institution. 
Rhodes, M. (2005). Employment policy: Between efficacy and experimentation. In H. Wallace, W. Wallace \& M. A. Pollack (Eds.), Policy-making in the European Union (fifth edition) (pp. 279-304). Oxford: Oxford University Press.

Richardson, J. (Ed.). (1982). Policy styles in western Europe. London: George Allen \& Unwin.

Richardson, J., Gustafsson, G., \& Jordan, G. (1982). The concept of policy style. In J. Richardson (Ed.), Policy styles in western Europe (pp. 1-16). London: George Allen \& Unwin.

Richardson, J. J. (1979). Policy making and rationality in Sweden: The case of transport. British Journal of Political Science, 9(3), 341-353.

RoadSafe. (2010). Driving for better business. Retrieved February 26, 2010, from www.drivingforbetterbusiness.com.

RoadSafe. (May 6, 2010). Personal interview with Campaign Director. Brussels, Belgium.

Royal Society for the Prevention of Accidents. (2010). MORR: Managing occupational road risk. Retrieved February 26, 2010, from http://www.rospa.com/morr/index.htm.

Royal Society for the Prevention of Accidents. (April 29, 2010). Personal interview with Occupational Safety and Health Advisor. Bracknell, England.

Ruin, O. (1982). Sweden in the 1970s: policy-making becomes more difficult. In J. Richardson (Ed.), Policy styles in western Europe (pp. 141-167). London: George Allen \& Unwin.

Russell, J. (2001). Review of HSWA Section 3 (Health and Safety Commission Paper HSC/01/P200). London: Health and Safety Commission.

Sabatier, P. (1998). The advocacy coalition framework: Revisions and relevance for Europe. Journal of European Public Policy, 5(1), 98-130.

Sabatier, P., \& Weible, C. M. (2007). The advocacy coalition framework: innovations and clarifications. In P. Sabatier (Ed.), Theories of the policy process (2nd ed) (pp. 189220). Boulder: Westview Press.

Sabatier, P. A., \& Jenkins-Smith, H. C. (1999). The advocacy coalition framework: An assessment. In P. A. Sabatier (Ed.), Theories of the policy process (pp. 117-166). Boulder, CO: Westview Press.

Scheresberg, C. d. B., \& Marolda, M. C. (2009). Traffic accidents at work: A social cost analysis. Brussels: European Commission, Directorate General Energy and Transport, Road Safety Unit.

Sedelmeier, U. (2005). Eastern enlargement: Toward a European EU? In H. Wallace, W. Wallace \& M. A. Pollack (Eds.), Policy-making in the European Union (fifth edition) (pp. 401-428). Oxford: Oxford University Press.

Siaroff, A. (1999). Corporatism in 24 industrial democracies: Meaning and measurement. European Journal of Political Research, 36, 175-205.

Stein, M., \& Turkewitsch, L. (2010). The European model of governance beyond Europe: The applicability of the concept of multi-level governance to the comparative study of intergovernmental relations in parliamentary and presidential federations. Paper presented at the 2010 IPSA International Conference "Is There a European Model of Governance? A Comparative Perspective".

Stein, M. B., \& Turkewitsch, L. (2008). The concept of multi-level governance in studies of federalism. Paper presented at the 2008 IPSA International Conference "International Political Science: New Theoretical and Regional Perspectives". 
Stevens, H. (2004). Transport policy in the European Union. London: Palgrave Macmillan.

Stone, D. (2004). Transfer agents and global networks in the 'transnationalization' of policy. Journal of European Public Policy, 11, 545-566.

Stone, D. A. (1989). Causal stories and the formation of policy agendas. Political Science Quarterly, 104, 281-300.

Sverdrup, U. (2003). Compliance and styles of conflict management in Europe (ARENA Working Paper 08/3). Oslo: Advanced Research on the Europeanisation of the Nation-State (ARENA).

Sverige Riksdag. (1974). Proposition 1974:86 KungI. Maj:ts proposition angående skjyldighet att använda bilbälte: Lag om ändring i lagen (1916: 312) angående ansvarighet för skada i följd av automobiltrafik. [Proposition 1974:86: His Majesty's bill on using seatbelts: Law amending the Law (1916: 312) concerning liability for damage in consequence of automobile traffic.]. Stockholm: Sverige Riksdag.

Sverige Riksdag. (1996/1997). Proposition 1996/1997: 137: Vision Zero and the traffic safe society. Stockholm: Sverige Riksdag.

Swedish Institute. (2007). The Swedish system of government (Publication FS 55 z). Stockholm: Swedish Institute.

Swedish Work Environment Authority. (2003/2004). Road safety -- A work environment issue. Stockholm: Swedish Work Environment Authority.

The Independent (UK). (February 25, 1994). Runaway lorry in crash that killed six had 'no brakes': Driver was unaware of danger, inquest told. Independent (UK). Retrieved from http://www.independent.co.uk/news/uk/runaway-lorry-in-crash-that-killed-sixhad-no-brakes-driver-was-unaware-of-danger-inquest-told-1396249.html

Trafikutskottets, Sverige Riksdag [Transport Committee, Riksdag]. (1971). Betänkande 1971:TU8 Trafikutskottets betänkande i anledning av motioner rörande trafiksäkerheten m. m. [Report 1971: TU8 Transport Committee's report in response to motions relating to road safety, etc.]. Stockholm: Sverige Riksdag.

Trafikutskottets, Sverige Riksdag [Transport Committee, Riksdag]. (1974). Betänkande 1974:TU15 Trafikutskottets betänkande i anledning av propositionen 1974:86 angående skyldighet att använda bilbälte jämte motioner [Report 1974: TU15 Transport Committee's report into the bill 1974:86 on duty to wear safety belts along with motions]. Stockholm: Sverige Riksdag.

Trafikutskottets, Sverige Riksdag [Transport Committee, Riksdag]. (1997/1998). Transport Committee's Report 1997/1998 TU 04: Vision Zero and the traffic safe society.

Stockholm: Sverige Riksdag.

Trafikverket. (2009). Driver licence fact sheet. Norrköping, Sweden: Trafikverket.

Trafikverket. (2010). Which authority does what within transportation? Retrieved October 4, 2010, from http://www.trafikverket.se/Om-Trafikverket/Spraksida/EnglishEngelska/Which-authority-does-what-within-transportation/

Trafikverket. (October 6, 2010). Personal interview with Deputy Head, Traffic Safety Unit. Geneva, Switzerland.

Tsebelis, G. (1995). Decision making in political systems: Veto players in presidentialism, parliamentarism, multicameralism and multipartyism. British Journal of Political Science, 25(3), 289-325.

U.S. Department of Labor. (2009). National Census of Fatal Occupational Injuries in 2008. Washington, DC: Bureau of Labor Statistics. 
United Nations General Assembly. (March 2, 2010). Improving global road safety (Resolution A/64/L.44/Rev.1). New York: United Nations.

Vägverket. (December 9, 1994). Vägverkets föreskrifter om personlig tidbok mm. [SRA regulations on personal logbook]. Vägverkets författningssamling (VVFS) [Swedish National Road Administration Statute Book] VVFS 1994:40.

Vägverket. (July 10, 1996a). Vägverkets föreskrifter (1996:200) om medicinska krav för innehav av körkort, traktorkort och taxiförarlegitimation mm. [SNRA regulations (1996:200) on medical requirements for driving license, tractor license and taxi driver's ID, etc.]. Vägverkets författningssamling (VVFS) [Swedish National Road Administration Statute Book] VVFS 1996:200.

Vägverket. (July 10, 1996b). Vägverkets föreskrifter om kursplaner, behörighet B. [Regulations concerning curriculum, class B]. Vägverkets författningssamling (VVFS) [Swedish National Road Administration Statute Book] VVFS 1996:168.

Vägverket. (May 11, 2001). Vägverkets föreskrifter om yrkeskunnande för yrkesmässig trafik. [SRA Regulations on Proficiency for Professional Use]. Vägverkets författningssamling (VVFS) [Swedish National Road Administration Statute Book] VVFS 2001:51.

Vägverket [Swedish Road Administration]. (2008). Safe traffic: Vision Zero on the move (2nd edition). Borlänge, Sweden: Vägverket.

Van Oudenaren, J. (2005). Uniting Europe: An Introduction to the European Union (second edition). Oxford: Rowman \& Littlefield Publishers.

Varone, F., Rothmayr, C., \& Montpetit, É. (2007). Comparing biotechnology policy in Europe and North America: A theoretical framework. In É. Montpetit, C. Rothmayr \& F. Varone (Eds.), The politics of biotechnology in North America and Europe: policy networks, institutions, and internationalization (pp. 1-33). Lanham, MD: Rowman \& Littlefield Publishers.

Vogel, D. (2003). The hare and the tortoise revisited: The new politics of consumer and environmental regulation in Europe. British Journal of Political Science, 33, 557-580.

Wallace, H. (2005). An institutional anatomy and five policy modes. In H. Wallace, W. Wallace \& M. A. Pollack (Eds.), Policy-making in the European Union (fifth edition) (pp. 49-90). Oxford: Oxford University Press.

Weston, M. (1991). An English reader's guide to the French legal system. Oxford: Berg Publishers Limited.

Wilks, S. (2005). Competition policy: Challenge and reform. In H. Wallace, W. Wallace \& M. A. Pollack (Eds.), Policy-making in the European Union (fifth edition) (pp. 113139). Oxford: Oxford University Press.

Wolman, H. (1992). Understanding cross national policy transfers: The case of Britain and the US. Governance, 5(1), 27-45.

Work-related Road Safety Task Group. (2001). Reducing at-work road traffic incidents: Report to government and the Health and Safety Commission. London, England: Health and Safety Commission and Department of Transport, Local Government, and Regions.

World Health Organization. (2009). Global status report on road safety: Time for action. Geneva: World Health Organization. 
World Health Organization, Department of Public Health and Environment. (May 4, 2010). Personal interview with Coordinator, Interventions for Health Environments Unit. Geneva, Switzerland.

Yrkestrafiken.se. (2010). Driving and rest. Retrieved November 1, 2010, from http://www.yrkestrafiken.se/Kor-och-vilotider/

Zippel, K. (2004). Transnational advocacy networks and policy cycles in the European Union: the case of sexual harassment. Social Politics, 11(1), 57-85. 


\section{Appendix A. Key Informant Interviews}

\begin{tabular}{|c|c|c|c|c|}
\hline Location & Organization & Title & Affiliation & Type \\
\hline $\begin{array}{l}\text { United } \\
\text { Kingdom }\end{array}$ & $\begin{array}{l}\text { Department for } \\
\text { Transport }\end{array}$ & $\begin{array}{l}\text { Senior Policy Adviser, } \\
\text { Road User Safety } \\
\text { Division }\end{array}$ & Government & Personal \\
\hline $\begin{array}{l}\text { United } \\
\text { Kingdom }\end{array}$ & $\begin{array}{l}\text { Health and Safety } \\
\text { Executive }\end{array}$ & Senior Policy Adviser & Government & Personal \\
\hline $\begin{array}{l}\text { United } \\
\text { Kingdom }\end{array}$ & $\begin{array}{l}\text { Royal Society for the } \\
\text { Prevention of } \\
\text { Accidents }\end{array}$ & $\begin{array}{l}\text { Occupational Safety and } \\
\text { Health Advisor }\end{array}$ & $\mathrm{NGO}$ & Personal \\
\hline $\begin{array}{l}\text { United } \\
\text { Kingdom }\end{array}$ & RoadSafe & Campaign Director & $\mathrm{NGO}$ & Personal \\
\hline France & Eurogip & Project Manager & $\begin{array}{l}\text { Government/ } \\
\text { Social } \\
\text { Partners } \\
\end{array}$ & Personal \\
\hline France & $\begin{array}{l}\text { Institut national de } \\
\text { recherche et de } \\
\text { securité }\end{array}$ & Head of Road Risk & Government & Personal \\
\hline France & $\begin{array}{l}\text { Institut national de } \\
\text { recherche et de } \\
\text { securité }\end{array}$ & $\begin{array}{l}\text { Coordinator, International } \\
\text { Relations }\end{array}$ & Government & Personal \\
\hline France & $\begin{array}{l}\text { Caisse Nationale } \\
\text { l'Assurance Maladie } \\
\text { des Travailleurs } \\
\text { Salariés }\end{array}$ & $\begin{array}{l}\text { Consulting Engineer, } \\
\text { Direction des Risques } \\
\text { Professionnels }\end{array}$ & $\begin{array}{l}\text { Government/ } \\
\text { Social } \\
\text { Partners }\end{array}$ & Personal \\
\hline France & $\begin{array}{l}\text { Caisse Regionale } \\
\text { d'Assurance Maladie } \\
\text { des Travailleurs } \\
\text { Salariés d'Ile-de- } \\
\text { France }\end{array}$ & Consulting Engineer & $\begin{array}{l}\text { Government/ } \\
\text { Social } \\
\text { Partners }\end{array}$ & Personal \\
\hline Sweden & Trafikverket & $\begin{array}{l}\text { Deputy Head, Traffic } \\
\text { Safety Unit }\end{array}$ & Government & Personal \\
\hline Sweden & Arbetsmiljöverket & Safety Specialist & Government & Phone \\
\hline Sweden & Arbetsmiljöverket & Jurist & Government & E-mail \\
\hline $\begin{array}{l}\text { European } \\
\text { Commission }\end{array}$ & $\begin{array}{l}\text { DG Mobility } \\
\text { Transport }\end{array}$ & $\begin{array}{l}\text { Policy Officer, Road } \\
\text { Safety }\end{array}$ & $\begin{array}{l}\text { Government/ } \\
\text { IO }\end{array}$ & Personal \\
\hline $\begin{array}{l}\text { European } \\
\text { Commission }\end{array}$ & $\begin{array}{l}\text { DG Employment, } \\
\text { Social Affairs, and } \\
\text { Equal Opportunities }\end{array}$ & Policy Officer & $\begin{array}{l}\text { Government/ } \\
\text { IO }\end{array}$ & Personal \\
\hline
\end{tabular}




\begin{tabular}{|c|c|c|c|c|}
\hline Location & Organization & Title & Affiliation & Type \\
\hline $\begin{array}{l}\text { European } \\
\text { Commission }\end{array}$ & EU-OSHA & Project Manager (2) & $\begin{array}{l}\text { Government/ } \\
\text { IO }\end{array}$ & Personal \\
\hline $\begin{array}{l}\text { European } \\
\text { Union }\end{array}$ & $\begin{array}{l}\text { European Transport } \\
\text { Safety Council }\end{array}$ & Policy Director & $\begin{array}{l}\text { Government// } \\
\text { NGO }\end{array}$ & Personal \\
\hline $\begin{array}{l}\text { European } \\
\text { Union } \\
\end{array}$ & $\begin{array}{l}\text { European Transport } \\
\text { Safety Council }\end{array}$ & Project Officer & $\begin{array}{l}\text { Government/ } \\
\text { NGO }\end{array}$ & Personal \\
\hline International & $\begin{array}{l}\text { World Health } \\
\text { Organization }\end{array}$ & $\begin{array}{l}\text { Chief, Interventions for } \\
\text { Healthy Environments } \\
\text { Department of Public } \\
\text { Health and Environment }\end{array}$ & 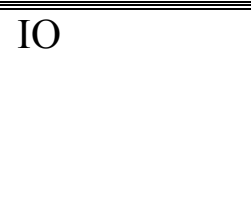 & Personal \\
\hline International & $\begin{array}{l}\text { Global Road Safety } \\
\text { Partnership }\end{array}$ & Chief Executive & NGO & Personal \\
\hline International & $\begin{array}{l}\text { International Labour } \\
\text { Organization }\end{array}$ & $\begin{array}{l}\text { Technical Specialist (Ports } \\
\text { and Transport) } \\
\text { Sectoral Activities }\end{array}$ & $\mathrm{IO}$ & Personal \\
\hline
\end{tabular}




\section{Appendix B. Interview Schedules}

\section{United Kingdom}

\section{Occupational Safety and Health Advisor Royal Society for the Prevention of Accidents Birmingham, England}

Interview date: April 29, 2010

\section{Institutional Structure}

Q: I am interested in learning about how work-related road safety gradually came to be recognized as a distinct policy issue in the UK. Could you please give me some background on what you see as the most important events, the most important individuals or organizations, and any other factors that have contributed?

Probe for: Key events or media attention, legislation, academics/research, NGO pressure, companies' concern about risk management

Q: Could you please describe the role of RoSPA in influencing policy for occupational road safety?

Q: In many countries, policymaking for occupational road safety is spread across a number of government ministries, including transport, labor, health, and social security. I am interested in learning how this works in the UK. Could you please comment on the extent to which responsibility for occupational road safety is spread across different government agencies?

Q: In the UK, is work-related road safety viewed as most closely linked to transport policy, to occupational health and safety policy, or to some other policy area?

Q: What effect does this have on how government deals with the issue?

\section{Policy}

Q: I am particularly interested in the fact that in different countries, different ideas are used to justify how occupational road risk ought to be managed and who ought to manage it. Could you please comment on the nature of these discussions in the UK?

Q: In the UK, what do you think is the prevailing philosophy? To what degree should government specify how the private sector manages occupational road risk?

\section{Interest Groups}


Work-related road risk seems to be viewed as a significant occupational safety issue for the UK, and there also seems to be considerable activity on a number of fronts to address the problem.

Q: In addition to RoSPA, what are the non-governmental organizations, trade associations, and other groups that have been most active in promoting occupational road safety in the UK?

Q: Have the activities of international organizations had an influence on policy or practice within the UK -- for example, UN resolutions on road safety, or campaigns by groups such as victims' organizations?

\section{EU Directives}

Q: To what extent have EU directives changed how businesses within the UK manage workrelated road risk?

Q: From what you have observed, to what extent have EU directives changed the way the HSE, the Department for Transport, and other UK government agencies address occupational road safety?

Q: Are there any important points about occupational road safety in the UK that you would like to add?

\section{Senior Policy Advisor}

Services Transportation and Safety Unit

Operational Strategy Division

Health \& Safety Executive

London, England

Interview date: April 30, 2010

\section{Institutional Structure}

Q: Could you please describe the role of the Health and Safety Executive in setting or influencing policy for occupational road safety?

Q: In many countries, policymaking for occupational road safety is spread across a number of government ministries, including transport, labor, health, and social security. I am interested in learning how this works in the UK. Could you please comment on the extent to which responsibility for occupational road safety is spread across different government agencies?

If not addressed:

Q: Is policy and regulation for operation of large trucks and buses managed separately from policy and regulation for light trucks and passenger vehicles used for work? 
Q: In the UK, is work-related road safety viewed as more closely linked to transport policy, to occupational health and safety policy, or to some other policy area?

Q: What effect does this have on how government deals with the issue?

Q: Could you please describe any methods for coordinating policy across the agencies that have some responsibility for occupational road safety?

Q: Are HSE policies related to occupational road safety dictated from the central government level, or are there elements of policy where Scotland, Wales, and Northern Ireland or the individual counties have some discretion?

\section{Policy}

Q: I have read the 2003 HSE guidance document, Driving at Work, which states that occupational health and safety law applies to on-the-road work activities as to all work activities, and the associated risks should be managed within the health and safety management system. How is this guidance integrated into your agency's processes for ensuring that organizations comply with safety and health law?

Q: I'm interested in learning what happens in the UK when there is a work-related road traffic fatality. Could you please tell me about the process for reporting and investigation, and also which agencies are involved?

Q: I understand that motor vehicle crashes are not included in the Reporting of Injury, Diseases and Dangerous Occurrences Regulations (RIDDOR). Can you provide some history and background information on this issue that will help me to understand why this is the case?

Q: I believe that in the UK, as in the U.S., motor vehicle crashes that occur while commuting to or from work are not considered to be work-related crashes and are therefore covered through neither reporting systems for occupational injuries nor workers' compensation insurance. Could you please explain what led to the determination that crashes while commuting are not workrelated incidents?

Q: I am particularly interested in the fact that in different countries, different ideas are used to justify how occupational road risk ought to be managed and who ought to manage it. Could you please comment on the nature of these discussions in the UK?

Q: In the UK, what do you think is the prevailing philosophy? To what degree should government specify how the private sector manages occupational road risk?

\section{Interest Groups}

Work-related road risk seems to be viewed as a significant occupational safety issue for the UK, and there also seems to be considerable activity on a number of fronts to address the problem. 
Q: What are the non-governmental organizations, trade associations, and other groups that have shown the greatest interest in policy for occupational road safety?

Q: Have any policy decisions within the HSE related to occupational road safety been influenced by the activity of international organizations or advocacy groups - for example, UN resolutions on road safety, or campaigns by groups such as victims' organizations?

\section{EU Directives}

Q: Please describe what happens in the UK when a new EU directive relevant to work-related road safety comes into force.

Probe to ascertain factors such as:

Q: Is the task of translating into national law assigned to a lead agency?

Q: How does the consultation process work? Who is involved?

Q: Have EU directives on occupational road safety required changes in national legislation, or have they been implemented through bureaucratic processes?

As I mentioned earlier, one of the aims of my research is to assess how well the UK, France, and Sweden have transposed directives that are relevant to occupational road safety into their national law.

Present the directives I have judged to be relevant to this research.

Q: Are there any important directives that I have missed?

Q: In your opinion, are any of these directives I have identified not applicable to occupational road safety?

Q: To what extent have EU directives influenced national policy decisions for occupational road safety?

If to a moderate or large extent:

Q: Which EU directives do you consider to have required the most substantive changes in your national law?

Q: Have EU directives led to the creation of any new programs or institutions in the UK to implement or enforce these directives?

If to a limited extent:

Q: Why have EU directives had limited influence?

Q: In your opinion, how accurately has the UK transposed the EU directives that apply to occupational road safety?

Q: Are there particular cases you would describe as clear successes or failures? 
Q: Has the UK interpreted the EU Framework Directive for occupational safety and health as requiring risk assessment for work-related driving?

Q: Has the UK, by legislation or regulation, formally designated the road as a work environment: For purposes of occupational risk assessment?

For enforcement of occupational safety regulations?

\section{Other queries}

Q: In my reading, I have seen some reference to the Health and Safety Commission (HSC). Can you explain to me its role in occupational road safety?

Q: Part of my research will be to assess how the UK has incorporated EU directives into national regulations. Could you please tell me the best source on the Internet for locating the text of UK regulations that pertain to work-related road safety?

Q: Are there any important points about occupational road safety in the UK that you would like to add?

Senior Policy Adviser

Road User Safety Division

Department for Transport

London, England

Interview date: April 30, 2010

\section{Institutional Structure}

Q: Could you please describe the role of the Department for Transport in setting or influencing policy for occupational road safety?

Q: In many countries, policymaking for occupational road safety is spread across a number of government ministries, including transport, labor, health, and social security. I am interested in learning how this works in the UK. Could you please comment on the extent to which responsibility for occupational road safety is spread across different government agencies?

If not addressed:

Q: Is policy and regulation for operation of large trucks and buses managed separately

from policy and regulation for light trucks and passenger vehicles used for work?

Q: In your opinion, is work-related road safety viewed in the UK as most closely linked to transport policy, to occupational health and safety policy, or to some other policy area?

Q: What effect does this have on how government deals with the issue? 
Q: Could you please describe any methods for coordinating policy across the government agencies that have some responsibility for occupational road safety?

Q: Are Department for Transport policies related to occupational road safety dictated from the central government level, or are there elements of policy where Scotland, Wales, and Northern Ireland or the individual counties have some discretion?

\section{Policy}

Q: I'm interested in learning what happens in the UK when there is a work-related road traffic fatality. Could you please tell me about the process for reporting and investigation, and also which agencies are involved?

Q: I am particularly interested in the fact that in different countries, different ideas are used to justify how occupational road risk ought to be managed and who ought to manage it. Could you please comment on the nature of these discussions in the UK?

Q: In the UK, what do you think is the prevailing philosophy? To what degree should government specify how the private sector manages occupational road risk?

\section{EU Directives}

Q: Please describe what happens in the UK when a new EU directive relevant to work-related road safety comes into force.

Probe to ascertain factors such as:

Q: Is the task of translating into national law assigned to a lead agency?

Q: How does the consultation process work? Who is involved?

Q: Have EU directives on occupational road safety required changes in national legislation, or have they been implemented through bureaucratic processes?

As I mentioned earlier, one of the aims of my research is to assess how well the UK, France, and Sweden have transposed directives that are relevant to occupational road safety into their national law.

Present the directives I have judged to be relevant to this research.

Q: Are there any important directives that I have missed?

Q: In your opinion, are any of these directives I have identified not applicable to occupational road safety?

Q: To what extent have EU directives influenced national policy decisions for occupational road safety?

If to a moderate or large extent: 
Q: Which EU directives do you consider to have required the most substantive changes in your national law?

Q: Have EU directives led to the creation of any new programs or institutions in the UK to implement or enforce these directives?

If to a limited extent:

Q: Why have EU directives had limited influence?

Q: In your opinion, how accurately has the UK transposed the EU directives that apply to occupational road safety?

Q: Are there particular cases you would describe as clear successes or failures?

Q: Has the UK interpreted the EU Framework Directive for occupational safety and health as requiring risk assessment for work-related driving?

Q: Has the UK, by legislation or regulation, formally designated the road as a work environment: For purposes of occupational risk assessment?

For enforcement of occupational safety regulations?

\section{Interest Groups}

Work-related road risk seems to be viewed as a significant occupational safety issue for the UK, and there also seems to be considerable activity on a number of fronts to address the problem.

Q: What are the non-governmental organizations, trade associations, and other groups that have shown the greatest interest in policy for occupational road safety?

Q: To what extent have policy decisions within the Department for Transport related to occupational road safety been influenced by the activity of international organizations or advocacy groups - for example, UN resolutions on road safety, or campaigns by groups such as victims' organizations?

\section{Other queries}

Q: Part of my research will be to assess how the UK has incorporated EU directives into national regulations. Could you please tell me the best source on the Internet for locating the text of UK regulations that pertain to work-related road safety?

Q: Are there any important points about occupational road safety in the UK that you would like to add?

\section{Campaign Director \\ RoadSafe \\ London, England}


Interview date: May 6, 2010

\section{Institutional Structure}

Q: I am interested in learning about how work-related road safety gradually came to be recognized as a distinct policy issue in the UK. Could you please give me some background on what you see as the most important events, the most important individuals or organizations, and any other factors that have contributed?

\section{Probe for: Key events or media attention, legislation, academics/research, NGO pressure, companies' concern about risk management}

Q: Could you please describe the role of RoadSafe in influencing policy for occupational road safety?

Q: In many countries, policymaking for occupational road safety is spread across a number of government ministries, including transport, labor, health, and social security. I am interested in learning how this works in the UK. Could you please comment on the extent to which responsibility for occupational road safety is spread across different government agencies?

Q: In the UK, is work-related road safety viewed as most closely linked to transport policy, to occupational health and safety policy, or to some other policy area?

Q: What effect, if any, does this have on how government deals with the issue?

\section{Policy}

Q: I am particularly interested in the fact that in different countries, different ideas are used to justify how occupational road risk ought to be managed and who ought to manage it. Could you please comment on the nature of these discussions in the UK?

Q: In the UK, what do you think is the prevailing philosophy? To what degree should government specify how the private sector manages occupational road risk?

\section{Interest Groups}

Work-related road risk seems to be viewed as a significant occupational safety issue for the UK, and there also seems to be considerable activity on a number of fronts to address the problem.

Q: In addition to RoadSafe, what are the non-governmental organizations, trade associations, and other groups that have been most active in promoting occupational road safety in the UK?

Q: To what extent have the activities of international organizations had an influence on policy or practice within the UK -- for example, UN resolutions on road safety, or campaigns by groups such as victims' organizations? 


\section{EU Directives}

Q: To what extent have EU directives changed how businesses in the UK manage work-related road risk?

Q: From what you have observed, to what extent have EU directives changed the way the HSE, the Department for Transport, and other UK government agencies address occupational road safety?

Q: Are there any important points about occupational road safety in the UK that you would like to add?

\section{France}

Project Manager

Eurogip

Paris, France

Chef de projet Risk Routier [Head of Road Risk]

Institut national de recherche et de securité (INRS)

Paris, France

Chargée de la coordination des relations internationales [Coordinator, International

Relations]

Institut national de recherche et de securité (INRS)

Paris, France

Ingénieur Conseil [Consulting Engineer]

Caisse Nationale l'Assurance Maladie des Travailleurs Salariés, Direction des Risques

Professionnels (CNAMTS-DRP)

Paris, France

Ingénieur Conseil [Consulting Engineer]

Caisse Regionale d'Assurance Maladie des Travailleurs Salariés d'Ile-de-France (CNAMTS-

DRP, Île-de-France)

Paris, France

Interview date: April 28, 2010

\section{Institutional Structure}

Q: Could you please describe the role of your agencies in setting or influencing policy for occupational road safety? 
Q: In many countries, policymaking for occupational road safety is spread across a number of government ministries, including transport, labor, health, and social security. I am interested in learning how this works in France. In addition to your agencies, which other agencies in France have some responsibility for policy for occupational road safety?

If not addressed:

Q: Is policy and regulation for operation of large trucks and buses managed separately from policy and regulation for light trucks and passenger vehicles used for work?

Q: In France, is work-related road safety viewed as most closely linked to transport policy, to occupational health and safety policy, or to some other policy area?

Q: What effect does this have on how the government deals with the issue?

Q: Could you please describe any methods for coordinating policy across the agencies that have some responsibility for occupational road safety?

Q: I'm interested in learning what happens in France when there is a work-related road traffic fatality. Could you please tell me about the process for reporting and investigation, and also which agencies are involved?

Q: Which agency or agencies in France collect data on work-related motor vehicle crashes?

If not mentioned:

Q: Which data system collects data on crashes that occur while commuting to or from work?

\section{Policy}

Q: I am particularly interested in the fact that in different countries, different ideas are used to justify how occupational road risk ought to be managed and who ought to manage it. Could you please comment on the nature of these discussions in France?

Q: In France, what do you think is the prevailing philosophy? To what degree should government specify how the private sector manages occupational road risk?

\section{If not mentioned:}

I have read about the Committee for the Prevention of Occupational Road Accidents (Comité Pour la Prévention du Risque Routier Professionel), which I understand is supported from workers' compensation funds and in its advisory role puts forward proposals on work related road safety. Is this group still active, and if so, what role does it play?

\section{If not mentioned:}


I have also seen reference to the French Agency for Environmental and Occupational Health Safety (AFSSET). What role does it play in setting policy for occupational road safety?

Q: What led to the decision to cover motor vehicle crashes while commuting under workers' compensation?

Q: I understand that workers' compensation is managed through regional health insurance funds. If this is correct, could you tell me how much discretion or flexibility is given to these regional bodies in setting compensation levels and giving advice on risk assessment and crash prevention?

\section{EU Directives}

Q: Please describe what happens in France when a new EU directive relevant to work-related road safety comes into force.

Probe to ascertain factors such as:

Q: Is the task of translating into national law assigned to a lead agency?

Q: How does the consultation process work? Who is involved?

Q: Have EU directives on occupational road safety required changes in national legislation, or have they been implemented through bureaucratic processes?

As I mentioned earlier, one of the aims of my research is to assess how well the UK, France, and Sweden have transposed directives that are relevant to occupational road safety into their national law.

Present the directives I have judged to be relevant to this research.

Q: Are there any important directives that I have missed?

Q: In your opinion, are any of these directives I have identified not applicable to occupational road safety?

Q: To what extent have EU directives influenced national policy decisions for occupational road safety?

If to a moderate or large extent:

Q: Which EU directives do you consider to have required the most substantive changes in French law?

Q: Have EU directives led to the creation of any new programs or institutions in France to implement or enforce these directives?

If to a limited extent:

Q: Why have EU directives had limited influence? 
Q: In your opinion, how accurately has France transposed the EU directives that apply to occupational road safety?

Q: Are there particular cases you would describe as clear successes or failures?

Q: Has France interpreted the EU Framework Directive for occupational safety and health as requiring risk assessment for work-related driving?

Q: Has French law or regulation formally designated the road as a work environment:

For purposes of occupational risk assessment?

For enforcement of occupational safety regulations?

\section{Interest Groups}

Q: What are the non-governmental organizations and trade associations that have shown the greatest interest in policy for occupational road safety in France?

Q: Have any policy decisions within France related to occupational road safety been influenced by the activity of international organizations or advocacy groups - for example, UN resolutions on road safety, or campaigns by groups such as victims' organizations?

Q: Are there any important points about occupational road safety in France that you would like to add?

\section{Sweden}

Deputy Head, Traffic Safety Unit

Trafikverket

Börlange, Sweden

Interview date: October 6, 2010

\section{Focusing events}

Q: Could you please tell me about any events or decisions by the government which led Sweden to give greater attention to policy on work-related road safety?

\section{Institutional Structure}

Q: In many countries, policymaking for occupational road safety is spread across a number of government ministries, including transport, labor, health, and social security. I am interested in learning how this works in Sweden. Could you please comment on the extent to which responsibility for occupational road safety is spread across different government agencies?

If not addressed: 
Q: Is policy and regulation for operation of large trucks and buses managed separately from policy and regulation for light trucks and passenger vehicles used for work?

Q: Could you please explain the difference between the roles of the Swedish Transport Administration and the Swedish Transport Agency?

If not addressed:

Q: Does the Transport Administration oversee the Transport Agency, or are they separate agencies at the same level of the government bureaucracy?

If not addressed:

Q: Does the Swedish Transport Administration have any direct role in setting or influencing policy for occupational road safety?

Q: Could you please explain the role of the Work Environment Authority in setting or influencing policy for occupational road safety?

Q: Has Sweden interpreted the EU Framework Directive for occupational safety and health as requiring risk assessment for work-related driving?

Q: In your opinion, is work-related road safety viewed in Sweden as most closely linked to transport policy, to occupational health and safety policy, or to some other policy area?

Q: What effect does this have on how government deals with the issue?

Q: Could you please describe any methods for coordinating policy across the government agencies that have some responsibility for occupational road safety?

Q: To what degree is Swedish policy for the road transport industry linked to environmental policy?

Q: Are government policies related to occupational road safety dictated from the central government level, or are there certain policy areas - for example, regular driver licensing or granting certificates of professional competencies - where counties or municipalities have some authority?

\section{Legislation}

Q: In the area of transport safety law, it appears that the Road Traffic Ordinance of 1998 covers road safety behavior in a detailed manner. I've also found a number of other statutes, ordinances, and regulations that address specific topics such as licensing or hours of work. Are there any comprehensive pieces of transport legislation that I may have missed which would be relevant for work-related road safety?

Q: Was the 1998 Road Traffic Ordinance the first national legislation requiring all vehicle occupants to use seat belts? 
Q: Some transport regulations seem to have been enacted at the level of the Ministry of Enterprise, Energy, and Communications, while others were published at the level of the Vägverket and then Transportstyrelsen. What determines the level of government at which these regulations are developed?

Q: It seems that the Work Environment Act gives a framework for all of the occupational safety regulations. Are there any other comprehensive occupational safety and health laws you would recommend I review?

\section{Policy}

Q: I am particularly interested in the fact that in different countries, different ideas are used to justify how occupational road risk ought to be managed and who ought to manage it. Could you please comment on how work-related road safety fits into Vision Zero? Are there any Swedish models or philosophies other than Vision Zero that have been used to guide policy for workrelated road safety?

\section{EU Directives}

Q: Please describe what happens in Sweden when a new EU directive relevant to work-related road safety comes into force.

Probe to ascertain factors such as:

Q: Is the task of translating into national law assigned to a lead agency?

Q: How does the consultation process work? Who is involved?

Q: Have EU directives on occupational road safety required changes in national

legislation, or have they been implemented through bureaucratic processes?

Q: To what extent have EU directives influenced national policy decisions for occupational road safety?

If to a moderate or large extent:

Q: Which EU directives do you consider to have required the most substantive changes in your national law?

Q: Have EU directives led to the creation of any new programs or institutions in the UK to implement or enforce these directives?

If to a limited extent:

Q: Why have EU directives had limited influence?

Q: Sweden seems to have been several months late in completing its first transposition of the Driving License directive (91/439/EEC)? Can you provide any background information as to why this was the case?

\section{Interest Groups}


Q: What are the non-governmental organizations, trade associations, and other groups that have shown the greatest interest in policy for occupational road safety?

Q: To what extent have policy decisions related to occupational road safety taken by the Swedish Transport Administration been influenced by the activity of international organizations or advocacy groups - for example, UN resolutions on road safety, or campaigns by groups such as victims' organizations?

Q: Are there any important points about occupational road safety in Sweden that you would like to add?

\section{Safety Specialist \\ Arbetsmiljöverket \\ Stockholm, Sweden}

Date of phone interview: November 11, 2010

One of the topics I am interested in is the history of occupational road safety as a policy issue. Often, I find that it is the responsibility of the transport agencies in a country, but that the occupational safety agency is not very much involved. I find some evidence that in Sweden, the Work Environment Authority has been consulted on the issue along with the transport agencies.

Q: Is this correct, and if so, could you please comment on how the Work Environment Authority has been involved in deciding policy for occupational road safety?

Q: Were there any events in the larger society that brought occupational road safety to the attention of government or the public?

Q: I see that in Sweden, the work injury insurance scheme provides compensation for road traffic injuries while commuting to or from work, in addition to those that occur on the job. Could you please give me some background information on this policy? For example, how was it decided, and how long has it been in effect?

Q: It seems that the Work Environment Act gives a framework for all of the occupational safety regulations. I also know about the Provisions on systematic work-environment management (AFS 2001:1). Are there any other occupational safety and health laws you would recommend I review?

Q: Does the Work Environment Authority enforce both the Working Time Act and the Road Transport Working Time Act?

Q: Are government policies related to occupational road safety dictated from the central government level, or are there certain policy areas - for example, regular driver licensing or granting certificates of professional competencies - where counties or municipalities have some authority? 
Q: Has the Work Environment Authority worked cooperatively with any non-governmental organizations, employer groups, or labor unions to develop policies or initiatives related to occupational road safety?

Q: [Deputy Head, Road Safety Unit, Trafikverket] has explained to me that the guidance document called "Road Safety - A Work Environment Issue" was developed jointly between the Work Environment Authority and Vägverket. Are the labor inspectors in the Work Environment Authority still including road safety in their inspections?

Q: Please describe what happens in Sweden when a new EU directive relevant to work-related road safety comes into force.

Probe to ascertain factors such as:

Q: Is the task of translating into national law assigned to a lead agency?

Q: How does the consultation process work? Who is involved?

Q: Have EU directives on occupational road safety required changes in national legislation, or have they been implemented through bureaucratic processes?

Q: Are there cases in which Sweden has influenced EU directives on road safety?

\section{Jurist}

\section{Arbetsmiljöverket} Stockholm, Sweden

Questions answered by e-mail: December 6, 2010

Q: I found a reference to a Swedish ordinance (SFS 1994:1297) on working time and rest periods for workers who drive vehicles under 3.5 tonnes. Here is a link to this ordinance: http://www.notisum.se/rnp/sls/lag/19941297.htm

Is this ordinance still in place?

If YES:

Q: Who is responsible for enforcing this ordinance?

Q: The EU does not have a similar directive or regulation. Has Sweden tried to encourage the EU to issue a directive on this topic?

Q: When did Sweden add the provision to the Working Time Act that allowed collective bargaining agreements to exempt employees from the law entirely? Was it part of the original 1982 legislation, or was it added later after Sweden joined the EU?

I have read some literature that indicates that Sweden had some difficulty in transposing the first EU Working Time Directive after Sweden joined the European Union. From I have read, there seem to have been two problems. The first problem is that the Swedish regulations allowed too many exceptions to the EU requirement for a maximum work week of 48 hours. The second problem is that the Swedish law referred to the provisions of the EU Working Time Directive, 
but did not write these provisions directly into its national law. Most of the problems seem to have been resolved in 2005 with some amendments to the Working Time Act for Sweden. I have had quite a difficult time understanding the changes in the Working Time Act after Sweden joined the EU.

Q: Was there a case in the European Court of Justice against Sweden for incomplete transposition of this directive?

Q. Does the Work Environment Authority enforce the laws for working time in the road transport industry, or just the general rules for working time under the 1982 Working Time Act and its amendments?

The 2003 EU Working Time Directive says that member states have the option NOT to apply Article 6 concerning the maximum average working time of 48 hours, as long as it has measures in place to ensure that the average working week does not exceed 48 hours. However, it is possible for a worker to work more than 48 hours over a 7-day period if the employer has first obtained the worker's agreement. I believe that Sweden allows an exemption from the maximum working hours if there is a collective bargaining agreement.

Q: Does Sweden also allow this kind of agreement between an employer and an individual worker?

Q: Has Sweden exercised its option to apply Article 6 (the "individual opt-out") for 2003/88/EC?

\section{Article 22}

\section{Miscellaneous provisions}

A Member State shall have the option not to apply Article 6, while respecting the general principles of the protection of the safety and health of workers, and provided it takes the necessary measures to ensure that:

a. no employer requires a worker to work more than 48 hours over a sevenday period, calculated as an average for the reference period referred to in Article 16(b), unless he has first obtained the worker's agreement to perform such work;

b. no worker is subjected to any detriment by his employer because he is not willing to give his agreement to perform such work;

Q: Article 3 of the EU 2003 Working Time Directive states that "Member States shall take the measures necessary to ensure that every worker is entitled to a minimum daily rest period of 11 consecutive hours per 24-hour period." Did this provision exist in the original version of Sweden's 1982 Working Time Act, or was it added by SFS 2005:165?

\section{European Union}




\section{Policy Officer \\ European Commission - DG Employment, Social Affairs, and Equal Opportunities Luxembourg}

Interview date: May 5, 2010

Q: I am interested in learning about how work-related road safety gradually came to be recognized as a distinct policy issue in the EU. Could you please give me some background on what you see as the most important events, the most important individuals or organizations, and any other factors that contributed?

Probe for: Key events or media attention, legislation, academics/research, NGO pressure, companies' concern about risk management

Q: It seems to me that policy for occupational road safety at EU level would be covered under a number of different directorates, ranging from Transport to Employment, Social Affairs, and Equal Opportunities, Environment, and competition policy. Could you please comment on this point?

If true:

Q: Could you please explain how policy is coordinated across these directorates?

\section{Policy}

Q: Within the Directorate for Employment, are work-related motor vehicle crashes viewed primarily as a hazard for the transport sector, or as a multi-sectoral problem?

Q: In the EU, is work-related road safety viewed as most closely linked to transport policy, to occupational health and safety policy, or to some other policy area?

Q: In the U.S., one of the challenges in explaining the importance of occupational road safety to policy makers is that many people think that the only workers at risk are drivers of large commercial vehicles, who are already covered by government safety regulations. Could you please comment on the extent to which this is true in the EU?

Q: How does the fact that the EU has competence in some policy areas and member states have competence in other areas affect policy for work-related road safety?

Q: I'm interested in learning where and how ideas for EU directives and policies originate. Are there examples you can cite in which policy ideas from an individual member state influenced policy at EU level, either in the form of an EU directive or in some other way?

In some countries, the dominant policy direction is to call for government intervention in transport or occupational safety only insofar as is necessary to ensure fair business competition and meet minimum safety standards. In other countries, transport services and worker protection 
may be closely linked to social welfare, therefore; strong government intervention is viewed as appropriate.

Q: In your work at the European Commission, what differences have you observed among member states with respect to views about the appropriate role of government intervention in occupational road safety?

Q: Are there EU member states that you see as leaders or innovators in managing occupational road risk?

\section{EU Directives}

As I mentioned earlier, one of the aims of my research is to assess how well the UK, France, and Sweden have transposed directives that are relevant to occupational road safety into their national law.

Present the directives I have judged to be relevant to this research.

Q: Are there any important directives that I have missed?

Q: In your opinion, are any of these directives I have identified not relevant to occupational road safety?

Q: What is the role of your Directorate in monitoring how well EU member states have transposed EU directives into national laws?

\section{Interest Groups}

Q: What are the non-governmental organizations, trade associations, and other groups that have been most active in promoting occupational road safety at EU level?

Q: Have any policy decisions at EU level related to occupational road safety been influenced by the activity of international organizations or advocacy groups - for example, UN resolutions on road safety, or campaigns by groups such as victims' organizations?

Q: Are there any important points about occupational road safety in the EU that you would like to add?

\section{Project Manager (2) \\ Working Environment Information Unit \\ EU-OSHA}

Bilbao, Spain

Interview date: May 5, 2010

\section{Institutional Structure}


Q: I am interested in learning about how work-related road safety gradually came to be recognized as a distinct policy issue in the EU. Could you please give me some background on what you see as the most important events, the most important individuals or organizations, and any other factors that contributed?

Probe for: Key events or media attention, legislation, academics/research, NGO pressure, companies' concern about risk management

Q: Could you please describe the role of EU-OSHA in making or influencing policy for occupational road safety?

Q: With which EU directorates have you worked most closely on the topic of work-related road safety?

Q: I believe that EU social policy has provisions for sector-level social dialogue, one of which is in the road transport sector, where the IRU and the ETF are the voices for employers and workers. I would expect that occupational road safety would be brought up in this particular forum. Is this the case, and if so, can you provide any information about the nature of those discussions?

Q: Are there any other sector-level dialogues where occupational aspects of road safety would also be a topic for discussion?

Q: Is dialogue with social partners generally organized by sector? Are there examples in which the focal point might be a specific issue or hazard as it affects multiple sectors?

If emphasis is on dialogue by sector: Q: Does emphasis on dialogue by sector make it difficult to develop a comprehensive response to occupational road risk?

Q: Which of the 'social partners' are most interested in work-related road safety?

Q: What has the EU process of social dialogue accomplished thus far in promoting work-related road safety?

Q: Have any policy decisions within EU-OSHA related to occupational road safety been influenced by the activity of international organizations or advocacy groups - for example, UN resolutions on road safety, or campaigns by groups such as victims' organizations?

Q: How does the fact that the EU has competence in some policy areas and member states have competence in other areas affect policy for work-related road safety?

Q: I know that some EU member states have different ideas about the definition of a workrelated road traffic injury. From the perspective of EU-OSHA, is work-related road safety limited to driving during the work day, or does it also cover commuting to or from work? 


\section{EU Directives}

As I mentioned earlier, one of the aims of my research is to assess how well the UK, France, and Sweden have transposed directives that are relevant to occupational road safety into their national law.

Present the directives I have judged to be relevant to this research.

Q: Are there any important directives that I have missed?

Q: In your opinion, are any of these directives I have identified not relevant to occupational road safety?

\section{Policy}

Q: Within EU-OSHA, are work-related motor vehicle crashes viewed primarily as a hazard for the transport sector, or as a multi-sectoral problem?

Q: In the EU, is work-related road safety viewed as most closely linked to transport policy, to occupational health and safety policy, or to some other policy area?

Q: In the U.S., one of the challenges for convincing policymakers that occupational road safety should be addressed is the perception that the workers at risk are primarily drivers of large commercial vehicles, who are already covered by government safety regulations. Could you please comment on the extent to which this is true in the EU?

Q: I'm interested in learning where and how ideas for EU directives and policies originate. Are there examples you can cite in which policy ideas from an individual member state influenced policy at EU level, either in the form of an EU directive or in some other way?

In some countries, the dominant policy direction is to call for government intervention in transport or occupational safety only insofar as is necessary to ensure fair business competition and meet minimum safety standards. In other countries, transport services and worker protection may be closely linked to social welfare, therefore; strong government intervention is viewed as appropriate.

Q: In your work at EU-OSHA, what differences have you observed among member states with respect to views about the appropriate role of government intervention in occupational road safety?

Q: Are there EU member states that you see as leaders or innovators in managing occupational road risk?

Q: Are there any important points about occupational road safety in the EU that you would like to add? 


\section{Policy Officer, Road Safety \\ European Commission - DG MOVE \\ Brussels, Belgium}

Interview date: May 6, 2010

Q: I am interested in learning about how work-related road safety gradually came to be recognized as a distinct policy issue in the EU. Could you please give me some background on what you see as the most important events, the most important individuals or organizations, and any other factors that contributed?

Probe for: Key events or media attention, legislation, academics/research, NGO pressure, companies' concern about risk management

Q: It seems to me that policy for occupational road safety at EU level would be covered under a number of different directorates, ranging from Transport to Employment, Social Affairs, and Equal Opportunities, Environment, and competition policy. Could you please comment on this point?

If true:

Q: Could you please explain how policy is coordinated across these directorates?

\section{Policy}

Q: Within DG MOVE, are work-related motor vehicle crashes viewed primarily as a hazard for the transport sector, or as a multi-sectoral problem?

Q: In the EU, is work-related road safety viewed as most closely linked to transport policy, to occupational health and safety policy, or to some other policy area?

Q: In the U.S., one of the challenges in explaining the importance of occupational road safety to policy makers is that many people think that the only workers at risk are drivers of large commercial vehicles, who are already covered by government safety regulations. Could you please comment on the extent to which this is true in the EU?

Q: How does the fact that the EU has competence in some policy areas and member states have competence in other areas affect policy for work-related road safety?

Q: I'm interested in learning where and how ideas for EU directives and policies originate. Are there examples you can cite in which policy ideas from an individual member state influenced policy at EU level, either in the form of an EU directive or in some other way?

In some countries, the dominant policy direction is to call for government intervention in transport or occupational safety only insofar as is necessary to ensure fair business competition and meet minimum safety standards. In other countries, transport services and worker protection 
may be closely linked to social welfare, therefore; strong government intervention is viewed as appropriate.

Q: In your work at the European Commission, what differences have you observed among member states with respect to views about the appropriate role of government intervention in occupational road safety?

Q: Are there EU member states that you see as leaders or innovators in managing occupational road risk?

\section{EU Directives}

As I mentioned earlier, one of the aims of my research is to assess how well the UK, France, and Sweden have transposed directives that are relevant to occupational road safety into their national law.

Present the directives I have judged to be relevant to this research.

Q: Are there any important directives that I have missed?

Q: In your opinion, are any of these directives I have identified not relevant to occupational road safety?

Q: What is the role of your Directorate in monitoring how well EU member states have transposed EU directives into national laws?

\section{Interest Groups}

Q: What are the non-governmental organizations, trade associations, and other groups that have been most active in promoting occupational road safety at EU level?

Q: Have any policy decisions at EU level related to occupational road safety been influenced by the activity of international organizations or advocacy groups - for example, UN resolutions on road safety, or campaigns by groups such as victims' organizations?

Q: Are there any important points about occupational road safety in the EU that you would like to add?

\section{Policy Director \\ Project Officer \\ European Transport Safety Council \\ Brussels, Belgium}

Interview date: May 7, 2010 
Q: I am interested in learning about how work-related road safety gradually came to be recognized as a distinct policy issue in the EU and also for the European Transport Safety Council. Could you please give me some background on what you see as the most important events, the most important individuals or organizations, and any other factors that contributed?

\section{Probe for: Key events or media attention, legislation, academics/research, $N G O$ pressure, companies' concern about risk management}

\section{Policy}

Q: Within your organization, are work-related motor vehicle crashes viewed primarily as a hazard for the transport sector, or as a multi-sectoral problem?

Q: In the EU, is work-related road safety viewed as most closely linked to transport policy, to occupational health and safety policy, or to some other policy area?

Q: In the U.S., one of the challenges in explaining the importance of occupational road safety to policy makers is that many people think that the only workers at risk are drivers of large commercial vehicles, who are already covered by government safety regulations. Could you please comment on the extent to which this is true in the EU?

Q: How does the fact that the EU has competence in some policy areas and member states have competence in other areas affect policy for work-related road safety?

In some countries, the dominant policy direction is to call for government intervention in transport or occupational safety only insofar as is necessary to ensure fair business competition and meet minimum safety standards. In other countries, transport services and worker protection may be closely linked to social welfare, therefore; strong government intervention is viewed as appropriate.

Q: In your work at the European Transport Safety Council, what differences have you observed among member states with respect to views about the appropriate role of government intervention in occupational road safety?

Q: Are there EU member states that you see as leaders or innovators in managing occupational road risk?

Q: I'm interested in learning where and how ideas for EU directives and policies originate. Are there examples you can cite in which policy ideas from an individual member state have influenced policy at EU level, in the form of a directive or in some other way?

Q: The ETSC has recommended that the Spanish Presidency champion the issue of work-related road safety. What results do you hope to see from this effort?

Q: If the Spanish Presidency does take up this issue, how would such an initiative make its way through the EU system? 


\section{EU Directives}

As I mentioned earlier, one of the aims of my research is to assess how well the UK, France, and Sweden have transposed directives that are relevant to occupational road safety into their national law.

Present the directives I have judged to be relevant to this research.

Q: Are there any important directives that I have missed?

Q: In your opinion, are any of these directives I have identified not relevant to occupational road safety?

Q: What are the non-governmental organizations, trade associations, and other groups that have been most active in promoting occupational road safety at EU level?

Q: Have any policy decisions at EU level related to occupational road safety been influenced by the activity of international organizations or advocacy groups - for example, UN resolutions on road safety, or campaigns by groups such as victims' organizations?

Q: Are there any important points about occupational road safety in the EU that you would like to add?

\section{International Organizations}

\section{Chief Executive \\ Global Road Safety Partnership \\ Geneva, Switzerland}

Interview date: May 4, 2010

Q: I am interested in learning about how work-related road safety gradually came to be recognized as a distinct policy issue in Europe. Could you please give me some background on what you see as the most important events, the most important individuals or organizations, and any other factors that contributed?

Probe for: Key events or media attention, legislation, academics/research, NGO pressure, companies' concern about risk management

Q: Could you please describe briefly the components of the GRSP program that are most directly related to promoting occupational road safety?

The World Report on Road Traffic Injury Prevention stresses the importance of coordinating road safety policy across all government ministries and industrial sectors that have a stake in the 
issue. In many countries, occupational road safety policy straddles OSH and transport, agencies that may not have a strong history of coordination. It may also be addressed within ministries that handle environment, health, social insurance, or industrial policy.

Q: How does the fact that many government agencies may share responsibility for work-related road safety affect governments' ability to develop comprehensive and coordinated responses?

Q: Are there cases in which the multi-sectoral nature of occupational road safety can be used to advantage?

Q: From your observations, is occupational road safety generally seen by European policymakers as most closely related to transport policy, to occupational safety and health, or to some other policy area?

Q: In the U.S., one of the challenges for convincing policymakers that occupational road safety should be addressed is the perception that the workers at risk are primarily drivers of large commercial vehicles, who are already covered by government safety regulations. Could you please comment on the extent to which this is true in Europe?

\section{Policy}

Q: I am particularly interested in the fact that in different countries, different ideas are used to justify how occupational road risk ought to be managed and who ought to manage it. Could you please comment on what you have observed through your experiences in the countries my research is focusing on - the UK, France, and Sweden?

Q: What are the most effective arguments we can make to convince policymakers, businesses, and others that work-related road safety is an important policy issue?

Q: What effects do you think ISO 39001 will have on organizational practices for road safety management in Europe?

\section{Interest Groups}

Q: I'm particularly interested in the role of interest groups in shaping policies for work-related road safety. Who are the interest groups you see as the most important influences on development of policies for occupational road safety in Europe? Here, I'm interested in groups active at any level of government, and representing any kind of stakeholder - business, academia, civil society, labor, and so forth.

Q: To what extent have the activities of international organizations had an influence on policy or practice within Europe -- for example, UN resolutions on road safety, or campaigns by groups such as victims' organizations?

Q: Are there any important points about occupational road safety in Europe that you would like to add? 


\section{Chief, Interventions for Healthy Environments Department of Public Health and Environment World Health Organization Geneva, Switzerland}

Interview date: May 4, 2010

Q: Could you please describe the linkage between the work of your department and work-related road safety?

Q: As a participant in the UN Road Safety Collaboration, I am aware that the Department of Violence and Injury Prevention is a focal point within the WHO for prevention of road traffic injuries in general. Is there any coordination between that department and the Department of Public Health and Environment to address occupational aspects of road safety?

Q: How does your department interact with the European Union and with individual EU member states when there is a public health or safety concern of mutual interest?

The World Report on Road Traffic Injury Prevention stresses the importance of coordinating road safety policy across all government ministries and industrial sectors that have a stake in the issue. In many countries, occupational road safety policy straddles OSH and transport, agencies that may not have a strong history of coordination. It may also be addressed within ministries that handle environment, health, social insurance, or industrial policy.

Q: How does the fact that many government agencies may share responsibility for work-related road safety affect governments' ability to develop comprehensive and coordinated responses?

Q: Are there cases in which the multi-sectoral nature of occupational road safety can be used to advantage?

Q: Within your agency, are work-related motor vehicle crashes viewed primarily as a hazard for the transport sector, or as a multi-sectoral problem?

Q: From your observations, is occupational road safety generally seen by European policymakers as most closely related to transport policy, to occupational safety and health, or to some other policy area?

Q: In the U.S., one of the challenges for convincing policymakers that occupational road safety should be addressed is the perception that the workers at risk are primarily drivers of large commercial vehicles, who are already covered by government safety regulations. Could you please comment on the extent to which this is true in Europe?

Q: I am particularly interested in the fact that in different countries, different ideas are used to justify how occupational road risk ought to be managed and who ought to manage it. Could you 
please comment on what you have observed through your experiences in the countries my research is focusing on - the UK, France, and Sweden?

Q: What are the most effective arguments we can make to convince policymakers, businesses, and others that work-related road safety is an important policy issue?

\section{Interest Groups}

Q: I'm particularly interested in the role of interest groups in shaping policies for work-related road safety. Who are the interest groups you see as the most important influences on development of policies for occupational road safety in Europe? Here, I'm interested in groups active at any level of government, and representing any kind of stakeholder - business, academia, civil society, labor, and so forth.

Q: Are there any important points about occupational road safety that you would like to add?

Technical Specialist (Ports and Transport)

Sectoral Activities Department

International Labour Organization

Geneva, Switzerland

Interview date: October 7, 2010

Q: Could you please describe the work of your department in ILO to address road safety for road transport workers?

Q: How does ILO interact with the European Union and individual EU member states when there is a public health or safety concern of mutual interest?

Q: Within the ILO, are work-related motor vehicle crashes viewed primarily as a hazard for the transport sector, or as a multi-sectoral problem?

Q: To your knowledge, is road safety addressed within the ILO by sector programs other than the Transport Sector?

Q: I am interested in learning about how work-related road safety gradually came to be recognized as a distinct policy issue in Europe. Could you please tell me what you see as the most important events, the most important individuals or organizations, and any other factors that contributed?

Probe for: Key events or media attention, legislation, academics/research, NGO pressure, companies' concern about risk management

The World Report on Road Traffic Injury Prevention stresses the importance of coordinating road safety policy across all government ministries and industrial sectors that have a stake in the 
issue. In many countries, occupational road safety policy straddles OSH and transport, agencies that may not have a strong history of coordination. It may also be addressed within ministries that handle environment, health, social insurance, or industrial policy.

Q: How does the fact that many government agencies may share responsibility for work-related road safety affect governments' ability to develop comprehensive and coordinated responses?

Q: From your observations, is occupational road safety generally seen by European policymakers as most closely related to transport policy, to occupational safety and health, or to some other policy area?

Q: The European Union has implemented a large number of directives that affect the way the road transport industry operates across borders of member states. How has this changed the way the individual member states have undertaken their national legislation and regulation?

Q: Although directives are set by the European Union, enforcement of directives such as the Road Transport Working Time Directive is the responsibility of the member states. In your opinion, how does this arrangement affect the consistency with which the resulting national laws are enforced across EU member states?

Q: How effective has the EU directive requiring a Certificate of Professional Competence for road transport operators been in creating fairer competition?

Q: Has this directive, combined with the directive requiring drivers to have a Certificate of Professional Competence, created safer working conditions for road transport workers in the EU?

Q: My research is focusing on policies for work-related road safety in the United Kingdom, France, and Sweden. Could you please comment on any innovative approaches taken by any of these three countries to reduce occupational road risk?

Q: Could you please comment on the current status of European social dialogue involving the road transport sector?

If not addressed:

Q: Because of the increase in the number of EU regulations and directives involvement, is social dialogue that once took place at national level now moving to regional or EU level?

Q: Are there any other points that you would like to add? 


\title{
Curriculum Vitae
}

\author{
Stephanie G. Pratt, Ph.D. \\ Research Health Scientist \\ National Institute for Occupational Safety and Health \\ Division of Safety Research \\ 1095 Willowdale Road, Mail Stop H-1808 \\ Morgantown, WV 26505
}

Phone: (304) 285-5992 (Office)

E-mail: sgp2@cdc.gov

(304) 919-1121 (Mobile)

\section{Education}

- B.M., 1977 (Music Performance), West Virginia University, Morgantown, WV

- M.M., 1979 (Music Performance), West Virginia University, Morgantown, W

- M.A, 1987 (Sociology), West Virginia University, Morgantown, WV

- Ph.D., 2011 (Political Science), West Virginia University, Morgantown, WV

\section{Professional Experience}

- Library Technical Assistant, West Virginia University Health Sciences Library, Morgantown, WV (1979-1983).

- Senior Program Coordinator, West Virginia University Office of Health Services Research, Morgantown, WV (1983-1993).

- Research Health Scientist, National Institute for Occupational Safety and Health, Division of Safety Research, Morgantown, WV (1993-present). Lead subject matter specialist in NIOSH for occupational road safety issues. Coordinator, NIOSH Center for Motor Vehicle Safety, which supports cross-NIOSH and international collaborations to reduce injuries from occupational crashes, 2004-present. Coordinator of NIOSH program portfolio and National Occupational Research Agenda implementation for the Transportation, Warehousing, and Utilities industry sector, 2006-2009.

\section{Organizational Affiliations}

- Network of Employers for Traffic Safety, Board of Directors (ex officio), 2000-present

- ANSI Z-15 Committee, Safe Practices for Motor Vehicle Operations, 2001-present

- U.S. Federal Agencies Roundtable on Global Road Safety, 2004-present

- Transportation Research Board: Vehicle User Characteristics Committee (AND10), 2007-present, Committee on Trucking Industry Research (AT060), 2007-2008

- Road Traffic Injury Research Network, 2008-present

- United Nations Road Safety Collaboration, 2008-present

\section{Honors}

- Six "On-the-Spot" NIOSH performance awards and two "Special Act" awards, 1998-2008, for exemplary efforts in research proposal development, data analysis and writing tasks, and leadership and organizational skills. 
- Selected for NIOSH long-term training program, 2008-2010, to pursue doctoral studies in policy analysis and international studies.

\section{Selected publications}

Castillo DN, Pratt SG, Mardis AL, Hendricks KJ [2002]. National Institute for Occupational Safety and Health (NIOSH) recommendations to the U.S. Department of Labor for changes to Hazardous Orders. Report to the U.S .Department of Labor, Employment Standards Administration, Wage and Hour Division. http://www.cdc.gov/niosh/docs/NIOSHRecsDOLHaz/pdfs/DOL-recomm.pdf

Hooper TI, DeBakey S, Pearse L, Pratt S, Hoffman K [2010]. The use of electronic pharmacy data to investigate prescribed medications and fatal motor vehicle crashes in a military population, 2002-2006. Accident Analysis and Prevention 42: 261-268.

Mardis AL, Pratt SG [2003]. NIOSH Alert: Preventing deaths, injuries, and illnesses of young workers. Cincinnati, OH: National Institute for Occupational Safety and Health. DHHS (NIOSH) Pub. No. 2003-128. http://www.cdc.gov/niosh/docs/2003128/pdfs/2003128.pdf

Mardis AL, Pratt SG [2003]. Nonfatal injuries to young workers in the retail trades and services industries in 1998. JOEM 45(3): 316-323.

Marsh SM, Pratt SG [2004]. Work-related roadway crashes: who's at risk? Cincinnati, OH: National Institute for Occupational Safety and Health. DHHS (NIOSH) Pub. No. 2004137.

Murray W, Pratt S [2007]. Worldwide occupational road safety review project. http://www.cdc.gov/niosh/contract-reports/WORS/WORS-04-10-2007.pdf

Murray W, Pratt S, Watson B [2008]. Sources of data on occupational road safety: an international review. Proceedings of the Australasian Research, Policing, and Education Conference, Adelaide, Australia, November 10-12, 2008. http://www.rsconference.com/pdf/RS080044.pdf

Murray W, Pratt S, Hingston J, Dubens E [2009]. Promoting global initiatives for occupational road safety: review of occupational road safety worldwide (white paper for International Conference on Road Safety at Work, Washington, DC, February 16-18, 2009). http://www.cdc.gov/niosh/programs/twu/global/pdfs/WhitePaper.pdf

Pratt SG [2003]. Work-related roadway crashes: challenges and opportunities for prevention (NIOSH Hazard Review). Cincinnati, OH: National Institute for Occupational Safety and Health. DHHS (NIOSH) Pub. No. 2003-119. http://www.cdc.gov/niosh/docs/2003119/pdfs/2003-119.pdf

Pratt SG [2004]. Work-related roadway crashes - United States, 1992-2002. MMWR 53(12): 260-264.

Pratt SG, Fosbroke DE, Marsh SM [2001]. Building safer highway work zones: measures to prevent worker injuries from vehicles and equipment. Cincinnati, $\mathrm{OH}$ : National Institute for Occupational Safety and Health. DHHS (NIOSH) Pub. No. 2001-128. http://www.cdc.gov/niosh/pdfs/01-128.pdf

Pratt SG, Le H, Marsh SM [2004]. Work-related roadway crashes: prevention strategies for employers. Cincinnati, OH: National Institute for Occupational Safety and Health. DHHS (NIOSH) Pub. No. 2004-136. http://www.cdc.gov/niosh/docs/2004136/pdfs/2004-136.pdf 
Pratt SG, Marsh SM, DeGuzman G [2005]. Older drivers in the workplace: crash prevention for employers and workers. Cincinnati, OH: National Institute for Occupational Safety and Health. DHHS (NIOSH) Pub. No. 2005-159. http://www.cdc.gov/niosh/docs/2005159/pdfs/2005-159.pdf

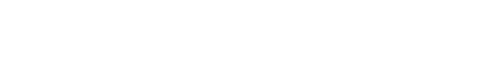

